\title{
Effect of Serrated Grain Boundaries on the Creep of 21-4N Manganese Austenitic Stainless Steel
}

by

\author{
Aleksander A. Wisniewski \\ B. Eng.
}

\begin{abstract}
A thesis submitted to the Faculty of Graduate Studies and Research in partial fulfillment of the requirements for the degree of

Master of Applied Science
\end{abstract}

Ottawa Carleton Institute for Mechanical and Aerospace Engineering

Department of Mechanical and Aerospace Engineering

\author{
Carleton University \\ Ottawa, Ontario \\ Canada
}

(C) Copyright

A. Wisniewski

September 2007 


$\begin{array}{ll}\begin{array}{l}\text { Library and } \\ \text { Archives Canada }\end{array} & \begin{array}{l}\text { Bibliothèque et } \\ \text { Archives Canada }\end{array} \\ \begin{array}{l}\text { Published Heritage } \\ \text { Branch }\end{array} & \begin{array}{l}\text { Direction du } \\ \text { Patrimoine de l'édition }\end{array} \\ \begin{array}{l}\text { 395 Wellington Street } \\ \text { Ottawa ON K1A ON4 }\end{array} & \begin{array}{l}\text { 395, rue Wellington } \\ \text { Ottawa ON K1A ON4 } \\ \text { Canada }\end{array}\end{array}$

Your file Votre référence ISBN: 978-0-494-33674-8 Our file Notre référence ISBN: 978-0-494-33674-8

NOTICE:

The author has granted a nonexclusive license allowing Library and Archives Canada to reproduce, publish, archive, preserve, conserve, communicate to the public by telecommunication or on the Internet, loan, distribute and sell theses worldwide, for commercial or noncommercial purposes, in microform, paper, electronic and/or any other formats.

The author retains copyright ownership and moral rights in this thesis. Neither the thesis nor substantial extracts from it may be printed or otherwise reproduced without the author's permission.
AVIS:

L'auteur a accordé une licence non exclusive permettant à la Bibliothèque et Archives Canada de reproduire, publier, archiver, sauvegarder, conserver, transmettre au public par télécommunication ou par l'Internet, prêter, distribuer et vendre des thèses partout dans le monde, à des fins commerciales ou autres, sur support microforme, papier, électronique et/ou autres formats.

L'auteur conserve la propriété du droit d'auteur et des droits moraux qui protège cette thèse. $\mathrm{Ni}$ la thèse ni des extraits substantiels de celle-ci ne doivent être imprimés ou autrement reproduits sans son autorisation.
In compliance with the Canadian

Privacy Act some supporting forms may have been removed from this thesis.

While these forms may be included in the document page count, their removal does not represent any loss of content from the thesis.
Conformément à la loi canadienne sur la protection de la vie privée, quelques formulaires secondaires ont été enlevés de cette thèse.

Bien que ces formulaires aient inclus dans la pagination, il n'y aura aucun contenu manquant.

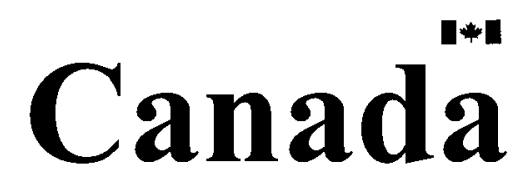




\begin{abstract}
Creep testing is carried out to determine the effect of serrated grain boundary morphology on the creep of a high temperature engineering alloy. $21-4 \mathrm{~N}$, a manganese austenitic stainless steel is the test material. Heat treatments are applied to produce microstructures with planar and serrated grain boundaries. The serrated grain boundary microstructure contains grain boundary reaction (GBR) nodules, and two heat treatments producing $\sim 10 \%$ and $\sim 16 \%$ GBR area fraction are used. Constant and increasing load creep tests show no effect on creep rate from the serrated grain boundaries. The serrated grain boundary microstructures show no improvements to creep rupture life as seen in other high temperature alloys capable of forming serrated grain boundaries. Thermodynamic instability of the serrated grain boundary microstructures as well as possible increased intergranular cracking from coarse grain boundary carbides and GBR nodules are identified as causes of the inferior creep properties of the serrated grain boundary microstructures.
\end{abstract}




\section{Acknowledgements}

First and foremost I would like to thank my parents, Elżbieta and Gustaw. Their love, patience and support throughout my life has been and continues to be tremendous. My fervent wish is to some day be able to repay them for the sacrifices they have made to allow me to come this far.

I would also like to thank my thesis supervisor Dr. Jonathan Beddoes for his patience and support. His guidance has been invaluable in the course of this project. As well, his curiosity and enthusiasm are contagious, keeping the project enjoyable and encouraging a need to know more.

Thanks also go to Dr. Richard Kearsey from NRC. His help has been appreciated since the very beginning of this project.

Special thanks go to Fred Barrett, who it seems can fix anything, no matter how complicated it may be. As well, the work of Alex Proctor and Kevin Sangster is much appreciated. They can make anything you ask for, from just about any material you give to them. 


\section{Table of Contents}

List of Tables..................................................................................iii

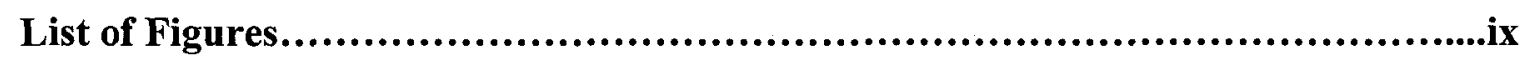

List of Appendices.......................................................................

Nomenclature............................................................................

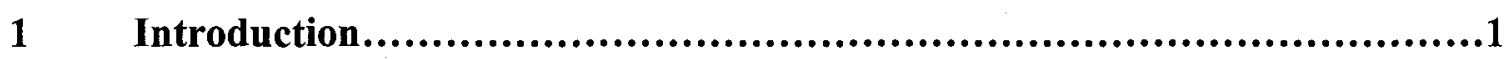

$1.1 \quad$ Importance of Creep ..........................................................

1.2 Role of Grain Boundaries in Creep ........................................

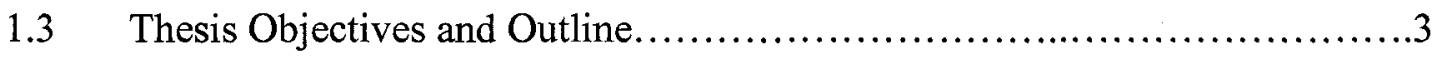

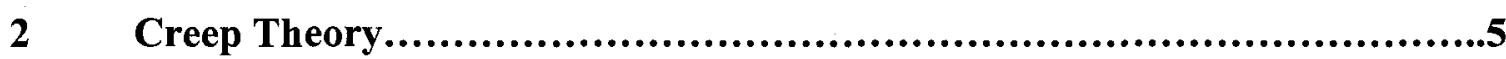

$2.1 \quad$ Dislocation Creep.................................................... 10

2.2 Diffusional Creep and Grain Boundary Sliding...............................13

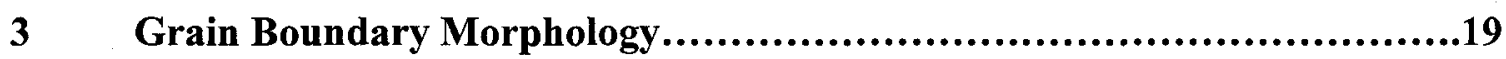

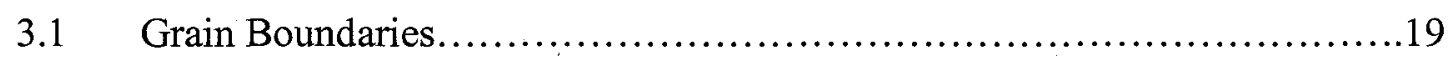

3.1.1 Role of Grain Boundaries in Creep..................................21

3.2 Serrated Grain Boundary Formation.....................................24

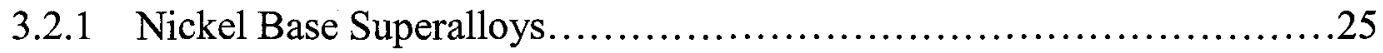

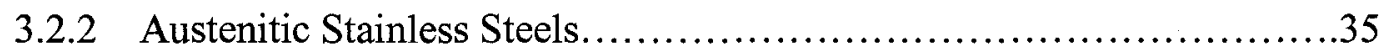

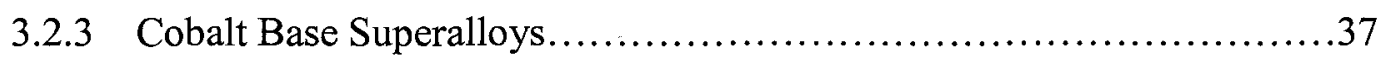

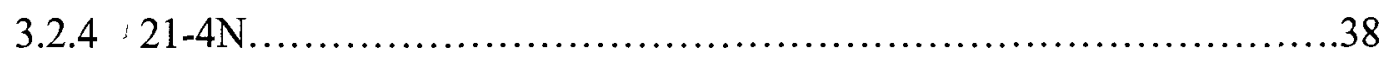

3.3 Effects of Serrated Grain Boundaries on Creep................................39

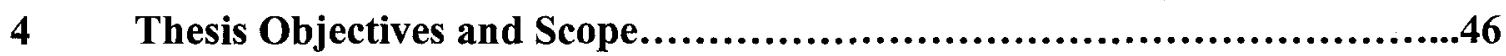

$5 \quad$ Materials and Experimental Methods...........................................48

5.1 21-4N: Manganese Stabilized Austenitic Stainless Steel.......................48

5.1.1 Chemistry and Microstructure............................................48

5.1.2 Effects of the Grain Boundary Reaction...............................54

5.1.3 Typical Properties and Applications....................................59 
5.2 Test Material........................................................60

5.3 Sample Heat Treatment...............................................62

5.4 Metallographic Preparation..............................................64

5.5 Creep Testing Procedure ...........................................65

5.5.1 Increasing Load Testing.....................................69

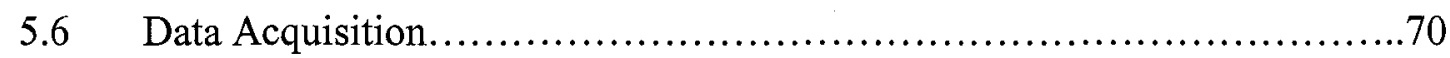

5.7 Metallographic Analysis............................................. 71

$5.8 \quad$ Creep Data Analysis.............................................. 72

Results.................................................................77

6.1 Heat Treated Microstructures........................................77

6.1.1 'NGB' Microstructure...............................................77

6.1.2 'SGB' \& 'SGB M' Microstructures..................................79

6.1.3 Microstructure Comparison......................................84

$6.2 \quad$ Creep Testing Results................................................ 87

6.2.1 Constant Load Tests..........................................87

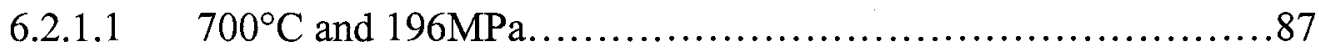

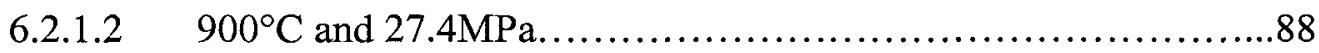

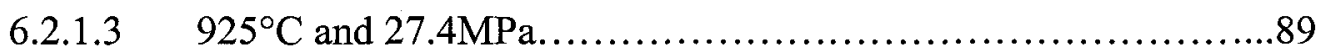

6.2.2 Increasing Load Tests.......................................90

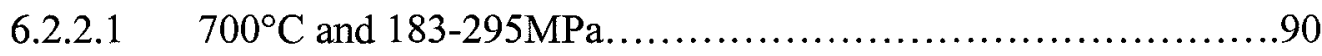

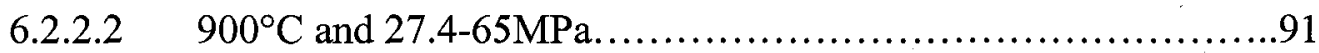

$6.3 \quad$ Creep Tested Microstructures...........................................94

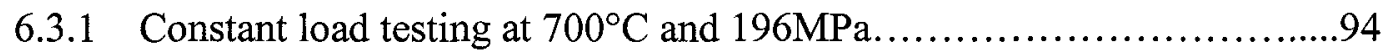

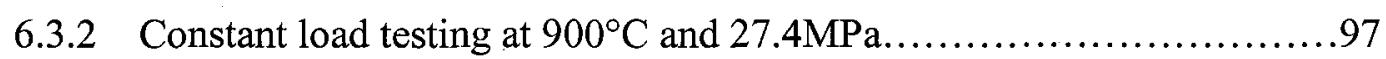

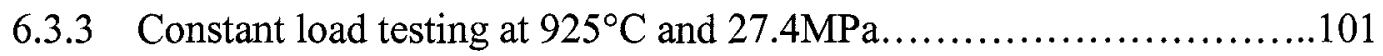

$6.4 \quad$ Aged Microstructures............................................... 103

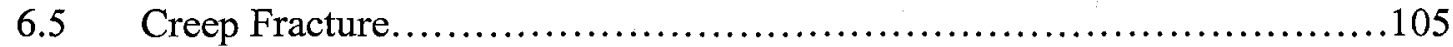

7 Discussion.

7.1 Heat Treated Microstructures......................................114

7.2 Creep Testing Results and Resulting Microstructures......................116 
7.3 Effect of Serrated Grain Boundaries on Creep Rate.

8 Summary, Conclusions and Recommendations for Future Work

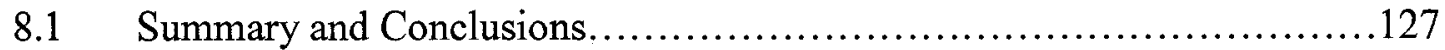

8.2 Recommendations for Future Work......................................128

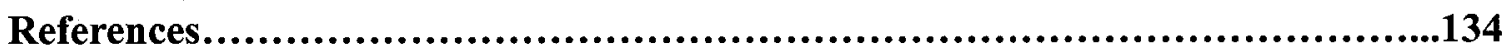

Appendix A: Typical 21-4N Material Properties.....................................143

Appendix B: Metallographic Preparation..........................................144

Appendix C: Creep Testing Procedure.............................................148

Appendix D: Data Acquisition System..................................................166

Appendix E: $\theta$ Projection Analysis Results..........................................181 


\section{List of Tables}

Table 1: Creep processes considered to be dominant in pure metals based on temperature and stress and associated $n$ and $Q_{c}$ values $[3, p .47] \ldots \ldots \ldots \ldots \ldots . . .10$

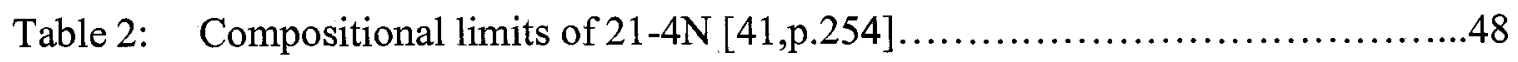

Table 3: Composition of 21-4N test material as provided by manufacturer and from independent tests............................................61

Table 4: Heat treatments used on $21-4 \mathrm{~N}$ test material............................62

Table 5: $\quad$ Results of $\theta$-Projection analysis for $700^{\circ} \mathrm{C}$ and $196 \mathrm{MPa} \ldots \ldots \ldots \ldots \ldots . \ldots . \ldots 8$

Table 6: Results of $\theta$-Projection analysis for $900^{\circ} \mathrm{C}$ and $27.4 \mathrm{MPa} \ldots \ldots \ldots \ldots \ldots . \ldots . \ldots 9$

Table 7: $\quad$ Results of $\theta$-Projection analysis for $925^{\circ} \mathrm{C}$ and $27.4 \mathrm{MPa} \ldots \ldots \ldots \ldots \ldots . \ldots . \ldots$

Table 8: Comparison of creep rupture lives. ...............................117

Table 9: Chemical compositions of 21-4N used by Tanaka et al. [22] and test material used in the current study.....................................118

Table 10: Chemical compositions of 304 and 316 used by Hong et al. (wt.\%) [72-73]

Table 11: Heat treatments required to produce serrated and planar grain boundaries in 304 and 316 [72-73] 


\section{List of Figures}

Figure 1: Simple lever loading machine for tensile creep testing......................5

Figure 2: Typical creep curve for a constant load test showing the three stages of creep, namely: primary, secondary and tertiary creep

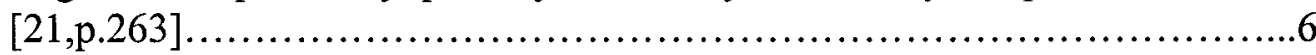

Figure 3: Effect of increasing stress and temperature on a typical creep

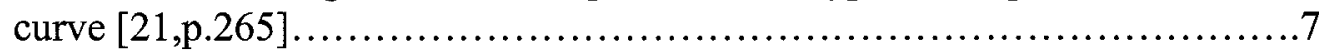

Figure 4: Typical Arrhenius plot of experimental rate data $[21, \mathrm{p} .156] \ldots \ldots \ldots \ldots \ldots \ldots . .8$

Figure 5: Testing at the same stress and various temperatures can be used to produce a plot giving the activation energy $\mathrm{Q}_{\mathrm{c}}$ for creep $[3, \mathrm{p} .20] \ldots \ldots \ldots \ldots . . .9$

Figure 6: Testing at the same temperature and various stresses can produce

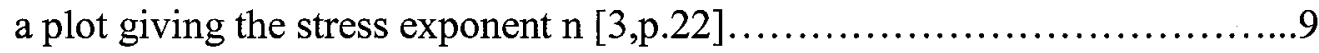

Figure 7: Pile up of gliding dislocations followed by climb $[3, \mathrm{p} .43] \ldots \ldots \ldots \ldots \ldots \ldots \ldots 11$

Figure 8: Shearing of $\gamma^{\prime}$ particles in a dilute $\gamma / \gamma^{\prime}$ alloy strained two per cent

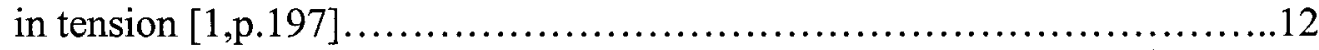

Figure 9: Dislocation passing particles through Orowan looping $[5, \mathrm{p} .179] \ldots \ldots \ldots \ldots \ldots .12$

Figure 10: Dislocation local and general climb over particles $[37, p .156] \ldots \ldots \ldots \ldots \ldots \ldots 13$

Figure 11: Stress directed diffusion of atoms in Nabarro-Herring creep [5,p.208] .......14

Figure 12: Schematic of denuded zone formation in a material with precipitates

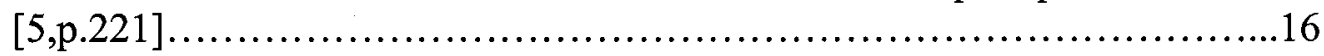

Figure 13: Denuded zone formation in $\mathrm{Mg} 0.5 \% \mathrm{Zr}$ alloy $[1, \mathrm{p} .57] \ldots \ldots \ldots \ldots \ldots \ldots \ldots \ldots \ldots$

Figure 14: A) Equiaxed grains, B) Result of diffusional creep without GBS,

C) GBS occurring simultaneously with diffusional creep resulting

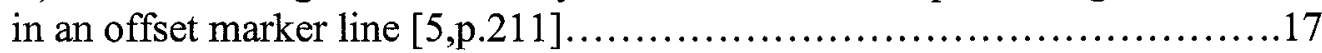

Figure 15: Grain boundaries separate grains of different crystallographic orientation $[41$, p.34]

Figure 16: Small angle tilt boundary made up of edge dislocations of Burgers vector $\mathbf{b}$, separated by a distance $\mathbf{d}[38, \mathrm{p} .65]$ 
Figure 17: Grains from beta brass showing polyhedral nature and planar facets of grain boundaries [2,p.191].

Figure 18: A) Wedge type cracks at grain boundary triple points, B) Cavities along grain boundaries [2,p.871]

Figure 19: A) Wedge crack formed due to GBS, B) Wedge crack formed due to accumulating cavities $[37$, p.215]

Figure 20: A) Cavity forming at ledge due to GBS, B) Cavity forming from vacancy condensation, C) Cavity forming through a dislocation mechanism, D) Cavity forming at a particle [37,p.220].

Figure 21: Planar (A) and serrated (B) grain boundaries in nickel base superalloy PWA 1113 [43].

Figure 22: Schematic diagram of Tu-Turnbull mechanism $[51] \ldots \ldots \ldots \ldots \ldots \ldots \ldots \ldots \ldots . . .26$

Figure 23: A) Tu-Turnbull mechanism of grain boundary serration through cellular precipitation [52], B) and C) Serrated grain boundary morphology of IN $718[50 ; 53]$. .28

Figure 24: Serrated grain boundary micrographs, A) IN 738 [63],

B) MERL76 [62].

Figure 25: Model showing serrated grain boundary formation by cooling through $\gamma$ solvus range from solution treatment [54]...

Figure 26: Schematic of grain boundary serration model based on $\gamma$ migration in Nickel base superalloys [54].

Figure 27: Formation of serrated grain boundary through asymmetric $\gamma^{\prime}$ precipitate growth [66] .33

Figure 28: Asymmetric $\gamma^{\prime}$ precipitate growth causing grain boundary serrations, revealed through deep etching [66]

Figure 29: Fan type serration in model alloy of Henry et al. [57]. .35

Figure 30: Formation of serrated grain boundaries followed by carbide precipitation in 304 stainless steel [71]. 36

Figure 31: GBR nodules in HS-21 [31]. .38

Figure 32: Creep tests of 21-4N with serrated grain boundaries (solid line) and planar grain boundaries (broken line) [23] 
Figure 33: Creep tests of cobalt base superalloys L-605 and HS-21 with serrated grain boundaries (solid line) and planar grain boundaries (broken line) [30-31].

Figure 34: Creep tests of nickel base superalloy IN718 with serrated grain boundaries (solid line) and planar grain boundaries (broken line) [28]

Figure 35: Comparison of creep rates between serrated grain boundary samples (solid line, circle) and planar grain boundary samples (broken line, triangle) in $21-4 \mathrm{~N}$ [23].

Figure 36: Comparison of creep rates for cobalt base superalloys: A) L-605, serrated grain boundaries (solid line, circle), planar grain boundaries (broken line, triangle) [30] B) HS-21, serrated grain boundaries (solid line, open symbol), planar grain boundaries (broken line, filled symbol) [31]

Figure 37: Creep test results of IN718 and IN738LC with serrated and planar grain boundaries [53]...

Figure 38: Effect of alloying additions on the solubility of $\mathrm{N}$ in liquid $18 \mathrm{Cr}-8 \mathrm{Ni}$ alloys at $1600^{\circ} \mathrm{C}$ and $1 \mathrm{~atm} \mathrm{~N}_{2}[33, \mathrm{p} .31]$.

Figure 39: Effect of alloy additions on the solid solution hardening of austenite $[33, p .16]$.

Figure 40: Fe-Cr-Mn austenitic steel with $0.18 \% \mathrm{C}$ and $0.38 \% \mathrm{~N}-$ (a) $1204^{\circ} \mathrm{C}$ solution annealed and aged at $871^{\circ} \mathrm{C}$ for $16 \mathrm{hrs}$. (b) $1204^{\circ} \mathrm{C}$ solution annealed and aged at $982^{\circ} \mathrm{C}$. (c) $1204^{\circ} \mathrm{C}$ solution annealed and aged at $927^{\circ} \mathrm{C}$. (d) $1204^{\circ} \mathrm{C}$ solution annealed and aged at $1038^{\circ} \mathrm{C}[33, \mathrm{p} .28] \ldots . . .52$

Figure 41: A) Schematic diagram showing sequence of development of cellular precipitation [94,p.324], B) Grain boundary reaction nodule in $21-4 \mathrm{~N}$ .53

Figure 42: Effect of the grain boundary reaction on material properties [96] .55

Figure 43: Effect of the grain boundary reaction on rupture time, elongation and minimum creep rate [91].

Figure 44: Effect of the grain boundary reaction on creep curve shape [91] .57

Figure 45: Room temperature fracture of 21-4N with grain boundary reaction nodules [92]. .58

Figure 46: Engine valve [97]. 
Figure 47: As received 21-4N bar stock and sample slug. ....

Figure 48: As received microstructure of the 21-4N bar stock.

Figure 49: A - Lindberg furnace, B - Lindberg/Blue furnace controller, C - Yokogawa program temperature controller, D - Omega Type K thermocouple.

Figure 50: Creep sample geometry.

Figure 51: A - Creep rupture frame, B - Leeds \& Northrup furnace control unit, C - Omega DP462 digital panel thermometer, D - Solartron Metrology OD5 conditioning module, E - Satec RT-214 single LVDT extensometer, F - Extensometer micrometer, G - Solartron Metrology LVDT.

Figure 52: A - National Instruments USB data acquisition system, B - signal lines from LVDT conditioning modules, $\mathrm{C}-\mathrm{USB}$ connection to PC laptop. .70

Figure 53: LabView data acquisition user interface. 70

Figure 54: The $\theta$ Projection method treats the creep curve as decaying primary and accelerating tertiary sections [3].... .73

Figure 55: Comparison of measured engineering strain and calculated true strain.... .74

Figure 56: Truncated data overlaid on full true strain data for 'NGB' sample tested at $27.4 \mathrm{MPa}$ and $900^{\circ} \mathrm{C}$

Figure 57: Comparison of actual data to $\theta$ Projection method curve fit. .75

Figure 58: Difference in strain between $\theta$ fit equations and actual data. 76

Figure 59: Microstructural evolution during the 'NGB' heat treatment...................78

Figure 60: Grain boundaries of partially and fully heat treated 'NGB' microstructure. .78

Figure 61: Microstructural evolution during the 'SGB' heat treatment. .80

Figure 62: Grain boundaries of partially and fully heat treated 'SGB' microstructure.

xii 
Figure 63: Effect of cooling rate on amount of GBR precipitated after solutionizing at $1200^{\circ} \mathrm{C}$ for 1 hour, followed by cooling to $1030^{\circ} \mathrm{C}$ and water quenching....

Figure 64: Representative micrographs showing effect of cooling rate on area fraction of GBR.

Figure 65: Comparison of 'SGB M' and SGB' heat treated microstructures

Figure 66: Micrographs of fully heat treated microstructures .85

Figure 67: Grain boundaries of fully heat treated microstructures .86

Figure 68: Constant load creep curves at $700^{\circ} \mathrm{C}$ and $196 \mathrm{MPa}$. 87

Figure 69: Constant load creep curves at $900^{\circ} \mathrm{C}$ and 27.4MPa.... .89

Figure 70: Constant load creep curves at $925^{\circ} \mathrm{C}$ and $27.4 \mathrm{MPa}$ .90

Figure 71: Increasing load creep curves at $700^{\circ} \mathrm{C}$ and $183-295 \mathrm{MPa}$.

Figure 72: Strain rate vs stress plot from increasing load tests at $700^{\circ} \mathrm{C}$ and $183-295 \mathrm{MPa}$

Figure 73: Increasing load creep curves at $900^{\circ} \mathrm{C}$ and $27.4-64.7 \mathrm{MPa}$ .92

Figure 74: Increasing load creep curves at $900^{\circ} \mathrm{C}$ and $27.4-65 \mathrm{MPa}$. 92

Figure 75: Strain rate vs stress plot from increasing load tests at $900^{\circ} \mathrm{C}$ and 27.4-65MPa.

Figure 76: Gauge section microstructures after constant load creep testing at $700^{\circ} \mathrm{C}$ and $196 \mathrm{MPa}$

Figure 77: Gauge section grain boundaries after constant load creep testing at $700^{\circ} \mathrm{C}$ and $196 \mathrm{MPa}$

Figure 78: Gauge section microstructures after constant load creep testing at $900^{\circ} \mathrm{C}$ and $27.4 \mathrm{MPa}$. .98

Figure 79: Gauge section grain boundaries after constant load creep testing at $900^{\circ} \mathrm{C}$ and $27.4 \mathrm{MPa}$.

Figure 80: Gauge section grain boundaries of prematurely failed 'SGB' sample after constant load creep testing at $900^{\circ} \mathrm{C}$ and $27.4 \mathrm{MPa}$.

xiii 
Figure 81: Gauge section GBR nodule morphology in prematurely failed 'SGB' sample and fully heat treated but untested 'SGB' sample.

Figure 82: Gauge section microstructures after constant load creep testing at $925^{\circ} \mathrm{C}$ and $27.4 \mathrm{MPa}$

Figure 83: Gauge section grain boundaries after constant load creep testing at $925^{\circ} \mathrm{C}$ and $27.4 \mathrm{MPa}$.

Figure 84: 'NGB' and 'SGB' microstructures after $\sim 1800$ hour aging at $900^{\circ} \mathrm{C} \ldots \ldots \ldots 103$

Figure 85: 'NGB' and 'SGB' grain boundaries after $\sim 1800$ hour aging at $900^{\circ} \mathrm{C} \ldots \ldots . .104$

Figure 86: Creep fracture surfaces from constant load tests at $700^{\circ} \mathrm{C}$ and $196 \mathrm{MPa}$......106

Figure 87: Gauge section intergranular cracking from constant load tests at $700^{\circ} \mathrm{C}$ and $196 \mathrm{MPa}$

Figure 88: Gauge section intergranular cracking from constant load tests at $900^{\circ} \mathrm{C}$ and $27.4 \mathrm{MPa}$........

Figure 89: Gauge section intergranular cracking from constant load tests at $925^{\circ} \mathrm{C}$ and $27.4 \mathrm{MPa}$

Figure 90: Gauge section intergranular cracks at GBR nodules in 'SGB' and SGB M' samples tested at $700^{\circ} \mathrm{C}$ and $196 \mathrm{MPa}$.

Figure 91: Gauge section grain boundary cavities away from grain boundary triple points in 'SGB' and 'SGB M' samples tested at $700^{\circ} \mathrm{C}$ and $196 \mathrm{MPa}$.

Figure 92: Gauge section grain boundary cavities away from grain boundary triple points in 'SGB' and 'SGB M' samples tested at $900^{\circ} \mathrm{C}$ and 27.4MPa.

Figure 93: Gauge section grain boundary cavities 'NGB' sample tested at $900^{\circ} \mathrm{C}$ and $27.4 \mathrm{MPa}$.

Figure 94: Gauge section intergranular cracks at and propagating into GBR nodules in 'SGB' prematurely failed and 'SGB M' samples tested at $900^{\circ} \mathrm{C}$ and $27.4 \mathrm{MPa}$.

Figure 95: Gauge section micrographs showing an increase in grain boundary cavities in a 'NGB' sample tested at $925^{\circ} \mathrm{C}$ and $27.4 \mathrm{MPa}$, and a prevalence of cracks at GBR nodules in a 'SGB' sample also tested at $925^{\circ} \mathrm{C}$ and $27.4 \mathrm{MPa}$

xiv 
Figure 96: PWA 1113 constant load creep curves at $705^{\circ} \mathrm{C}$ and $690 \mathrm{MPa} \ldots \ldots \ldots \ldots \ldots . . . .131$

Figure 97: PWA 1113 constant load creep curves at $750^{\circ} \mathrm{C}$ and $550 \mathrm{MPa} \ldots \ldots \ldots \ldots \ldots \ldots . . . .131$

Figure 98: PWA 1113 constant load creep curves at $800^{\circ} \mathrm{C}$ and $300 \mathrm{MPa} \ldots \ldots \ldots \ldots \ldots . . . .132$

Figure 99: PWA 1113 constant load creep curves at $800^{\circ} \mathrm{C}$ and $250 \mathrm{MPa} \ldots \ldots \ldots \ldots \ldots \ldots . . .132$ 


\section{List of Appendices}

Appendix A: Typical 21-4N Material Properties.................................143

Appendix B: Metallographic Preparation........................................... 144

Appendix C: Creep Testing Procedure........................................ 148

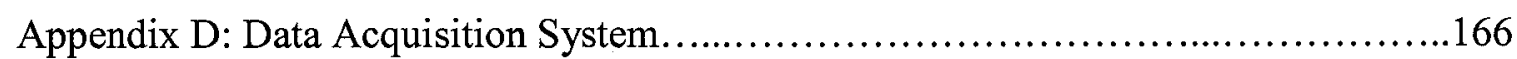

Appendix E: $\theta$ Projection Analysis Results................................... 181 


\section{Nomenclature}

\begin{tabular}{|c|c|}
\hline $\mathrm{T}_{\mathrm{m}}$ & absolute melting temperature \\
\hline GBS & grain boundary sliding \\
\hline$\dot{\varepsilon}_{S}$ & steady state creep rate \\
\hline$\sigma$ & stress \\
\hline $\mathrm{n}$ & stress exponent \\
\hline $\mathrm{Q}_{\mathrm{C}}$ & creep activation energy \\
\hline $\mathrm{R}$ & universal gas constant \\
\hline $\mathrm{T}$ & absolute temperature \\
\hline $\mathrm{QSD}_{\mathrm{SD}}$ & activation energy for self diffusion \\
\hline QCORE & activation energy for self diffusion along dislocation cores \\
\hline $\mathrm{Q}_{\mathrm{GB}}$ & activation energy for diffusion along grain boundaries \\
\hline$\Omega$ & volume of a vacancy \\
\hline $\mathrm{d}$ & average grain diameter \\
\hline $\mathrm{k}$ & Boltzmann's constant \\
\hline $\mathrm{D}_{\mathrm{SD}}$ & diffusion coefficient for lattice self diffusion \\
\hline $\mathrm{D}_{\mathrm{GB}}$ & diffusion coefficient for grain boundary diffusion \\
\hline$\theta$ & grain boundary misorientation angle \\
\hline$\gamma_{\mathrm{st}}$ & interfacial energy due to structural distortion caused by misfit dislocations \\
\hline$\delta$ & particle-matrix misfit \\
\hline$\mu$ & shear modulus \\
\hline TEM & transmission electron microscope \\
\hline GBR & grain boundary reaction \\
\hline
\end{tabular}

xvii 
LVDT linear variable differential transformer

DAQ data acquisition system

SEM scanning electron microscope

xviii 


\section{$1 \quad$ Introduction}

\subsection{Importance of Creep}

The importance of creep is evident from the description of the phenomenon. At high temperatures, typically above $0.5 \mathrm{~T}_{\mathrm{m}}$ (where $\mathrm{T}_{\mathrm{m}}$ is the absolute melting temperature), metal parts under load will experience continuously increasing strain $[1, \mathrm{p} .1]$. The continuously increasing and permanent strain runs against the need in engineering applications to maintain dimensional tolerances [2,p.891]. Apart from changes to component dimensions, the microstructure of the component will also change and continuing creep may lead to failure through creep fracture [1,p.1]. As such, materials capable of withstanding long periods of time under load and high temperature are required.

For moderate temperatures of around $550^{\circ} \mathrm{C}$, typical components requiring creep resistant materials include furnace parts, piping, bolts, steam turbine rotors, boiler tubes in power plants, etc. $[1, p .3]$. Up to around $1000^{\circ} \mathrm{C}$, parts requiring creep resistant materials are heat exchangers, furnace linings, boiler baffles, jet engine burner liners and exhaust systems, etc. $[1, p .3]$. The materials used in these applications typically include low alloy steels with $\mathrm{Cr}$, Mo, or $\mathrm{V}$ for the moderate temperatures and more expensive materials such as austenitic stainless steels or nickel-base superalloys for the higher temperatures $[1, \mathrm{p} .3]$.

The most extreme conditions in terms of creep exist in jet engines. Creep resistance in jet engines is critical for gas turbine blades which can experience material temperatures in excess of $1000^{\circ} \mathrm{C}[1, \mathrm{p} .3]$. Thus, both nickel and cobalt base superalloys are used extensively for the manufacture of gas turbine blades [1,p.3]. 
With continually increasing temperatures and stresses, new materials must be devised to withstand the more demanding conditions. This requires a greater understanding of the creep phenomenon. Increased understanding of creep will allow components and structures to be designed to be safe and economically viable [2,p.895]. The reality however is that high temperature creep resistant alloys are usually complex, and are developed for specific applications through empirical methods [1,p.2]. Another important point is that components subjected to creep are generally expected to have long service lives. In the case of aeroengine gas turbines, components generally have service lives of around 10,000 hours [3,p.6]. Testing to ascertain the creep properties of materials for several thousand hours is feasible though expensive. A far more difficult proposition would be testing up to 250,000 hours to ascertain the creep properties of materials required for power plants which typically have service lives in excess of 30 years $[3, p .6]$.

For the extremely long service lives desired of power plants for instance, short term testing (relatively speaking) makes it difficult to understand the creep mechanisms occurring [4,p.122]. The common practice of extrapolating long term creep behaviour from short term tests is possibly inaccurate as the material's microstructure could change unexpectedly well before the intended service life and cause failure [2,p.891].

The slow creep rates required for extremely long service lives are generally believed to be controlled by diffusional creep mechanisms [5,p.205]. However, controversy has arisen as to whether diffusional creep is a viable creep mechanism in engineering applications, and whether dislocation creep continues to dominate instead [620]. 


\subsection{Role of Grain Boundaries in Creep}

While the debate over diffusional creep continues, it is also important to note that grain boundaries play an important role in long term creep [4,p.122]. This is due to the fact that when diffusional creep occurs, grain boundary sliding (GBS) must also occur to prevent the formation of voids as the metal grains deform [5,p.211]. GBS can have a negative impact on creep properties however, as GBS which is not accommodated by diffusional mass flow can cause cracks to form, typically at grain boundary triple points $[2$, p.871; 3,p.53]. Grain boundaries also play a role in creep fracture as the typical failure mechanism is intergranular fracture as opposed to transgranular fracture which occurs at lower temperatures $[21, \mathrm{p} .264 ; 2, \mathrm{p} .870 ; 3, \mathrm{p} .50]$. Thus the inhibition of GBS is expected to be beneficial on creep properties. This has been noted when the grain boundary morphology of various metals has been changed to a zig-zag or serrated type, from the normal straight or planar type [22-32]. Improvements typically involve increased creep ductility and creep rupture life. What is not completely understood, is what effect the inhibition of GBS will have on diffusional creep in terms of the creep rate. Thus, the interrelationship of diffusional creep and GBS presents an opportunity to study the effects of grain boundary morphology on the creep rate of metals.

\subsection{Thesis Objectives and Outline}

The objective of this thesis is thus to help elucidate the role of grain boundary morphology on the creep rate of engineering alloys. This involves creep testing a high temperature engineering alloy capable of forming planar and serrated grain boundaries. 
The material investigated is $21-4 \mathrm{~N}$, a manganese stabilized austenitic stainless steel that typically sees use in automotive engine exhaust valves [33,p.68;34;35,p.24]. It is known to be able to form serrated grain boundaries [22-24].

This thesis is part of a larger research project being undertaken at Carleton University which involves creep testing of a number of engineering alloys such as nickel base superalloys and other austenitic stainless steels. Of particular interest are the effects of grain boundaries and intergranular second phase particles on the creep rate during the period before the minimum creep rate, as opposed to the effect on creep ductility or creep rupture life. Thus, the main objectives of this thesis can be summarized as follows:

1. Establish heat treatment procedures to produce $21-4 \mathrm{~N}$ creep samples with planar and serrated grain boundaries.

2. Determine the effect(s) of the serrated grain boundaries on the creep rate through constant load and increasing load creep tests on the planar and serrated grain boundary creep samples.

3. Outline possible future work required to achieve the overall research objectives. 


\section{Creep Theory}

Creep is defined as time dependent plastic deformation [5,p.14]. It becomes a concern in engineering applications at temperatures above roughly $0.5 \mathrm{~T}_{\mathrm{m}}$ (where $\mathrm{T}_{\mathrm{m}}$ is the absolute melting temperature). This deformation is permanent and cannot be recovered when the load is removed as the material's structure undergoes changes through numerous deformation mechanisms, the primary ones being dislocation slip and climb, grain boundary sliding (GBS) and diffusion [2,p.844].

Mechanical testing to determine creep properties is typically done under tensile creep conditions using apparatus as seen in Figure 1.

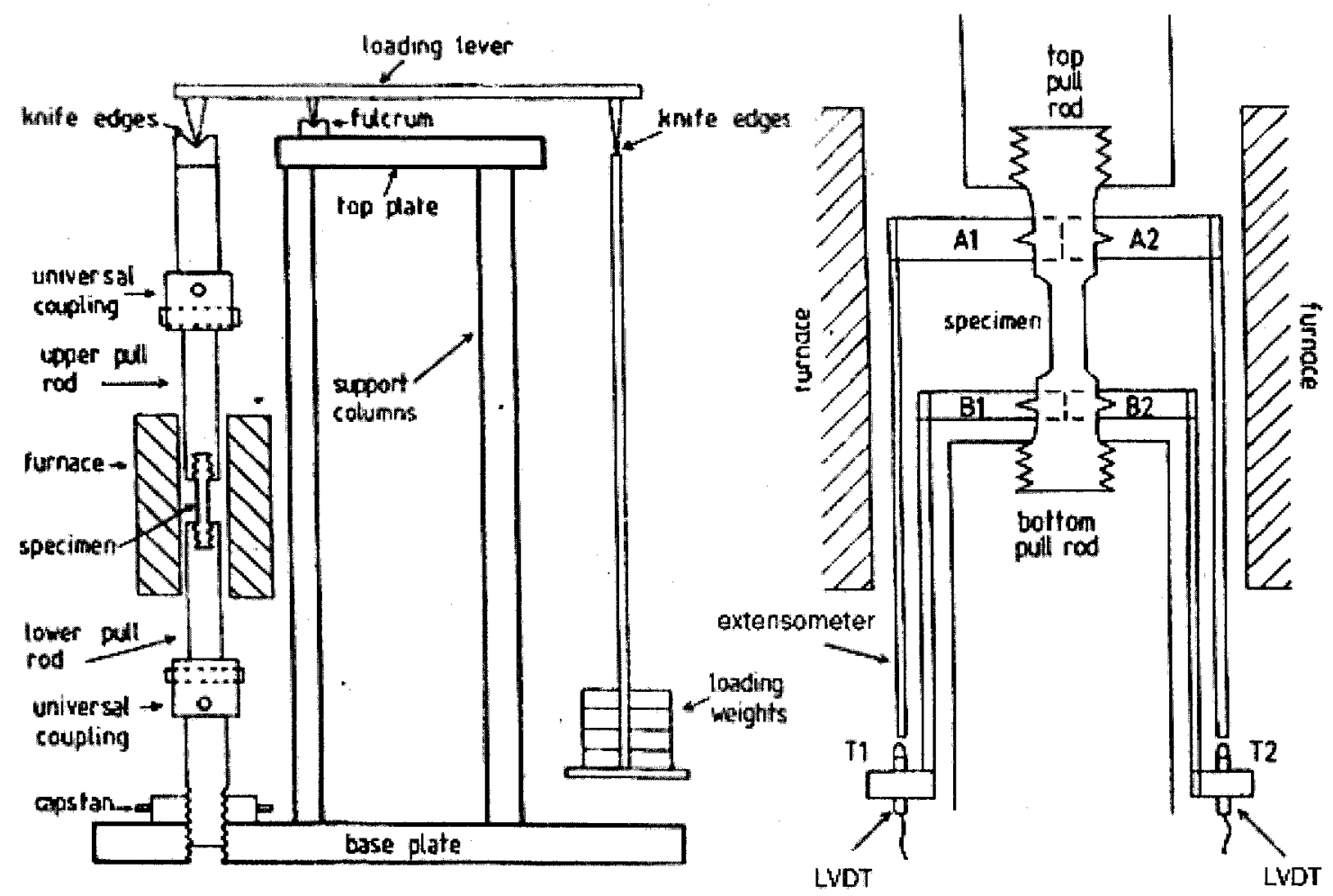

Figure 1: Simple lever loading machine for tensile creep testing. The extensometer with LVDTs mounted on the specimen measures strain by the displacement of A1/A2 from B1/B2. Without an extensometer the machine is a creep rupture frame capable of only measuring rupture time [3,p.10,p.12].

The creep sample is brought up to test temperature in the furnace and then the load is applied through a loading lever. Axial load application is maintained through the 
universal couplings. The particular test apparatus shown in Figure 1 is a constant load type of machine as the stress experienced by the sample increases as it deforms over time. There are constant stress machines which compensate for the sample deformation with cams, however the most common is creep testing at constant load [3,p.15].

A constant load test using an extensometer would typically produce a time vs. strain plot, known as a creep curve, as seen in Figure 2.

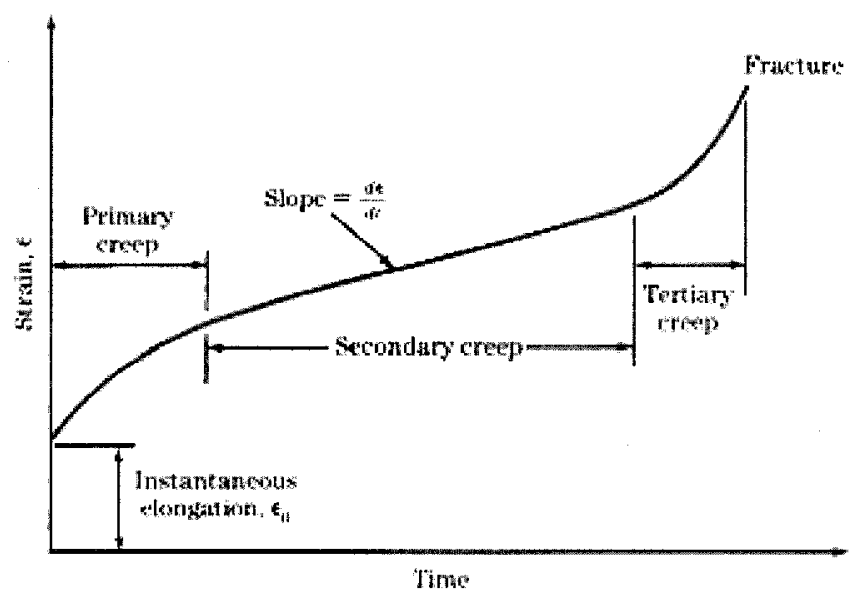

Figure 2: Typical creep curve for a constant load test showing the three stages of creep, namely: primary, secondary and tertiary creep $[21, \mathrm{p} .263]$.

A typical creep curve also shows the three stages of creep. The first stage, known as primary creep, is a transient as it includes an instantaneous elongation from load application and then decreasing strain rate as the sample strain hardens to support the load $[1$, p. $15 ; 21$, pp.263-264; 36,p.245]. The strain rate then becomes steady in the secondary stage, where there is a balance between strain hardening and recovery processes $[21$, p.264; 36,pp.245-246; 37,p.3]. This steady state strain rate is known as the creep rate. Finally, the strain rate begins to increase in the tertiary stage as voids and cracks continuously form within the sample increasing the stress further $[1, \mathrm{p} .16$; 21,p.264; 36,p.249]. Finally, the sample will fail by fracture as the voids and cracks 
coalesce into larger cavities [36,p.249]. It is also possible for there to be no clearly defined secondary stage of creep but rather a direct transition from primary to tertiary. This produces a 'minimum' strain rate that is usually assumed to be equivalent to the creep rate $[5, \mathrm{p} .15]$

The typical effects of temperature and stress can be seen in Figure 3, that an increase in stress and/or temperature accelerates the creep rate.

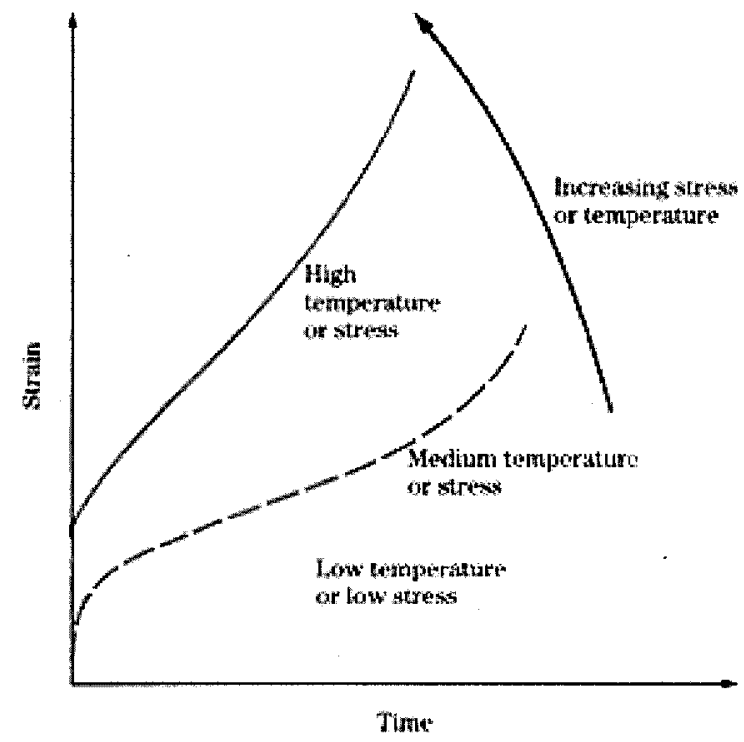

Figure 3: Effect of increasing stress and temperature on a typical creep curve [21,p.265].

It is assumed that the most important parameter is the steady state creep rate $\left(\dot{\varepsilon}_{S}\right)$ which is believed to be dependent on stress and temperature, but in an independent manner [3,p.19]:

$$
\dot{\varepsilon}_{S}=u(\sigma) \cdot v(T)
$$

The steady state creep rate is believed to obey Arrhenius' rate kinetics and 'Norton's Law' which results in a power law representation of creep rate:

$$
\dot{\varepsilon}_{S}=A \sigma^{n} \exp \left(-Q_{C} / R T\right)
$$


If the dependence on stress $\left(\sigma^{n}\right)$ is removed from equation (2), it shows that creep is rate dependant on temperature similarly to processes such as diffusion and oxidation [3,p.21]. With $\sigma^{n}$ removed, the Arrhenius rate equation is seen [21,p.155]:

$$
\text { Rate of reaction }=C \exp (-Q / R T)
$$

Here $\mathrm{C}$ is a constant, $\mathrm{Q}$ is the activation energy, $\mathrm{R}$ is the universal gas constant and $\mathrm{T}$ is the absolute temperature. Determining the activation energy then requires measuring the reaction rate at different temperatures to produce a plot as seen in Figure 4.

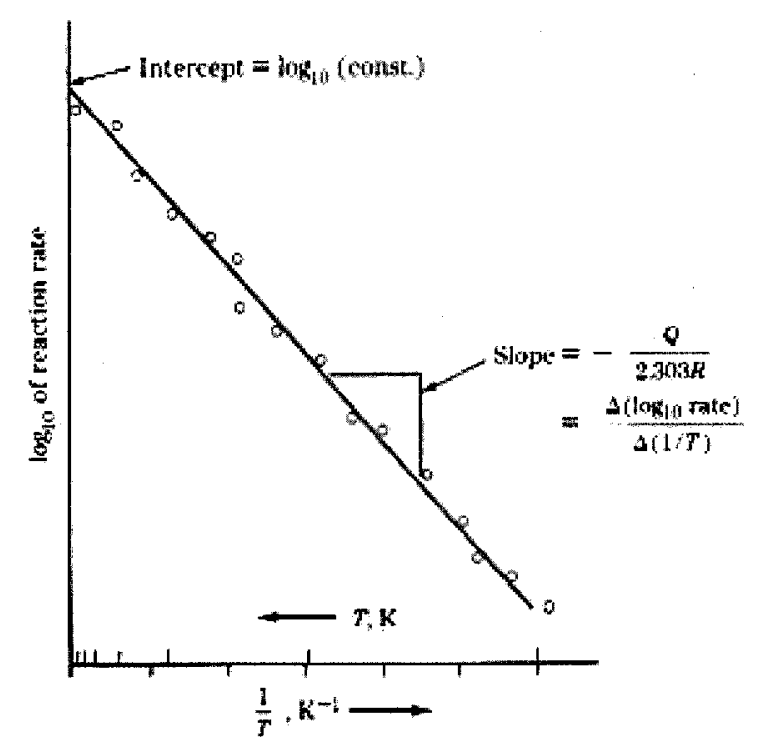

Figure 4: Typical Arrhenius plot of experimental rate data [21,p.156].

The activation energy for creep is found by testing at the same stress but at various temperatures and plotting $\ln \dot{\varepsilon}_{S}$ vs $(1 / T)$ as seen in Figure 5. 


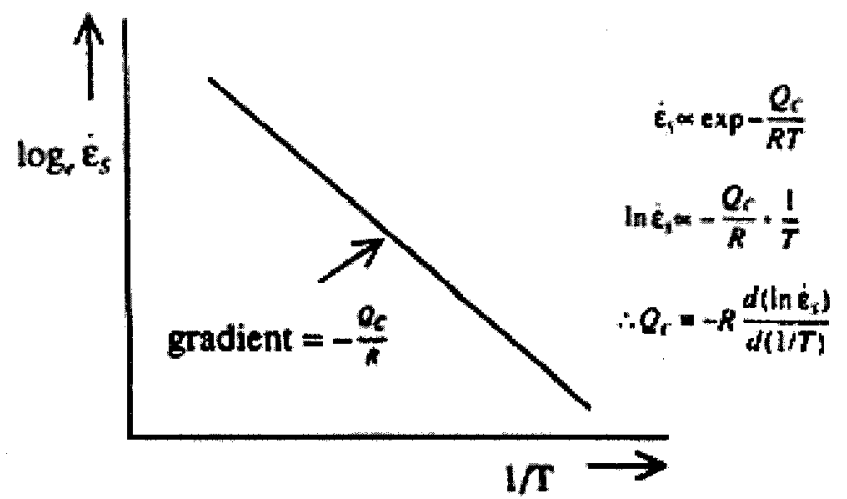

Figure 5: Testing at the same stress and various temperatures can be used to produce a plot giving the activation energy $Q_{c}$ for creep [3,p.20].

Given that creep is not solely dependent on temperature, the effect of stress must also be determined. This is done through the so called 'Norton's Law' which is simply $[3$, p.22]:

$$
\dot{\varepsilon}_{s} \propto \sigma^{n}
$$

Here $\sigma$ is the stress and $\mathrm{n}$ is the stress exponent. The stress exponent is determined by testing at constant temperature and various stresses, and plotting $\log \dot{\varepsilon}_{s}$ vs $\log \sigma$ as seen in Figure 6.

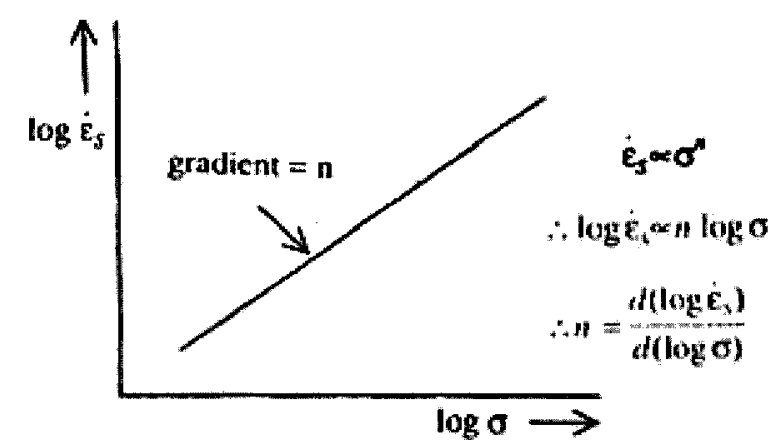

Figure 6: Testing at the same temperature and various stresses can produce a plot giving the stress exponent n $[3, \mathrm{p} .22]$.

In general, creep can be considered to be either due to dislocation slip and climb or diffusion of atoms [2,p.844]. For pure metals and simple alloys, which mechanism is 
dominant can generally be inferred from the values of the stress exponent $\mathrm{n}$ and activation energy $Q_{C}$, as seen in Table 1.

Table 1: Creep processes considered to be dominant in pure metals based on temperature and stress and associated $\mathrm{n}$ and $\mathrm{Q}_{\mathrm{c}}$ values [3,p.47]. ( $\mathrm{Q}_{\mathrm{SD}}$ - activation energy for self diffusion, $\mathrm{Q}_{\mathrm{CORE}}$ - activation energy for self diffusion along dislocation cores, $\mathrm{Q}_{\mathrm{GB}}$ - activation energy for diffusion along grain boundaries)

\begin{tabular}{|l|c|c|c|c|}
\hline Creep Process & Temperature & Stress & $\begin{array}{c}\mathrm{n} \\
\text { value }\end{array}$ & $\begin{array}{c}\mathrm{Q}_{\mathrm{c}} \\
\text { value }\end{array}$ \\
\hline $\begin{array}{l}\text { high temperature } \\
\text { dislocation creep }\end{array}$ & $\begin{array}{c}\text { above } \\
\sim 0.7 \mathrm{~T}_{\mathrm{m}}\end{array}$ & intermediate/high & $>3$ & $\sim \mathrm{Q}_{\mathrm{SD}}$ \\
\hline $\begin{array}{l}\text { low temperature } \\
\text { dislocation creep }\end{array}$ & $\begin{array}{c}\sim 0.4 \text { to } \\
\sim 0.7 \mathrm{~T}_{\mathrm{m}}\end{array}$ & intermediate/high & $>3$ & $\mathrm{Q}_{\mathrm{CORE}}$ \\
\hline $\begin{array}{l}\text { high temperature } \\
\text { diffusional creep } \\
\text { (Nabarro-Herring) }\end{array}$ & $\begin{array}{c}\text { above } \\
\sim 0.7 \mathrm{~T}_{\mathrm{m}}\end{array}$ & low & $\sim 1$ & $\mathrm{Q}_{\mathrm{SD}}$ \\
\hline $\begin{array}{l}\text { low temperature } \\
\text { diffusional creep } \\
\text { (Coble creep) }\end{array}$ & $\begin{array}{c}\sim 0.4 \text { to } \\
\sim 0.7 \mathrm{~T}_{\mathrm{m}}\end{array}$ & low & $\sim 1$ & $\mathrm{Q}_{\mathrm{GB}}$ \\
\hline
\end{tabular}

\subsection{Dislocation Creep}

At relatively high stresses and temperatures dislocation climb and glide are thought to be the most common deformation mechanisms during creep [2,p.852; $5, \mathrm{p} .19]$. Climb and glide are the recovery processes that balance strain hardening in secondary creep to produce a steady state creep rate. As the dislocation slips on its slip planes, it encounters obstacles which create dislocation pile ups; this is the hardening stage [3,p.43; 5,p.30]. Climb is necessary for the dislocation to free itself of obstacles that impede its slip, which can make climb rate controlling [2,p.955]. The slip and climb process is shown schematically in Figure 7. After climb has occurred, the dislocation can be annihilated by encountering a dislocation of opposite sign or it may slip on a new glide plane, most likely encountering another obstacle soon after [2,p.852;3,p.43;38,p.95]. 


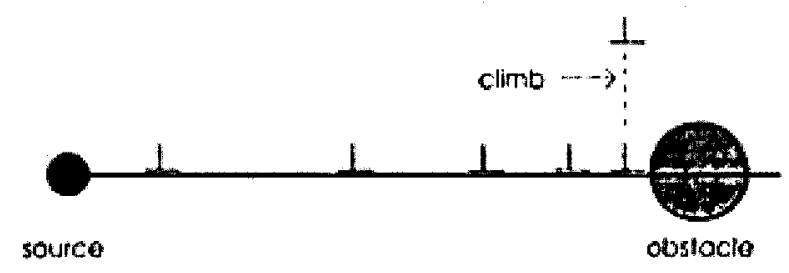

Figure 7: Pile up of gliding dislocations followed by climb [3,p.43].

For a pure metal or a simple alloy, one of two dislocation creep processes may occur, which are differentiated by the size of the obstacle the dislocation will encounter $[38, \mathrm{p} .94]$. The first is when the obstacle is on the scale of the dislocation core (a few interatomic distances) and can be passed by thermal agitation with the aid of stress; this is known as glide controlled creep. The second creep process is when the obstacle is too large to be overcome by thermal agitation. These larger obstacles are created by other dislocations through fluctuating internal stress fields or dislocations forming tangles or barriers by locking-up [38,p.96]. The larger obstacles may disappear through a thermally activated process, making it recovery controlled creep since diffusion is required to remove the obstacles before glide can continue [38,p.96].

In precipitation or dispersion strengthened alloys, dislocations face increased numbers of obstacles thereby improving the creep resistance. Depending on the applied stress, dislocations can overcome the obstacles in several ways. If the stress is high enough, dislocations can simply shear the obstacles as seen in Figure $8[1, p .95]$. 


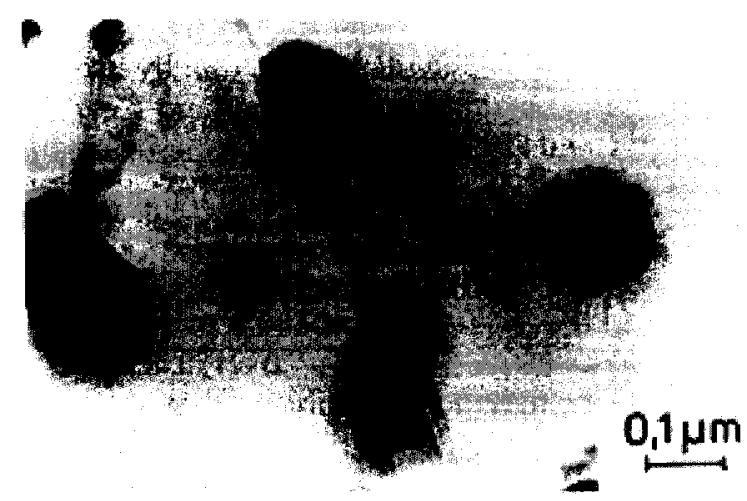

Figure 8: Shearing of $\gamma^{\prime}$ particles in a dilute $\gamma / \gamma^{\prime}$ alloy strained two per cent in tension $[1, p .197]$.

As the stress is decreased, dislocations can bypass obstacles either through Orowan looping or climb. Orowan looping is shown in Figure 9 where a dislocation passes a row of particles and leaves Orowan loops, or dislocation loops, around the obstacles [1,p.85,p.195; 5,p.179].

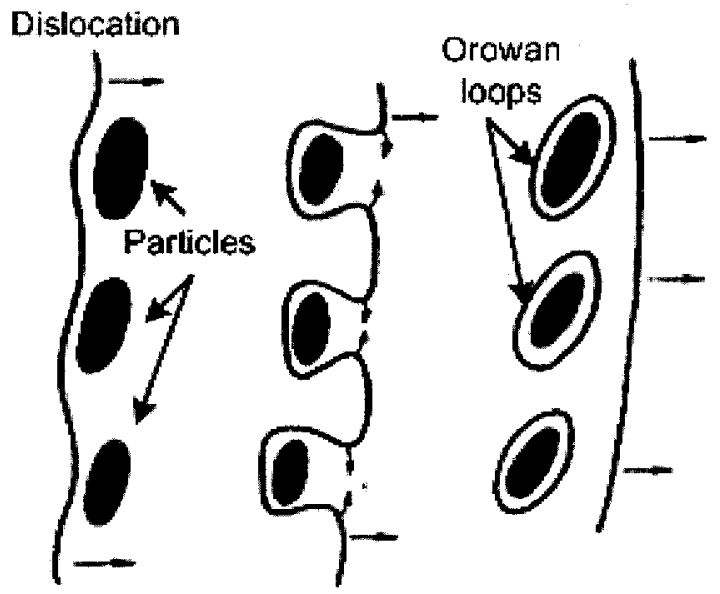

Figure 9: Dislocation passing particles through Orowan looping [5,p.179].

Dislocations can also climb over obstacles, either through local or general climb as seen in Figure 10. 


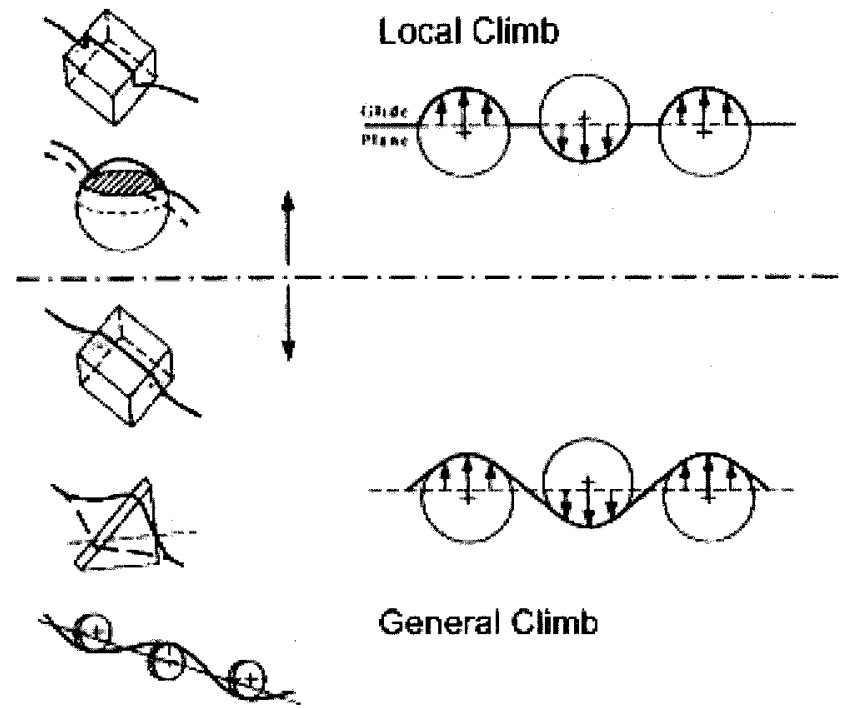

Figure 10: Dislocation local and general climb over particles [37,p.156].

As mentioned earlier, one of the deformation processes during creep is grain boundary sliding (GBS) which may occur during dislocation creep as an accommodation process. However, the role of GBS in high stress conditions which favour dislocation motion is believed to be minimal. One reason is that if enough glide systems are operative, then GBS is not required as an accommodation process [1,p.37; 5,p.211]. Also, the higher stresses required for dislocation creep will mean that the deformation within the grains will be fast compared to the deformation from GBS [5,p.248]. Thus in dislocation dominated creep, GBS has a very small role in the creep strain and creep rate. It is more important for intergranular creep fracture which will be covered in greater detail in Section 3.1.1 [5,p.248].

\subsection{Diffusional Creep and Grain Boundary Sliding}

Diffusional creep in general occurs at high temperatures and low stresses. At these conditions it is known as Nabarro-Herring creep and diffusion occurs within the grains $[5$, p.205; 36,p.248; 38,p.195]. At lower temperatures accompanied by low 
stresses, diffusional creep occurs by diffusion along grain boundaries and is known as Coble creep [2,p.845; 5,p.205; 36,p.249; 38,p.200].

Figure 11 shows the basic physical concept of diffusional creep, that is stress directed diffusional mass transport [5,p.205].

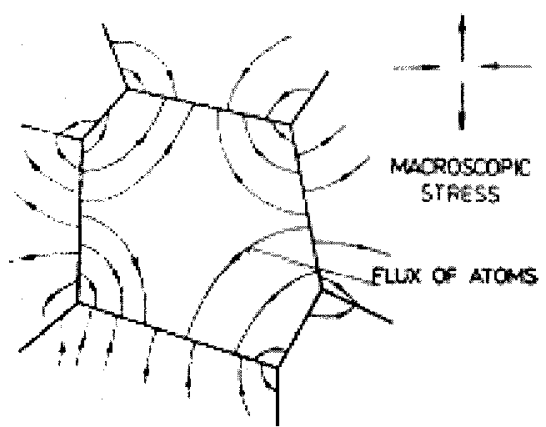

Figure 11: Stress directed diffusion of atoms in Nabarro-Herring creep [5,p.208].

When a tensile stress is applied, vacancies are formed on grain boundaries normal to the tensile axis $[1$, p.54; 36,p.248; 37,p.91]. A basic assumption of Nabarro-Herring and Coble diffusional creep is that grain boundaries are perfect sources and sinks for vacancies which are required to accomplish the mass transport $[2$, p.845; 5, p.206; 36,p.248]. Thus there is a concentration gradient of vacancies between grain boundaries under tension and those in compression. This concentration gradient provides the driving force for the flow of vacancies from boundaries in tension to those in compression $[1$, p.54; 2, p.845; 3, p. $35 ; 36$, p. $248 ; 37$, p.91]. In response, there is a counter flow of atoms from grain boundaries in compression to those in tension. This then leads to an extension of the grain in the tensile direction [3,p.32]. Equation (5) gives the creep rate for lattice diffusional creep (Nabarro-Herring creep) [3,p.34; 5,p.208; 38,p.198]:

$$
\dot{\varepsilon}=K \frac{D_{s d} \sigma \Omega}{d^{2} k T}
$$


Here $\mathrm{K}$ is a constant, $\mathrm{D}_{\mathrm{SD}}$ is the diffusion coefficient for lattice self-diffusion, $\sigma$ is the stress at the grain boundary, $\Omega$ is the volume of a vacancy, $d$ is the average grain diameter, $\mathrm{k}$ is Boltzmann's constant and $\mathrm{T}$ is the temperature.

The relation for the creep rate of grain boundary diffusional creep (Coble creep) is a simple modification of Equation (5) [3,p.35; 5,p.209; 38,p.200]:

$$
\dot{\varepsilon}=K \frac{D_{g b} \delta \Omega \sigma}{d^{3} k T}
$$

Diffusion is considered to be occurring in a narrow zone of width $\delta$ along the grain boundaries, where "the area of grain boundary zone intersecting a unit area of a polycrystal of average grain diameter, $d$, is given by $(\delta / d)$ " [3,p.35]. For both lattice and grain boundary diffusional creep, there is a clear grain size dependence. Thus, both mechanisms are dominant with finer grain sizes. Which type of diffusional creep will be dominant also depends on the temperature. This is due to the activation energy being lower for grain boundary diffusion than for lattice self-diffusion diffusion $\left(\mathrm{Q}_{\mathrm{GB}}<\mathrm{Q}_{\mathrm{SD}}\right)$. Thus at lower temperatures, it is easier for diffusion to take place along the grain boundaries than within the grain boundaries. The activation energy affects the diffusion coefficient as seen in equation (7). The relation given by Equation (7) makes the creep rate of diffusional creep processes consistent with the power law relationship given in Equation (2) [3,p.34].

$$
D=D_{0} \exp -(Q / R T)
$$

An important phenomenon observed, that shows diffusional mechanisms are operating, is that of denuded zone formation. This is seen in materials with precipitates, where the faces of grains in tension become free of precipitates as atoms diffuse there from boundaries in compression. The grain faces in compression then show an increase 
in precipitates. Figure 12 shows a schematic of denuded zone formation while Figure 13 shows the formation of denuded zones in a crept sample of $\mathrm{Mg} 0.5 \% \mathrm{Zr}$ alloy.

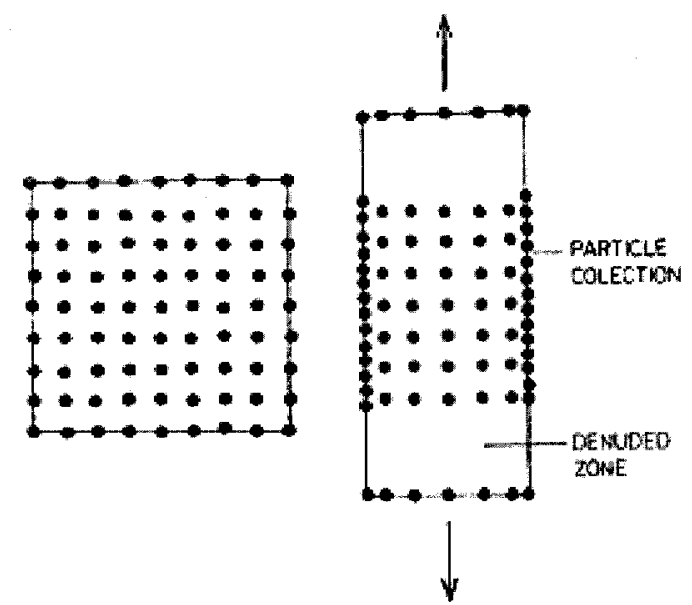

Figure 12: Schematic of denuded zone formation in a material with precipitates [5,p.221].
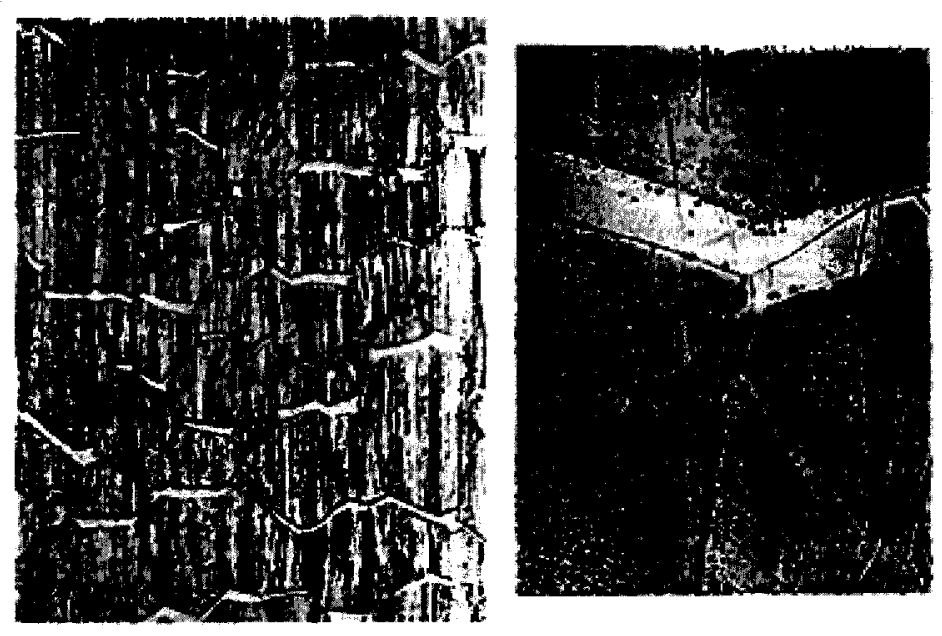

Figure 13: Denuded zone formation in $\mathrm{Mg} 0.5 \% \mathrm{Zr}$ alloy [1,p.57].

While Nabarro-Herring creep is generally considered to be only applicable at very high temperatures and low stresses, Coble creep is what allows diffusional mechanisms to be applicable at lower temperatures; thereby making it a concern in engineering applications $[1$, p. $55 ; 5$, p. $205 ; 37$, p.91].

An important point associated with these diffusional creep theories is the need for an accommodation process to prevent void formation due to mass transport [5,p.211]. 
This is where grain boundary sliding (GBS) comes into play. The accommodation of diffusional creep through grain boundary sliding is illustrated in Figure 14. The diffusion of atoms from boundaries under compression to those in tension will create incoherency between grains; GBS eliminates this [37,p.95].

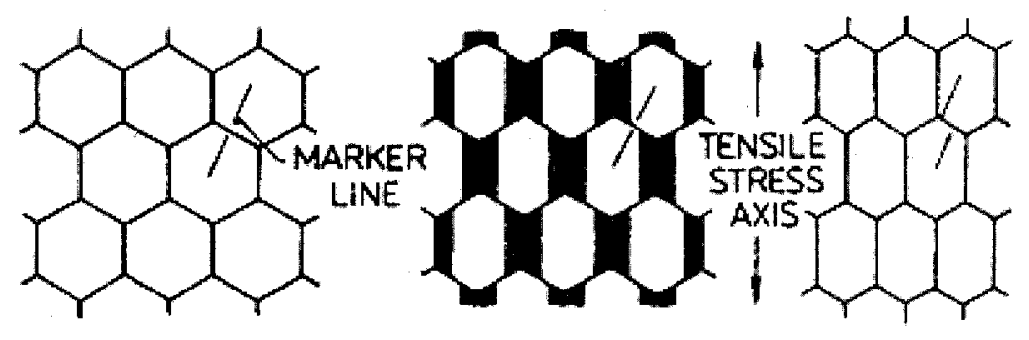

A

B

$\mathrm{C}$

Figure 14: A) Equiaxed grains, B) Result of diffusional creep without GBS, C) GBS occurring simultaneously with diffusional creep resulting in an offset marker line [5,p.211].

While Figure 14 shows GBS as an accommodation process for diffusional creep, the opposite could in fact occur [5,p.246;38,p.195]. That is that GBS occurs and diffusion accommodates it by supplying matter to the forming voids. The two creep processes are thus thought to be cooperative, and the contributions of each cannot be separately identified [5,p.211; 37,p.95; 38,p.195;39].

While it may appear that the physical processes controlling high temperature creep at low stresses are well understood, there is in fact controversy regarding the matter [6-20]. The list of works cited in regards to this debate is not exhaustive, though the fundamental issues are well presented. In short, the arguments against the theory of diffusional creep are that the experimental creep rates are not always in agreement with predictions from theory, the dependence of creep rate on stress and grain size, as determined from experiments, is not always as predicted and that denuded zones are not due to diffusional creep, but from the dissolution of particles at shearing and migrating grain boundaries $[9 ; 12-13 ; 17 ; 19]$. Detractors of the diffusional creep theory would 
replace it with a dislocation creep process such as Harper-Dorn creep along with GBS [9; $13 ; 17]$.

Harper-Dorn creep is also a creep mechanism that only occurs at high temperatures and low stresses [40]. Although it is a dislocation creep mechanism, it has similarities to diffusional creep in that the stress exponent is one and the activation energy is that of lattice self-diffusion [40]. It also predicts higher creep rates than diffusional creep, thereby addressing one of the problems with the diffusional creep theory. Unlike diffusional creep, Harper-Dorn creep does not have a grain size dependence, but it is believed to only occur when the dislocation density is extremely low [40]. Another requirement is that the test material purity be very high, which could rule out the occurrence of Harper-Dorn creep in engineering alloys [40].

Returning to diffusional creep, supporters of the theory point out though that it may be more useful to investigate why diffusional creep may be suppressed or modified instead of trying to replace it entirely [12]. However, the supporters of diffusional creep also acknowledge that the numerical theory is complicated by factors such as nonuniformity of stress due to varying lengths of diffusional paths, shape of grains and distribution of grain sizes [19]. There is also the possibility that the assumption of grain boundaries being perfect sources and sinks of vacancies is incorrect $[12 ; 19]$. Thus, it is apparent that further research is required to either refine the diffusional creep theory or find a suitable alternative by first disproving diffusional creep and then providing an alternative that is based on determinable physical processes and capable of providing accurate predictions for engineering applications. 


\section{$3 \quad$ Grain Boundary Morphology}

\subsection{Grain Boundaries}

Metals are crystalline structures which after most solidification processes are polycrystalline [41,p.33]. Due to these many crystals, or 'grains', boundaries form to separate the grains; as each has a different orientation of its crystalline lattice with respect to its neighbouring grains [21,p.145].

A simple description of grain boundary structure is islands of good fit (grains) separated by lines of bad fit (grain boundaries) [36,p.97; 42]. Referring to Figure 15, the grain boundaries are planar crystalline lattice imperfections that separate grains of different orientation, which can be understood as complex arrays of dislocations [2,p.168; 21, p.145; 36,p.97; 38,p.63]. The crystalline order of the grains generally remains constant right up to the grain boundary, which is normally several atomic diameters wide $[21$, p.146; 36,p.43; 38,p.66].

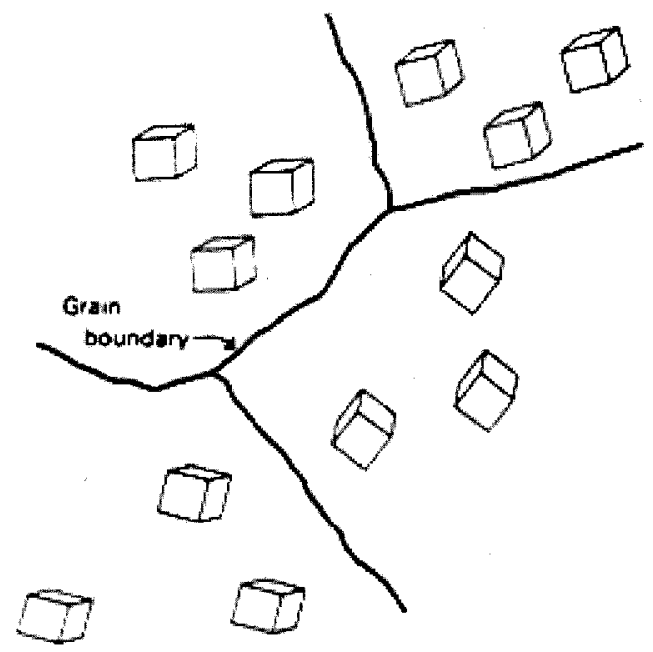

Figure 15: Grain boundaries separate grains of different crystallographic orientation [41,p.34].

A characteristic of grain boundaries is the misorientation angle $(\theta)$, which can be seen in a small angle tilt boundary in Figure 16. The lattice misorientation caused by 
grain boundaries can be represented as a planar array of dislocations [2,p.169; 38,p.64]. A common grain boundary would have a misorientation angle larger than $10-15^{\circ}$, which would class them as high angle grain boundaries [36,p.43; 38,p.65]. The high angle boundaries can then only be described as complex arrays of dislocations, as the simple dislocation structure shown in Figure 16 no longer applies.

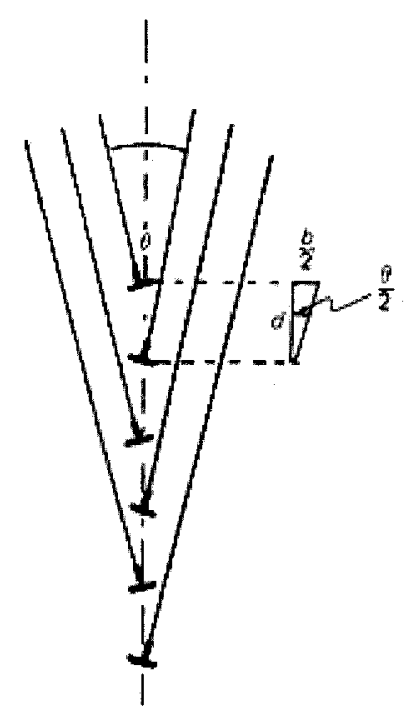

Figure 16: Small angle tilt boundary made up of edge dislocations of Burgers vector $\mathbf{b}$, separated by a distance $\mathbf{d}[38, \mathrm{p} .65]$.

The disarray in grain boundaries gives them higher energy than the grains themselves, which makes them regions of chemical reactivity [36,p.43; 41,p.34]. This results in a region where nucleation and growth of precipitates is easier, which is also aided by the fact that diffusion is more rapid along grain boundaries due to the lower atomic packing [21,p.147]

There also exist 'coincidence site boundaries' which are in less disarray and have lower interfacial energy as a result [36,p.98]. These 'coincidence site boundaries' occur at interfaces where two crystals have a number of lattice sites that coincide [2,p.195]. The crystals in effect share lattice sites [36,p.98]. This type of boundary with a 
sufficiently large amount of coincidence sites is believed to have higher mobility and could support rapid grain growth [2,p.195].

Figure 17, provides a less abstract depiction of grains and grain boundaries, showing how grains are in fact polyhedra and the usual planar nature of grain boundaries.

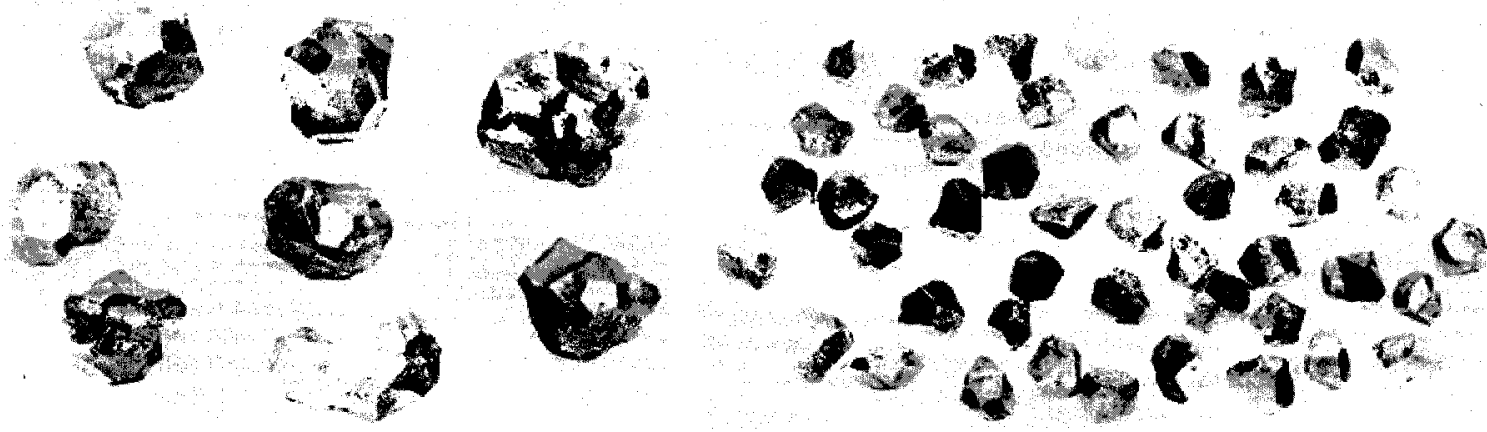

Figure 17: Grains from beta brass showing polyhedral nature and planar facets of grain boundaries $[2, \mathrm{p} .191]$.

\subsubsection{Role of Grain Boundaries in Creep}

Apart from grain boundary sliding (GBS) and acting as a source of vacancies, grain boundaries play an important role in the fracture of materials during creep [36,p.247]. Under creep conditions, materials tend to fail by intergranular fracture, as opposed to transgranular fracture typically seen at lower temperatures $[2, \mathrm{p} .870 ; 3, \mathrm{p} .50$; 21,p.264]. This intergranular fracture occurs at the end of the tertiary stage of creep which is marked by an increasing creep rate.

The increasing creep rate during the tertiary stage is due to necking of the creep test specimen and more importantly due to cavities and cracks forming preferentially on grain boundaries; both processes leading to an increase in the effective stress $[1, \mathrm{p} .16$; 21, p.264; 36,p.249]. The cavities/cracks continuously form on grain boundaries during creep, though their effect becomes noticeable during the tertiary stage of creep [5,p.344]. As was mentioned in Section 2, these cavities and cracks eventually coalesce into defects 
sufficiently large to propagate and fracture the test specimen [3,p.51]. Figure 18 shows the two types of cavities and cracks which lead to intergranular failure. These cavities and cracks nucleate early in the creep life and continue to form simultaneously during the creep process $[2$, p.817; 3,p.51; 5,p.344] The cracks tend to occur more often in high stress and high strain rate conditions, while the cavities favour lower stresses and lower strain rates [2,p.874].
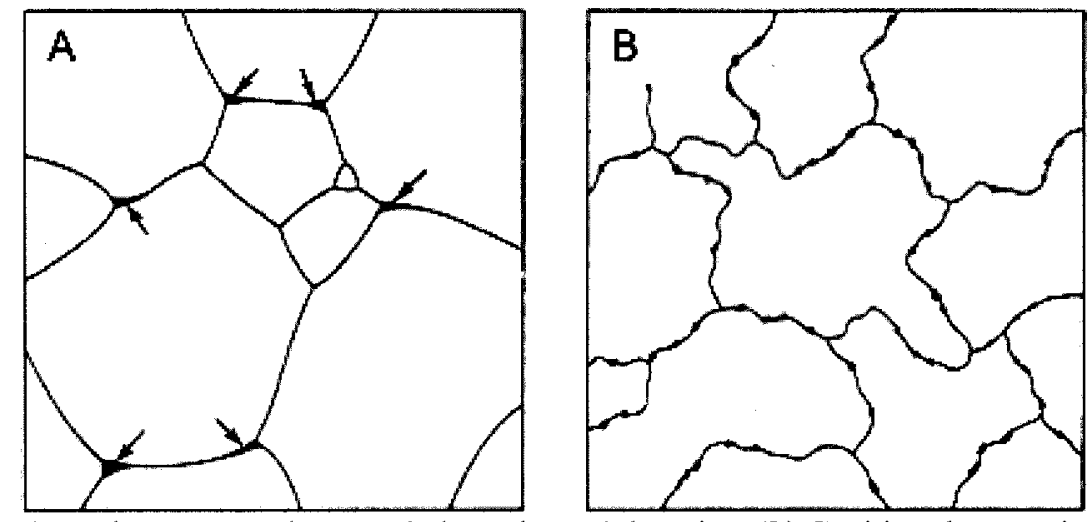

Figure 18: A) Wedge type cracks at grain boundary triple points, B) Cavities along grain boundaries $[2, \mathrm{p} .871]$.

The wedge cracks seen in Figure 18 are generally attributed to GBS which is not accommodated, leading to a stress concentration high enough to cause a crack to form $[2, p .871 ; 3, p .53]$. There is also the possibility that the wedge cracks are just a product of accumulating cavities $[2, p .874]$. The two possibilities are shown in Figure 19. These cracks occur at the junction of grains, making them also known as triple point cracks. 

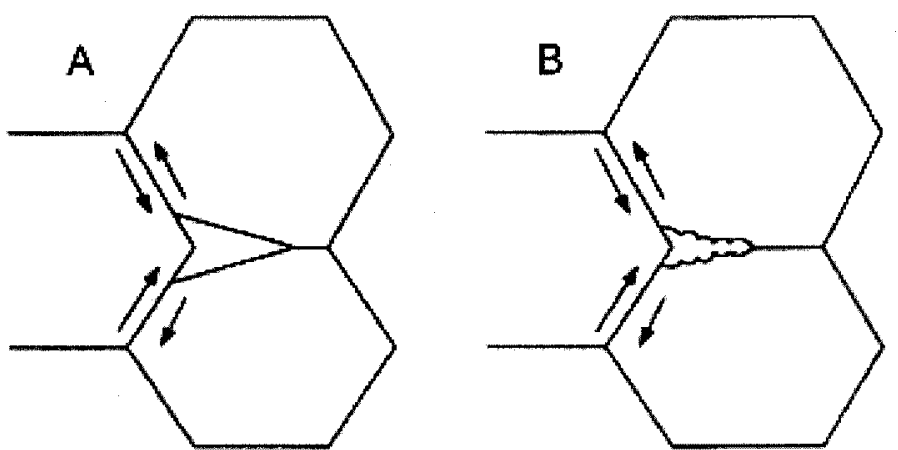

Figure 19: A) Wedge crack formed due to GBS, B) Wedge crack formed due to accumulating cavities $[37$, p.215].

Cavities generally nucleate inhomogeneously on grain boundaries transverse to the tensile axis $[1$, p.16;3,p.51; 5,p.346; 36,p.249]. Their method of formation is also often attributed to GBS along a grain boundary which may feature discontinuities such as jogs/ledges or hard particles $[2$, p.873; 3,p.54; 37,p.218]. The possibility also exists that they may form due to vacancy diffusion which could be assisted by GBS, or they may even form by a dislocation mechanism [2,p.876; 3,p.54; 5,p.344; 37,p.218]. Refer to Figure 20 for the various possible cavity formation mechanisms. 
A

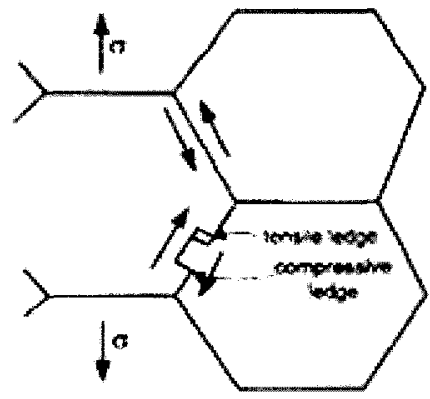

C

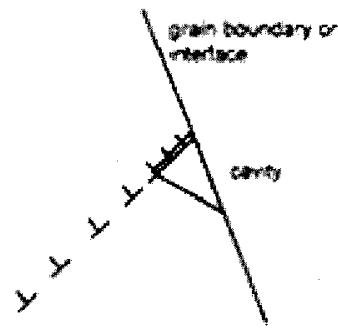

B
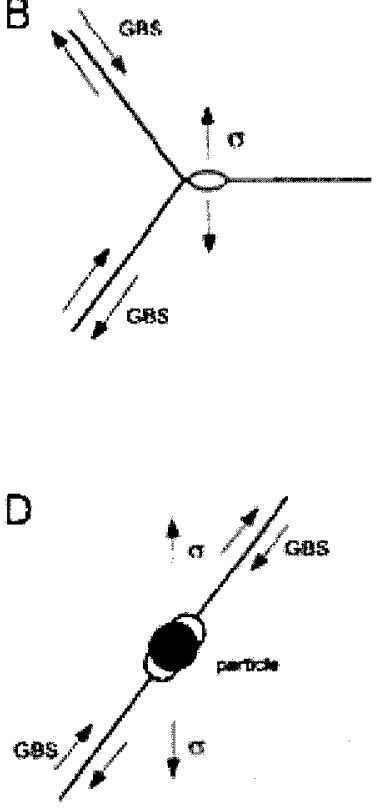

Figure 20: A) Cavity forming at ledge due to GBS, B) Cavity forming from vacancy condensation, C) Cavity forming through a dislocation mechanism, D) Cavity forming at a particle $[37, \mathrm{p} .220]$.

The effect of GBS is noteworthy since it not only provides an accommodation mechanism for diffusional creep, but it is also believed to be a source of damage during creep. Thus the importance of grain boundaries in creep is reinforced, with efforts to reduce grain boundary sliding likely being very beneficial.

\subsection{Serrated Grain Boundary Formation}

Grain boundaries are planar defects of the crystalline lattice which most commonly appear as approximately straight lines during metallographic analysis.

However, the morphology of a grain boundary can be changed to a serrated or zig-zag morphology as shown in Figure 21 . This changes the grain boundary from a mostly flat plane to a surface with 'hills' and 'dips'. 


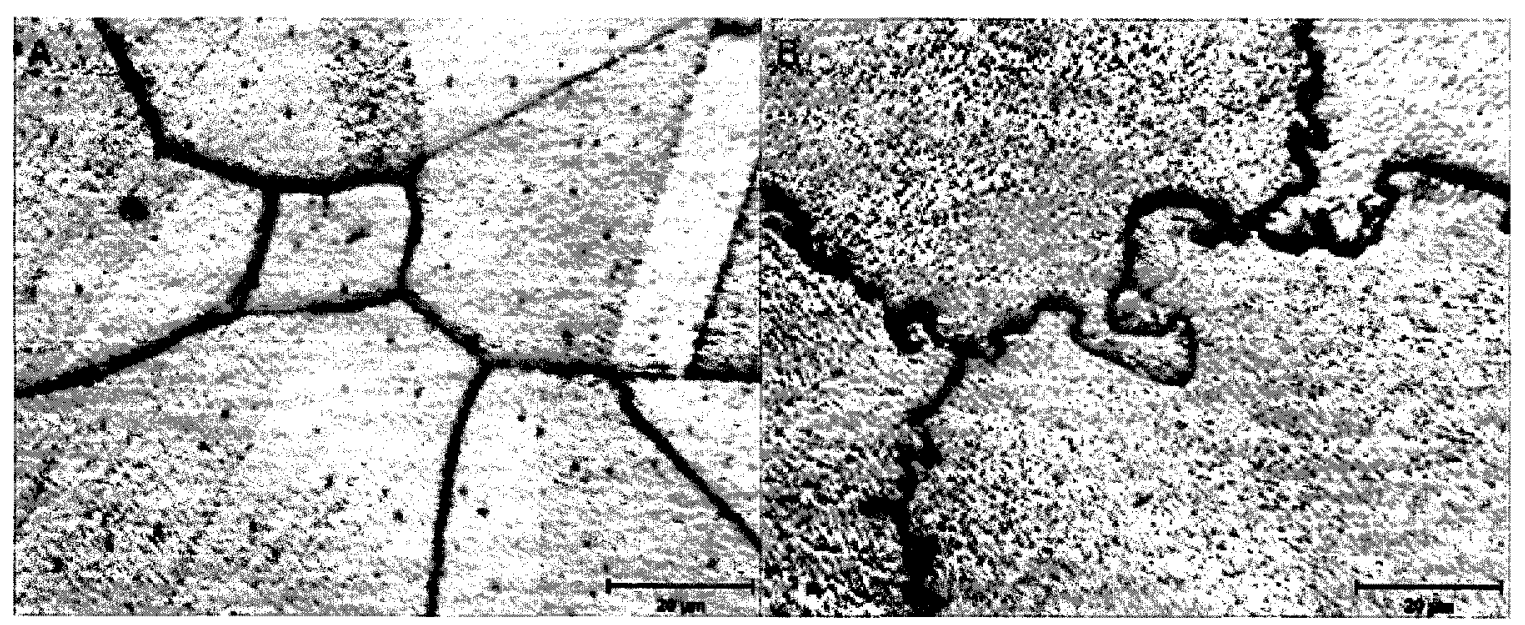

Figure 21: Planar (A) and serrated (B) grain boundaries in nickel base superalloy PWA 1113 [43].

Serrated grain boundaries can occur in different materials including nickel and cobalt base superalloys, as well as various types of austenitic stainless steels. The serrations form during heat treatment involving solutionizing followed by furnace cooling and/or isothermal aging. Grain boundary serrations can also arise as a result of high temperature deformation in various materials [44-47]. The following sections describe the formation of grain boundary serrations in various materials, specifically through the use of heat treatments.

\subsubsection{Nickel Base Superalloys}

Serrated grain boundary formation in nickel base superalloys can be divided into alloys with a base composition similar to IN 718 and those with high $\gamma^{\prime}$ volume fraction [4,p.110]. In both cases, serrations occur as a result of the precipitation of secondary phases. The precipitates are intermetallic compounds; $\delta$ orthorhombic $\mathrm{Ni}_{3} \mathrm{Nb}$ for IN 718 type alloys and $\gamma^{\prime}$ fcc ordered $\mathrm{Ni}_{3}(\mathrm{Al}, \mathrm{Ti})$ for high $\gamma^{\prime}$ volume fraction alloys [4,p.110; $48, \mathrm{p} 25]$. 
In IN 718 type alloys, the Tu-Turnbull mechanism is believed to occur which involves controlled cellular precipitation of the $\delta \mathrm{Ni}_{3} \mathrm{Nb}$ phase at grain boundaries $[4$, p.110; 28; 49-50]. The Tu-Turnbull mechanism was originally outlined for a lead-tin bicrystal; the process is shown schematically in Figure 22 [51].
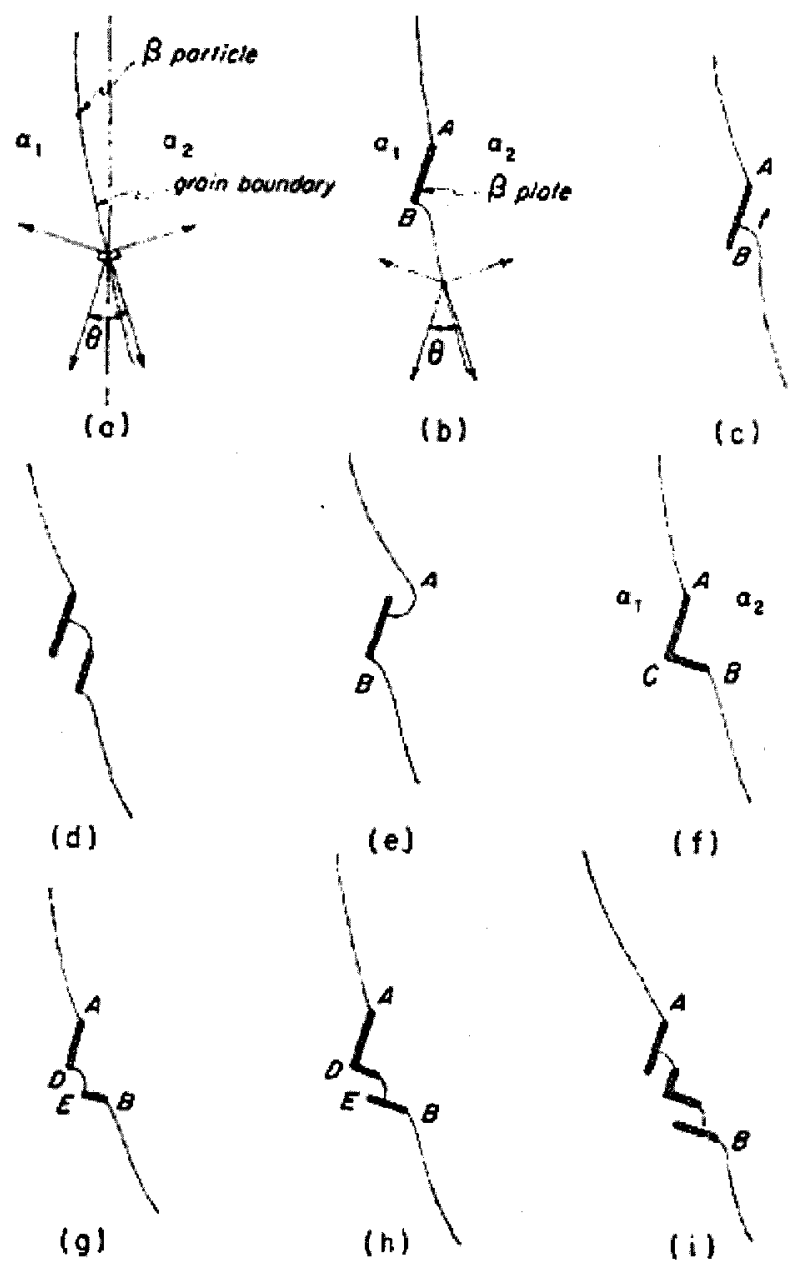

Figure 22: Schematic diagram of Tu-Turnbull mechanism [51].

The process is explained by $\mathrm{Tu}$ and Turnbull as follows:

"In the earliest stage of precipitation, lamellae $(\beta)$ are found lying along the grain boundary; later they become embedded into the matrix with one set of tips still in the boundary... Fig. [22(b)] shows a plate along the boundary after considerable growth. Its orientation follows the crystallographic directions $\alpha_{1} \ldots$ this means that the left hand side of the tin plate is lying on the habit plane of $\alpha_{1} \ldots$ but the right hand side of the plate does 
not lie on the habit plane of $\alpha_{2} \ldots$ The existence of [a] difference between the surface free energies of the opposite sides of the plate produces a driving force which tends to replace the high energy interface $\alpha_{2}-\beta$ by the lower energy $\alpha_{1}-\beta$. This replacement is accomplished by the up and right motion of the boundary at B in Fig. [22(b)], followed by the motion illustrated in Fig. [22(c)]... which carries the boundary to the other end of the plate. This kind of motion of boundary B toward boundary A embeds the tin plate into grain $\alpha_{1} \ldots$ During the course of the motion of B, as in Fig. [22(c)], a second tin plate may form and lie parallel to the first one, see Fig. [22(d)]... in the same manner, a third one, a fourth one and more would appear successively and constitute a cell... [B]oundary A does not undergo the same kind of motion as B... [as] the boundary would have to be highly curved and this would be energetically unfavourable. On the other hand, it is apparent from Fig. [22(b)] that the configuration of boundary B is quite favourable for the branching of a plate out into a new part of it, as shown in Fig. [22(f)]... As the boundary... starts from $\mathrm{C}$ and moves in the direction shown by the arrow so as to traverse the plate, it may drain the $\mathrm{Sn}$ atoms away from the corner C. While this occurs, the configuration then changes to that shown in... Fig. [22(g)]. One reason for the drainage of Sn atoms may be to supply the tin for the branching of another plate at the position D (or E) see Fig. [22(h)]. When these processes are repeated, we obtain Fig. [22(i)]..." [51]

Thus the serrations are formed from grain boundary precipitates which branch and transfer into the matrix, with the driving force being the difference in surface free energy between the grain boundaries on either side of the precipitates [51]. These serrations are angular in nature (refer to Figure 23) unlike in the high $\gamma$ ' volume fraction alloys where the grain boundary serrations are wavy in nature [4,p.110]. A typical heat treatment used to produce these angular serrations involves solution treatment followed by furnace cooling to an aging temperature to precipitate the $\delta$ phase $[28,49-50]$. 

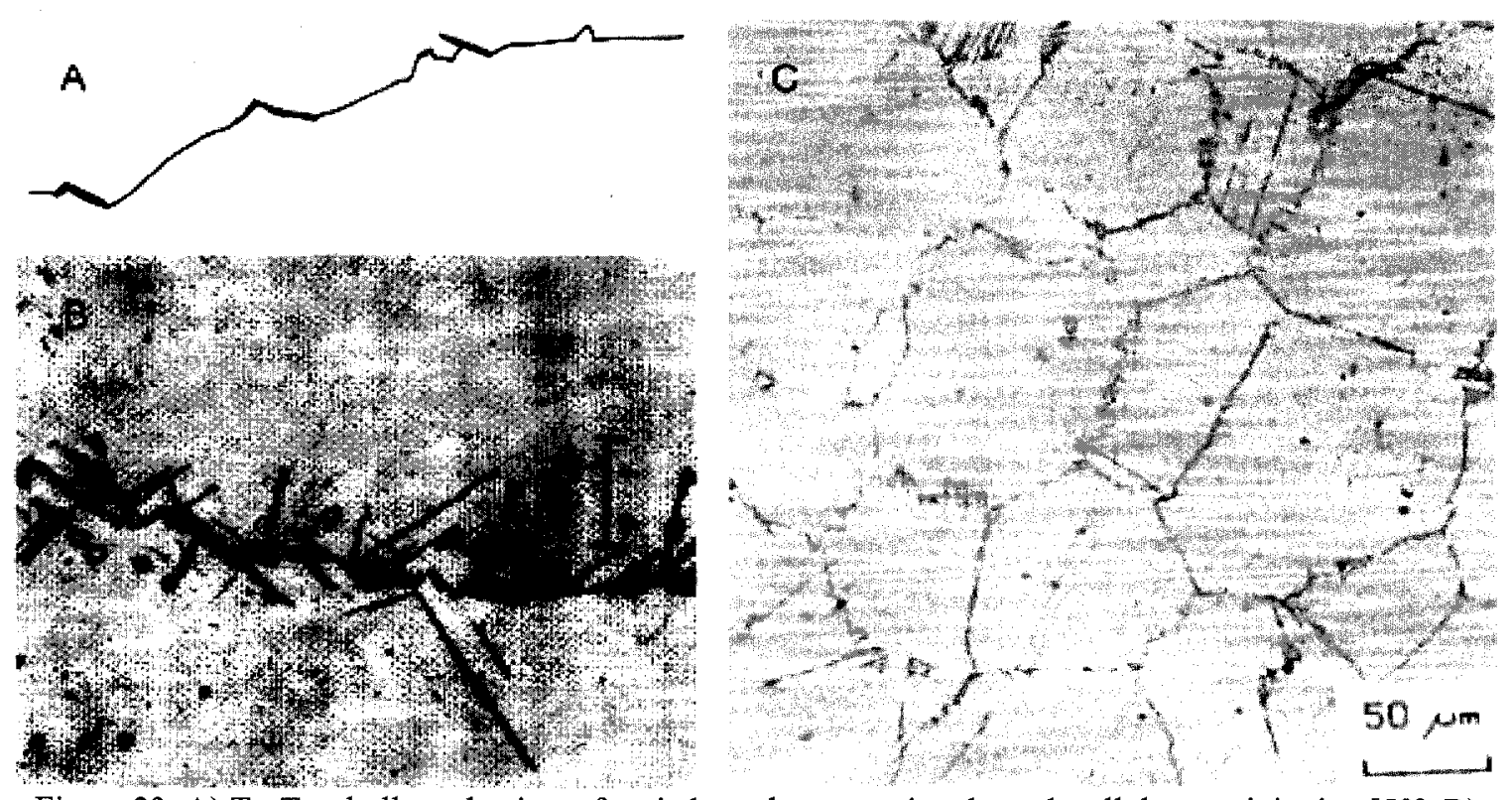

Figure 23: A) Tu-Turnbull mechanism of grain boundary serration through cellular precipitation [52], B) and C) Serrated grain boundary morphology of IN $718[50 ; 53]$.

High $\gamma^{\prime}$ volume fraction nickel base superalloys capable of forming serrated grain boundaries include alloys such as IN 792, IN 738, Nimonic 115, Astroloy, Alloy 713C, MERL76, Rene-80 and others $[26 ; 52 ; 54-60 ; 61-64 ; 65, p .83]$. Formation of grain boundary serrations is through solution heat treatment, specifically above the $\gamma^{\prime}$ solvus, followed by cooling at various rates through the $\gamma$ ' solvus range; where the cooling rate can vary greatly depending on the alloy. For example, IN 792 can form grain boundary serrations even during air cooling [58]. Cooling to some intermediate temperature is usually followed by isothermal aging and then cooling to room temperature. Refer to Figure 24 for micrographs of serrated grain boundaries. 

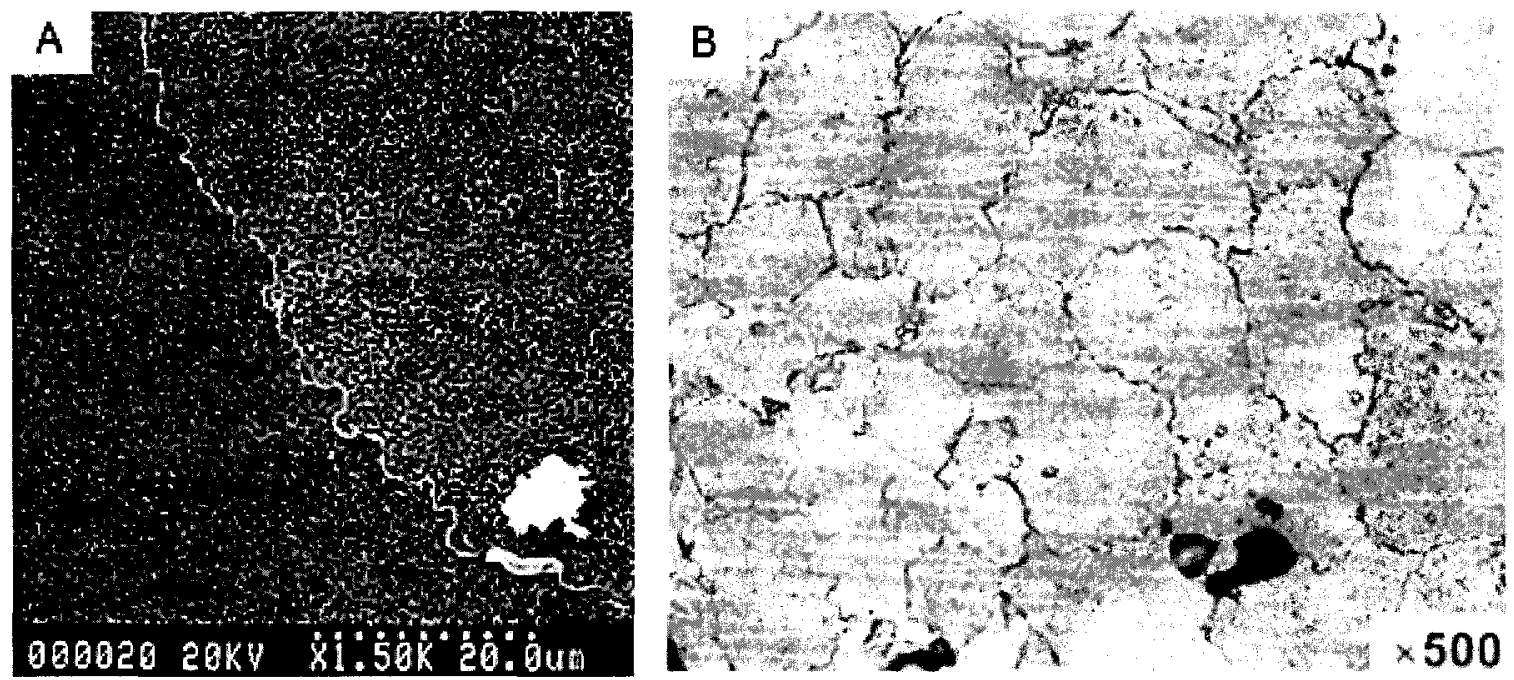

Figure 24: Serrated grain boundary micrographs, A) IN 738 [63], B) MERL76 [62].

The formation of serrated grain boundaries in high $\gamma^{\prime}$ volume fraction alloys is linked to the precipitation of $\gamma$. Referring to Figure 25, early theories were that cooling through the $\gamma^{\prime}$ solvus range from the solutionizing temperature results in heterogeneous precipitation of $\gamma^{\prime}$ at the grain boundaries [26;58-59]. The growth of these precipitates and continued grain boundary migration is thus the cause of grain boundary serrations [26; 58-59]. It was also believed that cooling through the $\gamma^{\prime}$ solvus range too quickly would result in small $\gamma^{\prime}$ precipitates, and lead to planar grain boundaries [59]. Eventually, precipitation of $\mathrm{M}_{23} \mathrm{C}_{6}$ carbides at the grain boundaries and precipitation of $\gamma$ within the grains stopped the grain boundary migration [26; 58-59]. 

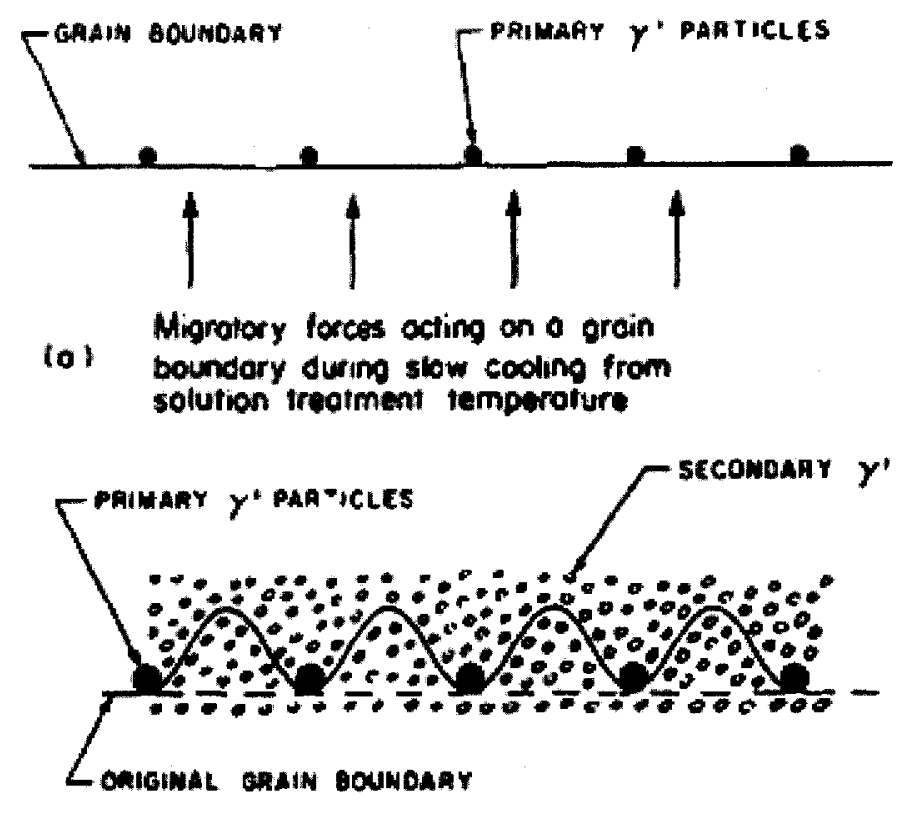

(b) Serroted arain boundaries formed on
cooling from sotution ireorment to
portial solution treatment temperotures

Figure 25: Model showing serrated grain boundary formation by cooling through $\gamma$ ' solvus range from solution treatment [54].

A later theory put forward by Koul et al. also concludes that serrated grain boundary formation is related to $\gamma^{\prime}$ precipitation $[52 ; 54-55]$. The formation of serrations is again closely linked to the cooling rate through the $\gamma^{\prime}$ solvus range [52]. Some basic requirements determine whether an alloy is capable of forming serrated grain boundaries. The first is that the $\gamma^{\prime}$ solvus must be higher than the $\mathrm{M}_{23} \mathrm{C}_{6}$ solvus, so that the grain boundaries are not pinned before the $\gamma^{\prime}$ begins to precipitate $[52 ; 54-55]$. The second requirement is a minimum grain boundary $\gamma^{\prime}$ particle size, below which serrated grain boundaries will not form [52]. This critical particle size is given below:

$$
\mathrm{r}=3 \gamma_{\mathrm{st}} / 4 \mu \delta^{2}
$$

where $\gamma_{\mathrm{st}}$ is the interfacial energy due to structural distortion caused by the misfit dislocations, $\delta$ is the particle-matrix misfit, and $\mu$ is the shear modulus of the matrix [52]. 
The theory by Koul et al. however differs from previous ones, as it rejects the idea that grain boundaries are mobile enough to migrate between the grain boundary $\gamma^{\prime}$ particles and cause sufficient serration. Instead, it is proposed that grain boundary serrations occur as a result of the movement of primary $\gamma^{\prime}$ found on the grain boundaries $[52 ; 54-55]$. This theory is shown schematically in Figure 26 . The theory suggests that $\gamma$ nucleates on one side of a grain boundary, and that the coherency strains of the $\gamma$ particle and grain boundary interface must be accommodated [54-55]. The coherency strains are then accommodated due to the net strain energy difference between the two grains $\mathrm{A}$ and $\mathrm{B}$, as shown in Figure 26. This results in the movement of the $\gamma$ particle until the line tension of the grain boundary stops it [54-55]. Their evidence in support of this theory is that they find $\gamma$ particles of nearly elliptical shape, always on the concave side of serrations [54-55]. They also state that the magnitude of the force available to form serrations could be related to the $\gamma$ particle-matrix misfit, which they reason could be the explanation for changes in the minimum cooling rate required to form serrations in different alloys [55]. 

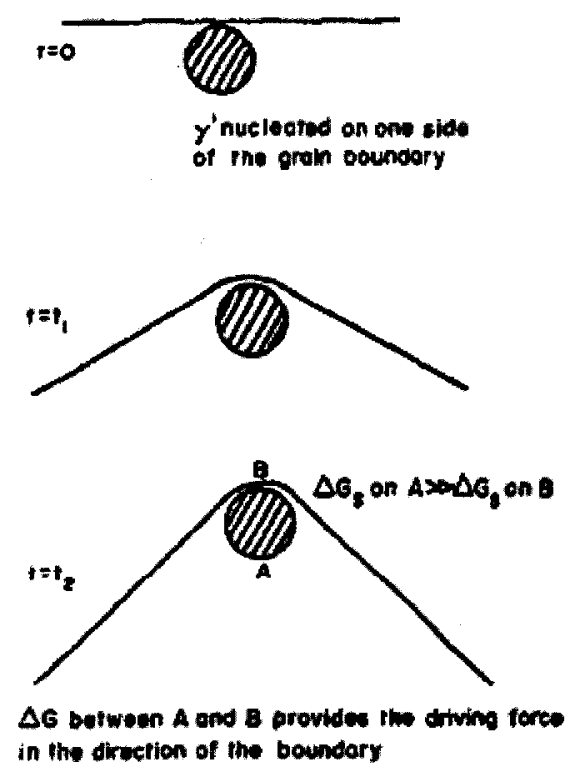

Figure 26: Schematic of grain boundary serration model based on $\gamma^{\prime}$ migration in Nickel base superalloys [54].

Later work by Danflou et al. suggests that serration of grain boundaries can be considered a type of discontinuous reaction requiring grain boundary migration [56]. These findings are different from that of Koul et al. in that serrations do not form from the movement of grain boundary $\gamma$ precipitates and that grain boundary migration is a requirement. Instead, the theory states that some of the precipitating $\gamma$ dissolves partially or completely in contact with migrating grain boundaries [56]. This then contributes to the growth of larger and more stable $\gamma^{\prime}$ precipitates in the opposite grain. Thus the grain boundary acts as a 'short-circuit' path for solute to quickly establish an equilibrium state through the growth of $\gamma^{\prime}$ on the grain boundaries; thereby pinning them and forming serrations [56]. Danflou et al. also noted that the size of the grain boundary serrations was not only affected by the cooling rate, but also by the coincidence of a grain boundary. They note that serrations of large amplitude were found on low coincidence or 
random grain boundaries, while small amplitude serrations are found on high coincidence boundaries [56].

Work by Henry et al. on a model nickel base superalloy purposely designed to minimize the misfit between the matrix and $\gamma$ precipitates, again highlighted the importance of $\gamma^{\prime}$ precipitation in the serration of grain boundaries [66]. It was found that the $\gamma^{\prime}$ precipitate growth mode affected the grain boundary morphology. Spherical precipitates with high nucleation density produced planar grain boundaries while dendritic precipitates caused serrations to form [66]. Refer to Figure 27 for an illustration of how the dentritic precipitate growth causes grain boundary serrations. Initially a $\gamma$ precipitate coherent with one grain forms at a grain boundary. Once the precipitate has sufficiently grown, dendritic growth will occur at the matrix and grain boundary interfaces. Due to the solutionizing heat treatment, the matrix is supersaturated with solute and diffusion occurs at the matrix and grain boundary interfaces [66]. The largest precipitate growth is at the grain boundary interface due to rapid grain boundary diffusion from a wider area, causing asymmetric growth as seen in Figure 27.

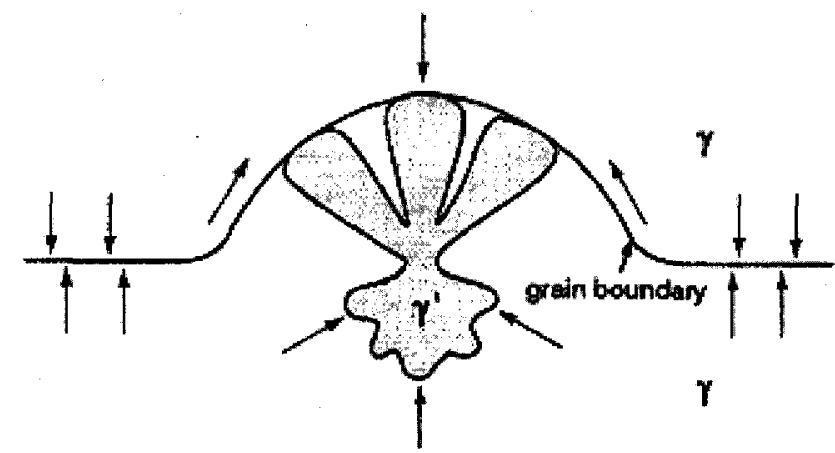

Figure 27: Formation of serrated grain boundary through asymmetric $\gamma^{\prime}$ precipitate growth [66].

An important point made by Henry et al. is that without deep etching of the matrix, only discrete $\gamma^{\prime}$ precipitates are seen at the grain boundary serration peaks. 
Referring to Figure 28, only etching to the point of deeply grooving the grain boundaries will expose the true nature of the $\gamma^{\prime}$ precipitate growth [66]. These results differ from that of Koul et al. in that serrations are formed in an alloy with low misfit between the matrix and $\gamma$ precipitates. As well, formation of grain boundary serrations is again shown not to be due to migration of grain boundary $\gamma^{\prime}$ precipitates [66].
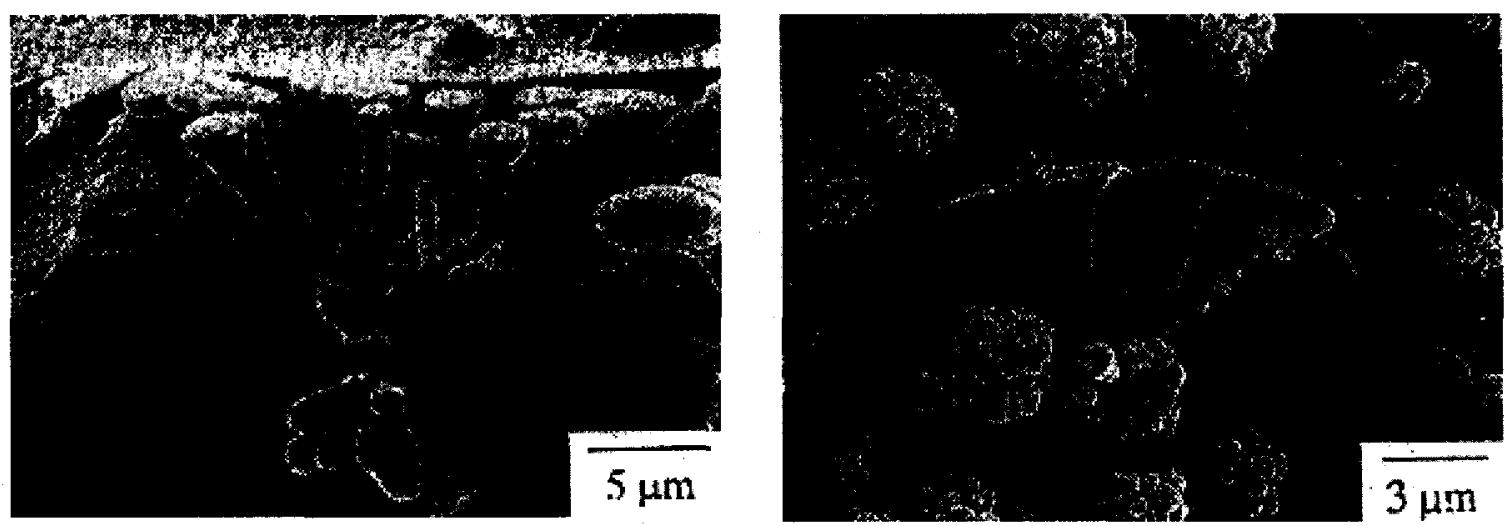

Figure 28: Asymmetric $\gamma$ ' precipitate growth causing grain boundary serrations, revealed through deep etching [66].

The work of Letellier et al. appears to confirm that of Henry et al. [61]. They also show that the precipitation of $\gamma^{\prime}$ causes movement of the grain boundary, leading to serrations. Nucleation of $\gamma^{\prime}$ at a grain boundary and growth into an adjacent grain occurs, likely caused by increased grain boundary diffusion and mobility [61].

Most recently, Danflou et al. use the low matrix and $\gamma$ misfit alloy developed by Henry et al., as well as Astroloy, and produce grain boundary serrations through an isothermal heat treatment just below the $\gamma$ ' solvus [57]. In both alloys, dendritic $\gamma$ precipitate growth is seen, pushing the grain boundaries and forming serrations. Also, a new category of grain boundary serration is seen in the alloy of Henry et al. [57]. This new category of serration can be seen in Figure 29. The serration is like a 'fan', caused by a discontinuous reaction, in regions of low precipitate density. 


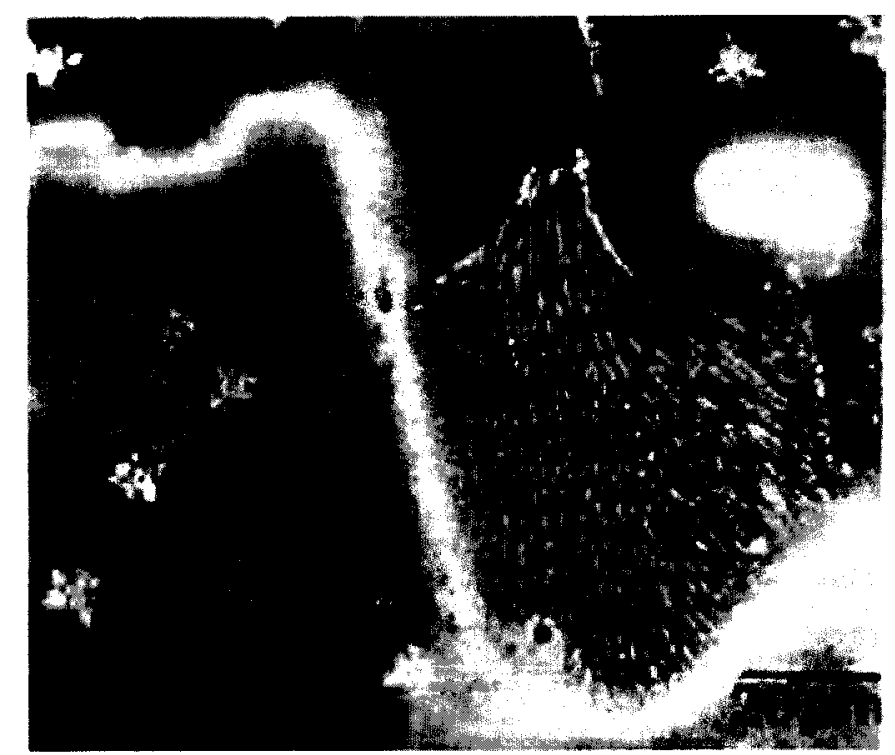

Figure 29: Fan type serration in model alloy of Henry et al. [57].

\subsubsection{Austenitic Stainless Steels}

While the formation of grain boundary serrations in austenitic stainless steels such as $21-12 \mathrm{~N}$ and 316 is known $[25,67]$, some of the most recent work has been concerned with 304 and 316 stainless steels [68-74]. This work is also the most interesting since it concludes that grain boundary serrations in these steels is not related to precipitate formation whatsoever. Hong et al. have found that grain boundary serrations occur before the precipitation of $\mathrm{M}_{23} \mathrm{C}_{6}$ carbides along the grain boundaries of 304 and 316 [68$69 ; 71]$. This can be seen in Figure 30. They ensured that this is correct through the use of transmission electron microscopy (TEM) and high resolution TEM, neither of which could detect carbide particles on the grain boundary just after serration occurred [69]. The serrations were formed in a similar manner as in nickel base superalloy, using a solution heat treatment, followed by furnace cooling and/or isothermal aging. 

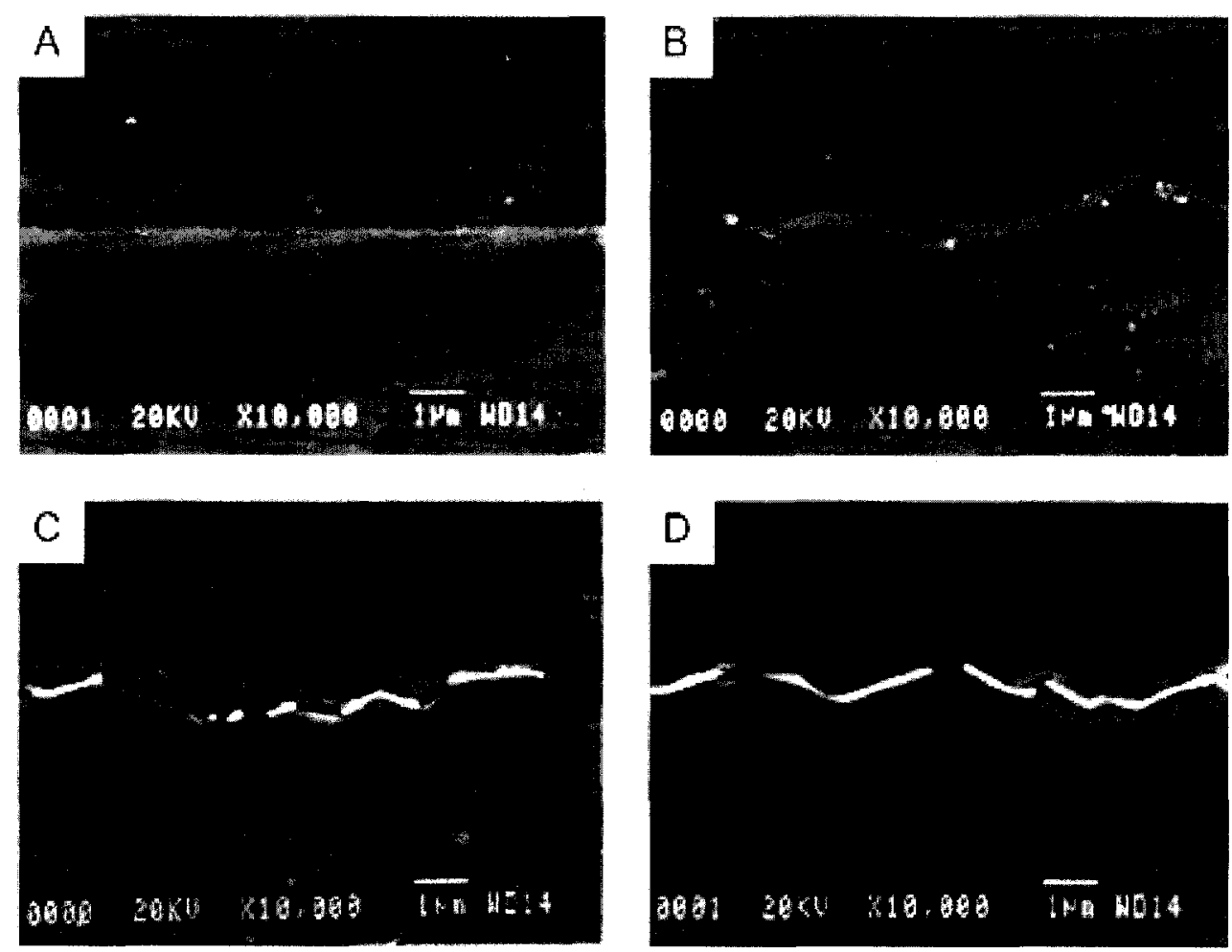

Figure 30: Formation of serrated grain boundaries followed by carbide precipitation in 304 stainless steel, A) after solution treatment, B) furnace cooled to aging temperature and aged for $5 \mathrm{~min}, \mathrm{C}$ ) furnace cooled to aging temperature and aged for $15 \mathrm{~min}$ and D) furnace cooled to aging temperature and aged for $3 \mathrm{hrs}$ [71].

It is also noted that the misorientation angle of the grain boundaries is larger in planar boundaries than in serrated ones [68]. Thus even with increased grain boundary area, they suggest that the driving force for grain boundary serration could be the reduction of interfacial free energy per unit area [68].

Hong et al. also noted that in both 304 and 316, the $\mathrm{M}_{23} \mathrm{C}_{6}$ carbides had a triangular morphology if they precipitated on a planar grain boundary, while on a serrated grain boundary they were planar $[69-70 ; 72-73]$. They state that the planar carbides have lower interfacial energy due to lower indices of the interfaces and lower misorientation angle $[70 ; 72-73]$. This also adds to their theory that grain boundary serration reduces the interfacial free energy per unit area. 
Their most recent work also identifies carbon as a critical element for the occurrence of grain boundary serration in 316 stainless steel [74]. They tested stainless steels with different carbon contents and found that high carbon content increases the amount of serrations while below a certain amount, there is no grain boundary serration [74]. They also carburized the low carbon stainless steel and then applied a heat treatment that would produce serrations which proved successful [74]. Their hypothesis is then that lattice distortional strain energy due to excess carbon near a grain boundary is the driving force for serrations [74].

\subsubsection{Cobalt Base Superalloys}

Some cobalt base superalloys capable of forming serrated grain boundaries are HS-21 and HS-25. As with nickel base superalloys there are different mechanisms for the formation of serrations, and a solution heat treatment is required, typically followed by furnace cooling. The work of Tanaka et al. includes both alloys [29-32; 75-78]. In HS-25, the grain boundaries are serrated through the precipitation of a tungsten rich phase with small amounts of $\mathrm{M}_{6} \mathrm{C}$ carbides $[30 ; 32 ; 75 ; 77-78]$. The precipitates are the same as the bcc tungsten rich $\alpha_{2}$ phase in Ni-20Cr-20W alloys [30]. The amount of precipitates formed is affected by the tungsten content of the alloy, with higher tungsten leading to more precipitates [78].

In HS-21, grain boundaries are serrated through the grain boundary reaction (GBR) $[29 ; 31 ; 76]$. The GBR forms nodules of rod-like $\mathrm{M}_{23} \mathrm{C}_{6}$ carbides that grow from one grain into another (refer to Figure 31 ) $[29 ; 31 ; 76]$. The carbon content of the alloy plays an important role in the formation of GBR. Since it contains approximately 0.25 
$w t \% \mathrm{C}$, this easily allows the formation of GBR during heat treatment $[29 ; 31]$. The amount of GBR formed is dependent on the supersaturation of carbon in the matrix, as an increase in intragranular precipitates reduces the amount of GBR; thereby showing a reduction in driving force from lowered carbon supersaturation [29]. Tanaka et al. also confirmed that the GBR was not formed as a result of an eutectoid reaction [29]. This GBR in HS-21 is very similar to that found in $21-4 \mathrm{~N}$ manganese austenitic stainless steel.

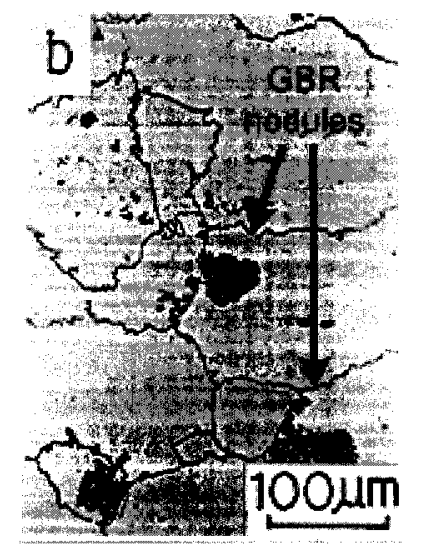

Figure 31: GBR nodules in HS-21 [31].

\section{$3.2 .4 \quad 21-4 N$}

In the manganese stabilized austenitic stainless steel $21-4 \mathrm{~N}$, Tanaka et al. have found that grain boundaries are serrated through the grain boundary reaction (GBR) [7982]. Further information about the GBR in $21-4 \mathrm{~N}$, as well as micrographs can be found in Section 5. As with the cobalt based superalloy HS-21, the GBR in $21-4 \mathrm{~N}$ is a nodule of rod-like $\mathrm{M}_{23} \mathrm{C}_{6}$ carbides. There are also $\mathrm{Cr}_{2} \mathrm{~N}$ nitrides in the GBR nodules of $21-4 \mathrm{~N}$ due to the large amounts of nitrogen present. Similarly to HS-21, supersaturation of the matrix is the driving force for the GBR; in the case of $21-4 \mathrm{~N}$ it is a supersaturation of carbon and nitrogen. Again, a solution heat treatment is required followed either by furnace cooling or isothermal aging to precipitate the GBR. 
As explained in Section 5, the GBR is a cellular type of precipitate which pushes the grain boundary into an adjacent grain, creating a serration. However, as seen in Figure 31, the GBR cannot be the source of all the grain boundary serrations in HS-21 or in $21-4 \mathrm{~N}$. It is apparent that there are serrations which were not formed through the GBR.

The work of Hong et al. on 304 and 316 stainless steel (refer to Section 3.2.2) may shed light on the grain boundary serrations free of GBR. They theorize that lattice distortional strain energy due to excess carbon near a grain boundary is the driving force for serrations [74]. This could apply to $21-4 \mathrm{~N}$ since it contains substantial amounts of carbon and nitrogen and to HS-21 since it also has large amounts of C [29; 41,p.254]. Thus the GBR nodules produce the largest serrations, while the smaller serrations could occur to reduce boundary energy, caused by supersaturation of carbon and/or nitrogen. It could also be possible that as with 304 and 316, the grain boundary serrations form and are then followed by intergranular carbides as well as the GBR.

\subsection{Effects of Serrated Grain Boundaries on Creep}

Serrated grain boundaries have been shown to have very beneficial effects on the creep properties of various materials. In general, the creep rupture life and creep ductility is increased in materials with serrated grain boundaries as opposed to planar grain boundaries [22-32]. This can be seen for 21-4N in Figure 32. 

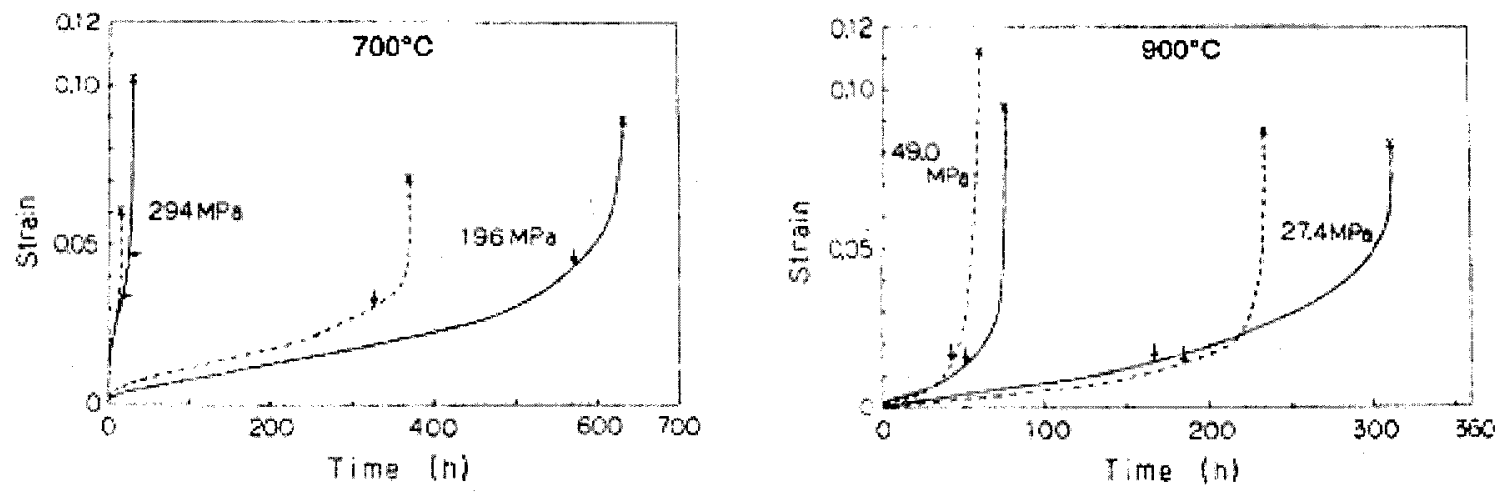

Figure 32: Creep tests of 21-4N with serrated grain boundaries (solid line) and planar grain boundaries (broken line) [23].

Similar trends occur in other stainless steels as well as nickel and cobalt base superalloys. Figures 33 and 34 show a similar trend for cobalt and nickel base superalloys.
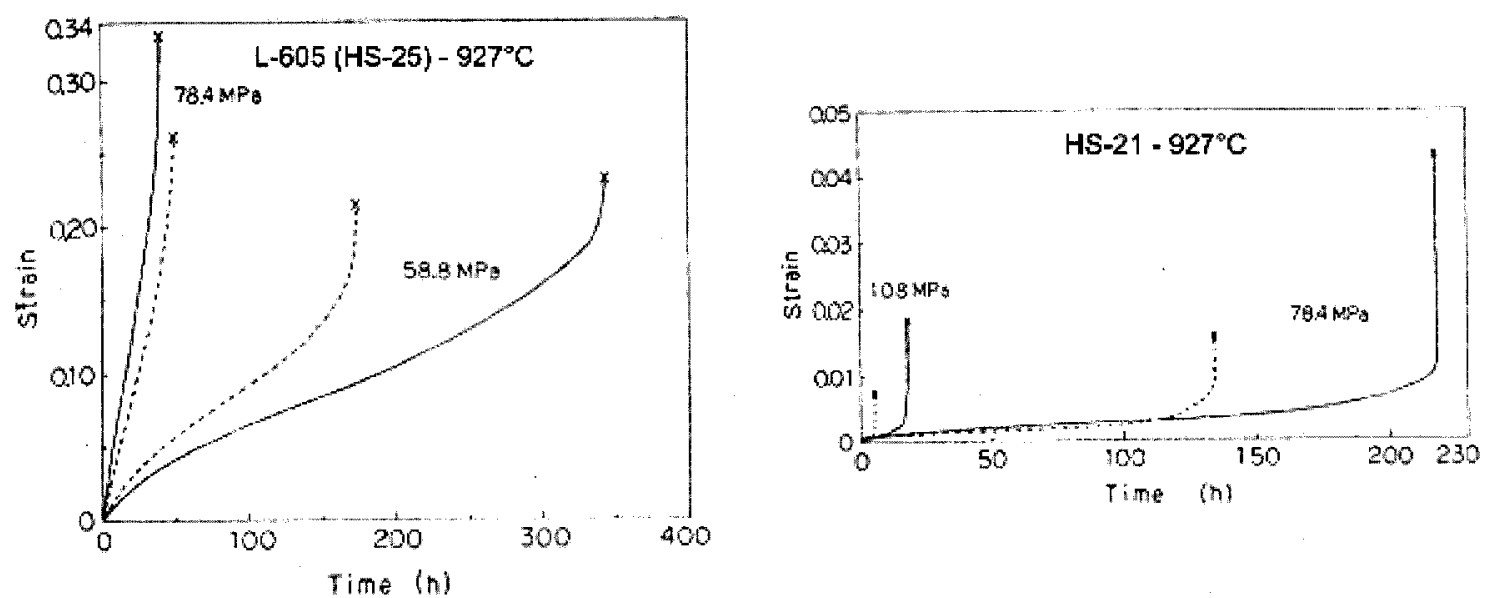

Figure 33: Creep tests of cobalt base superalloys L-605 and HS-21 with serrated grain boundaries (solid line) and planar grain boundaries (broken line) [30-31]. 


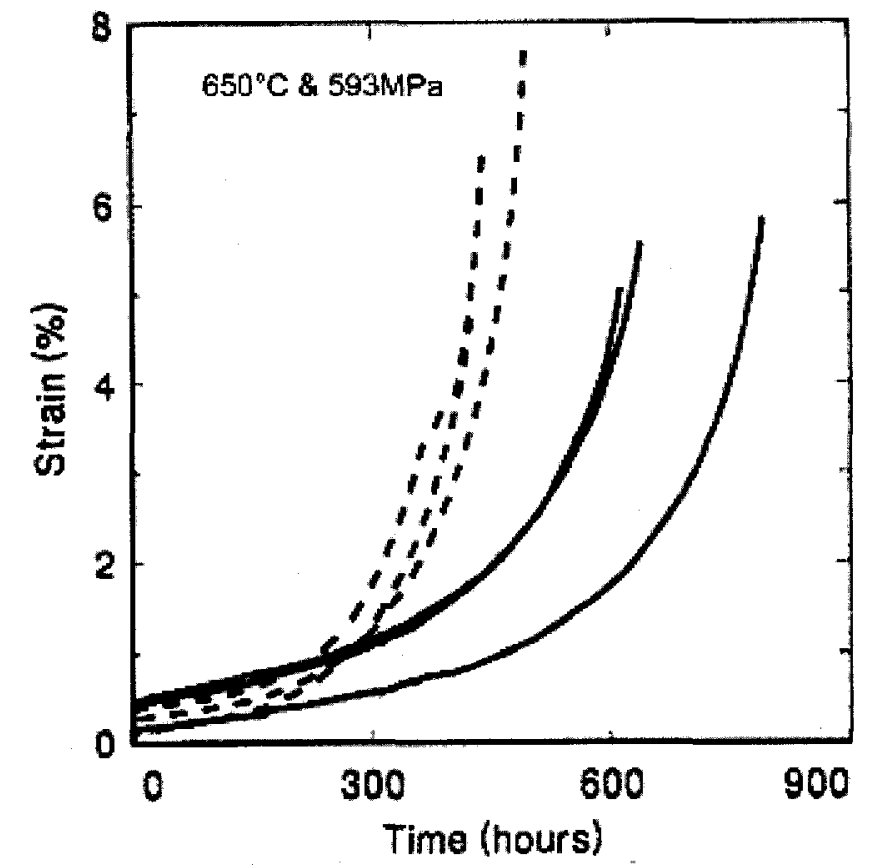

Figure 34: Creep tests of nickel base superalloy $\mathrm{N} 718$ with serrated grain boundaries (solid line) and planar grain boundaries (broken line) [28].

A common point seen in Figures 32,33 and 34 is that tertiary creep appears to be delayed in general for the serrated grain boundary samples. This would suggest that the serrated grain boundaries improve the damage tolerance of the materials during creep. The improvement to damage tolerance is supported by fatigue and creep-fatigue tests which show improvements to fatigue life in samples with serrated grain boundaries from various stainless steels and superalloys $[28-29 ; 49-50 ; 56-57 ; 62 ; 70-73 ; 75-76 ; 79-87]$.

Reasons for the improvement in damage tolerance include reduced grain boundary sliding (GBS), as well as increased resistance to crack propagation from an increased crack path, deflection of cracks at grain boundary serrations and even crack arrest at inflection points on the grain boundaries $[22-24 ; 56 ; 81 ; 83 ; 85]$. Hong et al. in their work on 304 and 316 stainless steel, claim however that improvements to the damage tolerance arise from higher cavitation resistance and not from a reduction of GBS [70-73]. The higher cavitation resistance is a result of modified carbide morphology 
occurring with serrated grain boundaries (refer to Section 3.2.2), which have lower interfacial energy. They reason that if GBS was occurring, then cavities would form the most on grain boundaries oriented at $45^{\circ}$ to the tensile axis. In their investigations however, they found the most amount of cavities on grain boundaries perpendicular to the tensile axis, and also found few if any wedge type cracks at grain triple points. They therefore concluded that GBS is not likely to be the main cause for cavity nucleation and believe that improvements to damage tolerance from serrated grain boundaries arise only from the modified carbides [70-73]. The general opinion though remains that GBS is a main cause for cavitation, and that serrated grain boundaries increase damage tolerance by inhibiting GBS.

Apart from improved damage tolerance leading to increased creep rupture life, the effect of serrated grain boundaries on the creep rate is unclear. Results from $21-4 \mathrm{~N}$ at intermediate temperatures and relatively high stresses show no difference in the creep rates between samples with serrated and planar grain boundaries (refer to Figure 35).

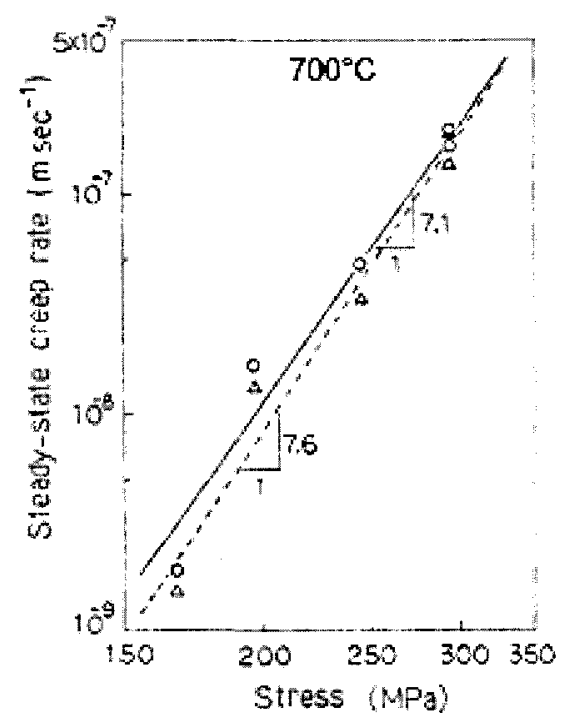

Figure 35: Comparison of creep rates between serrated grain boundary samples (solid line, circle) and planar grain boundary samples (broken line, triangle) in 21-4N [23]. 
The result shown in Figure 35 is not unexpected since the temperature and stresses are likely not in the regime of diffusional creep, where the link between diffusional creep and GBS could result in a lower creep rate for the serrated grain boundary samples. Similar outcomes are seen in Figure 36 for the cobalt base superalloys L-605 (HS-25) and HS-21.

A

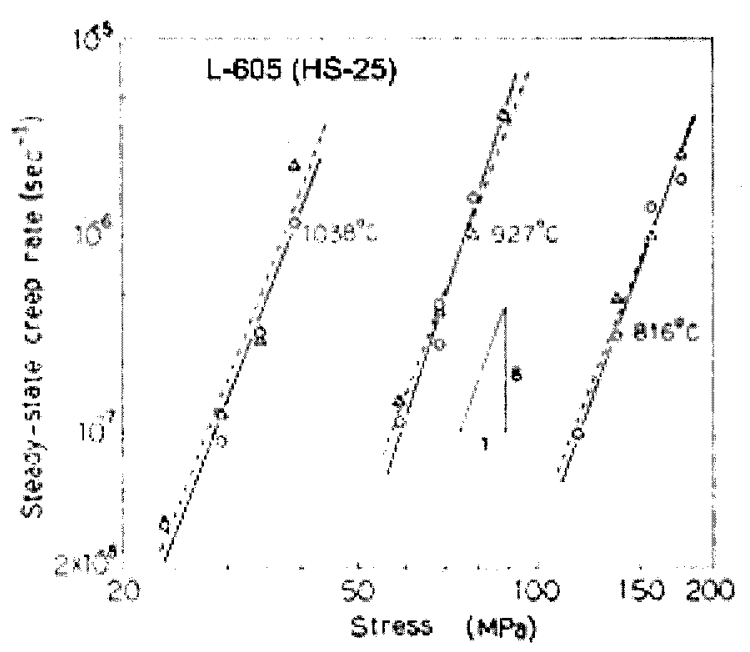

B $5 \times 10^{-3}$,

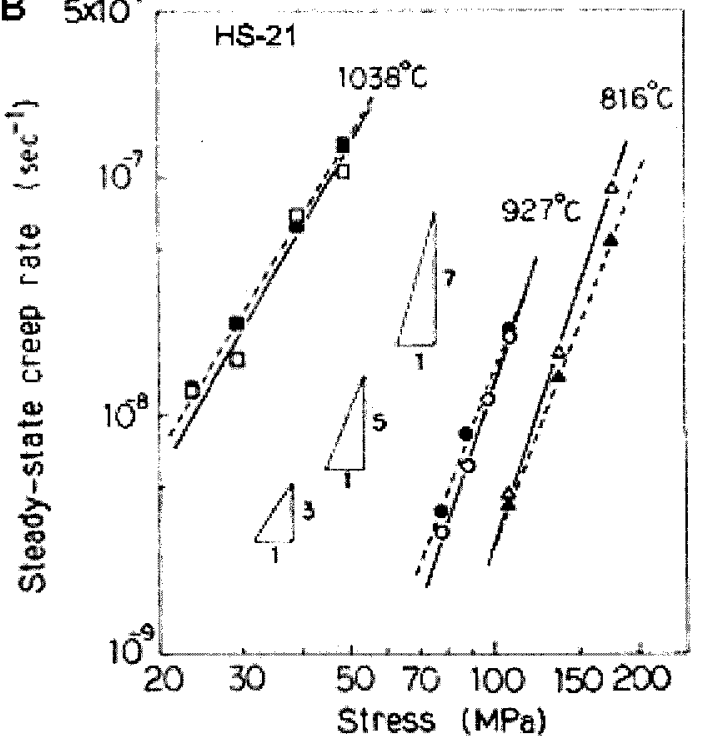

Figure 36: Comparison of creep rates for cobalt base superalloys: A) L-605, serrated grain boundaries (solid line, circle), planar grain boundaries (broken line, triangle) [30] B) HS-21, serrated grain boundaries (solid line, open symbol), planar grain boundaries (broken line, filled symbol) [31].

The results continue to show no difference in creep rate between serrated and planar grain boundaries, even at high temperatures such as $1038^{\circ} \mathrm{C}$, and low stresses. Later testing by the same workers on the same two cobalt base superalloys revealed that during high temperature creep tests at $1038^{\circ} \mathrm{C}$ and above, the planar grain boundary samples formed serrations [76-77]. Thus the previous results at high temperature and low stress, which could conceivably be in the diffusional regime for those materials, are likely not valid comparisons between serrated and planar grain boundary creep rates. 
Further confusing results on the effect of serrated grain boundaries on creep rate can be found in the work of Koul et al. on two nickel base superalloys [53]. Figure 37 shows the results of creep testing of IN718 and IN738LC samples which had serrated and planar grain boundaries.
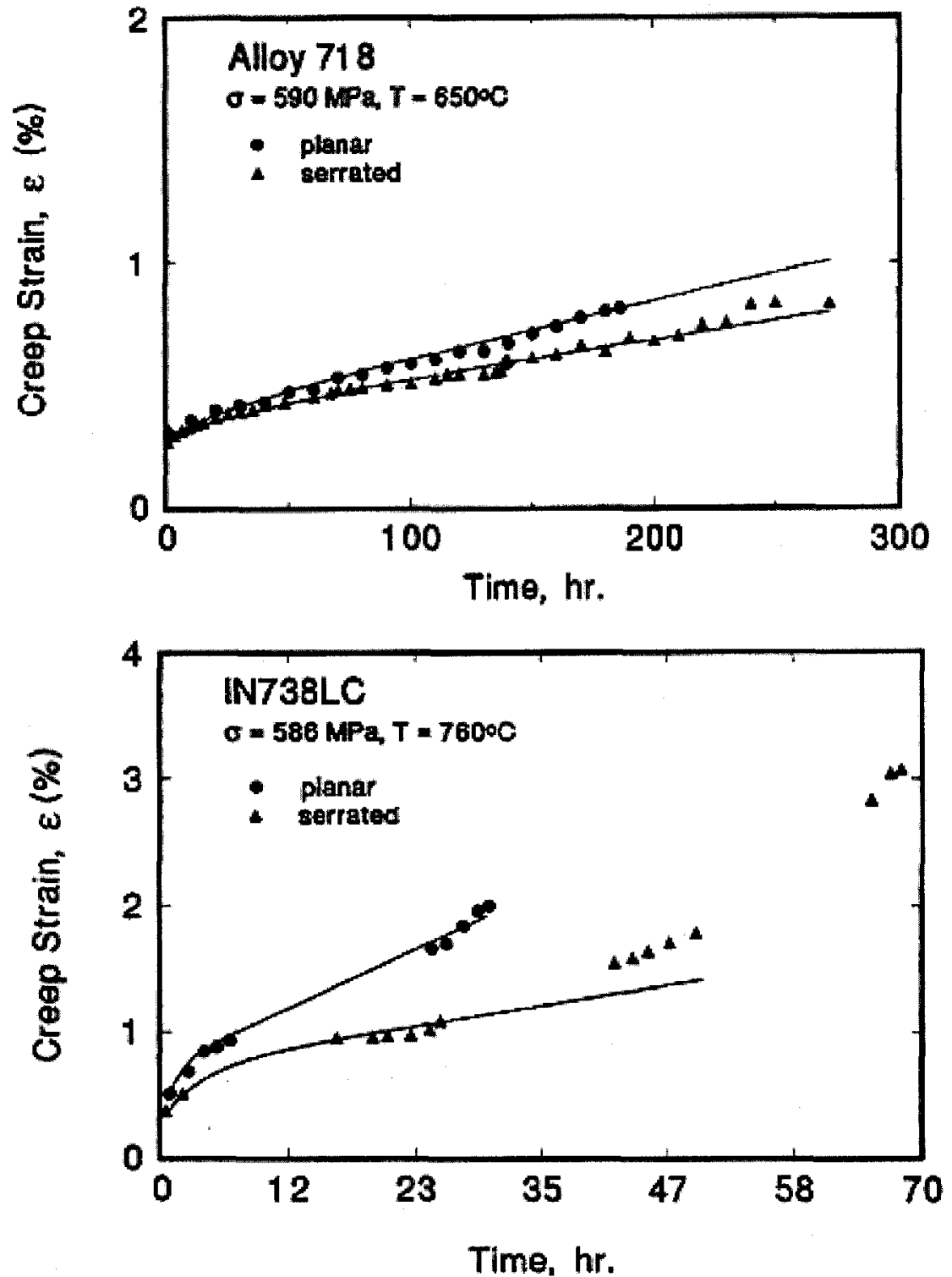

Figure 37: Creep test results of IN718 and IN738LC with serrated and planar grain boundaries [53].

The temperatures and stresses of the creep tests seen in Figure 37 are not in the diffusional regime making the lower creep rates of the serrated grain boundary samples 
difficult to explain. This puzzling result with nickel base superalloys as well as the unexpected change in grain boundary morphology in cobalt base superalloys leaves some doubt as to the exact effects of serrated grain boundaries on creep rate. The comparative tests between serrated and planar grain boundaries on 21-4N, HS-21 and L-605 reinforce the view that GBS has little effect on the creep mechanisms at intermediate temperatures and high stresses. The high temperature and low stress tests are in doubt which makes it difficult to assess whether or not GBS and diffusional creep are inextricably linked as predicted by theory. Thus there still exists a need to further clarify the effect of serrated grain boundaries on creep rate and possibly shed light on fundamental creep mechanisms. 


\section{Thesis Objectives and Scope}

This thesis is the beginning of a broader research project at the Department of Mechanical and Aerospace Engineering at Carleton University, which seeks to elucidate the role of grain boundaries on the creep rate of engineering alloys. One of the key areas of interest is the effect of grain boundaries and intergranular second phase particles on the creep strain rate during the time period prior to the minimum strain rate, as opposed to the effect on rupture time and strain. The project will use a series of engineering materials including cast nickel base superalloys such as IN738, wrought nickel base superalloys such as PWA 1113 and austenitic stainless steels such as 21-4N, 304 and 316.

The material being studied in this thesis is the manganese stabilized austenitic stainless steel $21-4 \mathrm{~N}$. The objectives of this thesis, within the scope of the overall research project are:

1 Identify heat treatment processes to produce microstructures in $21-4 \mathrm{~N}$ with planar and serrated grain boundaries.

2 Commence systematic creep testing of the planar and serrated grain boundary microstructures at identical temperatures and stresses to ascertain what effect the grain boundary serrations may have on primary creep and on the creep rate, in comparison to the planar grain boundary microstructure.

3 Analyze resulting microstructures after creep testing.

4 Determine the suitability of $21-4 \mathrm{~N}$ for further testing with respect to the overall research project goals.

5 Outline further possible work for the continuation of the research project. 
The result of the work to complete these objectives is outlined in the following sections of this thesis. First, Section 5 details the material used for testing and the experimental methods used. Section 6 outlines the results, first with the microstructural results of the various heat treatments applied to the test material. Then the creep testing results are outlined followed by the microstructures of the tested samples. The results are discussed in Section 7. Section 8 summarizes the results and outlines possible future work. 


\section{$5 \quad$ Materials and Experimental Methods}

\subsection{1-4N: Manganese Stabilized Austenitic Stainless Steel}

The material used to investigate the effects of serrated grain boundaries on creep is $21-4 \mathrm{~N}$. It is also known as EV8 in the SAE designation [88,p.6]. 21-4N was originally created by Armco Steel Co. but is now also produced by other companies [33,p.70]. As the material name suggests, Mn plays a large role in the material's properties by improving the solubility of $\mathrm{N}$.

\subsubsection{Chemistry and Microstructure}

21-4N is an austenitic stainless steel. As such it has a face centered cubic (f.c.c.) crystal structure. In terms of austenitics, it is a $\mathrm{Cr}-\mathrm{Mn}-\mathrm{N}$ alloy as opposed to the more typical Cr-Ni alloys, such as the $18 \mathrm{Cr}-8 \mathrm{Ni}$ steels [33,p.14; 89,p.6]. And more specifically it is a Fe-Cr-Mn-Ni-N alloy [33,p.22]. The f.c.c. structure of $21-4 \mathrm{~N}$ is maintained due to the Ni, Mn and $\mathrm{N}$ alloying additions, all of which are austenitizing elements [89,p.21]. The austenitic structure also provides improved solubility due to the larger lattice interstices [33,p.30]. The typical compositional limits of $21-4 \mathrm{~N}$ are given in Table 2 .

Table 2: Compositional limits of 21-4N [41,p.254].

\begin{tabular}{cccccc}
\hline \multicolumn{6}{c}{ Composition \% } \\
\hline $\mathbf{C}$ & $\mathbf{C r}$ & $\mathbf{M n}$ & $\mathbf{N}$ & $\mathbf{N i}$ & $\mathbf{S i}$ \\
$0.45-0.6$ & $20-23$ & $7-10$ & $0.3-0.5$ & $3-5$ & 0.25 \\
\hline
\end{tabular}

Chief among the alloying elements is $\mathrm{Cr}$, as it is essential in creating a passive $\mathrm{Cr}$ rich oxide surface film [89,p.3,p.133]. A minimum of about $11 \% \mathrm{Cr}$ is needed for the steel to be classified as stainless, and more typically the $\mathrm{Cr}$ content ranges from 16 to 
$26 \%[33$, p.9; 89, p.3,p.21]. The more typical $\mathrm{Cr}$ contents help in high temperature applications and oxidizing environments [89,p.6]. Chromium is also a ferritizing element and it also increases the solubility of $\mathrm{N}[89, \mathrm{p} .22]$.

While Ni can vary up to $35 \%, 21-4 \mathrm{~N}$ has a low content, compared to a typical $18 \mathrm{Cr}-8 \mathrm{Ni}$ steel. $\mathrm{Ni}$ is used to stabilize austenite but it also improves mechanical properties as well as improving corrosion resistance by promoting repassivation $[41, \mathrm{p} .37$; 89,p.6,p.133]. The low Ni content is due to economics, as Mn, a cheaper substitute, can be used to stabilize the austenite $[33, p .5 ; 41, p .37]$. However, the austenitizing power of $\mathrm{Ni}$ is double that of $\mathrm{Mn}$, making it necessary to use a 2:1 ratio of $\mathrm{Mn}$ to $\mathrm{Ni}$ in order to reduce the Ni content [33,p.15]. Figure 5.1 also shows the negative impact Ni has on the solubility of $\mathrm{N}$.

As stated above, $\mathrm{Mn}$ is substituted for Ni to stabilize the austenitic structure. Its content can vary up to $15 \%$, though above $10 \%$ it becomes a ferritizer [ 41, p. 140 ; 89,p.21]. The other important function of $\mathrm{Mn}$ is to increase the solubility of $\mathrm{N}[33, \mathrm{p} .5$; 41,p.37,p.140; 89,p.6,p.22]. This is where the economical advantage of substituting Mn for Ni improves.

The high solubility of $\mathrm{N}$ in $21-4 \mathrm{~N}$ is due to the $\mathrm{Cr}$ and $\mathrm{Mn}$ additions. Refer to Figure 38 for the effects of various alloying additions on the solubility of N. In effect, $\mathrm{Mn}$ and $\mathrm{N}$ are added together to replace $\mathrm{Ni}$; the $\mathrm{Mn}$ increases the solubility of $\mathrm{N}$ and both $\mathrm{Mn}$ and $\mathrm{N}$ help to stabilize the austenite [41,p.10]. Nitrogen is the stronger austenitizer of the two and it also provides solid solution strengthening, as well as improving the work hardening characteristics $[33$, p. $5 ; 41$, p.37,p.46,p.140; 89,p.6,p.134]. The addition of $\mathrm{N}$ to 
more common $\mathrm{Cr}-\mathrm{Ni}$ steels such as 304 and 316 has also shown positive effects by improving the high temperature strength $[89, \mathrm{p} .521]$.

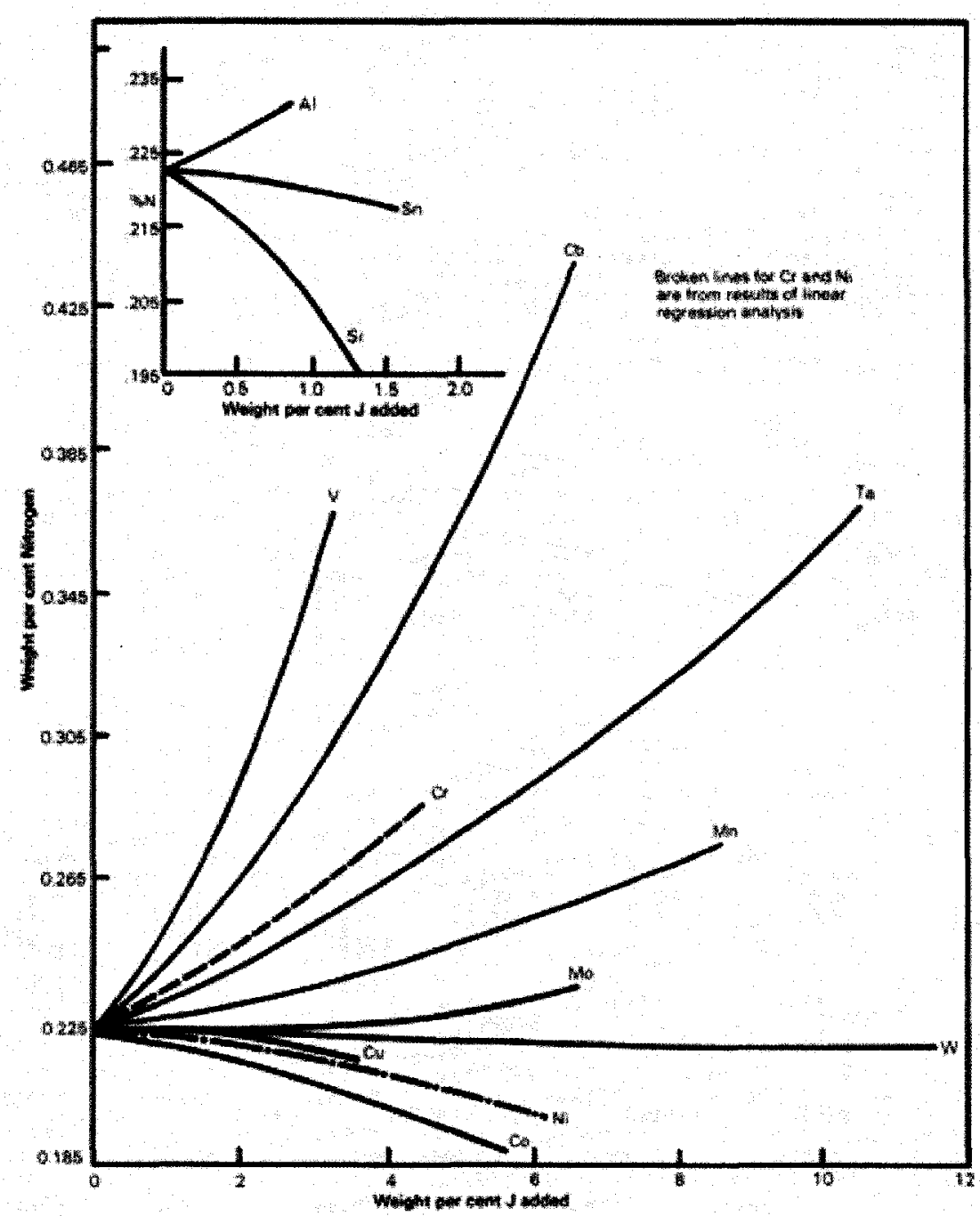

Figure 38: Effect of alloying additions on the solubility of $\mathrm{N}$ in liquid $18 \mathrm{Cr}-8 \mathrm{Ni}$ alloys at $1600^{\circ} \mathrm{C}$ and $1 \mathrm{~atm}$ $\mathrm{N}_{2}[33$, p.31].

Carbon, like nitrogen, is soluble in the fcc structure; meaning that it also helps to stabilize the fcc structure $[89$, p.6]. It also provides solid solution strengthening, which helps in high temperature applications [41,p.46; 89,p.134]. Refer to Figure 39 for the strengthening effects of various alloying elements. 


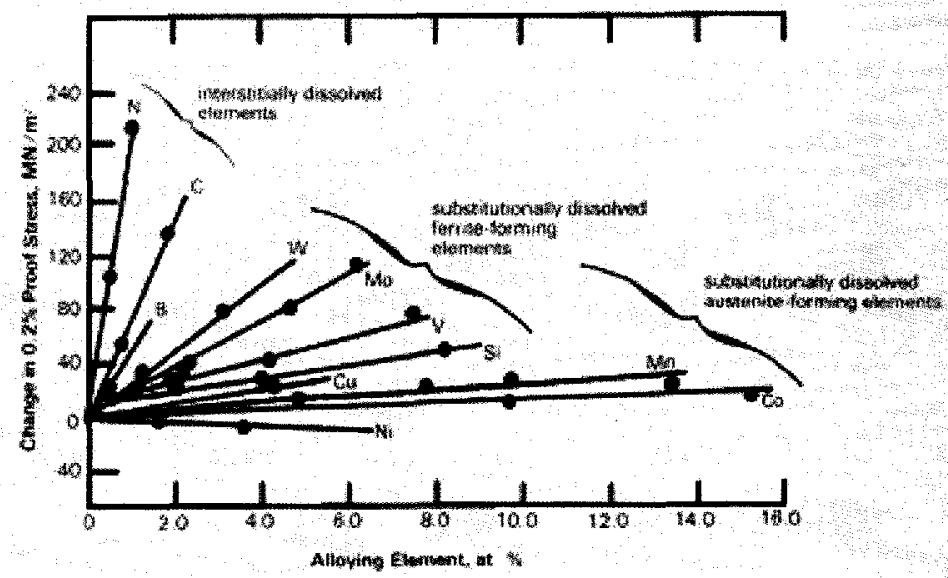

Figure 39: Effect of alloy additions on the solid solution hardening of austenite [33,p.16].

The chemistry of $21-4 \mathrm{~N}$ provides some microstructural features not found in typical Cr-Ni steels. While typical austenitic stainless steels can only be work hardened, this is not true for $21-4 \mathrm{~N}[41, \mathrm{p} .16 ; 89, \mathrm{p} .6]$. Due to the high $\mathrm{C}$ and $\mathrm{N}$ content, 21-4N can be effectively precipitation hardened after solution heat treating [33,p.28; 41,p.254]. The precipitation occurs either by aging at $700-1038^{\circ} \mathrm{C}$ or by control cooling from the solution heat treating temperature $\left(\sim 1200^{\circ} \mathrm{C}\right)[33, \mathrm{p} .28 ; 79 ; 90-92]$.

In manganese austenitic steel with $0.4 \% \mathrm{C}$ and $0.2-0.45 \% \mathrm{~N}$ the precipitates are either lamellar nodules formed on the grain boundaries or general Widmanstätten type precipitates [33, p.28]. The grain boundary precipitates are $\mathrm{M}_{23} \mathrm{C}_{6}$ carbides $\mathrm{Cr}_{2} \mathrm{~N}$ nitrides. These precipitates on grain boundaries are also reported for $21-4 \mathrm{~N}$ with $0.23-$ $0.55 \% \mathrm{C}$ and $0.40-0.60 \% \mathrm{~N}[79 ; 90-93]$. The grain boundary precipitation is referred to as the Grain Boundary Reaction (GBR). The GBR contains nodules of rod-like $\mathrm{M}_{23} \mathrm{C}_{6}$ carbides, $\mathrm{Cr}_{2} \mathrm{~N}$ nitrides and coarse $\mathrm{M}_{23} \mathrm{C}_{6}$ carbides form on the grain boundaries as well $[79 ; 90]$. Refer to Figure 40 for micrographs of the GBR. 


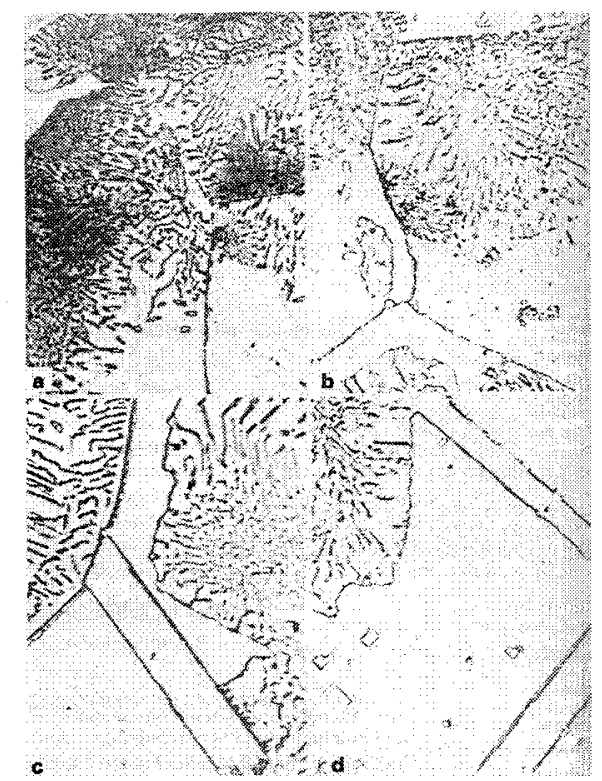

Figure 40: Fe-Cr-Mn austenitic steel with $0.18 \% \mathrm{C}$ and $0.38 \% \mathrm{~N}-$ - (a) $1204^{\circ} \mathrm{C}$ solution annealed and aged at $871^{\circ} \mathrm{C}$ for $16 \mathrm{hrs}$. (b) $1204^{\circ} \mathrm{C}$ solution annealed and aged at $982^{\circ} \mathrm{C}$. (c) $1204^{\circ} \mathrm{C}$ solution annealed and aged at $927^{\circ} \mathrm{C}$. (d) $1204^{\circ} \mathrm{C}$ solution annealed and aged at $1038^{\circ} \mathrm{C}[33, \mathrm{p} .28]$.

The driving force for the GBR is the supersaturation of $\mathrm{C}$ and $\mathrm{N}$ in the austenite matrix; as such, general or intragranular precipitation reduces the GBR [90; 93]. Given the morphological similarity of the GBR found in cobalt base superalloy HS-21 and the fact that the driving force for the GBR in HS-21 is carbon supersaturation; it would seem that the same type of reaction occurs in both $21-4 \mathrm{~N}$ and HS-21 (refer to section 3.2.3 for details on HS-21). Since the GBR in HS-21 is known not to be due to a eutectoid reaction, it is likely that the GBR is a type of cellular precipitation [29]. A schematic, as well as a GBR nodule in 21-4N can be seen in Figure 41. Cellular precipitation is morphologically similar to a eutectoid reaction hence why the GBR nodules are referred to as lamellar nodules [94,p.322]. In Figure 41, the grain boundary was originally straight, but as the precipitation develops, the boundary is pushed into a neighbouring grain [94,p.324]. This requires the transfer of solute to the tips of the precipitates pushing the grain boundary [94,p.325]. The transfer of solute is mostly diffusion along the grain 
boundary, though at higher temperatures diffusion within the matrix may contribute more [94,p.325]. This cellular precipitation thus creates a 'wavy' or serrated grain boundary in HS-21 and 21-4N.
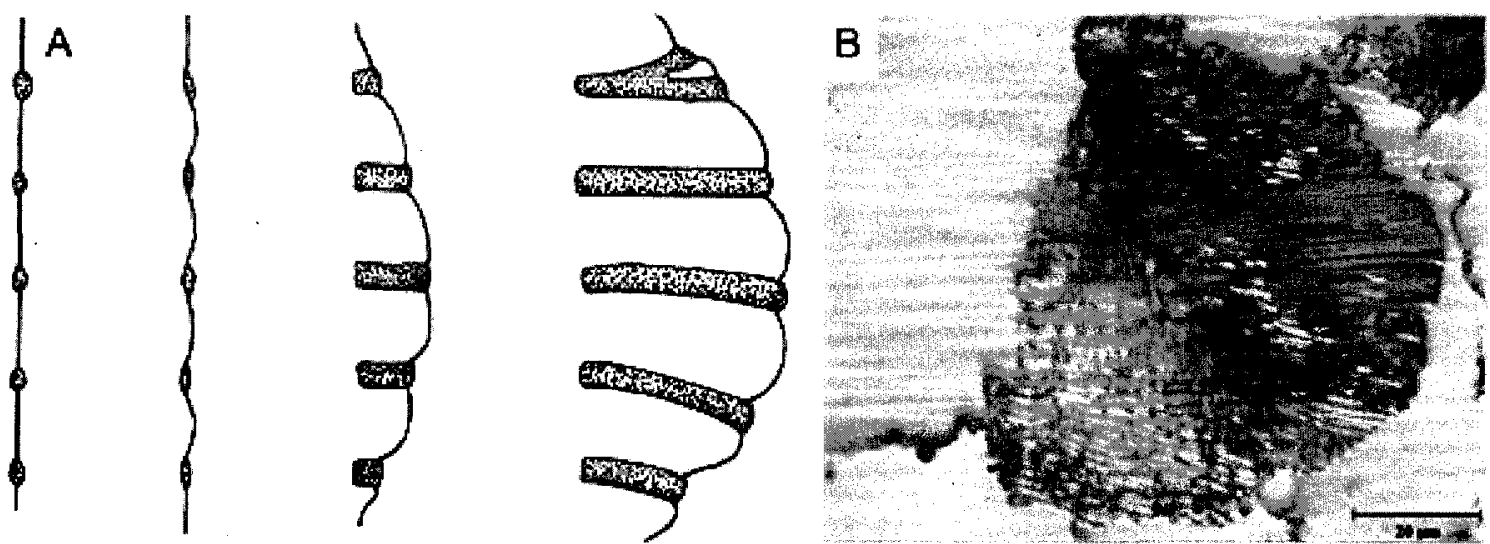

Figure 41: A) Schematic diagram showing sequence of development of cellular precipitation [94,p.324], B) Grain boundary reaction nodule in $21-4 \mathrm{~N}$.

A study on the effects of alloying additions on the GBR in an alloy of base composition similar to $21-4 \mathrm{~N}$, finds that the $\mathrm{N}$ content is essential [93]. Less than 0.1 wt $\% \mathrm{~N}$ produces no GBR, regardless the $\mathrm{C}$ content. Conversely, with more than $0.5 \mathrm{wt} \%$ $\mathrm{N}$ there is always GBR, even with very small $\mathrm{C}$ contents. The effect of varying the $\mathrm{N}$ to $\mathrm{C}$ ratio is also examined with steels with a total of $\sim 0.9 \mathrm{wt} \% \mathrm{C}$ and $\mathrm{N}$. As the $\mathrm{N}$ content is increased, the amount of GBR increases while intragranular precipitation is suppressed. Increased $\mathrm{C}$ content has the opposite effect. In general, increasing the $\mathrm{C}$ and $\mathrm{N}$ content increases the GBR but $\mathrm{N}$ is noted to be more effective.

A host of other alloying additions are examined in the same study, including $\mathrm{Nb}$, Mo, W, Mn, Cu and B [93]. Niobium, molybdenum and tungsten have the same effect on the GBR; that is that they substantially suppress the reaction and encourage intragranular precipitation. To achieve this effect, approximately $0.5 \mathrm{wt} \% \mathrm{Nb}$ can be used or $1 \mathrm{wt} \%$ of Mo or $\mathrm{W}$. As for the $\mathrm{Mn}$ and $\mathrm{Cu}$, both raise the solubility of $\mathrm{C}$ and $\mathrm{N}$ 
thereby suppressing the GBR. Roughly $13 \mathrm{wt} \% \mathrm{Mn}$ or $0.5 \mathrm{wt} \% \mathrm{Cu}$ is needed to do so. And finally small additions of B are effective in suppressing the GBR.

As was explained in section 3, the GBR is one source of grain boundary serrations in $21-4 \mathrm{~N}$. The amount of the grain boundary reaction also has an effect on the material properties and should be controlled accordingly.

\subsubsection{Effects of the Grain Boundary Reaction}

While the GBR is a source of grain boundary serrations in $21-4 \mathrm{~N}$, too much of the GBR will have a negative effect on the material properties. Approximately $8 \%$ GBR is needed to sufficiently serrate the grain boundaries [79-80]. Conveniently, around 8-10\% GBR is the optimum amount for substantially improving the creep rupture strength and imparting good ductility [91; 95-96]. Similarly, the fatigue strength can also be improved the most with approximately $8 \%$ GBR [79-80].

Referring to Figure 42, beyond 8-10\% GBR, at room temperature there is little effect on the tensile strength of $21-4 \mathrm{~N}$ until more than $60 \%$ GBR is present; at which point the strength decreases considerably [96]. There is also a steady decrease in the $0.2 \%$ proof stress with increasing amounts of GBR. The effect of the GBR on the tensile strength as well as other properties is seen at various temperatures. There is a notable increase in ductility at higher temperatures. 


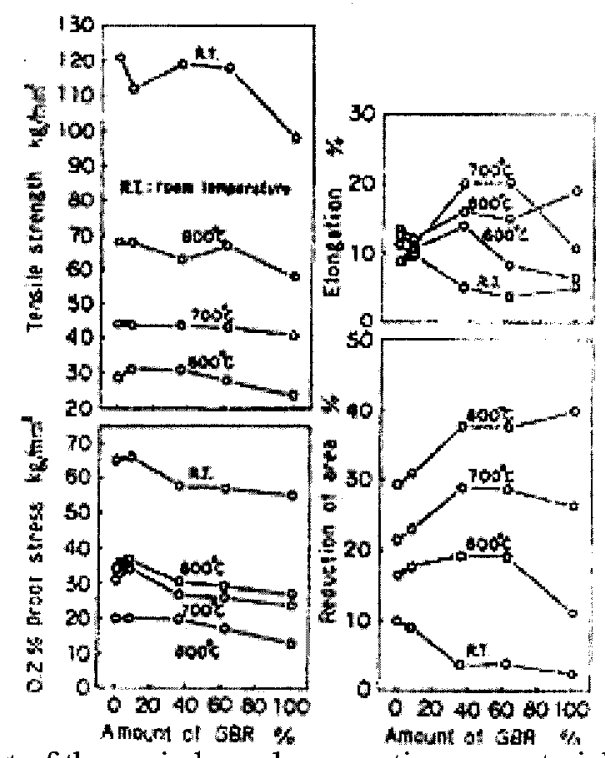

Figure 42: Effect of the grain boundary reaction on material properties [96].

Referring to Figure 43, the effect of the GBR reaction on high temperature properties also extends to creep ductility and the minimum creep rate. Both increase with rising amounts of the GBR reaching a maximum around 30\% GBR [91]. The positive effects of $\sim 10 \%$ GBR can be seen in figure 43 especially in increasing rupture time and elongation. Another more interesting trend is the way the minimum creep rate decreases at $\sim 10 \%$ GBR with increasing temperature. 

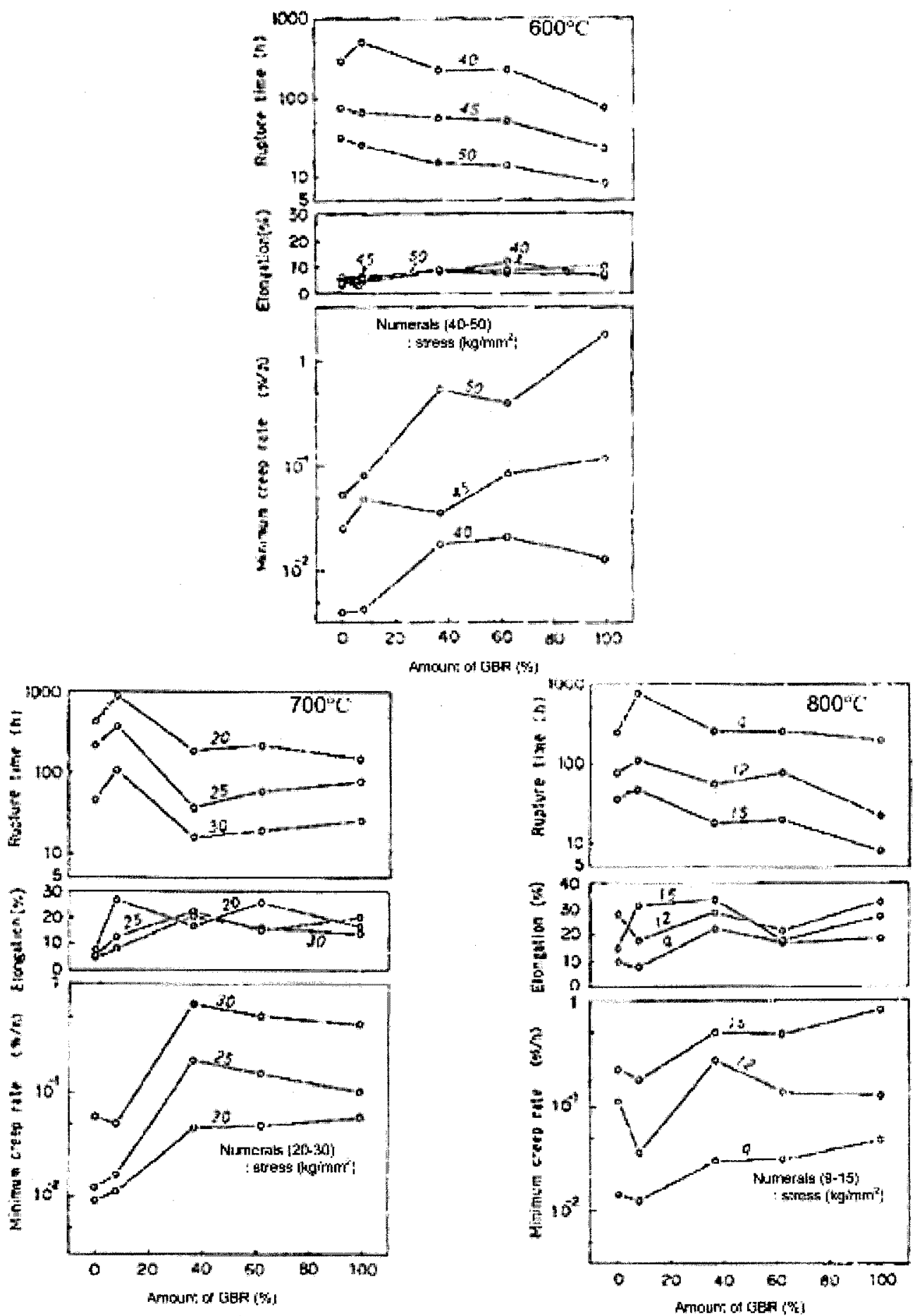

Figure 43: Effect of the grain boundary reaction on rupture time, elongation and minimum creep rate [91]. 
The amount of GBR reaction also has an effect on the shape of the creep curve, as seen in figure 44. The negative effect of excessive amounts of GBR on creep rupture time is clear.

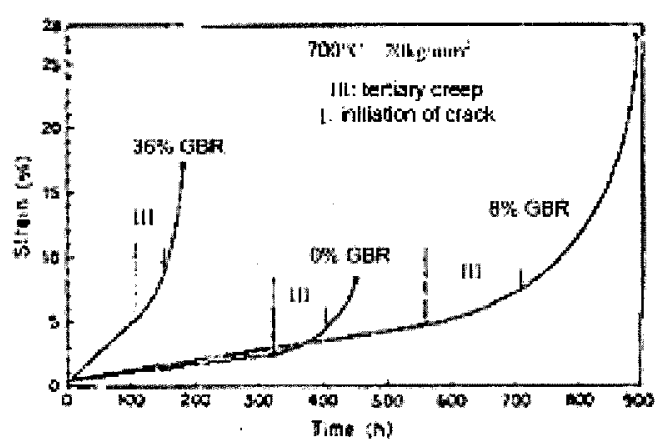

Figure 44: Effect of the grain boundary reaction on creep curve shape [91].

The negative effects of excess GBR can be linked to the GBR nodules. While larger GBR area percentage creates larger grain boundary serrations, it also means larger GBR nodules [79]. In fatigue testing of samples with $8 \%$ and $15 \% \mathrm{GBR}$, the larger nodules in the $15 \%$ GBR samples were frequently found to fracture perpendicular to the loading direction [80]. Cracks were also found to have originated within the GBR nodules of the $15 \%$ GBR samples [79]. No fractures were found to have initiated in the GBR nodules of the $8 \%$ GBR samples [79-80].

Theoretical work on the deformation and fracture of 21-4N with GBR nodules presents similar conclusions $[92 ; 96]$. Room temperature tensile tests have shown a decrease in ductility with GBR levels above $10 \%$, which can be seen in figure 42 [92; 96]. This decrease in ductility is from the fracture of rod-like precipitates in the GBR nodules $[92 ; 96]$, which is believed to occur as follows:

1) Microcracks form due to fracture of rod-like precipitates in GBR nodules. 
2) Voids form from microcracks and link together to fracture entire GBR nodules.

3) Rupture of specimen from propagation of cracks from GBR nodules to bordering grains [92].

This process can be seen schematically in Figure 45, and is due to tensile stresses applied to the rod-like precipitates. It was also concluded that with less than $10 \% \mathrm{GBR}$, this type of fracture has almost no effect on the strength and ductility of $21-4 \mathrm{~N}$ [92].
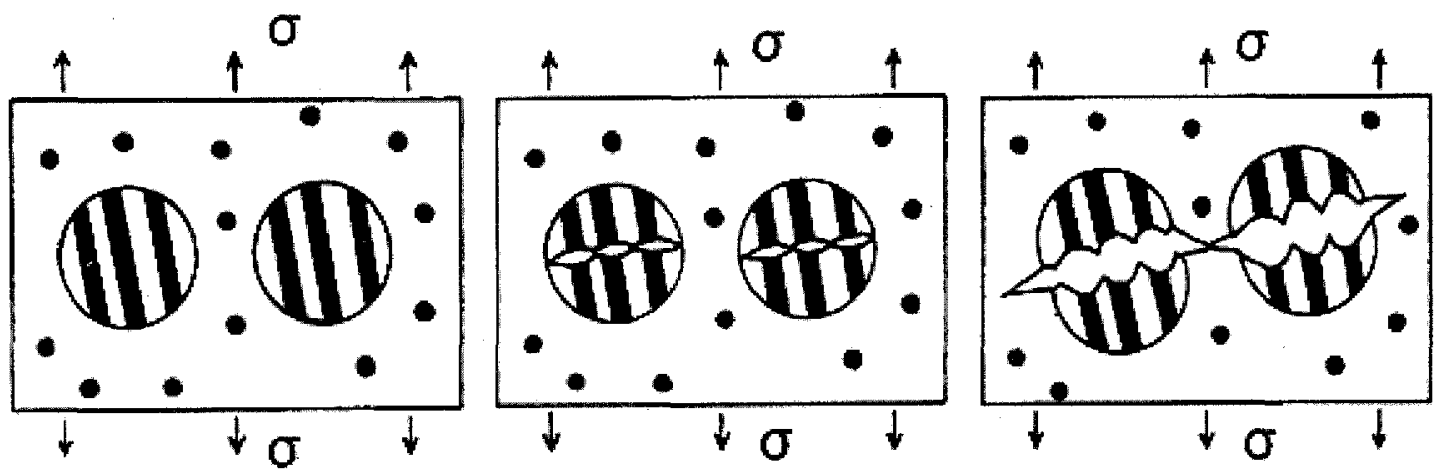

Figure 45: Room temperature fracture of $21-4 \mathrm{~N}$ with grain boundary reaction nodules [92].

At higher temperatures, it is theorized that cracks form at the interfaces of GBR nodules [96]. This is believed to be from a difference in plastic strain between the GBR nodules and matrix, due to a lack of deformation of the rod-like precipitates in the GBR nodules [96].

As stated before, the required amount of GBR to sufficiently serrate the grain boundaries is also the amount for greatest improvement to creep rupture strength. It is also clear that at $8-10 \%$ GBR, the GBR nodules are not a noticeable source of cracks which would negatively impact the material properties. Figure 42 also shows that at those levels of GBR, there is little effect on the tensile strength and proof stress. The same can be seen at higher temperatures in Figure 42. Thus the improvements to the 
creep properties seen in Figures 43 and 44 can be reasonably assumed to be due to the grain boundary serrations and not to some influence by the GBR at the modest amounts of $8-10 \%$. Due to the GBR, there may in fact be a minor decrease in creep properties since the interstitial $\mathrm{C}$ and $\mathrm{N}$ contents would be reduced; though the grain boundary serrations likely more than make up for this. The improvement to creep properties solely from the grain boundary serrations unfortunately cannot be investigated since the GBR always occurs when grain boundary serrations form in 21-4N.

\subsubsection{Typical Properties and Applications}

As an austenitic stainless steel, $21-4 \mathrm{~N}$ can be used in high temperature applications where it has good strength and oxidation resistance [33,p.68; 89,p.505,p.520]. It is also a stable austenitic steel, which retains its hot hardness after sustained exposure at high temperatures [33,p.68]. As such, its primary application is as automotive valve steel (Figure 46), though other uses are plates in hot-press forming of titanium and other high temperature materials [33,p.69].

The requirements for automotive valve steel are substantial, including creep and fatigue resistance, abrasion and galling resistance, tight dimensional tolerances and possibly accepting surface coatings [41,p.254]. Even with operating temperatures of $800^{\circ} \mathrm{C}$ occurring, the mechanical properties of $21-4 \mathrm{~N}$ are stable at those temperatures [41,p.254]. Also of interest is that engine operating temperature is similar to the aging temperature for $21-4 \mathrm{~N}$, resulting in hardening when the engine is operated for the first time [41,p.254]. Refer to Appendix A for some typical physical properties of 21-4N. 


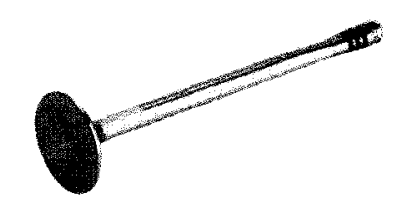

Figure 46: Engine valve [97].

\section{$5.2 \quad$ Test Material}

The material used for testing is provided as hot rolled bar stock of $7 / 8$ " diameter. Figure 47 shows the as received bar stock. Sample slugs of $\sim 4$ " length are cut from the bar stock before heat treatment.

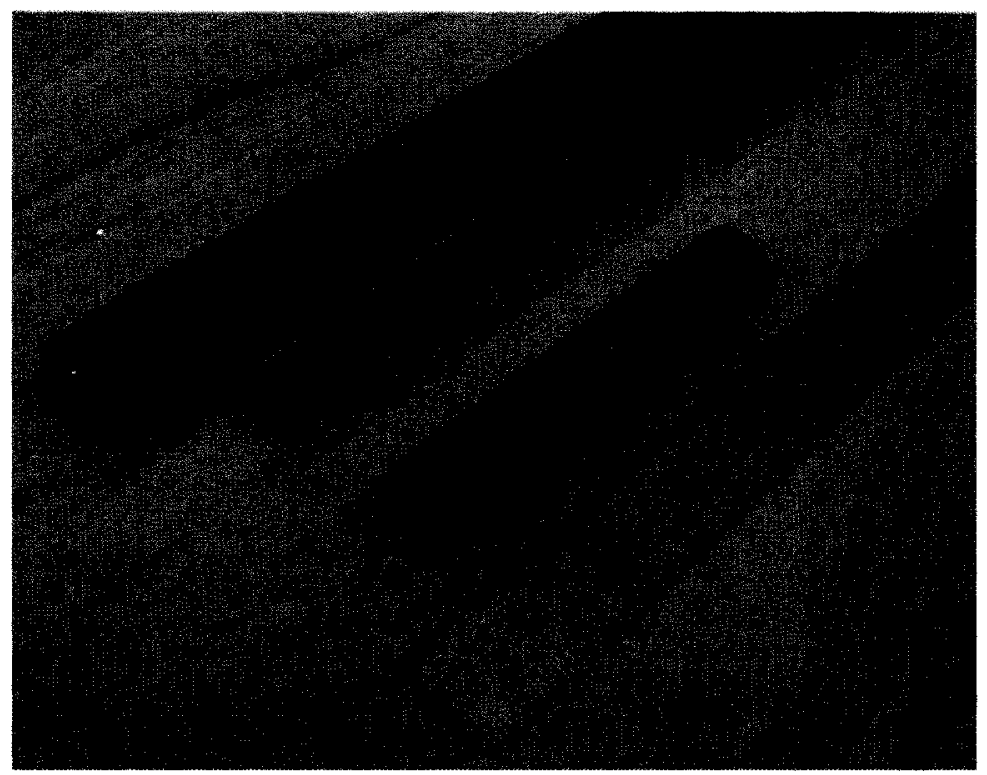

Figure 47: As received 21-4N bar stock and sample slug.

Small discs were also cut from the bar stock to discover effects of the heat treatments on the material (refer to sections 6 and 7 for further details). The manufacturer provided composition is shown in Table 3. As well, two pieces from the ends of the $21-4 \mathrm{~N}$ bar stock were analyzed by an independent company with a LECO furnace and optical emission spectroscopy; the results are listed in Table 3. Optical emission spectroscopy works on the principle that free atoms in energetic environments 
emit light in narrow wavelength intervals which are characteristic of the atom making them [98,p.21]. Identification of an element is done by measuring the line intensities of the characteristic lines of that element [98,p.21]. The LECO furnace features a highfrequency induction furnace and a solid state infrared detector [99].

Table 3: Composition of $21-4 \mathrm{~N}$ test material as provided by manufacturer and from independent tests.

\begin{tabular}{cccc}
\hline & Manufacturer Specified & Tested Sample 1 & Tested Sample 2 \\
\hline $\mathbf{C}$ & 0.530 & 0.49 & 0.55 \\
$\mathbf{C r}$ & 20.774 & 20.64 & 20.61 \\
$\mathbf{M n}$ & 8.185 & 8.33 & 8.34 \\
$\mathbf{N}$ & - & 0.39 & 0.39 \\
$\mathbf{N i}$ & 3.472 & 3.35 & 3.35 \\
$\mathbf{S i}$ & 0.179 & 0.19 & 0.18 \\
$\mathbf{P}$ & 0.041 & 0.030 & 0.029 \\
$\mathbf{S}$ & 0.001 & $<0.001$ & 0.001 \\
$\mathbf{V}$ & 0.089 & - & - \\
$\mathbf{W}$ & 0.029 & - & - \\
$\mathbf{M o}$ & 0.246 & 0.25 & 0.25 \\
$\mathbf{C o}$ & 0.035 & - & - \\
$\mathbf{C u}$ & 0.206 & - & - \\
$\mathbf{A l}$ & 0.013 & - & - \\
$\mathbf{T i}$ & 0.002 & - & - \\
$\mathbf{N b}$ & 0.020 & - & - \\
Ta & 0.003 & - & - \\
$\mathbf{S n}$ & 0.008 & - & \\
\hline
\end{tabular}

The results in Table 3 show that the $\mathrm{C}$ and $\mathrm{N}$ content is suitably high to allow for the occurrence of the grain boundary reaction. The manufacturer's specified composition is also sufficiently accurate, though the omission of the $\mathrm{N}$ content is perplexing.

A small disc of the 21-4N bar stock was also polished and etched; refer to Figure 48 for micrographs of the as received microstructure. The grain size is approximately $5 \mu \mathrm{m}$. 


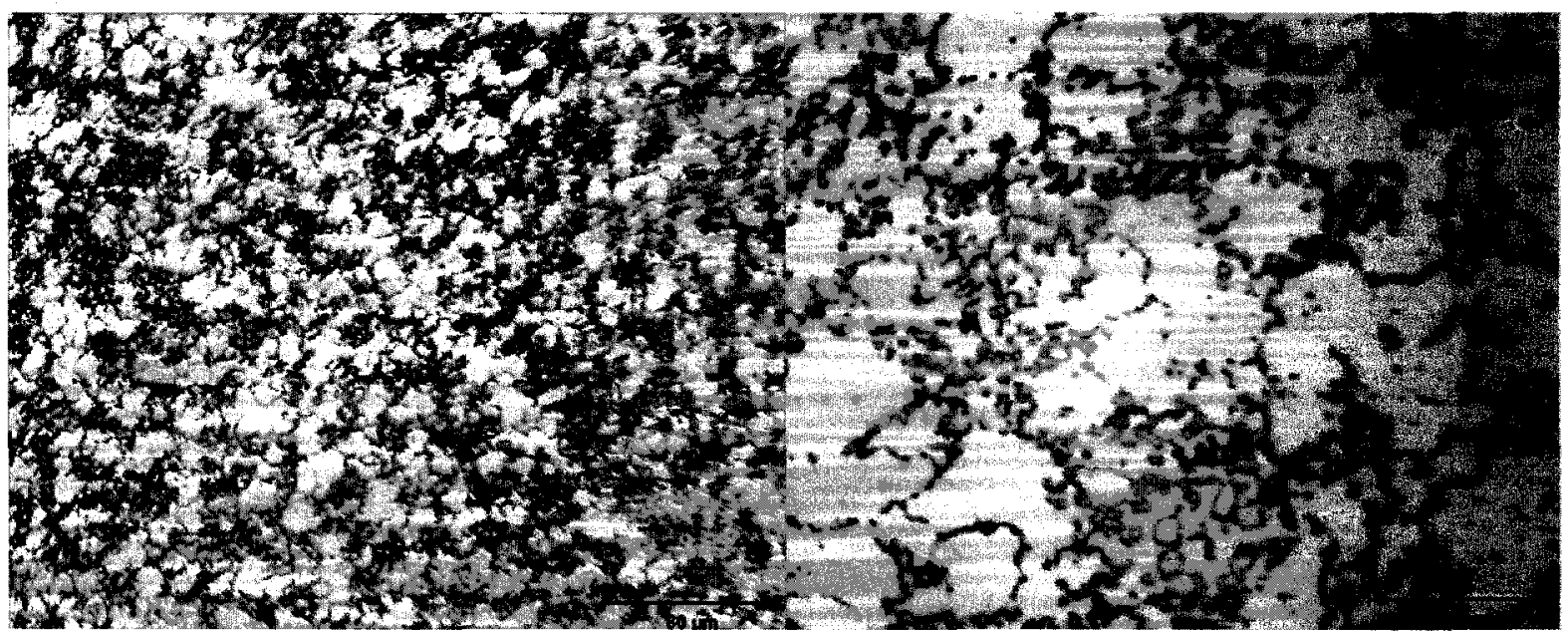

Figure 48: As received microstructure of the $21-4 \mathrm{~N}$ bar stock.

\subsection{Sample Heat Treatment}

Two general heat treatments are used to create samples with either planar grain boundaries or serrated grain boundaries. Refer to Section 6 for the resulting microstructures. Table 4 shows the heat treatments used. 'SGB' and 'NGB' are taken from the work of Tanaka et al. [22-23; 91]. 'SGB M' was developed as a refinement of 'SGB' after microstructural analysis of the 'SGB' heat treatment (refer to section 6 for further details).

Table 4: Heat treatments used on 21-4N test material.

\begin{tabular}{|c|c|}
\hline Specimen & Heat Treatment \\
\hline $\begin{array}{l}\text { SGB (serrated grain } \\
\text { boundaries) }\end{array}$ & $\begin{array}{l}1200^{\circ} \mathrm{C} \times 1 \mathrm{~h} \rightarrow \text { F.C. } \rightarrow 1030^{\circ} \mathrm{C} \rightarrow \text { W.Q. }+750^{\circ} \mathrm{C} \times 30 \mathrm{~h} \\
\rightarrow \text { A.C. }+1000^{\circ} \mathrm{C} \times 3 \mathrm{~h} \rightarrow \text { A.C. }\end{array}$ \\
\hline $\begin{array}{l}\text { SGB M (serrated grain } \\
\text { boundaries - modified) }\end{array}$ & $\begin{array}{l}1200^{\circ} \mathrm{C} \times 1 \mathrm{~h} \rightarrow \text { C.C. }\left(\sim 4^{\circ} \mathrm{C} / \mathrm{min}\right) \rightarrow 1030^{\circ} \mathrm{C} \rightarrow \text { W.Q. }+ \\
750^{\circ} \mathrm{C} \times 30 \mathrm{~h} \rightarrow \text { A.C. }+1000^{\circ} \mathrm{C} \times 3 \mathrm{~h} \rightarrow \text { A.C. }\end{array}$ \\
\hline $\begin{array}{l}\text { NGB (normal planar grain } \\
\text { boundaries) }\end{array}$ & $\begin{array}{l}1200^{\circ} \mathrm{C} \times 1 \mathrm{~h} \rightarrow \text { W.Q. }+700^{\circ} \mathrm{C} \times 30 \mathrm{~h} \rightarrow \text { A.C. }+1000^{\circ} \mathrm{C} \times \\
30 \mathrm{~h} \rightarrow \text { A.C. }\end{array}$ \\
\hline
\end{tabular}


The heat treatments are performed in a Lindberg furnace (type 51442) with a rated maximum temperature of $1200^{\circ} \mathrm{C}$. A Lindberg/Blue furnace controller is used (model CC58114PC-1) with a Yokogawa UP150 programmable temperature controller. An Omega Type $\mathrm{K}$ thermocouple is also used (part \# XCIB-K-2-2-3).

Two sample slugs are always heat treated simultaneously. Referring to Figure 49, it can be seen that the control thermocouple is inserted through the door of the furnace. The thermocouple is always located in between the two sample slugs and at their mid section. The position of the thermocouple is always established with the samples in place, before the furnace is brought up to temperature. Although the opening and closing of the furnace to load the sample slugs causes rapid temperature changes for the thermocouple, it is necessary to ensure the best possible temperature control at the sample slug mid sections.

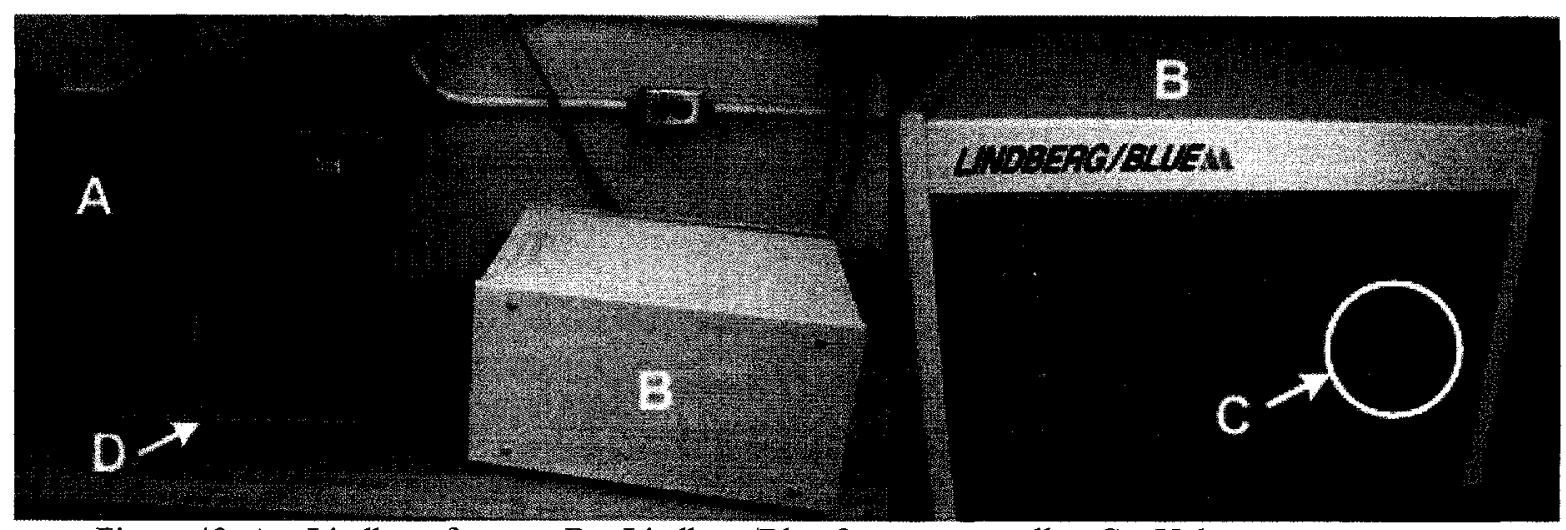

Figure 49: A - Lindberg furnace, B - Lindberg/Blue furnace controller, C - Yokogawa program temperature controller, D - Omega Type K thermocouple.

The quick loading of the sample slugs is also very important in the heat treating procedure, though it is only possible to load one sample at a time. As such, there is always an unavoidable temperature drop in the furnace. The temperature drop is always most severe for the initial part of the heat treatments at $1200^{\circ} \mathrm{C}$. Therefore, an extra five 
minutes is added to the heat treatment to allow the furnace to return to and stabilize at the required $1200^{\circ} \mathrm{C}$.

The furnace cooling in the 'SGB' heat treatment is done by shutting off the furnace controller after one hour and reconnecting the thermocouple to an Omega DP462 digital panel thermometer. The temperature is then monitored until it drops to $1030^{\circ} \mathrm{C}$ at which point the samples are withdrawn and placed into a bucket of cold tap water for quenching. The control cooling in the 'SGB M' heat treatment is done by using the programming functions of the Yokogawa programmable temperature controller. The programmed heat treatment also feature an extra five minutes to allow the furnace to stabilize at $1200^{\circ} \mathrm{C}$ after sample slug loading. Again, the sample slugs are removed and water quenched once they have reached $1030^{\circ} \mathrm{C}$. The air cooling is also straight forward, with the sample slugs being removed from the furnace and placed on separate ceramic bricks.

As mentioned in section 5.2, small discs are heat treated to investigate the effects of the heat treatments on the material microstructure. These discs are easier to heat treat by virtue of being able to load several at a time, thereby reducing the temperature drop in the furnace.

\subsection{Metallographic Preparation}

Sample slugs and small discs for microstructural analysis are cut from the $7 / 8$ " bar stock using an abrasive cutter. Tested creep samples are sectioned on a precision saw using an abrasive disc for rough cuts and a wafering blade for actual longitudinal sectioning. 
Mounted in bakelite, the metallographic samples are ground on 240,320, 400 and 600 grit emery cloths. They are then polished using 6 and 1 micron diamond polishing compounds on suitable polishing cloths. The polishing is finished using 0.3 micron alpha alumina on microcloth.

After both grinding and polishing, the samples are carefully rinsed and cleaned using dish soap. They are then cleaned ultrasonically in a mixture of distilled water and acetone. Finally they are rinsed with water, methanol and acetone before being blown dry and stored in plastic containers.

The next step is etching, which is done in a mixture of equal parts of $\mathrm{HNO}_{3}, \mathrm{HCl}$ and distilled water. The etchant is always prepared fresh in $120 \mathrm{~mL}$ batches which allows 4-5 samples to be etched. After initial mixing, the etchant is cooled to approximately $20^{\circ} \mathrm{C}$ and then stirred continuously as the samples were being etched. Each sample is etched for $\sim 35$ seconds, after which it is immediately dipped in distilled water and then rinsed under running water before being blown dry. For more details please refer to Appendix B.

\subsection{Creep Testing Procedure}

Creep tests are carried out using ASTM E 139-00 [100] and the ASM $10^{\text {th }}$ Edition, Volume 8: Mechanical Testing Handbook [101] as guidelines. Creep samples are machined from the $21-4 \mathrm{~N}$ sample slugs according to figure 50 . 

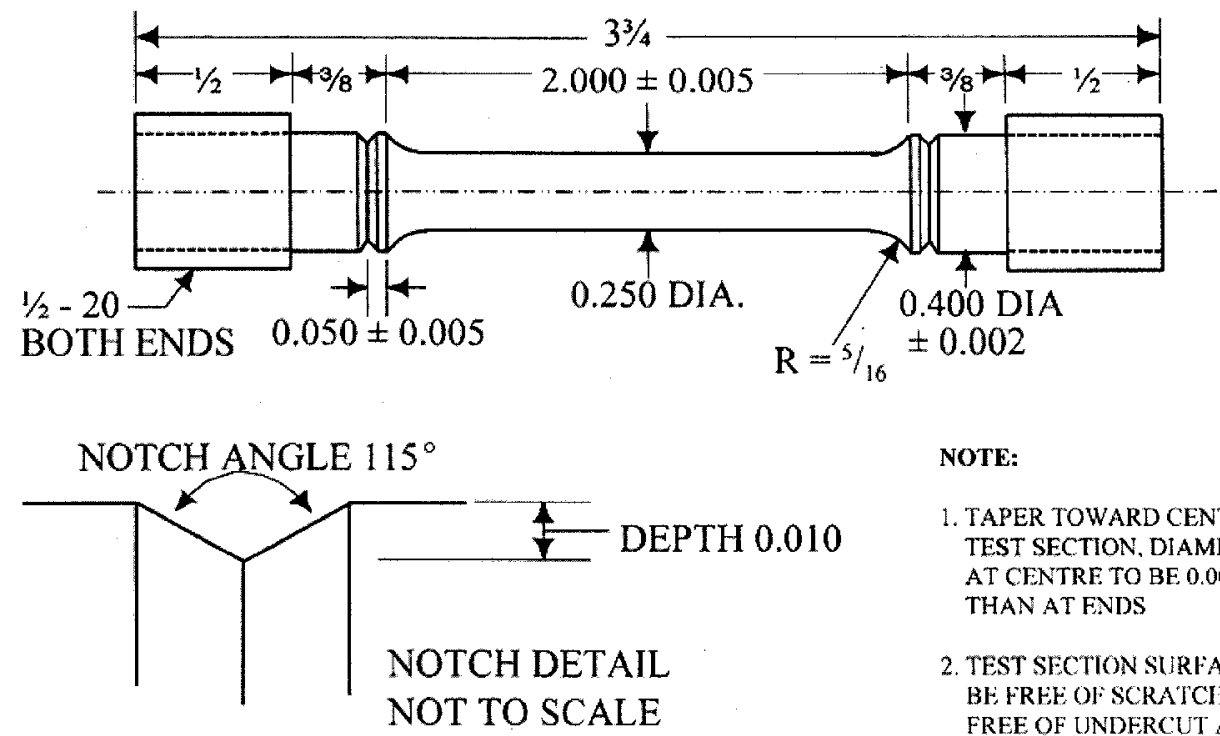

NOTE:

$$
\begin{aligned}
& \text { 1. TAPER TOWARD CENTRE OF } \\
& \text { TEST SECTION. DIAMETER } \\
& \text { AT CFNTRE TO BE } 0.001 \text { LESS } \\
& \text { THAN AT ENDS } \\
& \text { 2. TEST SECTION SURFACE TO } \\
& \text { BE FREE OF SCRATCHES AND } \\
& \text { FREE OF UNDERCUT AT } \\
& \text { FILLTT ENDS }
\end{aligned}
$$

Figure 50: Creep sample geometry.

The creep tests are run on Satec M3 constant load creep rupture test frames.

Solartron Metrology Linear Variable Differential Transformers (LVDTs) (part \# AX/1.5/S - 20119) with OD5 conditioning modules are used on Satec single (RT-214) and dual (DA-214) LVDT extensometers to measure the sample strain. Extensometers are attached to grooves machined in the specimen shoulders (refer to Figure 50). In the case of the dual LVDT extensometer, the actual creep strain is the average of the readings given by the two LVDTs.

Creep sample temperature is monitored using two Omega Type $\mathrm{K}$ thermocouples attached to the sample surface. The temperature is displayed on an Omega DP462 digital panel thermometer. The furnace is controlled with a Leeds \& Northrup unit. Reference can be made to Appendix $\mathrm{C}$ for full details of the testing procedure; however a general overview is given below. 


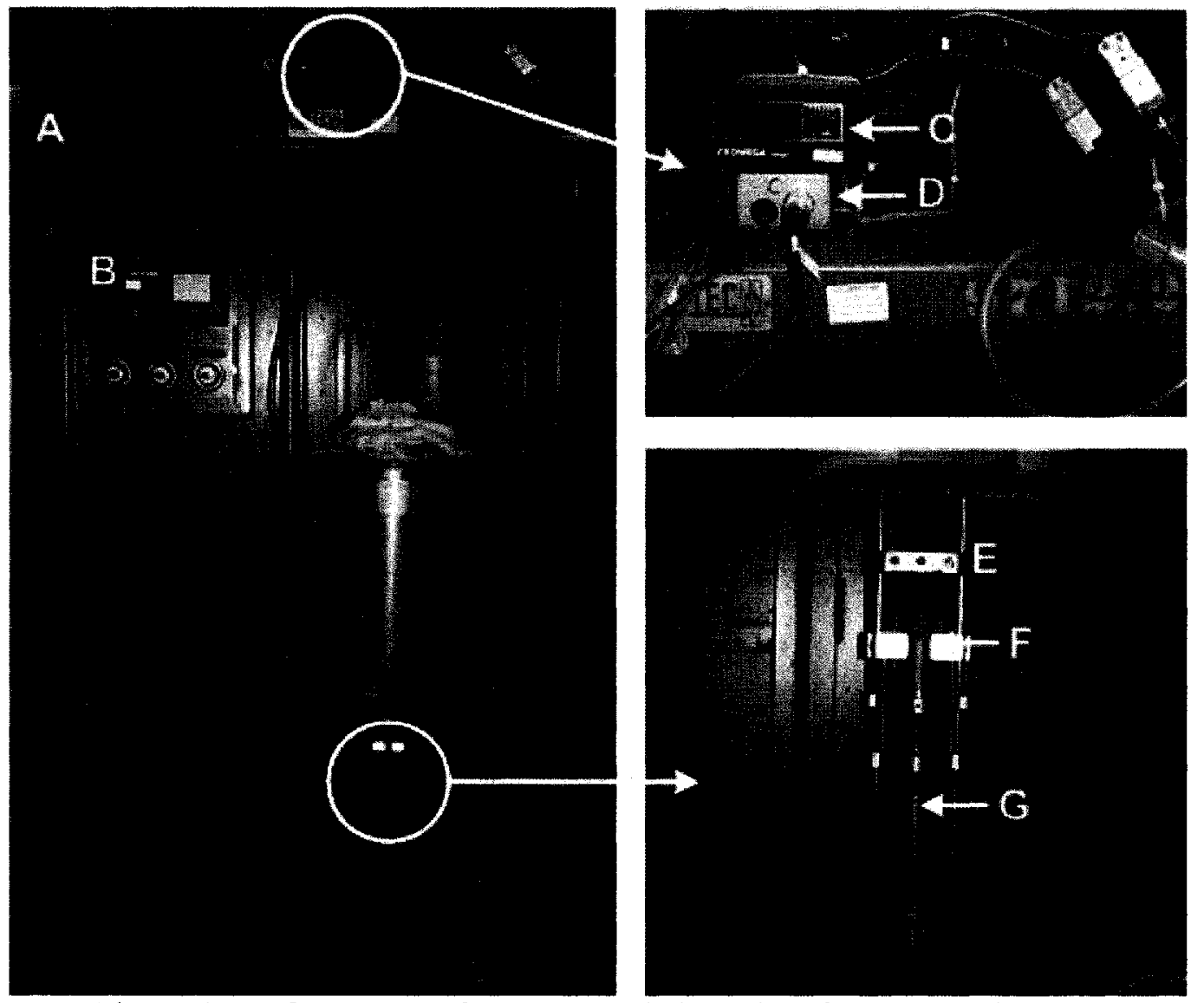

Figure 51: A - Creep rupture frame, B - Leeds \& Northrup furnace control unit, C - Omega DP462 digital panel thermometer, D - Solartron Metrology OD5 conditioning module, E - Satec RT-214 single LVDT extensometer, F - Extensometer micrometer, G - Solartron Metrology LVDT.

The LVDT is calibrated before every test using the micrometers mounted on the extensometer. The calibration gives the voltage signal of the LVDT when it is fully uncompressed (i.e. when the sample fails or creeps past the range of the LVDT) which is used to stop the data acquisition system. Also, the average change in voltage per unit length is calculated from the calibration, which is required to produce creep curves. Next the creep sample is measured and the gauge length and load needed are calculated. The gauge length is entered into the data acquisition system so that it can display the creep curves of running tests. 
The creep sample is then installed into the extensometer with all threaded connections being coated with boron nitride. The thermocouples are attached to the sample with thermocouple wire at the top and bottom of the gauge length. The sample and extensometer assembly are installed into the creep rupture frame with pull rods. The creep rupture frame furnace is closed and the ends are sealed with ceramic insulation.

The creep rupture frame furnace is brought up to testing temperature while monitoring the temperature across the creep sample gauge length. The temperature is never allowed to exceed the test temperature for any reason and was maintained within \pm $1^{\circ} \mathrm{C}$ during the test duration. The temperature difference between the two thermocouples on the gauge length is also maintained well below $1^{\circ} \mathrm{C}$, typically less than $0.5^{\circ} \mathrm{C}$. This is possible since the furnace has three zones, each of which are independently controlled. After test completion, the furnace is allowed to cool fully to room temperature before removing the sample and extensometer assembly.

Once the creep sample is steady at the test temperature, the load train is connected to the creep sample. The load is not applied and slack is maintained in the assembly, while the LVDT is installed into its mounting point on the extensometer. Then the LVDT is compressed as much as possible using the micrometer on the extensometer while keeping the LVDT in its linear range of operation (i.e. in its range of motion where the voltage change is related to the distance traveled through a linear relationship). Extreme care has to be taken to ensure the LVDT is not overly compressed before applying the test load and starting the test.

The data acquisition system is also prepared for the start of testing. Once it is prepared, as much slack as possible is removed from the load train assembly while 
monitoring the LVDT voltage signals to avoid straining the creep sample before the data acquisition is actually started. Typically, the point at which the test is ready to start is when the bottom portion of the load train is taught enough that it can not be easily moved by hand. At this point, the data acquisition system is started and the load is applied to the creep sample. Once started, the creep test is fully autonomous, with only observation of the creep curve and temperature across the creep sample surface. Minor corrections are made at times to the furnace in order to correct for discrepancies in the creep sample temperature due to changes in the test room. These corrections are infrequent and usually occur during significant shifts in the local weather.

\subsubsection{Increasing Load Testing}

This testing was just a modification of the constant load creep testing described in section 5.5. The goal of this testing was to find the strain rates at various loads while only testing one creep sample. This would greatly reduce the amount of testing required for the same amount of data. Thus the increasing load test involved several loads at a constant temperature. Before the test was started the loads that were desired were calculated and prepared. The initial load applied at the start was done just like a constant load test. Then using the creep curve being generated by the data acquisition system, the next load was applied once a roughly constant creep rate was achieved. The extra load had to be carefully added to the load train to avoid disturbing the test, beyond the increase in stress on the sample. Again, a roughly constant creep rate is allowed to occur before the next load was applied. This was continued until all the loads were applied or once the creep sample failed. 


\subsection{Data Acquisition}

Strain data is collected from the extensometer mounted LVDTs with a National Instruments (NI) USB-6008 Multifunction I/O data acquisition system (DAQ). The DAQ is connected via USB port to a PC laptop on which a LabView programmed user interface is operating. Refer to figures 52 and 53.

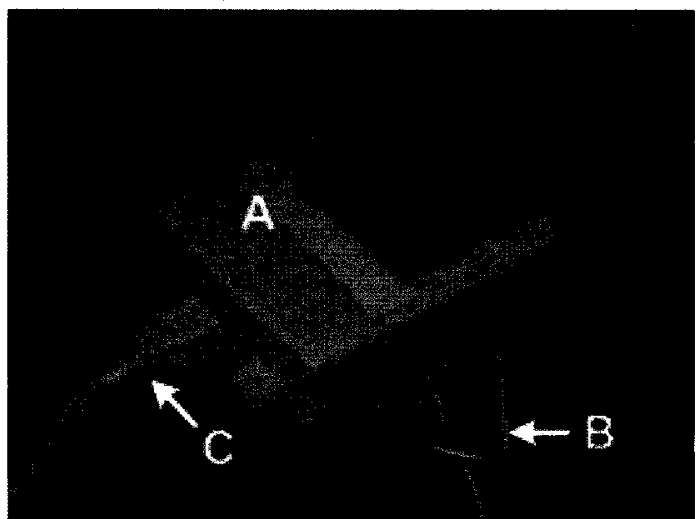

Figure 52: A - National Instruments USB data acquisition system, B - signal lines from LVDT conditioning modules, $\mathrm{C}$ - USB connection to PC laptop.

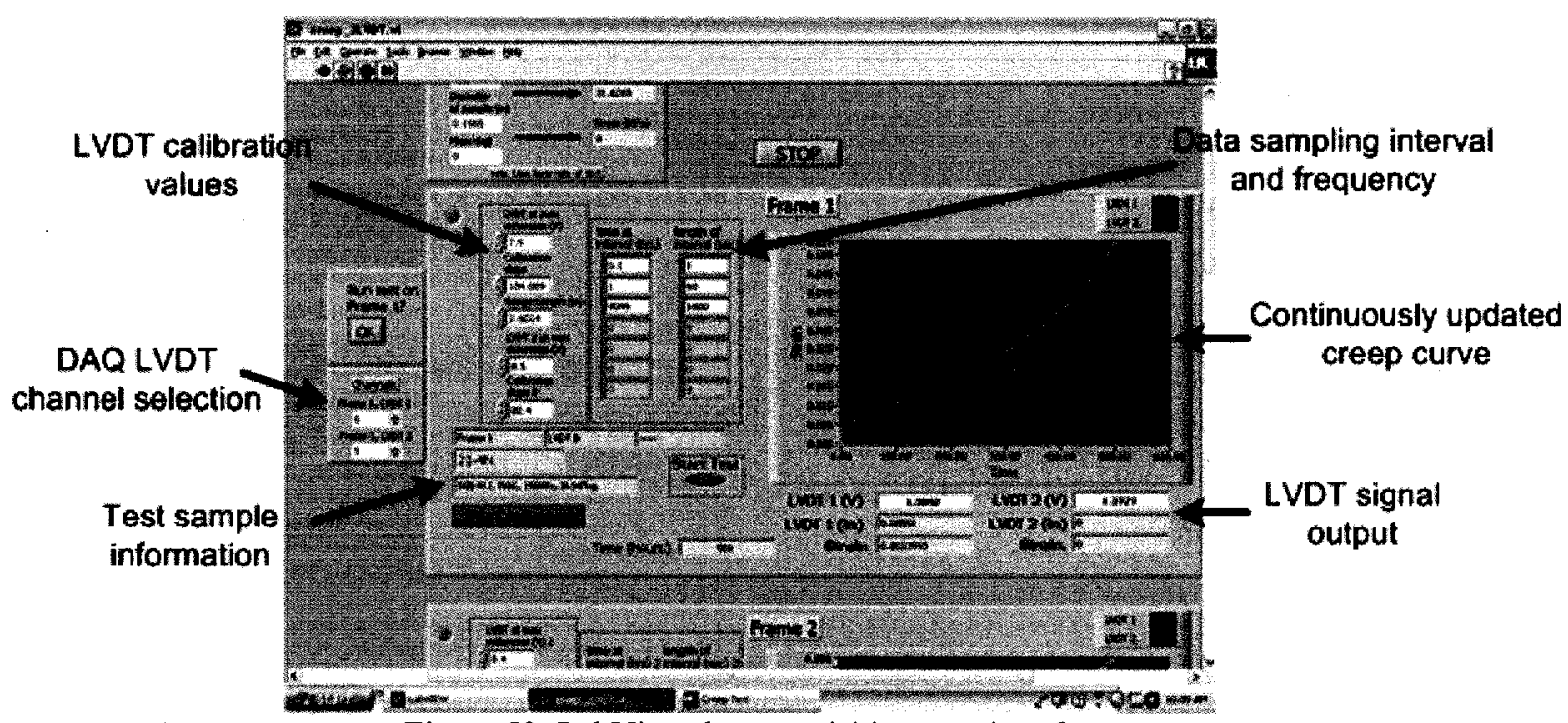

Figure 53: LabView data acquisition user interface.

With the NI DAQ, the LabView software data acquisition is capable of collecting data from multiple tests simultaneously, including tests using a dual LVDT extensometer. 
In the case of the dual LVDT, the LabView user interface displays the strain from each LVDT on the same plot of strain vs time.

The LVDT calibration data is input into the LabView user interface as well as the calculated gauge length of the creep samples. As well, intervals of time with specific strain sampling rates are input. Thus, the strain transient at the beginning of each test can be collected at a very high sampling rate for greater accuracy followed by a slower sampling rate once the creep curve enters the secondary and tertiary stages.

The data recorded for each tested sample includes the test time, voltage signal of LVDT, displacement of LVDT and strain of sample. As well, details about the sample and test conditions are also recorded. For further details, please see Appendix D.

\subsection{Metallographic Analysis}

Specimens for metallographic analysis are observed using an Olympus PME 3 optical microscope. Digital images are taken using Clemex Vision Lite image analysis software with a Clemex L 1.3M general purpose camera mounted on the PME 3 microscope.

Apart from taking micrographs, the Clemex software is used to analyze grain boundary reaction (GBR) area fractions and the grain size. In both cases the process is partially automated except for user intervention to correct for such things as incorrectly identified GBR and removal and/or addition of grain boundaries. For both analyses, roughly 30 images are used per metallographic specimen. The GBR results are given as an area percentage and the grain size was found from the average of the mean vertical and horizontal grain lengths measured. 
Some metallographic specimens have the grain size manually calculated from printed micrographs, again by measuring horizontal and vertical grain lengths from a series of lines and averaging the result. ASTM E 112-88 [102] is used as a guideline for both the software and manual grain size analyses.

\subsection{Creep Data Analysis}

Analysis of the creep data was performed on the constant load and increasing load test results. Strain rates were calculated from the increasing load test results by fitting straight lines to the regions of roughly constant strain rate. The constant load creep curves were modeled using the $\theta$-Projection method [3]. The $\theta$-Projection method was only used to model the creep curves and not to infer or extract any meaning about the physical processes occurring during creep. The basic equation used to model creep behaviour is given below and is also known as the 4- $\theta$ method due to the fact that it has four coefficients.

$$
\varepsilon=\theta_{1}\left(1-\mathrm{e}^{-\theta_{2} t}\right)+\theta_{3}\left(e^{\theta_{4} t}-1\right)
$$

Here $\varepsilon$ is the uniaxial true strain and $t$ is time. The equation is based on common characteristics of creep curves which can be seen in Figure 54. 


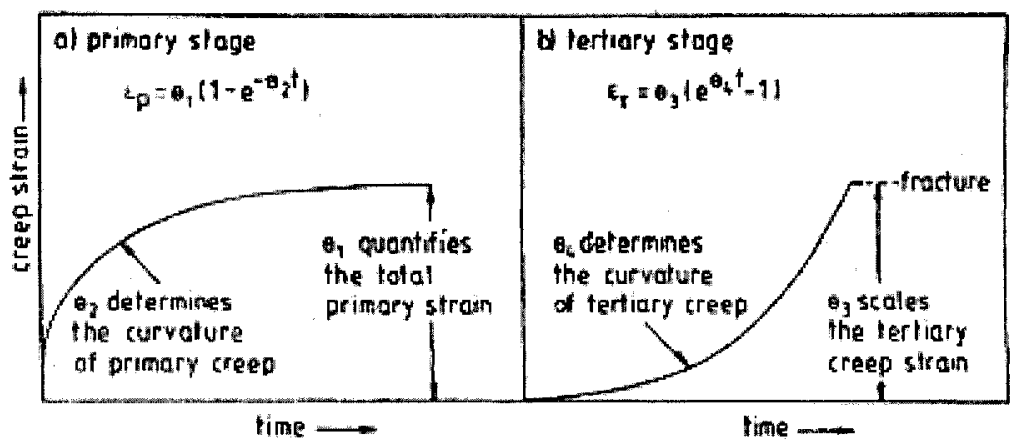

Figure 54: The $\theta$ Projection method treats the creep curve as decaying primary and accelerating tertiary sections [3].

If a creep curve can be accurately modeled using equation (9), then calculating the creep rate as well as creating strain vs. strain rate plots becomes a simple matter of differentiating equation (9) with respect to time. An issue with the 4- $\theta$ method is that it often does not accurately model the creep curve at low strains [103]. To account for this issue, the 6- $\theta$ method involves six coefficients and can be seen in equation (10).

$$
\varepsilon=\theta_{1}\left(1-e^{-\theta_{2} t}\right)+\theta_{3}\left(e^{\theta_{4} t}-1\right)+\theta_{5}\left(1-e^{-\theta_{6} t}\right)
$$

The 6- $\theta$ method is based on a general model function [103]:

$$
\varepsilon=\eta(\theta)=\sum_{\mathrm{i}=1}^{\mathrm{q}} \theta_{2 \mathrm{i}-1}\left(1-\mathrm{e}^{-\theta_{2 \mathrm{i}}}\right)
$$

It is believed that any experimental creep curve can be modeled by just increasing the number of terms; there being no theoretical limit to $\mathrm{q}$ [103]. Thus, the general form of the $\theta$ Projection method is used to model the constant load creep curves.

Although the $\theta$ Projection method should be used for uniaxial true strain from tests done at constant stress and constant temperature [104], the tests carried out on the 21-4N were done in constant load creep rupture frames. To conform better to the method 
requirements, the true strain is calculated from the engineering strain measured during testing using equation (12), where $\mathrm{e}$ is the engineering strain.

$$
\varepsilon=\ln (1+\mathrm{e}) .
$$

Using an 'NGB' sample that was tested at $27.4 \mathrm{MPa}$ and $900^{\circ} \mathrm{C}$ as an example, refer to figure 55 for a comparison of the calculated true strain and measured engineering strain.

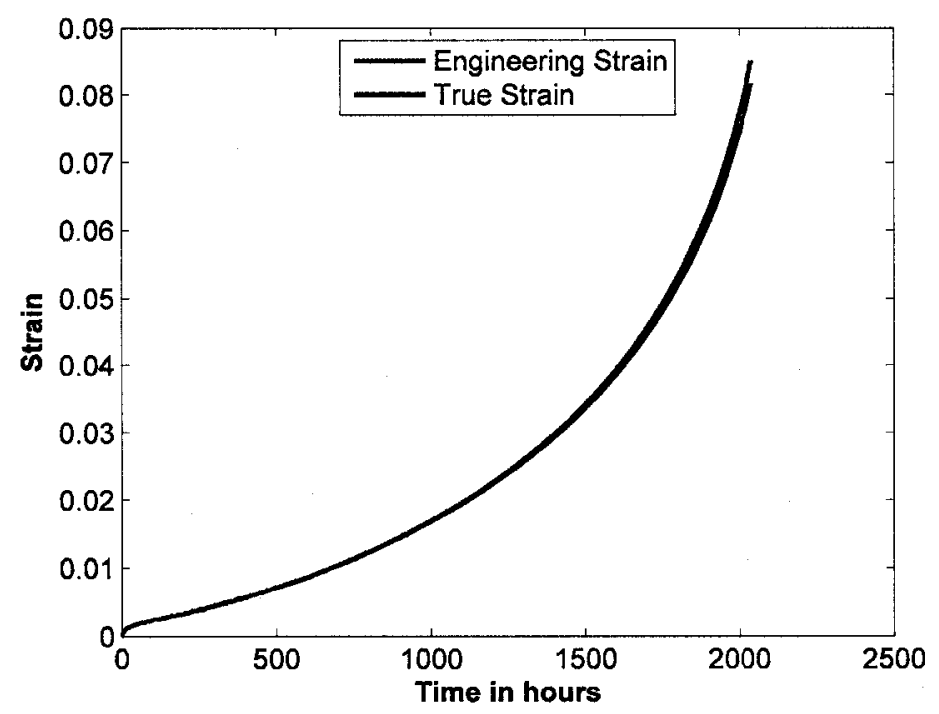

Figure 55: Comparison of measured engineering strain and calculated true strain.

The difference between the strains only becomes pronounced at higher strain levels. However this difference has little effect on the data analysis as the data is truncated to simplify the modeling process. This allows for greater accuracy in modeling the primary sections of the creep curves which are of greater concern than the tertiary sections. In each case, it is ensured that the truncation is done after the minimum creep rate occurred. Figure 56 shows how the data is truncated for this example creep data. Referring to Figure 55 it is seen that the difference between engineering and true strain is negligible for the truncated data set. 


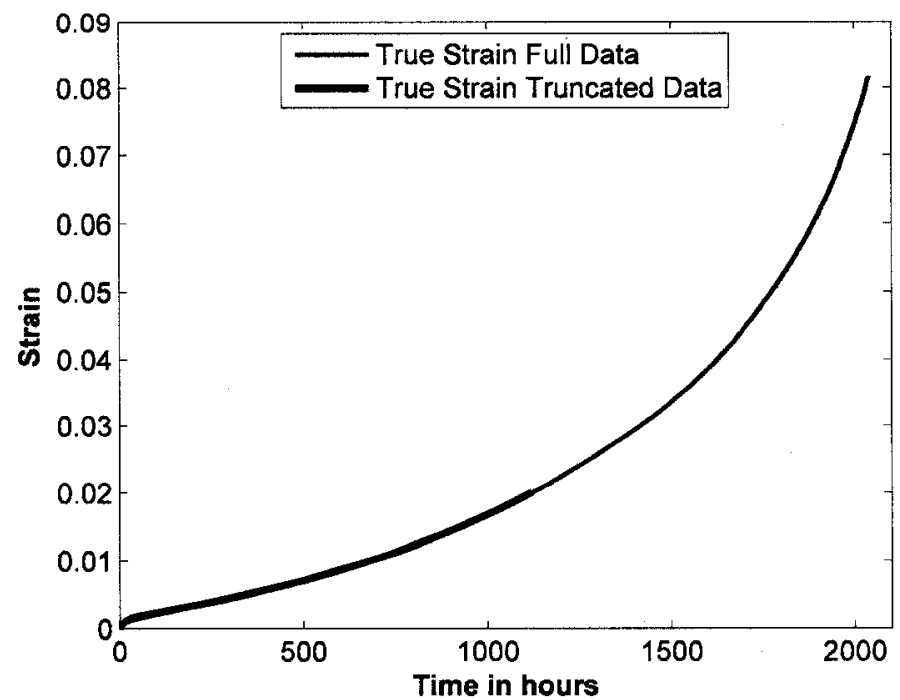

Figure 56: Truncated data overlaid on full true strain data for 'NGB' sample tested at $27.4 \mathrm{MPa}$ and $900^{\circ} \mathrm{C}$.

After the data is suitably truncated, a non-linear least squares solving algorithm is applied to solve for the $\theta$ Projection coefficients. This is in line with other research [103; 105]. For the current example, an $18-\theta$ fit is best to describe the truncated data. The curve fit equation is of the form given in equation (13).

$$
\varepsilon=\theta_{1}\left(1-\mathrm{e}^{-\theta_{2} \mathrm{t}}\right)+\theta_{3}\left(\mathrm{e}^{\theta_{4} \mathrm{t}}-1\right)+\theta_{5}\left(1-\mathrm{e}^{-\theta_{6} \mathrm{t}}\right)+\ldots .+\theta_{17}\left(1-\mathrm{e}^{-\theta_{18} \mathrm{t}}\right)
$$

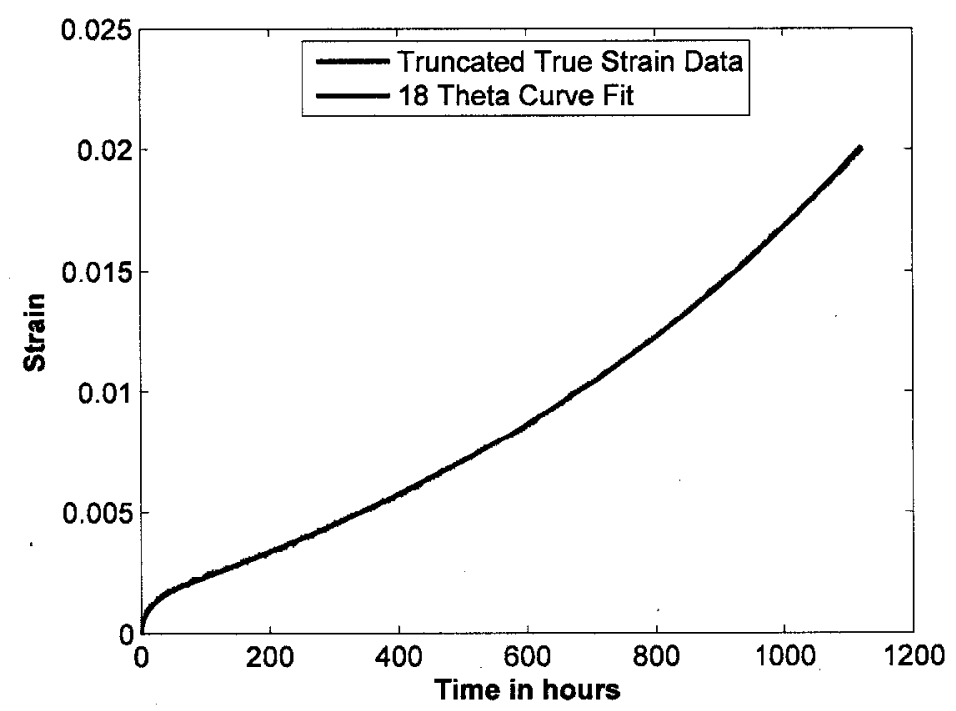

Figure 57: Comparison of actual data to $\theta$ Projection method curve fit. 
In each case of curve fitting, multiple equations of fit are attempted. The errors of these attempts can be seen in figure 58 for the current example.

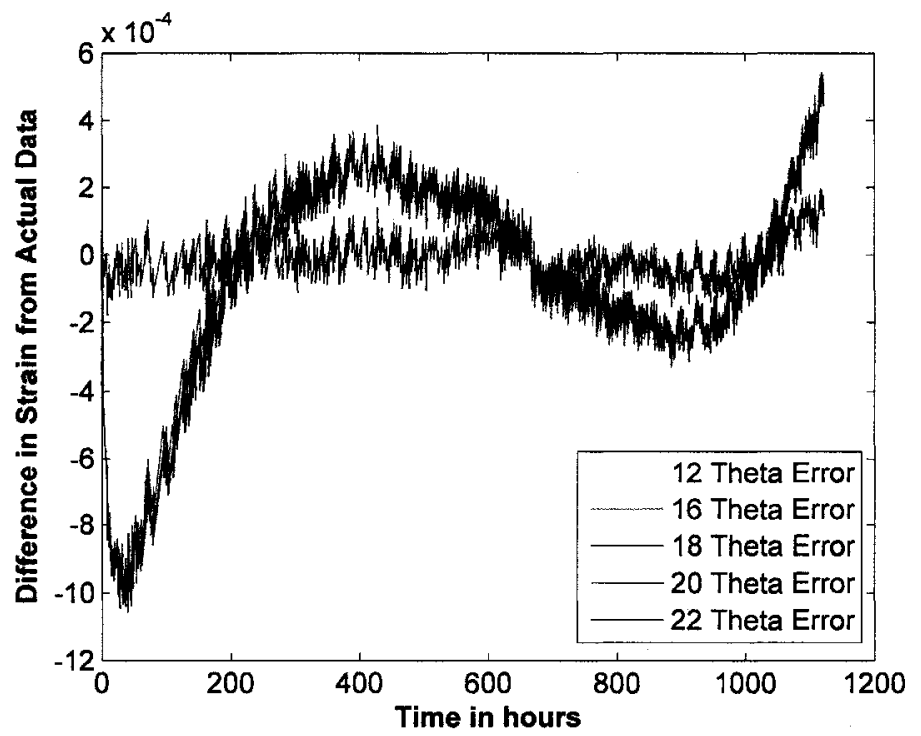

Figure 58: Difference in strain between $\theta$ fit equations and actual data.

Each sample's creep curve is modeled similarly, with at times several excellent $\theta$ Projection fits achieved. The minimum creep rates calculated from the $\theta$ fit equations are relatively consistent with at most $5 \%$ variation, but the time to minimum creep rate varied significantly. Thus the $\theta$ Projection results are used only to provide more accurate minimum creep rate data from the constant load test results. Refer to Appendix E for details on the individual $\theta$ Projection curve fits. 


\section{Results}

\subsection{Heat Treated Microstructures}

\subsection{1 'NGB' Microstructure}

As outlined in Section 5, three heat treatments were applied to the 21-4N test material. The first is the 'NGB' heat treatment which produces planar or normal grain boundaries. Figure 59, shows the microstructures after each step of the 'NGB' heat treatment. The first step of the heat treatment increases the grain size to $\sim 110 \mu \mathrm{m}$ and results in precipitate free grain interiors. The second step causes a large amount of precipitation at the grain boundaries and in the grain interiors, mostly adjacent to the grain boundaries. The final step of the heat treatment causes a more even distribution of precipitates, though there are still some concentrations next to grain boundaries.

Referring to Figure 60 , there is a marked change in the grain boundary structure between the second and final steps of the heat treatment. After the final step, there are some coarse carbides visible and almost negligible regions free of precipitates; likely due to the growth of the coarser carbides. The precipitate distribution also appears to be more even after the final step of the heat treatment. The carbides are not continuous in the fully heat treated microstructure. 


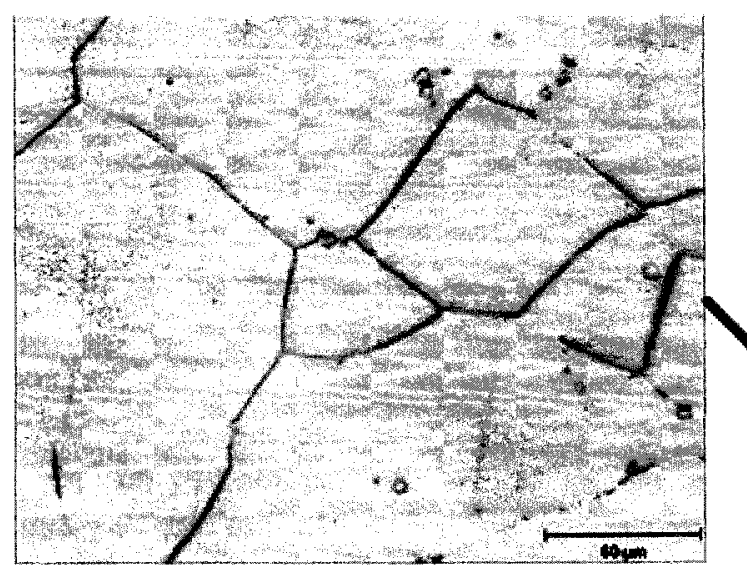

Slep l: $1200^{\circ} \mathrm{C} \times \mathrm{lh} \rightarrow \mathrm{W} Q \mathrm{Q}$
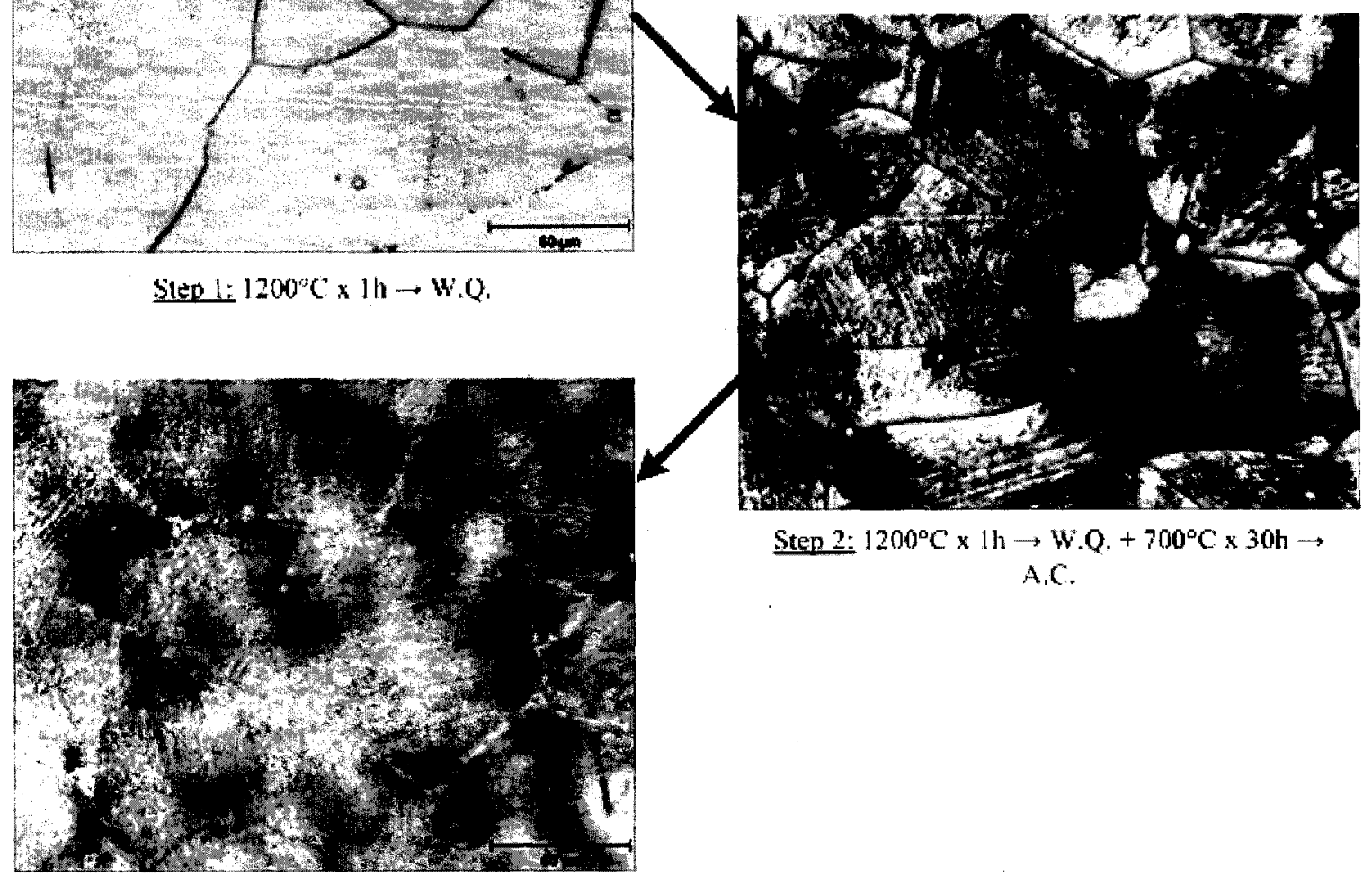

Step 2: $1200^{\circ} \mathrm{C} \times 1 \mathrm{~h} \rightarrow W . \mathrm{Q} .700^{\circ} \mathrm{C} \times 30 \mathrm{~h} \rightarrow$ A.C.

Sten 3: $1200^{\circ} \mathrm{C} \times 1 \mathrm{~h} \rightarrow$ W.Q. $+700^{\circ} \mathrm{C} \times 30 \mathrm{~h} \rightarrow$ $\mathrm{A} . \mathrm{C} .11000^{\circ} \mathrm{C} \times 30 \mathrm{~h} \rightarrow \mathrm{A} . \mathrm{C}$.

Figure 59: Microstructural evolution during the 'NGB' heat treatment.

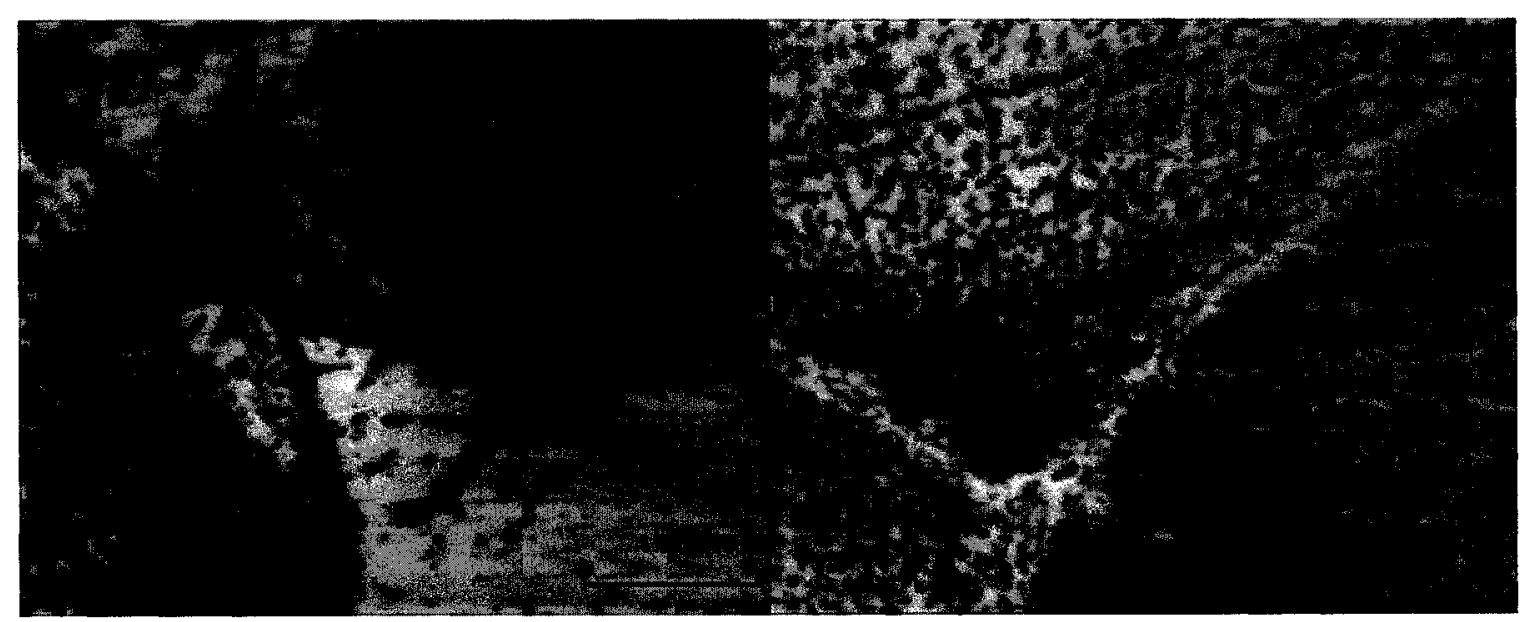

'NGB' Step 2

'NGB' Step 3 - Fully Heat Treated

Figure 60: Grain boundaries of partially and fully heat treated 'NGB' microstructure. 


\subsection{2 'SGB' \& 'SGB M' Microstructures}

'SGB' is the second heat treatment and produces serrated grain boundaries as well as Grain Boundary Reaction (GBR) nodules, as seen in Figure 61. The first step of the heat treatment increases the grain size to $\sim 94 \mu \mathrm{m}$, precipitates GBR nodules but leaves the grain interiors free of precipitates. The second step causes a large amount of precipitation at the grain boundaries, notably adjacent to the GBR nodules. There remain areas within the grain interiors free of precipitates. The final step of the heat treatment creates a more balanced distribution of precipitates though the microstructure is not nearly as uniform as the 'NGB' one. There still remain dense precipitates adjacent to the GBR nodules and some grain interiors have very sparse precipitates.

Referring to Figure 62, there is not a large difference in the grain boundary structure between the second and final steps of the heat treatment. The grain boundaries have coarse carbides of a more planar nature than the 'NGB' microstructure, though they follow the serrations of the grain boundaries. In some places, the carbides are nearly continuous. While the precipitates have been partially redistributed into the grain interiors, there remain dense precipitates adjacent to the GBR nodules. Compared to the 'NGB' microstructure, there are larger zones on either side of the grain boundaries free of precipitates, again likely due to the coarser grain boundary carbides. 


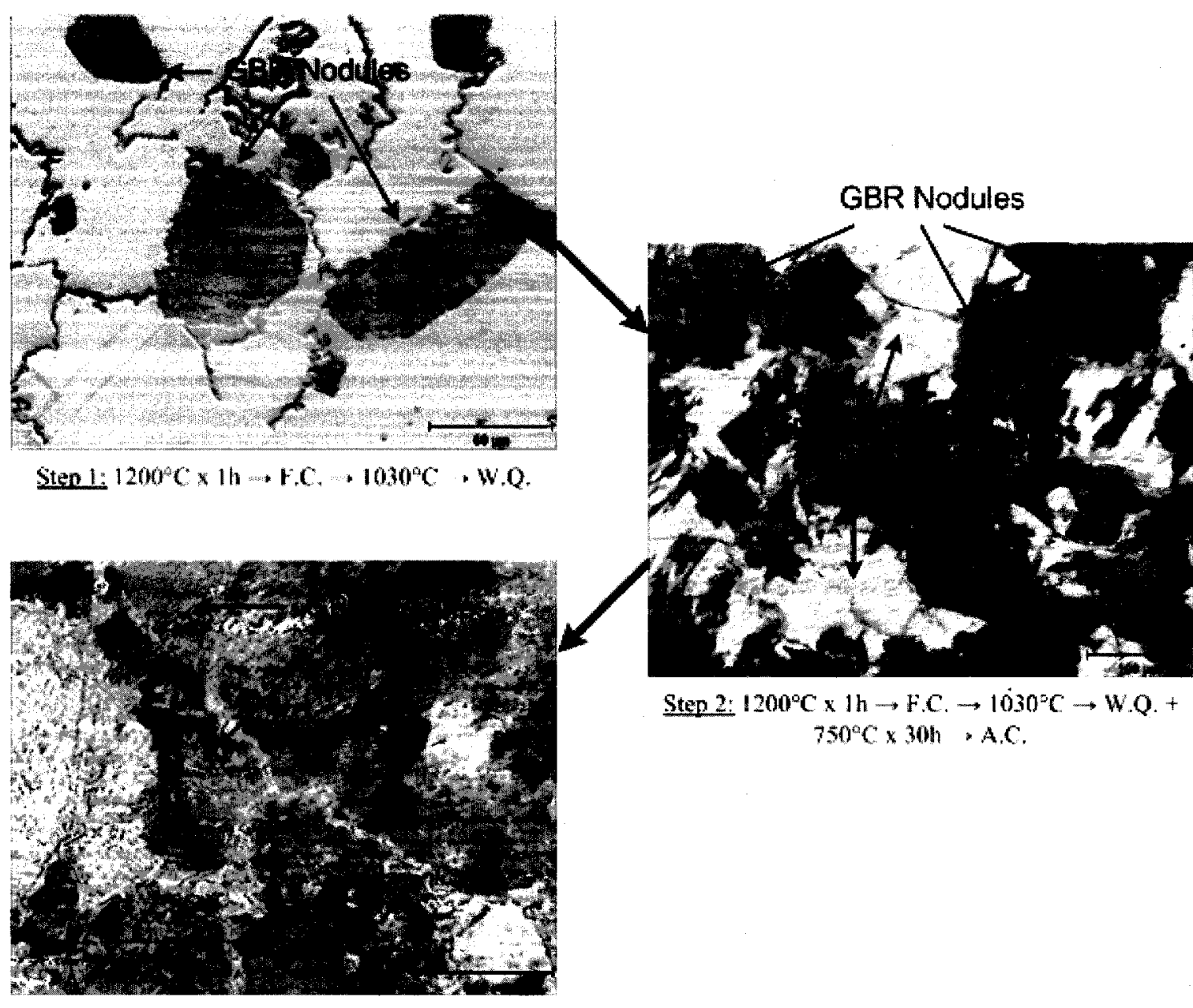

Step 3: $1200^{\circ} \mathrm{C} \times 1 \mathrm{~h} \rightarrow$ F.C. $\rightarrow 1030^{\circ} \mathrm{C} \rightarrow$ W.Q. +

$750^{\circ} \mathrm{C} \times 30 \mathrm{~h}+\mathrm{ACC} * 1000 \mathrm{C} \times 3 \mathrm{~h} \cdot \mathrm{A} . \mathrm{C}$.

Figure 61: Microstructural evolution during the 'SGB' heat treatment.

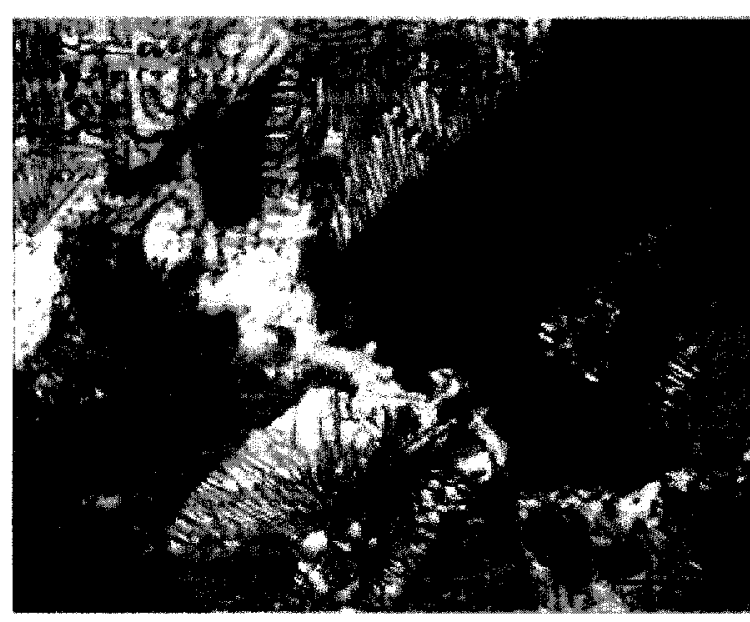

'SGB' Step 2

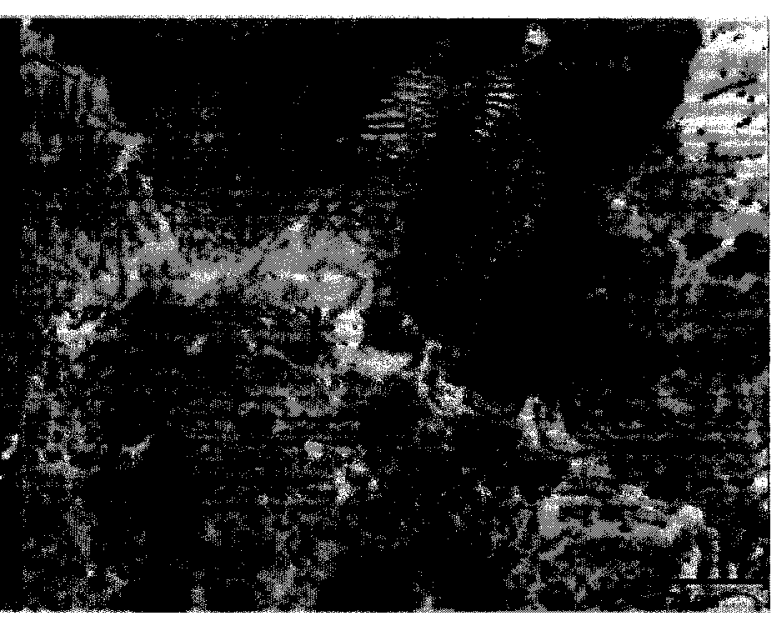

'SGB' Step 3 - Fully Heat Treated

Figure 62: Grain boundaries of partially and fully heat treated 'SGB' microstructure. 
The 'SGB' heat treatment produces $\sim 16 \%$ area fraction of GBR. This is an excessive amount, which as explained in Section 5, can have a negative impact on the creep properties. A new heat treatment was sought to produce serrated grain boundaries while controlling the amount of GBR closer to the ideal of 8-10\% area fraction.

The effect of varying the cooling rate after the solutionizing treatment was studied. Referring to Figure 63 , the $6^{\circ} \mathrm{C} / \mathrm{min}$ cooling rate corresponds to the furnace cooling used in the 'SGB' heat treatment. Figure 64 visually shows the effect of the cooling rate on the amount of GBR precipitated. From the results shown in Figure 63, a cooling rate of $4^{\circ} \mathrm{C} / \mathrm{min}$ was chosen to produce $\sim 10 \%$ area fraction GBR. The new heat treatment was designated 'SGB M' and is identical to the 'SGB' heat treatment, except for the cooling rate in the first step.

Referring to Figure 65, the only difference between the 'SGB' and 'SGB M' microstructures is the area fraction of GBR nodules. The grain size of the 'SGB M' microstructure is virtually identical to that of the 'SGB' at $\sim 90 \mu \mathrm{m}$. Due to the reduced amount of GBR in the 'SGB M' microstructure, it can be considered to be a more uniform microstructure than the 'SGB' one, though again it is not nearly as uniform as the 'NGB' microstructure. 


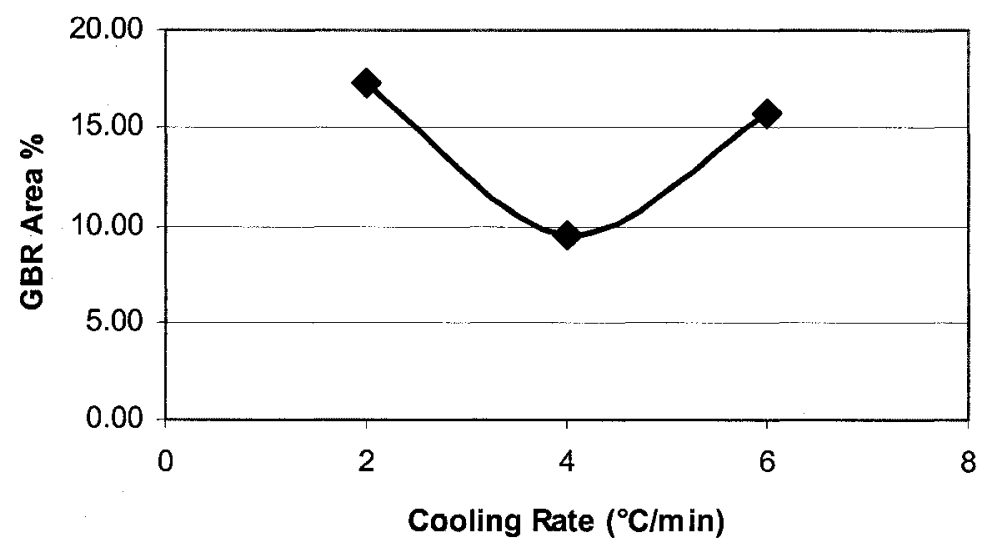

Figure 63: Effect of cooling rate on amount of GBR precipitated after solutionizing at $1200^{\circ} \mathrm{C}$ for 1 hour, followed by cooling to $1030^{\circ} \mathrm{C}$ and water quenching.

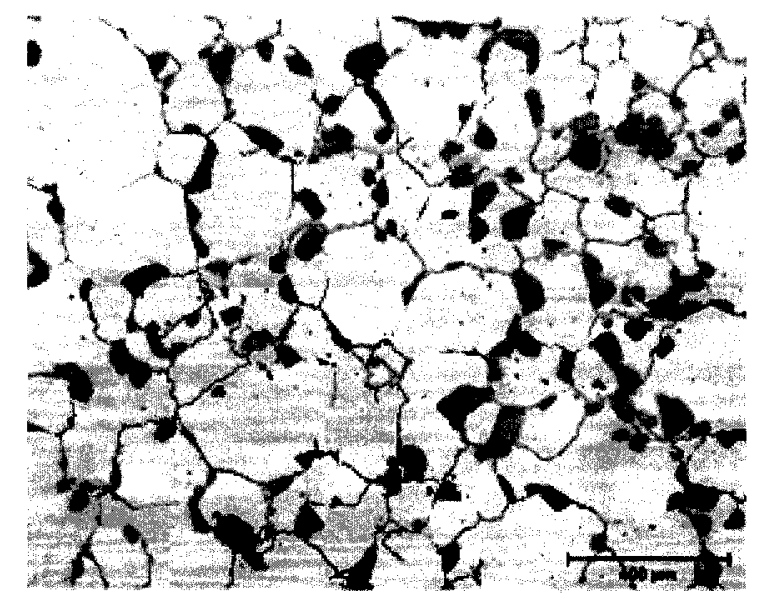

$6^{\circ} \mathrm{C} / \mathrm{min}$ cooling rate $(-16 \% \mathrm{GBR})$

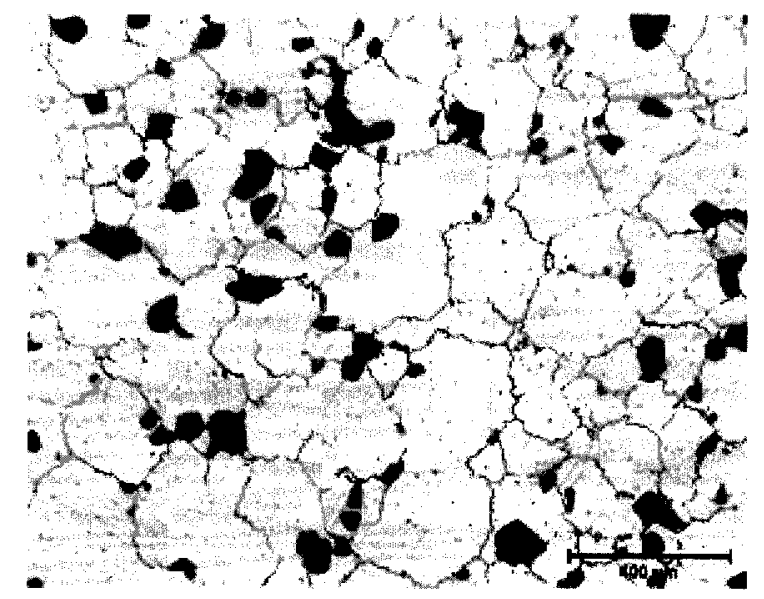

$4^{\circ} \mathrm{C} / \mathrm{min}$ cooling rate $(-10 \% \mathrm{GBR})$

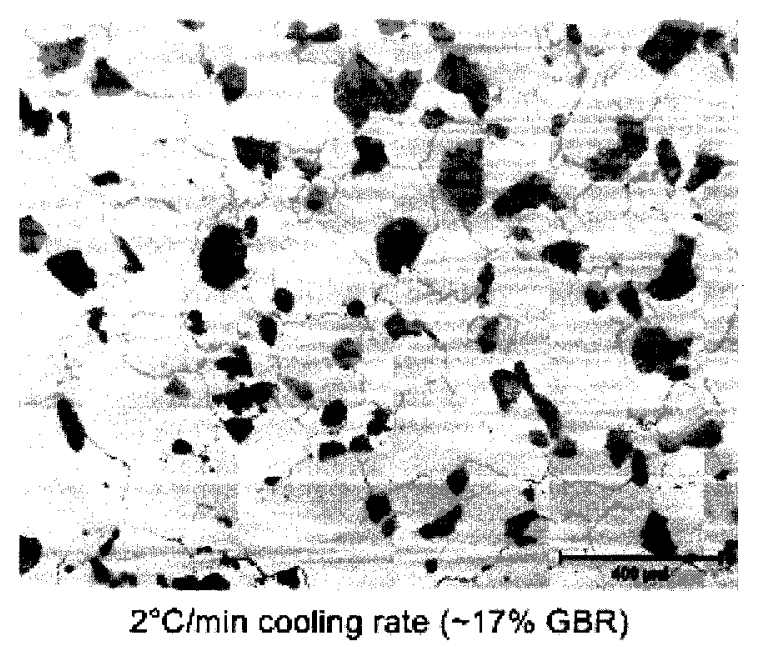

Figure 64: Representative micrographs showing effect of cooling rate on area fraction of GBR. 


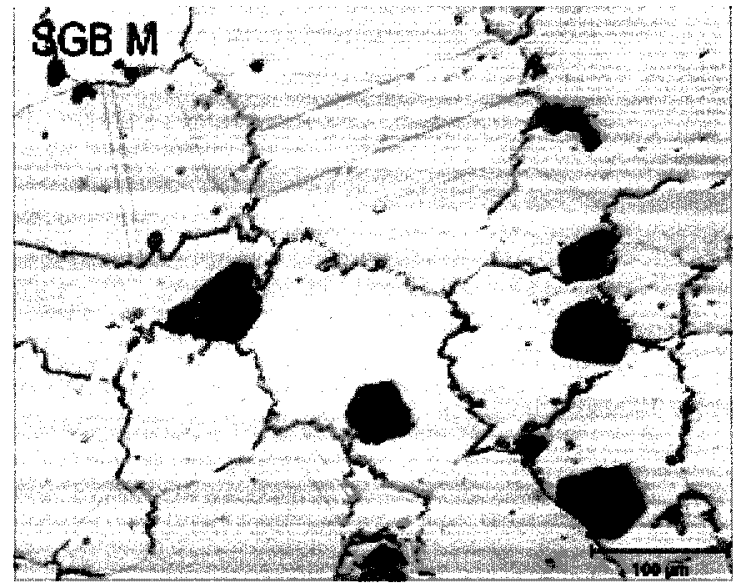

Step 1: $1200^{\circ} \mathrm{C} \times 1 \mathrm{~h} \rightarrow$ C.C. $\left(4^{\circ} \mathrm{C} / \mathrm{min}\right) \rightarrow$ $1030^{\circ} \mathrm{C} \rightarrow$ W.Q.

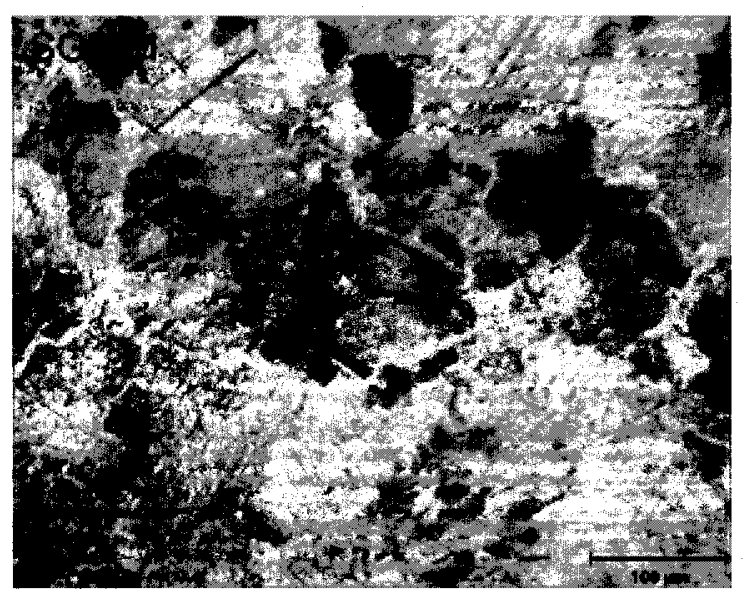

Fully Heat Treated: $1200^{\circ} \mathrm{C} \times 1 \mathrm{~h} \rightarrow \mathrm{C.C} .\left(4^{\circ} \mathrm{Cl}\right.$ $\min ) \rightarrow 1030^{\circ} \mathrm{C} \rightarrow$ W.Q. $+750^{\circ} \mathrm{C} \times 30 \mathrm{~h} \rightarrow$ A.C.

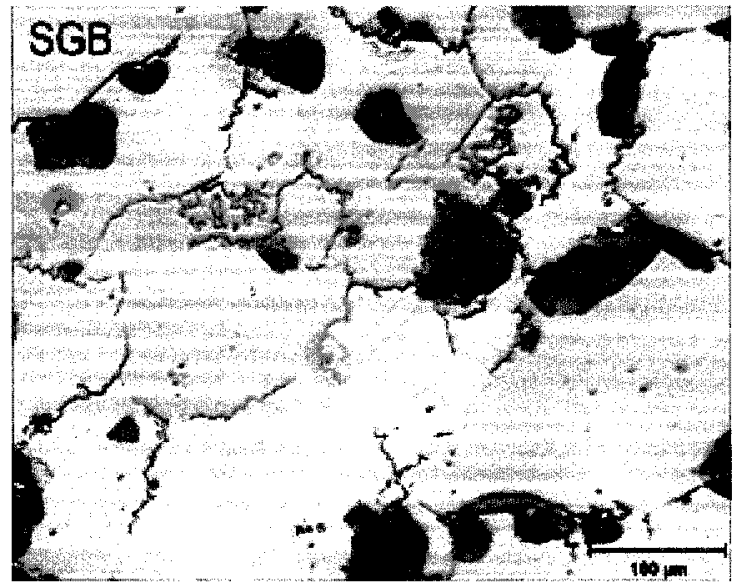

Step 1: $1200^{\circ} \mathrm{C} \times 1 \mathrm{~h} \rightarrow$ F.C. $\left(6^{\circ} \mathrm{C} / \mathrm{min}\right) \rightarrow$ $1030^{\circ} \mathrm{C} \rightarrow$ W.Q.

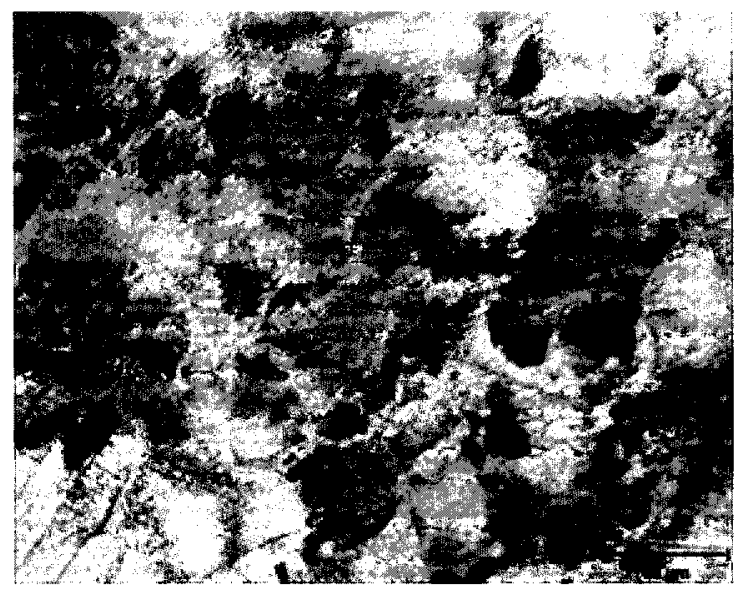

Fully Heat Treated: $1200^{\circ} \mathrm{C} \times 1 \mathrm{~h} \rightarrow$ F.C. $\left\{6^{\circ} \mathrm{Cl}\right.$ min) $\rightarrow 1030^{\circ} \mathrm{C} \rightarrow W . Q .+750^{\circ} \mathrm{C} \times 30 \mathrm{Ch} \rightarrow$ A.C. $+1000^{\circ} \mathrm{C} \times$ 3h $\rightarrow$ A.C.

$+1000^{\circ} \mathrm{C} \times 3 \mathrm{~h} \rightarrow \mathrm{A} . \mathrm{C}$.

Figure 65: Comparison of 'SGB M' and SGB' heat treated microstructures. 


\subsubsection{Microstructure Comparison}

Figures 66 and 67 show the general microstructures and grain boundaries of the three heat treatments for comparative purposes. Each microstructure ended up having a roughly equal grain size with the 'NGB' being $\sim 110 \mu \mathrm{m}$, the 'SGB' $\sim 94 \mu \mathrm{m}$ and the 'SGB M' $\sim 90 \mu \mathrm{m}$. As was noted earlier, the 'NGB' microstructure is more uniform in nature than the 'SGB' or 'SGB M' microstructures (refer to Figure 66). This nonuniformity of the 'SGB' and 'SGB M' microstructures is unavoidable due to the GBR being the cause of the grain boundary serrations.

Of note also are the grain boundaries shown in Figure 67. Apart from the GBR seen in the 'SGB' and 'SGB M' micrographs, the largest difference between the 'NGB' and 'SGB'/'SGB M' grain boundaries is the occurrence of coarse carbides. The 'NGB' grain boundaries show few coarse carbides of mostly globular type. The 'SGB' and 'SGB M' grain boundaries however show large amounts of coarse carbides that are mainly planar in configuration. They almost appear to be continuous in some areas. Again it can be noted that there are precipitate free zones in the 'SGB' and 'SGB M' microstructures immediately adjacent to the grain boundaries, likely due to the coarse carbides depleting elements for adjacent precipitates. 

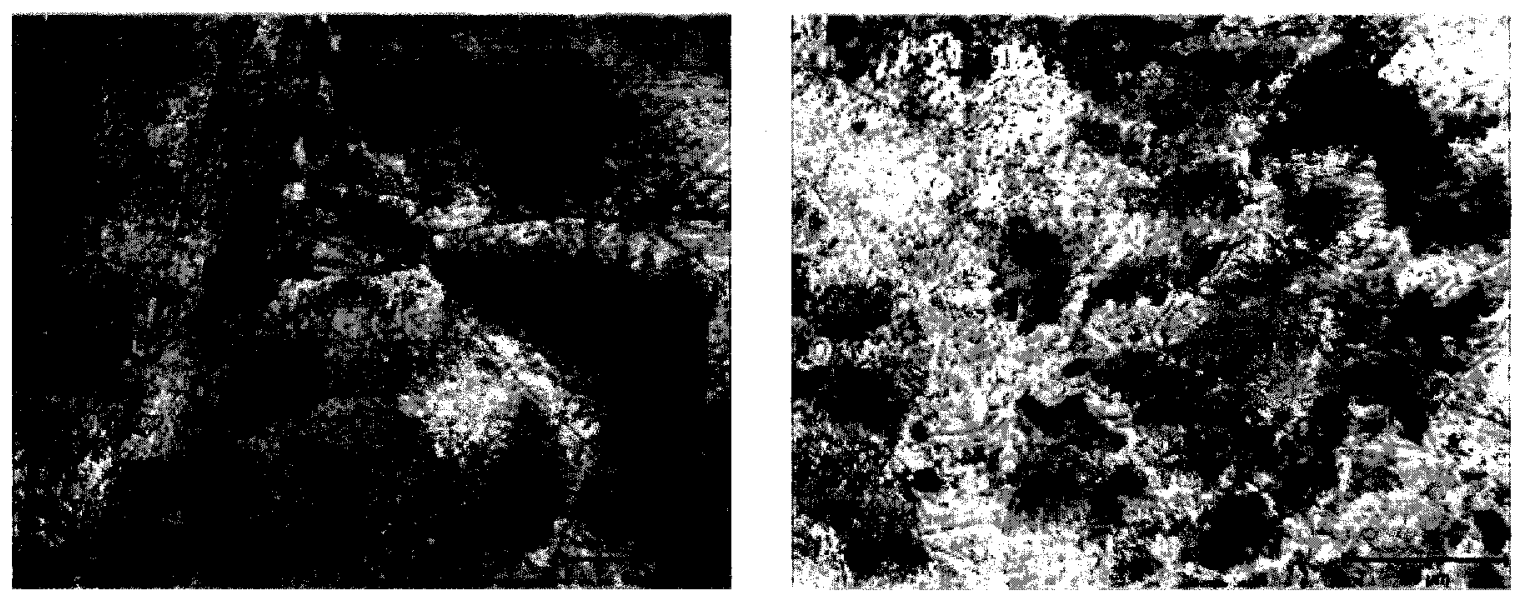

'NGB' 'SGB'

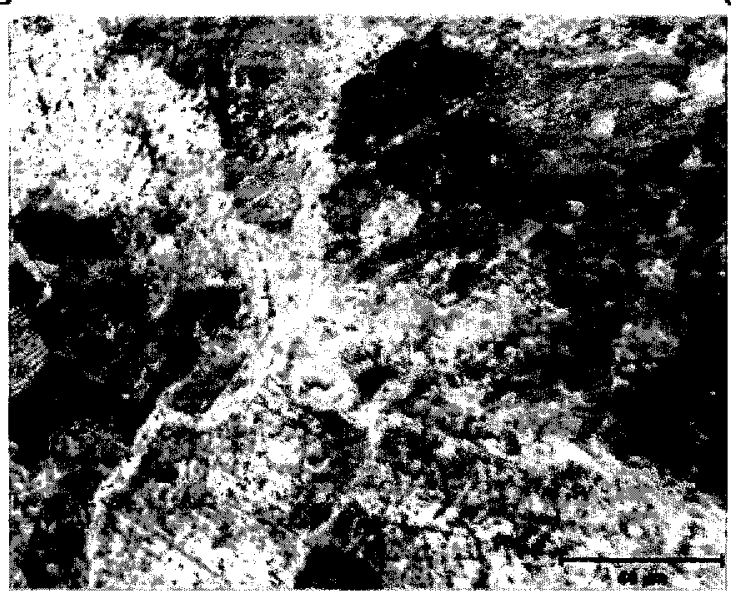

'SGB $\mathrm{M}^{\prime}$

Figure 66: Micrographs of fully heat treated microstructures. 

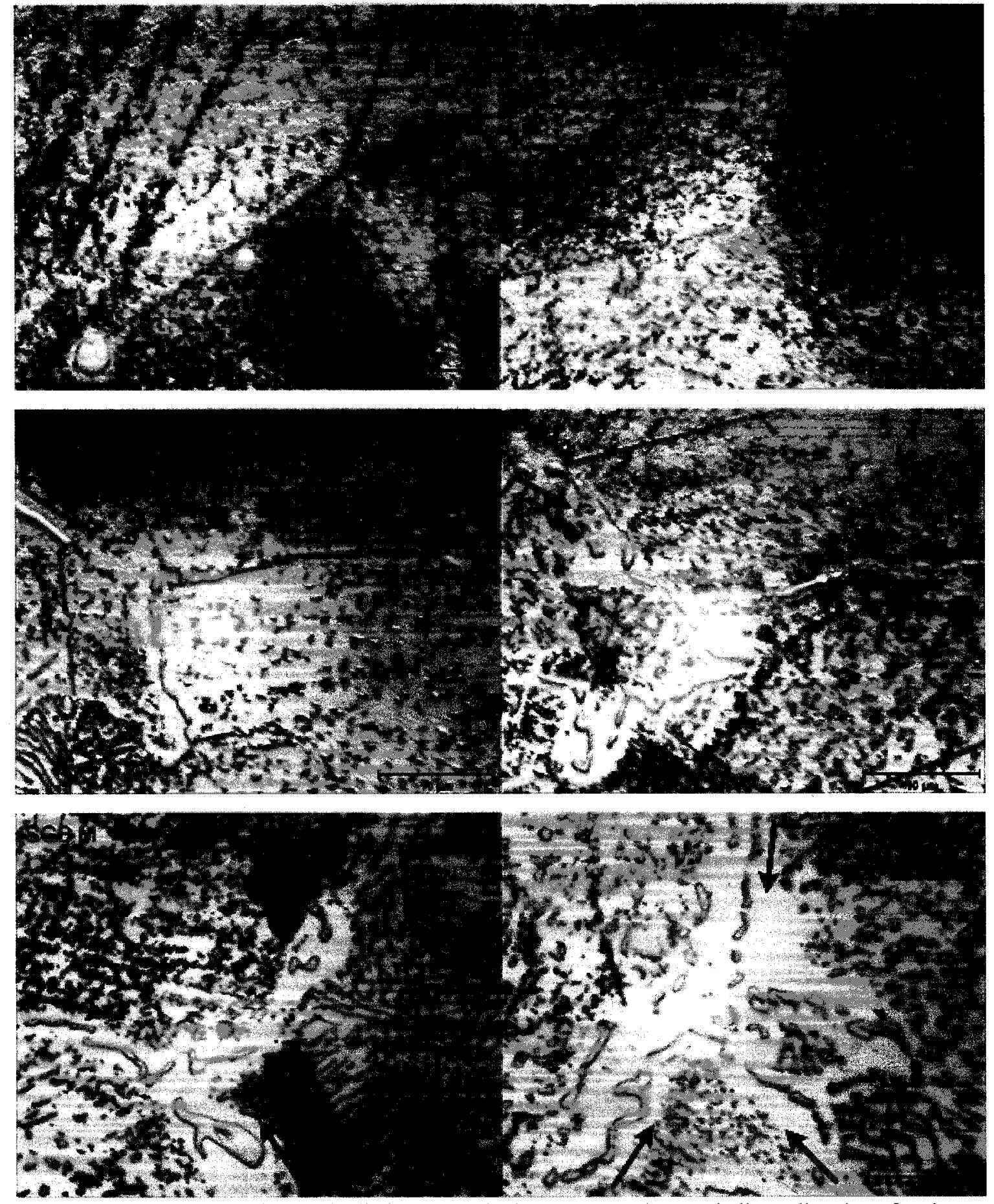

Figure 67: Grain boundaries of fully heat treated microstructures (arrows indicate direction of grain boundaries). 


\subsection{Creep Testing Results}

\subsubsection{Constant Load Tests}

\subsubsection{1 $\quad 700^{\circ} \mathrm{C}$ and $196 \mathrm{MPa}$}

The first creep tests were carried out to fracture at $700^{\circ} \mathrm{C}$ and $196 \mathrm{MPa}$, Figure 68 . Based on references [22-24] it is an unexpected result that the 'NGB' microstructure has creep performance superior to the 'SGB' microstructure and comparable to the 'SGB M' microstructure. Retests were performed to confirm these results. The second 'SGB' and 'NGB' tests however reaffirmed the original results. Refer to Figure 68 for the resulting creep curves and Table 5 for the strain rate results.

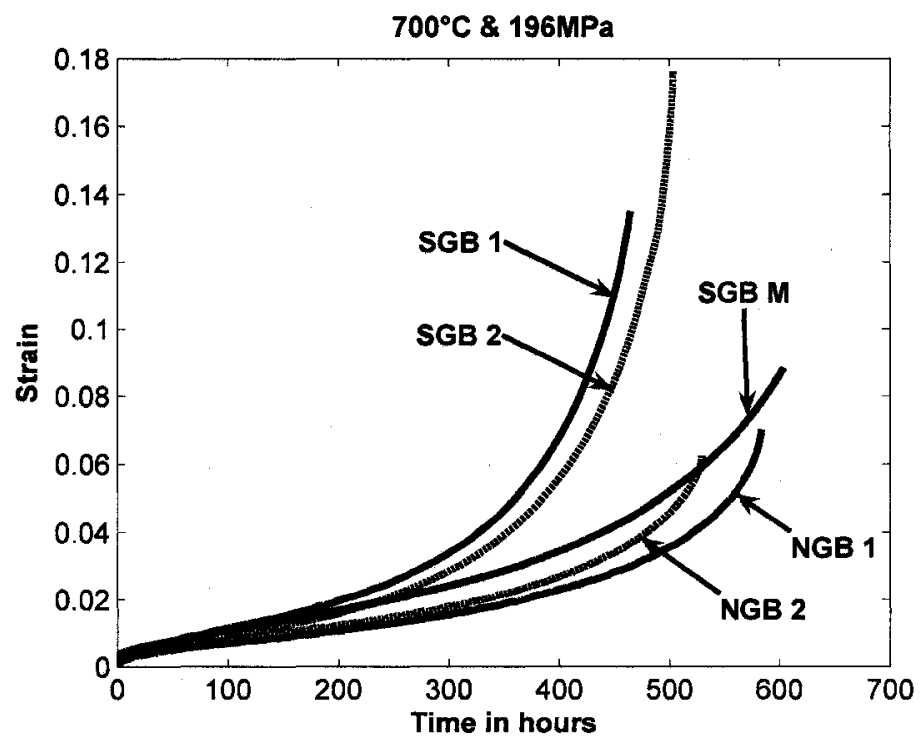

Figure 68: Constant load creep curves at $700^{\circ} \mathrm{C}$ and $196 \mathrm{MPa}$. 
Table 5: Results of $\theta$-Projection analysis for $700^{\circ} \mathrm{C}$ and $196 \mathrm{MPa}(* \theta$-Projection analysis for SGB 2 produced a poor fit of the primary stage of creep).

\begin{tabular}{cc}
\hline Sample & $\begin{array}{c}\text { Minimum Strain } \\
\text { Rate }(/ \mathbf{h})\end{array}$ \\
\hline NGB 1 & $3.7 \times 10^{-5}$ \\
NGB 2 & $4.0 \times 10^{-5}$ \\
SGB 1 & $7.1 \times 10^{-5}$ \\
SGB 2* & $5.8 \times 10^{-5}$ \\
SGB M & $5.9 \times 10^{-5}$ \\
\hline
\end{tabular}

\subsubsection{2 $\quad 900^{\circ} \mathrm{C}$ and $27.4 \mathrm{MPa}$}

The next creep tests carried out were constant load tests at $900^{\circ} \mathrm{C}$ and $27.4 \mathrm{MPa}$, Figure 69. One of the 'SGB' samples failed prematurely, requiring a retest of that microstructural condition. Given the length of the $900^{\circ} \mathrm{C}$ constant load creep tests, and the repeatability seen in the shorter $700^{\circ} \mathrm{C}$ tests, it was decided not to retest at $900^{\circ} \mathrm{C}$. In this case, the 'NGB' microstructure showed creep properties superior to both the 'SGB' and 'SGB M' microstructures. Again, this result is unexpected as according to references [22-24] the 'SGB M' microstructure should have had a noticeably longer creep rupture life. Table 6 summarizes the strain rate results. 


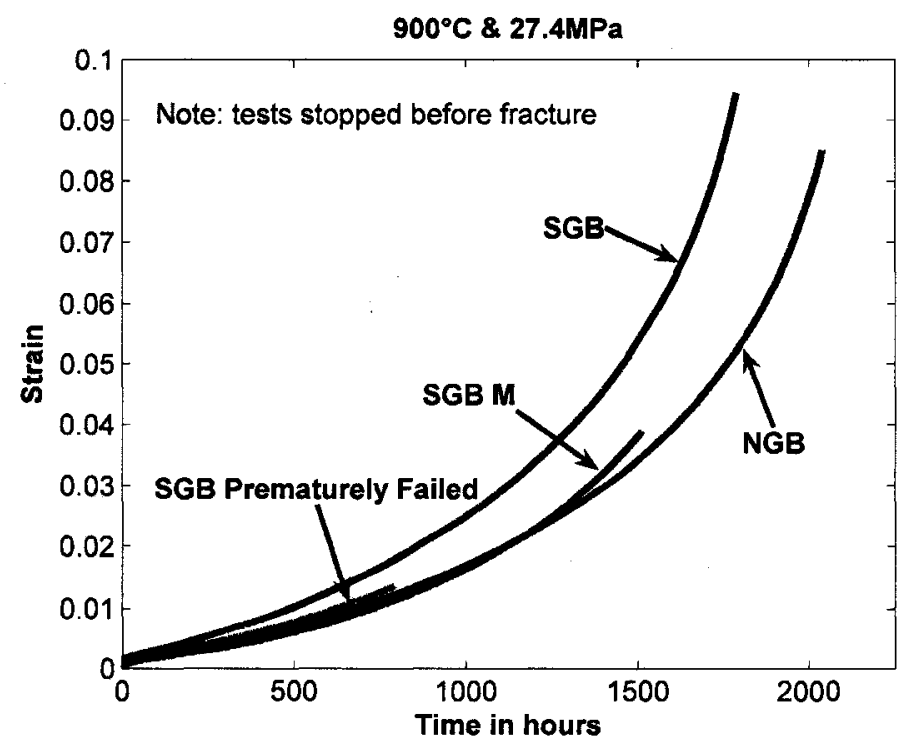

Figure 69: Constant load creep curves at $900^{\circ} \mathrm{C}$ and $27.4 \mathrm{MPa}$.

Table 6: Results of $\theta$-Projection analysis for $900^{\circ} \mathrm{C}$ and $27.4 \mathrm{MPa}$.

\begin{tabular}{cc}
\hline Sample & $\begin{array}{c}\text { Minimum Strain } \\
\text { Rate }(/ \mathbf{h})\end{array}$ \\
\hline NGB & $1.0 \times 10^{-5}$ \\
SGB & $1.4 \times 10^{-5}$ \\
SGB Prematurely & $1.1 \times 10^{-5}$ \\
Failed & $8.1 \times 10^{-6}$ \\
SGB M & \\
\hline
\end{tabular}

\subsubsection{3}

$925^{\circ} \mathrm{C}$ and $27.4 \mathrm{MPa}$

The final constant load creep tests were carried out at $925^{\circ} \mathrm{C}$ and $27.4 \mathrm{MPa}$, Figure 70. A similar trend continued with the 'NGB' microstructure outperforming the 'SGB' microstructure. In this case the 'NGB' microstructure had substantially better creep performance. It was decided not to test the 'SGB M' microstructure due to the extremely poor performance of the 'SGB' microstructure and partially due to increasing difficulty in removing tested specimens from the specimen grips after tests of such long duration and high temperatures. Table 7 summarizes the strain rate results. 


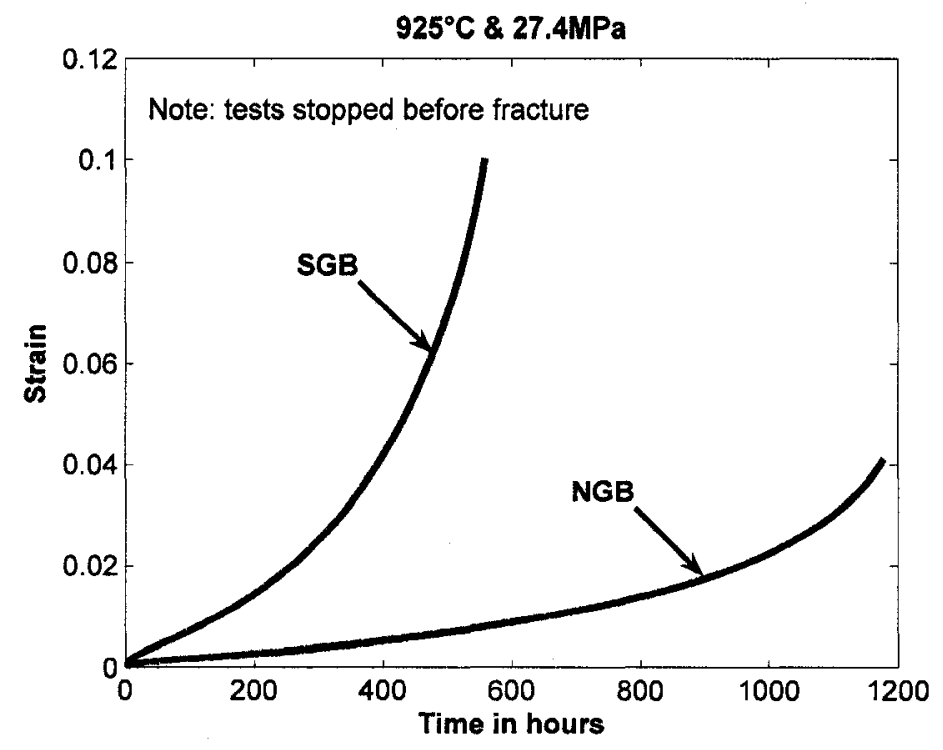

Figure 70: Constant load creep curves at $925^{\circ} \mathrm{C}$ and $27.4 \mathrm{MPa}$.

Table 7: Results of $\theta$-Projection analysis for $925^{\circ} \mathrm{C}$ and $27.4 \mathrm{MPa}$.

\begin{tabular}{cc}
\hline Sample & $\begin{array}{c}\text { Minimum Strain } \\
\text { Rate }(/ \mathbf{h})\end{array}$ \\
\hline NGB & $8.37 \times 10^{-6}$ \\
SGB & $4.83 \times 10^{-5}$ \\
\hline
\end{tabular}

\subsubsection{Increasing Load Tests}

\subsubsection{1 $\quad 700^{\circ} \mathrm{C}$ and $183-295 \mathrm{MPa}$}

As described in Section 5, increasing load tests were carried out to ascertain the creep rates of the different microstructural conditions while saving on the number of samples needed and the time to run individual tests. Figure 71 shows the creep curves of the increasing load tests run at $700^{\circ} \mathrm{C}$ while Figure 72 has the strain rates plotted against the stresses. The stress exponents for both the 'NGB' and 'SGB' microstructures are the same at $700^{\circ} \mathrm{C}$. The stress exponents in Figure 72 were calculated according to equation (4) in Section 2. 


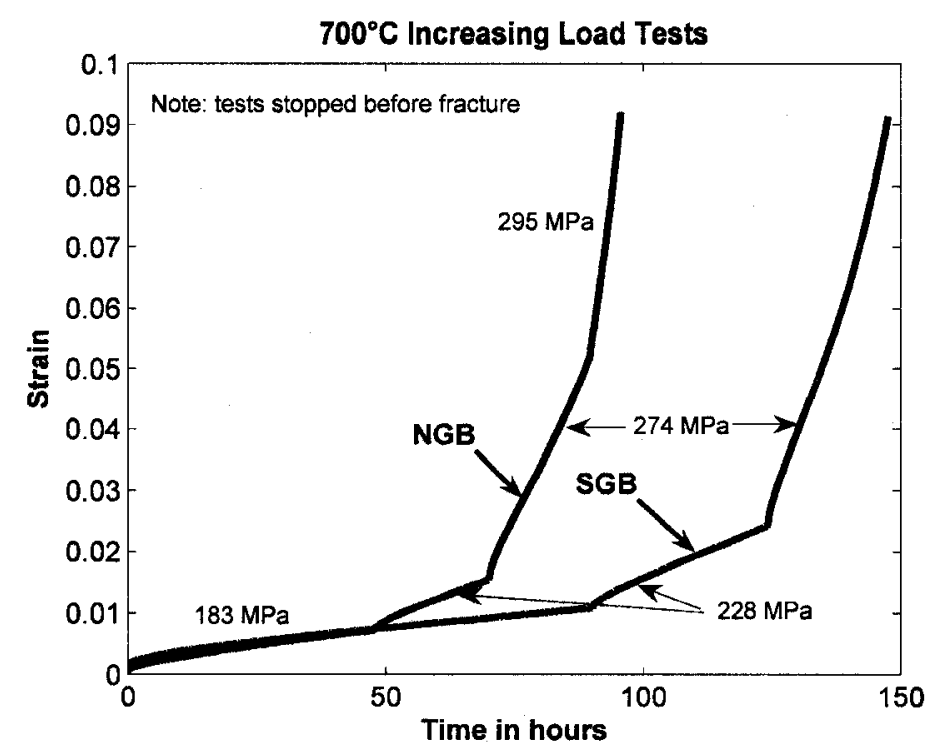

Figure 71: Increasing load creep curves at $700^{\circ} \mathrm{C}$ and $183-295 \mathrm{MPa}$.

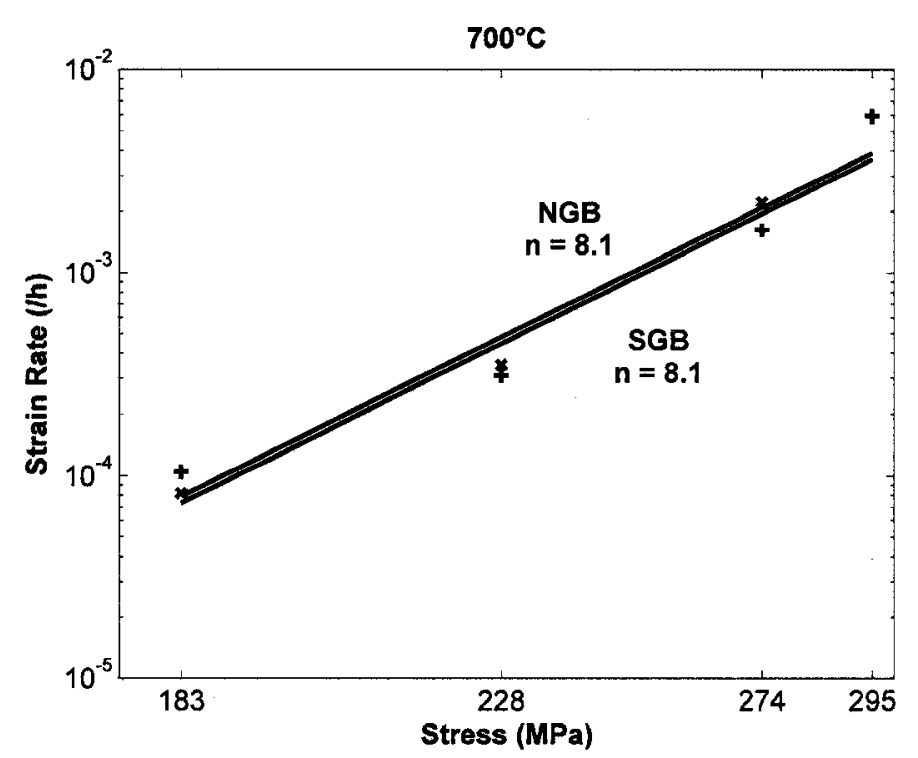

Figure 72: Strain rate vs stress plot from increasing load tests at $700^{\circ} \mathrm{C}$ and $183-295 \mathrm{MPa}$.

\subsubsection{2 $900^{\circ} \mathrm{C}$ and $27.4-65 \mathrm{MPa}$}

The next increasing load tests were run at $900^{\circ} \mathrm{C}$ and two sets of tests were run on the 'NGB' and 'SGB' microstructures. The results can be seen in Figures 73, 74 and 75. Figure 75 shows that overall the 'SGB' microstructure had a higher stress exponent, with the strain rates only increased in a linear fashion. The 'NGB' microstructure had a lower 
stress exponent initially, while there was a noticeable increase as the stress increased.

The stress exponents in Figure 75 were calculated according to equation (4) in Section 2.

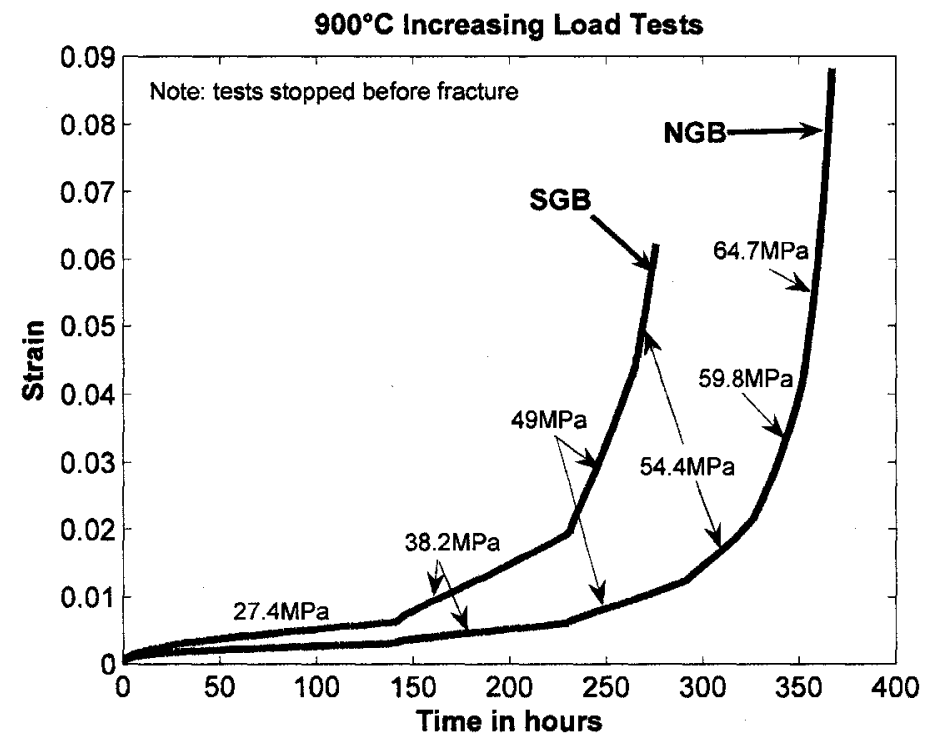

Figure 73: Increasing load creep curves at $900^{\circ} \mathrm{C}$ and 27.4-64.7MPa.

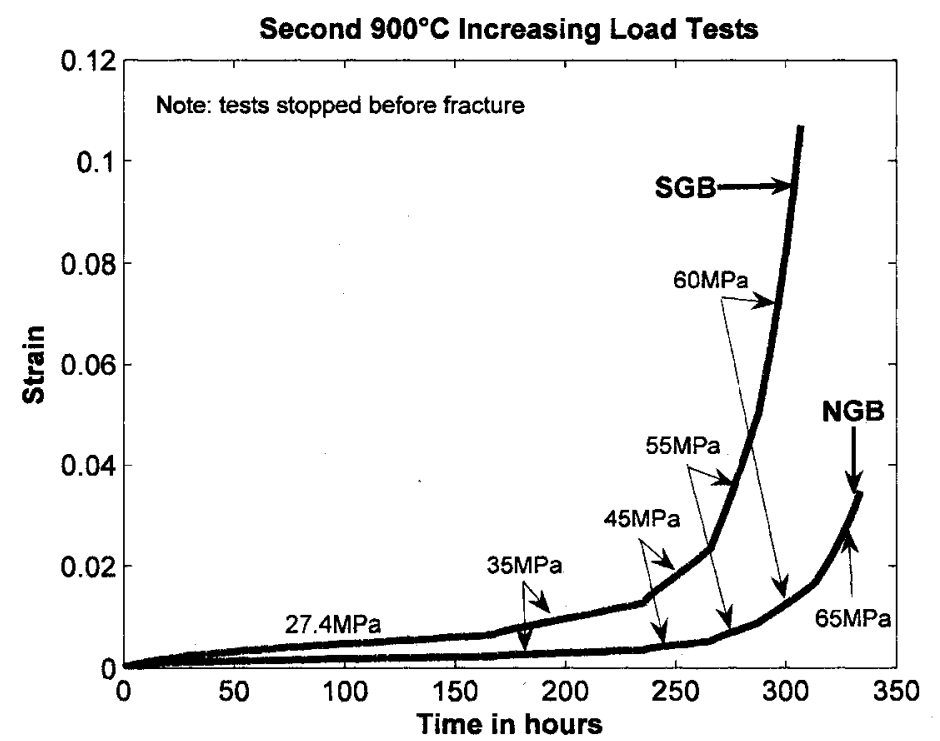

Figure 74: Increasing load creep curves at $900^{\circ} \mathrm{C}$ and $27.4-65 \mathrm{MPa}$. 


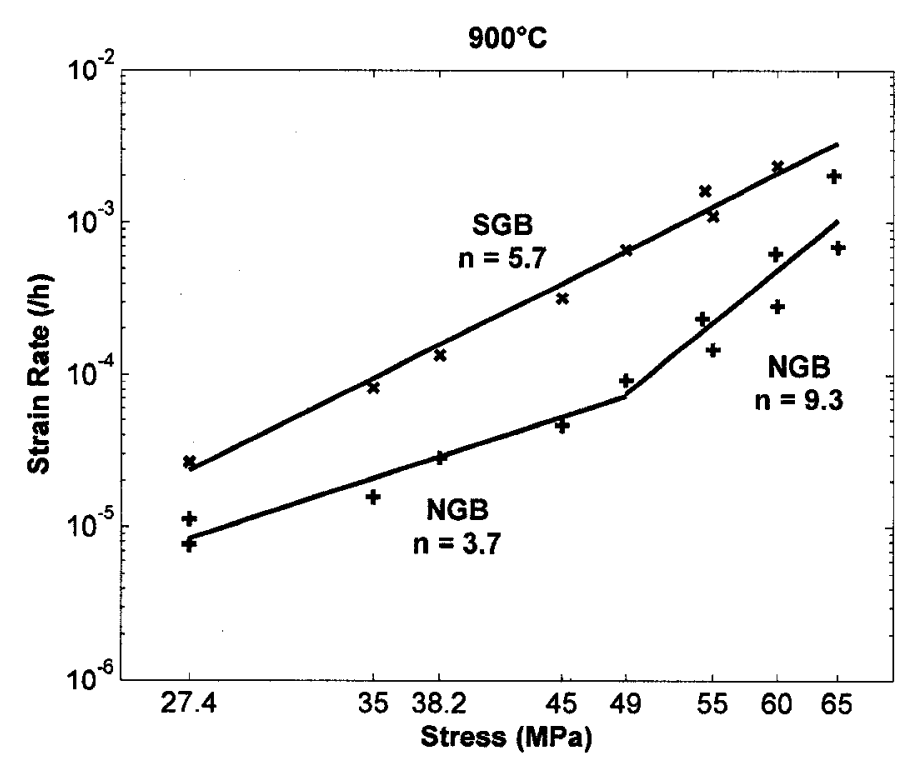

Figure 75: Strain rate vs stress plot from increasing load tests at $900^{\circ} \mathrm{C}$ and $27.4-65 \mathrm{MPa}$. 


\subsection{Creep Tested Microstructures}

\subsubsection{Constant load testing at $700^{\circ} \mathrm{C}$ and $196 \mathrm{MPa}$}

Figures 76 and 77 show the resulting general microstructures and grain boundaries of samples tested at $700^{\circ} \mathrm{C}$ and $196 \mathrm{MPa}$. The most striking feature of the resulting microstructures is that the 'SGB' microstructure appears very similar to the 'NGB' one. There is a similar distribution of precipitates within the grain interiors and there are areas of the 'SGB' sample where the grain boundaries are no longer serrated, but planar. There is also very little GBR left. The 'SGB M' sample on the other hand retains much of the GBR and most of the grain boundaries remain serrated, though the GBR nodules are no longer evenly distributed. It also contains planar grain boundaries in some areas. The precipitate distribution within the grains is similar to that of the 'NGB' and 'SGB' samples. This can be seen in better detail in Figure 77.

Also of note in Figure 77 is that the 'SGB' and 'SGB M' samples continue to show coarse planar carbides. The grain boundaries in these samples show nearly continuous carbides, with little space between the individual sections. 

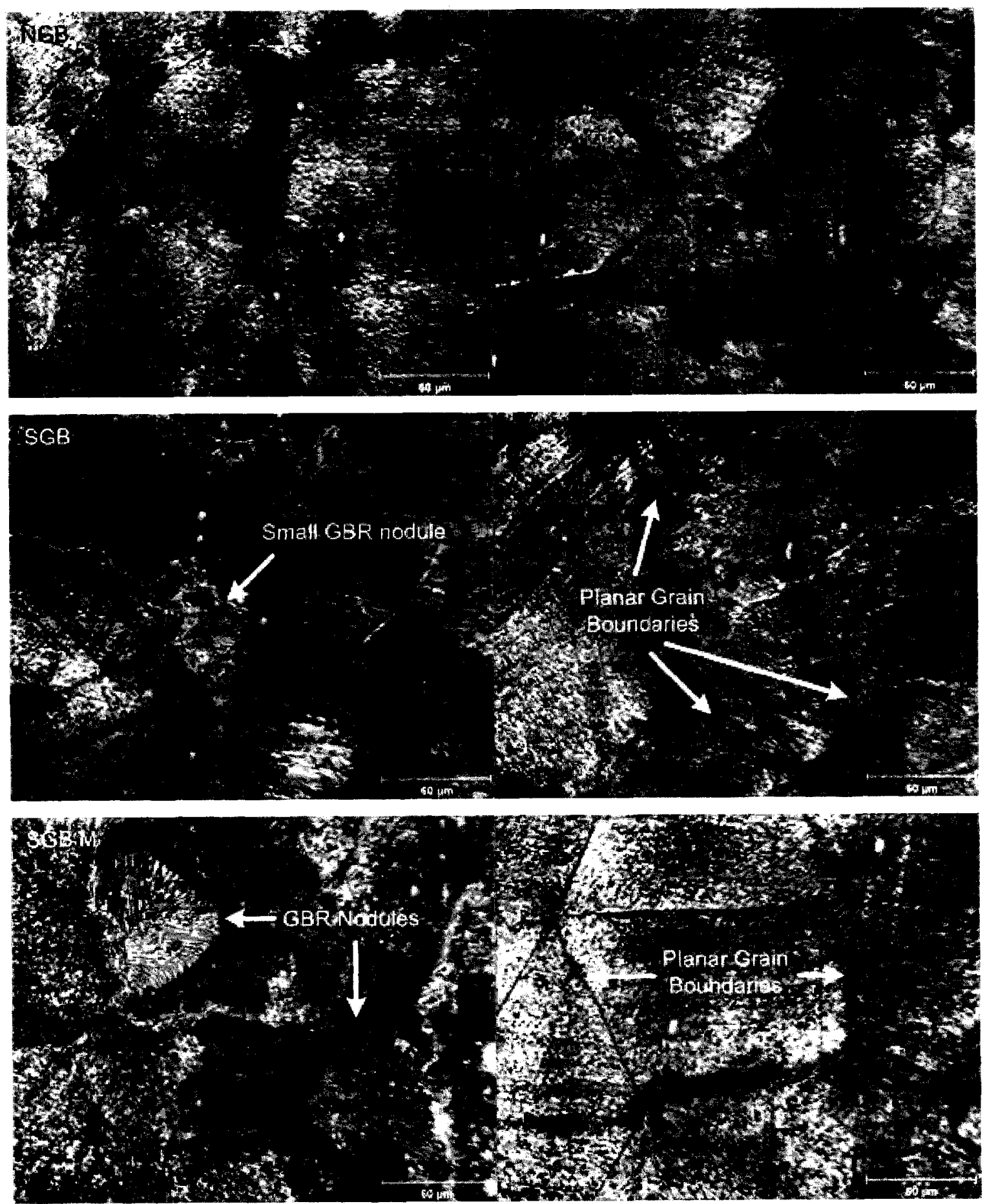

Figure 76: Gauge section microstructures after constant load creep testing at $700^{\circ} \mathrm{C}$ and $196 \mathrm{MPa}$. 

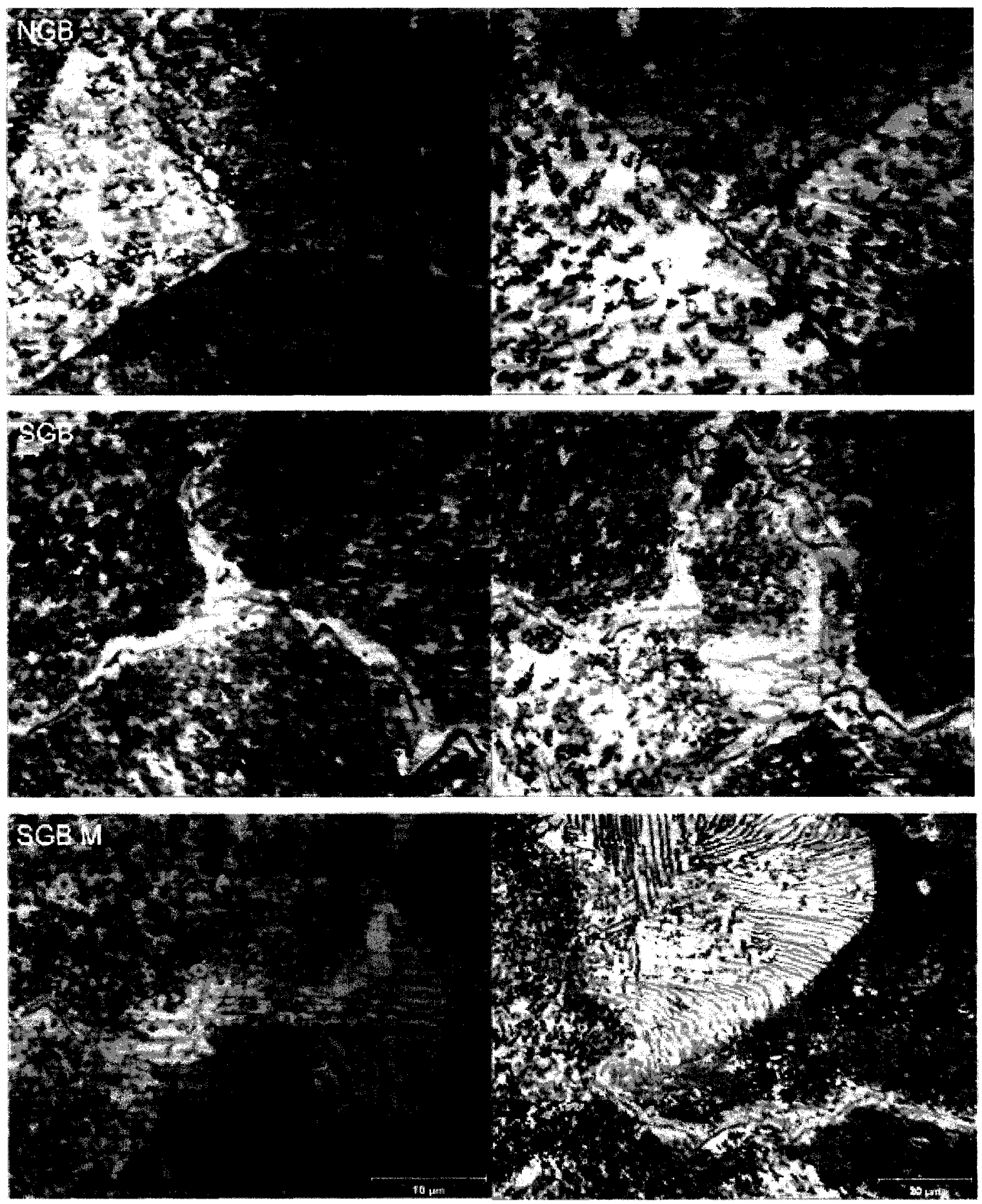

Figure 77: Gauge section grain boundaries after constant load creep testing at $700^{\circ} \mathrm{C}$ and $196 \mathrm{MPa}$. 


\subsubsection{Constant load testing at $900^{\circ} \mathrm{C}$ and $27.4 \mathrm{MPa}$}

After the $900^{\circ} \mathrm{C}$ constant load tests, the 'NGB' and 'SGB' samples had virtually identical microstructures. This can be seen in Figures 78 and 79. There is an even distribution of intragranular precipitates and the grain boundaries have coarse carbides and precipitate free zones. All the grain boundaries are planar in the 'SGB' sample and no GBR remains. The 'SGB M' sample, which was not tested as long as the 'NGB' and 'SGB' samples, appears to be changing in a similar manner as the 'SGB' sample. There are far fewer GBR nodules and they are almost all small remains. There are areas where the grain boundaries are planar. The grain boundaries contain coarse carbides similar to those in the 'SGB' and 'NGB' samples.

The 'SGB' sample that prematurely failed shows an intermediate step in the microstructural changes of the 'SGB' microstructure. Referring to Figure 80, there are no intragranular precipitates but the GBR nodules remain and the grain boundaries are still serrated. Figure 81 shows a change in the morphology of the GBR nodules. The GBR nodules are no longer made up of rod like precipitates as in the untested 'SGB' and 'SGB M' microstructures. The GBR nodule morphology has become similar to the dense precipitates surrounding the GBR nodule in the untested microstructure. 


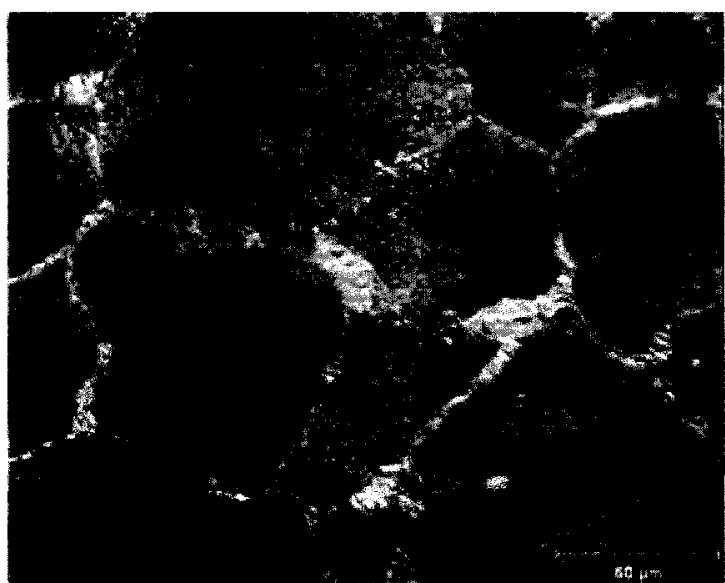

'NGB'

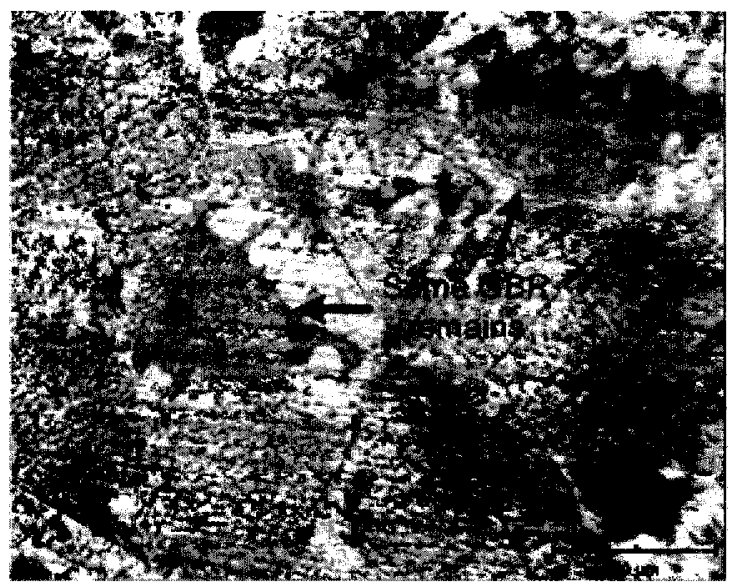

'SGB M'

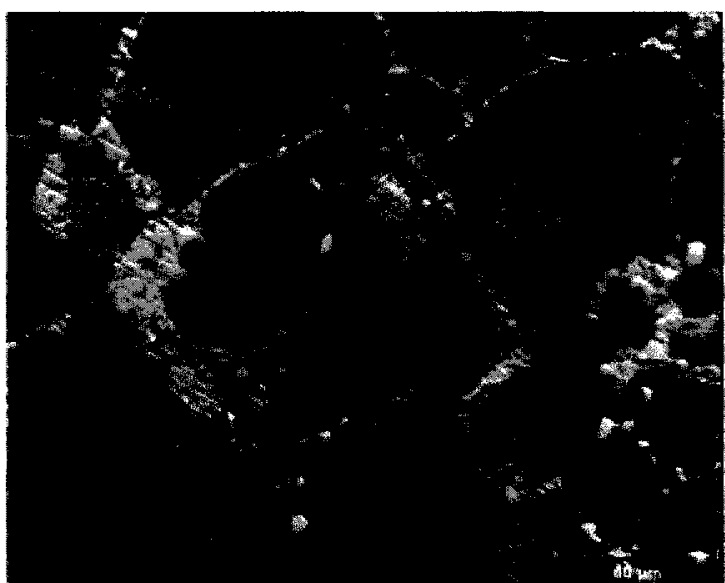

'SGB'

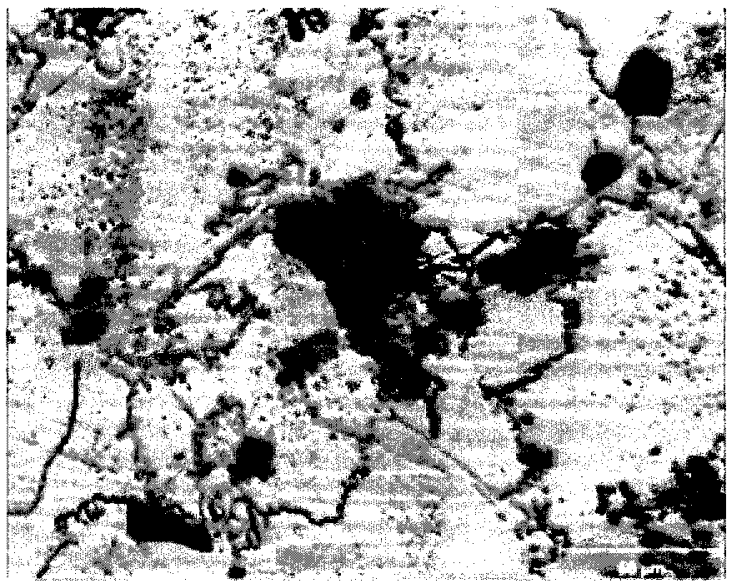

'SGB' Prematurely Failed

Figure 78: Gauge section microstructures after constant load creep testing at $900^{\circ} \mathrm{C}$ and $27.4 \mathrm{MPa}$. 

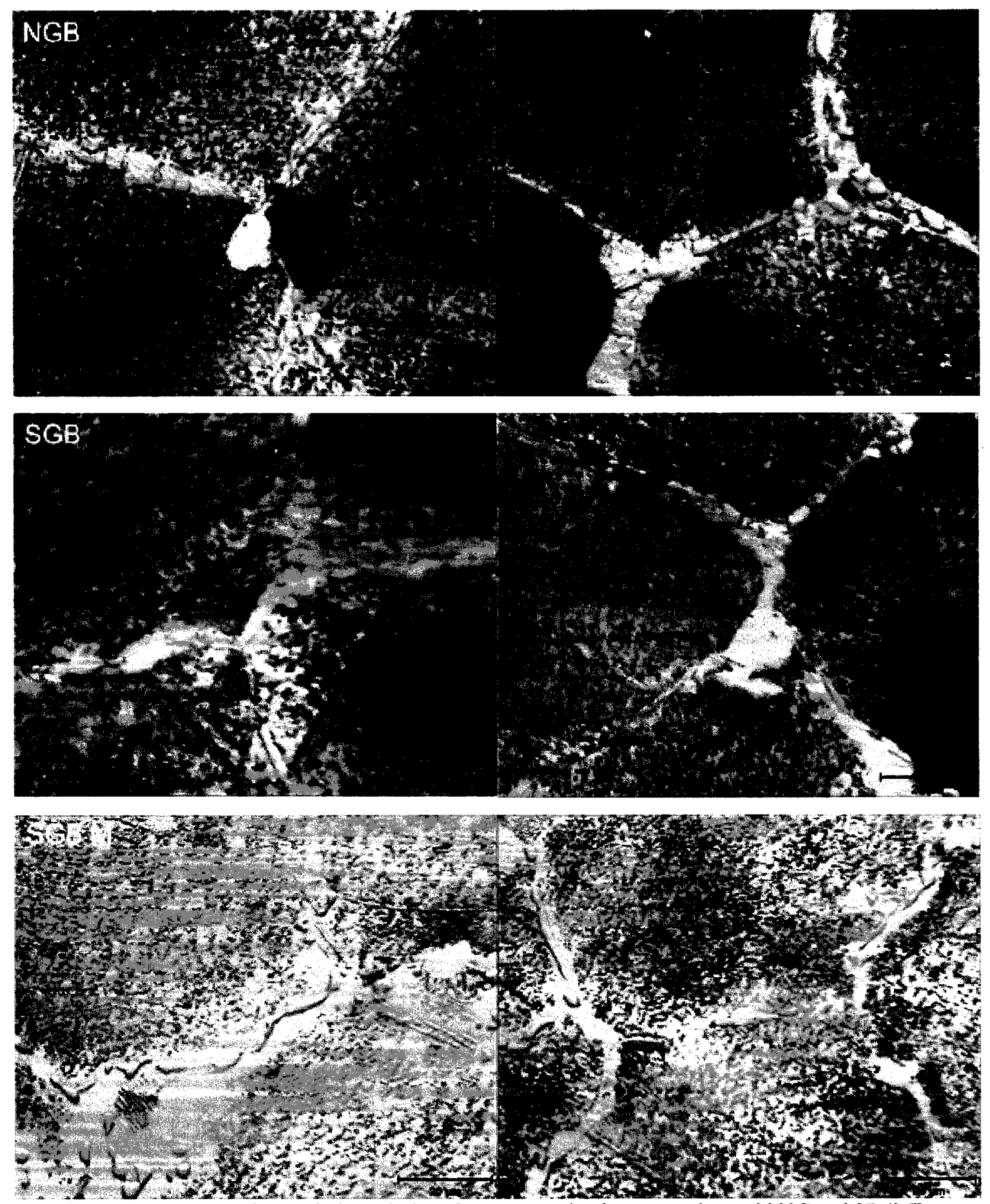

Figure 79: Gauge section grain boundaries after constant load creep testing at $900^{\circ} \mathrm{C}$ and $27.4 \mathrm{MPa}$. 


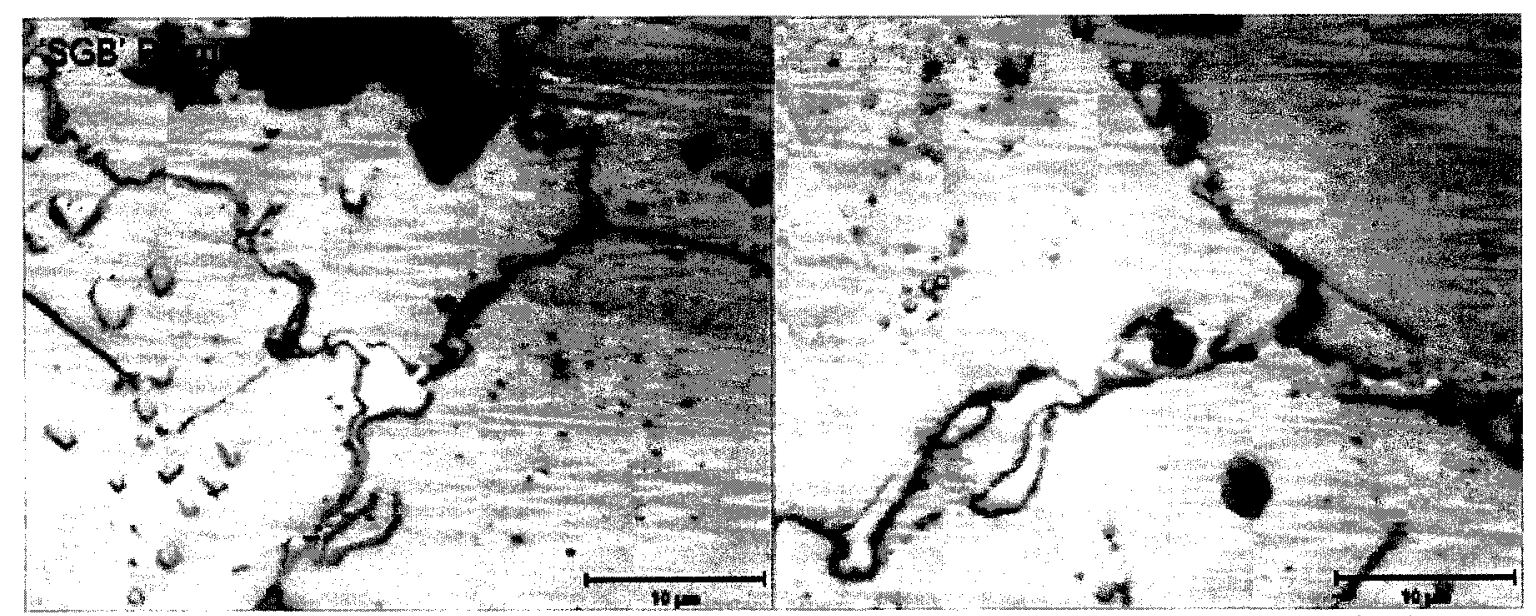

Figure 80: Gauge section grain boundaries of prematurely failed 'SGB' sample after constant load creep testing at $900^{\circ} \mathrm{C}$ and $27.4 \mathrm{MPa}$.

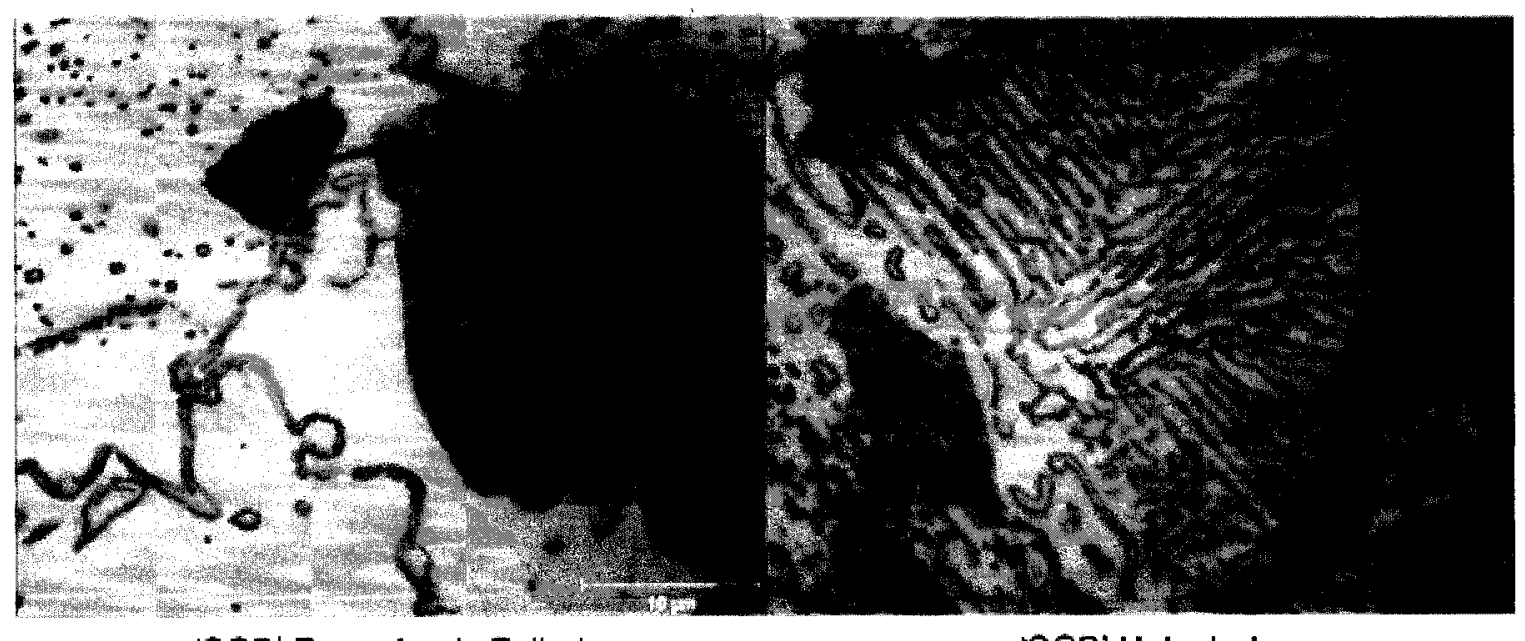

'SGB' Prematurely Failed

'SGB' Untested

Figure 81: Gauge section GBR nodule morphology in prematurely failed 'SGB' sample and fully heat treated but untested 'SGB' sample. 


\subsubsection{Constant load testing at $925^{\circ} \mathrm{C}$ and $27.4 \mathrm{MPa}$}

Again after the constant load tests at $925^{\circ} \mathrm{C}$ there are microstructural changes to both samples. For both 'NGB' and 'SGB' there is a more uniform distribution of precipitates within the grain interiors (refer to Figure 82). The 'SGB' sample also has fewer GBR nodules but the grain boundaries are still serrated in all areas. Both samples also show coarse grain boundary carbides (refer to Figure 83).

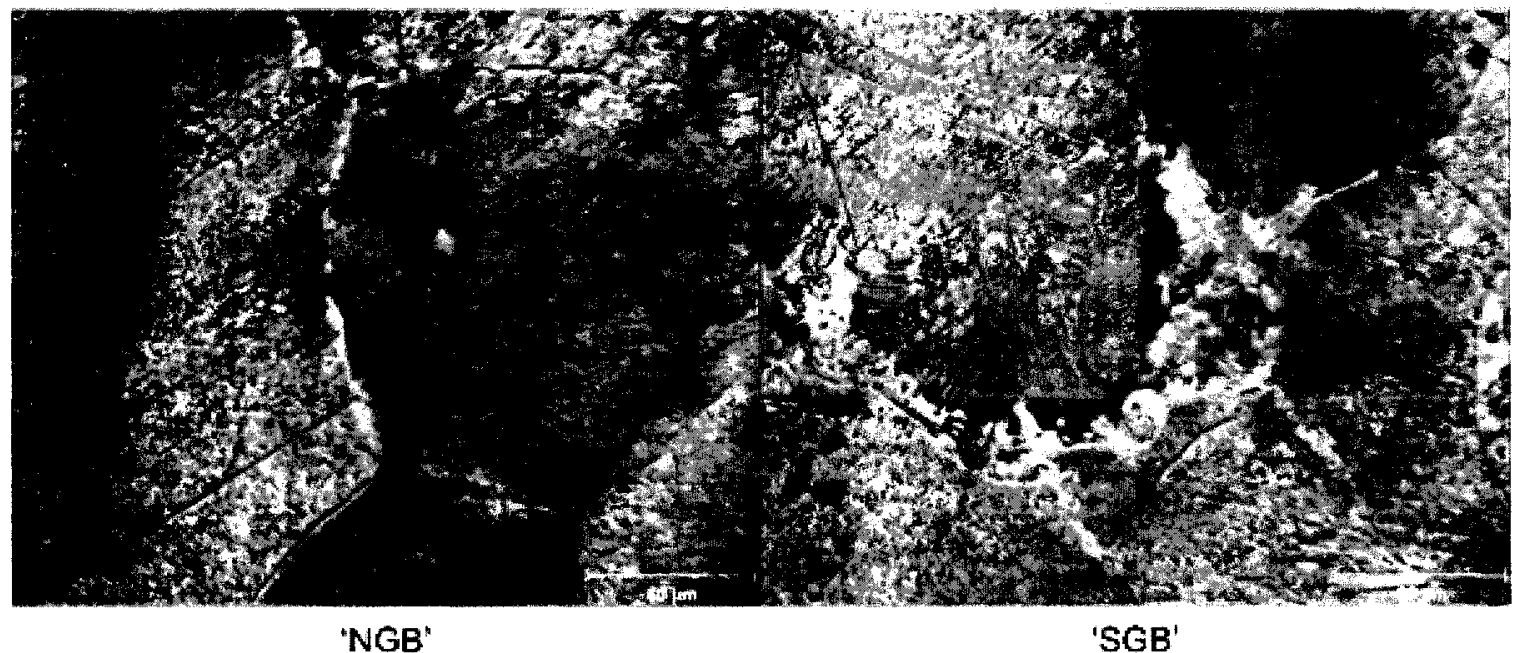

Figure 82: Gauge section microstructures after constant load creep testing at $925^{\circ} \mathrm{C}$ and $27.4 \mathrm{MPa}$. 

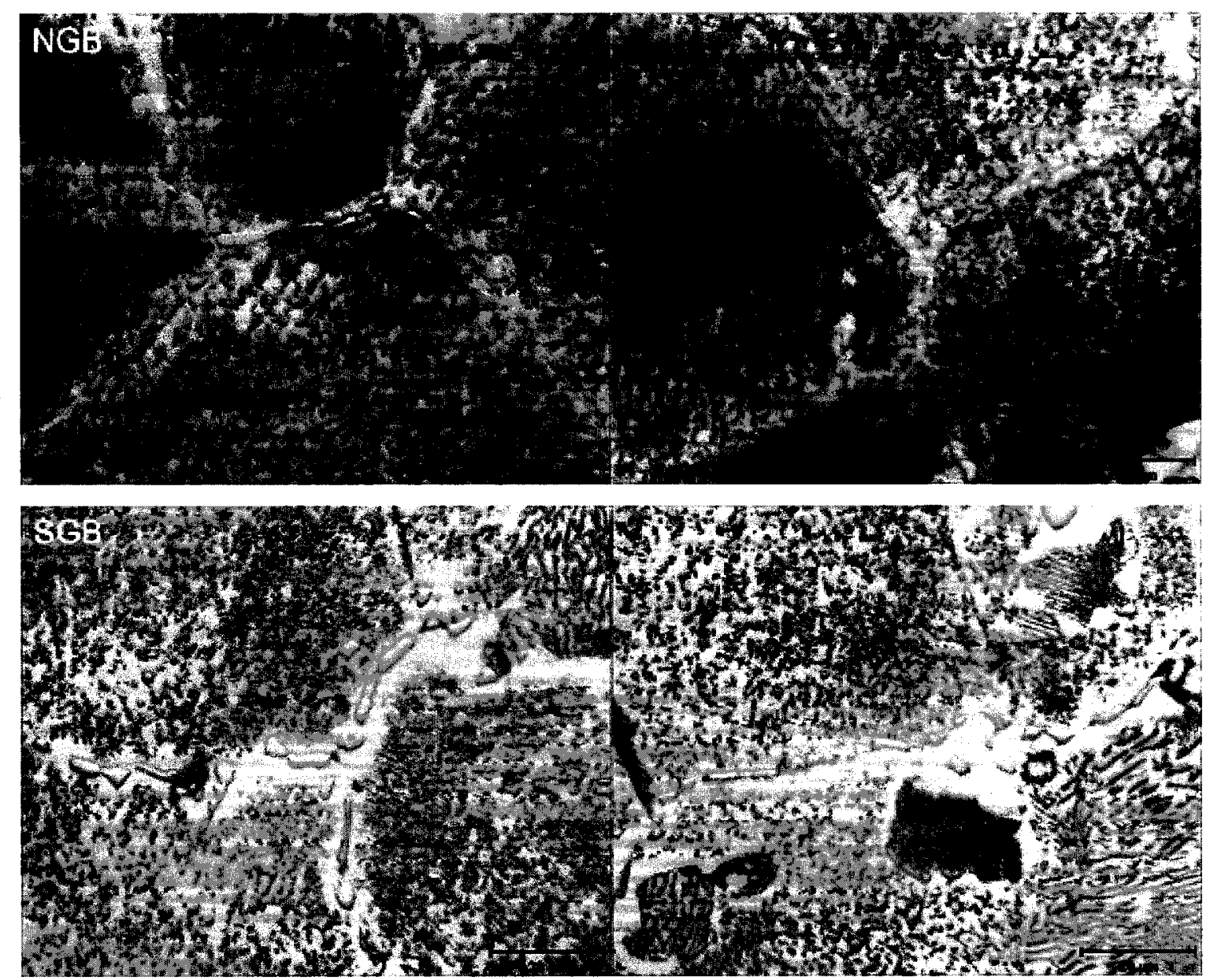

Figure 83: Gauge section grain boundaries after constant load creep testing at $925^{\circ} \mathrm{C}$ and $27.4 \mathrm{MPa}$. 


\subsection{Aged Microstructures}

Due to the microstructural changes observed during the constant load tests, 'NGB' and 'SGB' heat treated discs, cut from the bar stock, were aged at $900^{\circ} \mathrm{C}$ for a period of time similar to the length of the constant load tests at $900^{\circ} \mathrm{C}$. The resulting microstructures can be seen in Figures 84 and 85 . The changes to the microstructures are similar to those of the constant load tests at $900^{\circ} \mathrm{C}$, as the 'NGB' and 'SGB' microstructures appear to be the same. The 'SGB' microstructure still retains areas which were likely GBR nodules due to the coarse carbides concentrated in those areas. The 'SGB' sample however no longer has serrated grain boundaries. As well, both samples have coarse grain boundary carbides. The density of the intragranular precipitates is lower than that seen after the $900^{\circ} \mathrm{C}$ constant load tests, indicating an effect on the rate of microstructural change due to applied stress.

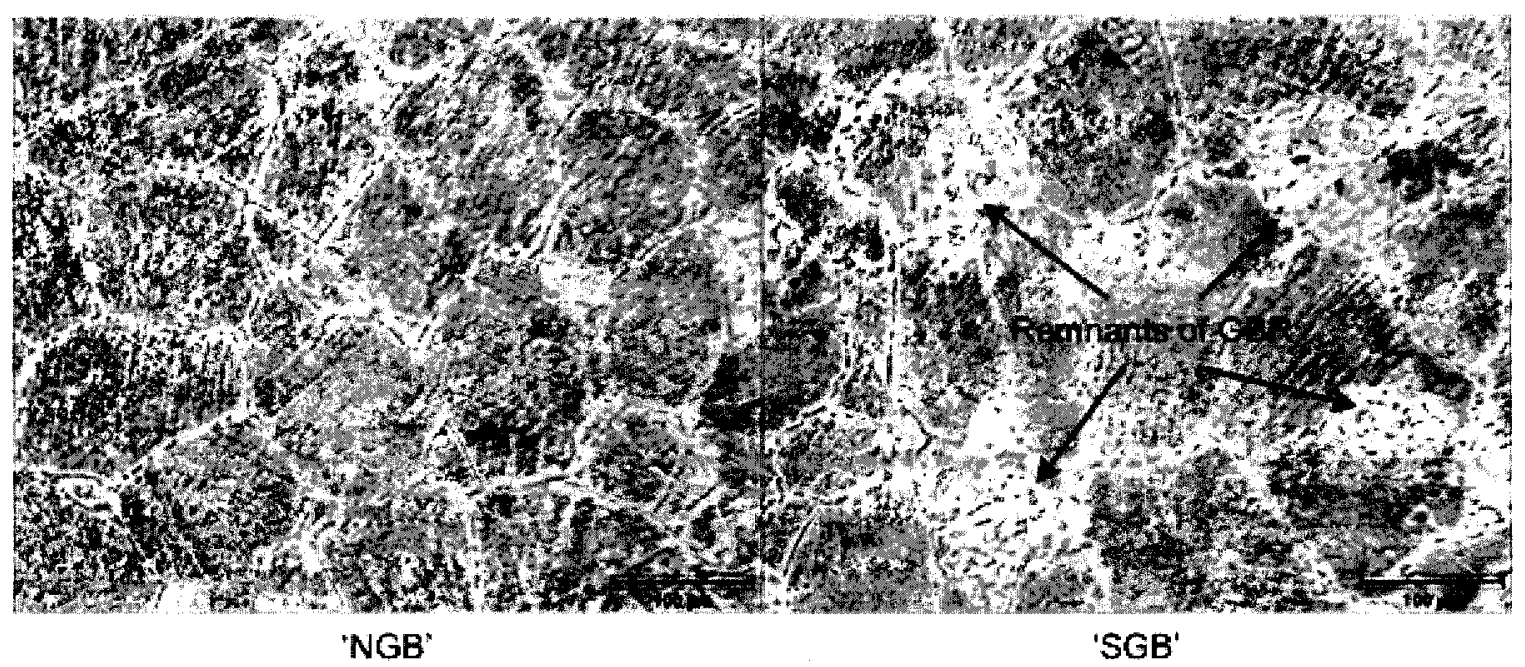

Figure 84: 'NGB' and 'SGB' microstructures after $\sim 1800$ hour aging at $900^{\circ} \mathrm{C}$. 


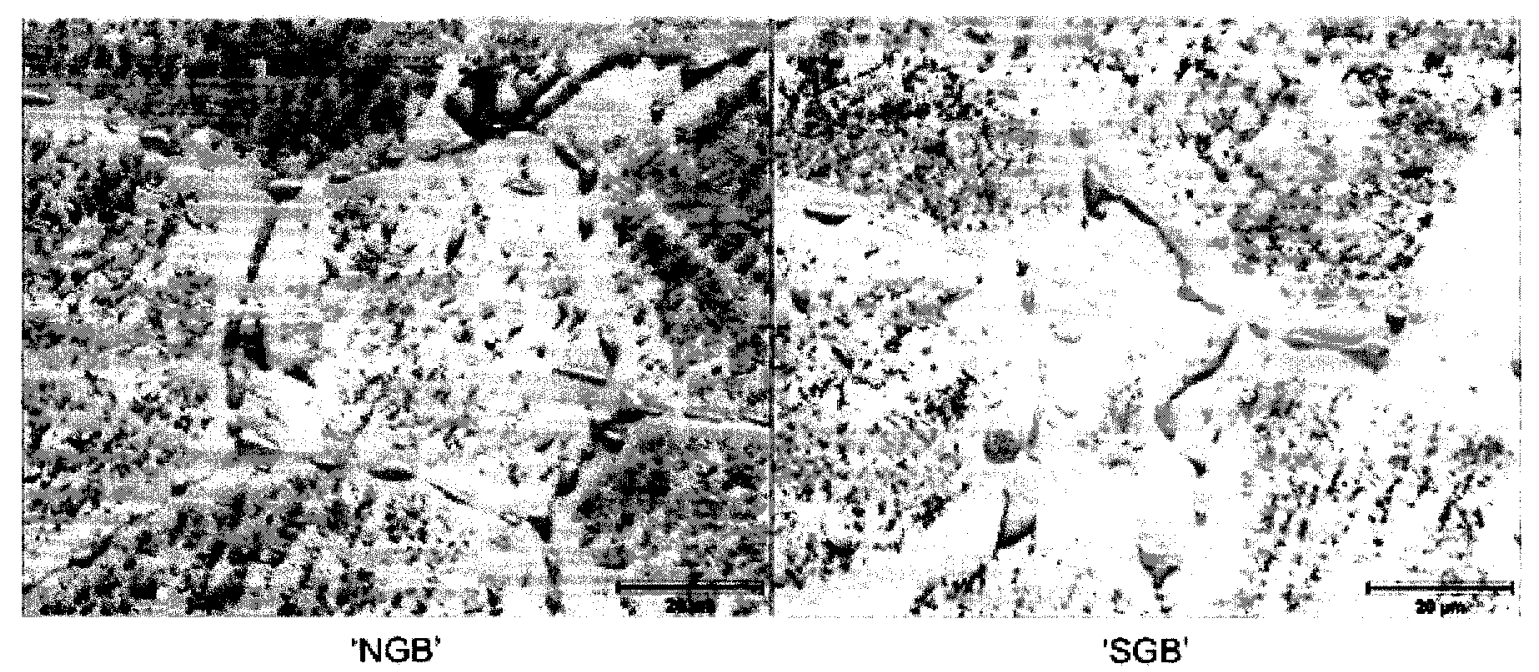

Figure 85: 'NGB' and 'SGB' grain boundaries after $\sim 1800$ hour aging at $900^{\circ} \mathrm{C}$. 


\subsection{Creep Fracture}

Only the constant load tests at $700^{\circ} \mathrm{C}$ and $196 \mathrm{MPa}$ were crept to fracture. Figure 86 shows SEM images of the fracture surfaces. In all cases, the intergranular nature of creep fracture is apparent. The 'SGB' and 'SGB M' samples also show grain boundary serrations as the grain surfaces are not as smooth as the 'NGB' sample. Instead, they appear to have 'rises' and 'dips', and generally a more rough surface appearance. Figure 87 also shows intergranular cracks in the samples crept at $700^{\circ} \mathrm{C}$ and $196 \mathrm{MPa}$.

Even though the samples crept at $900^{\circ} \mathrm{C}$ and $925^{\circ} \mathrm{C}$ did not fracture, figures 88 and 89 show that they would have likely failed by intergranular fracture also. 


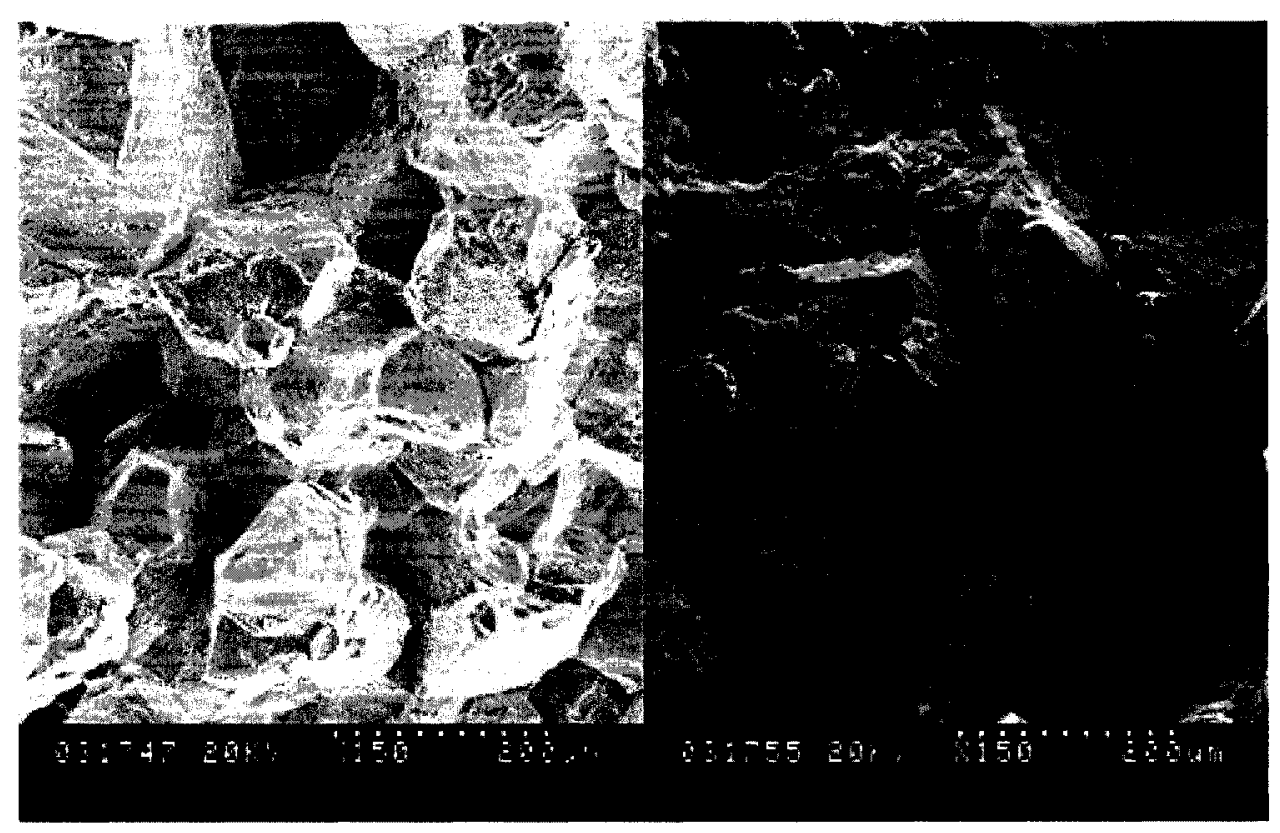

NGB"

'SGB'

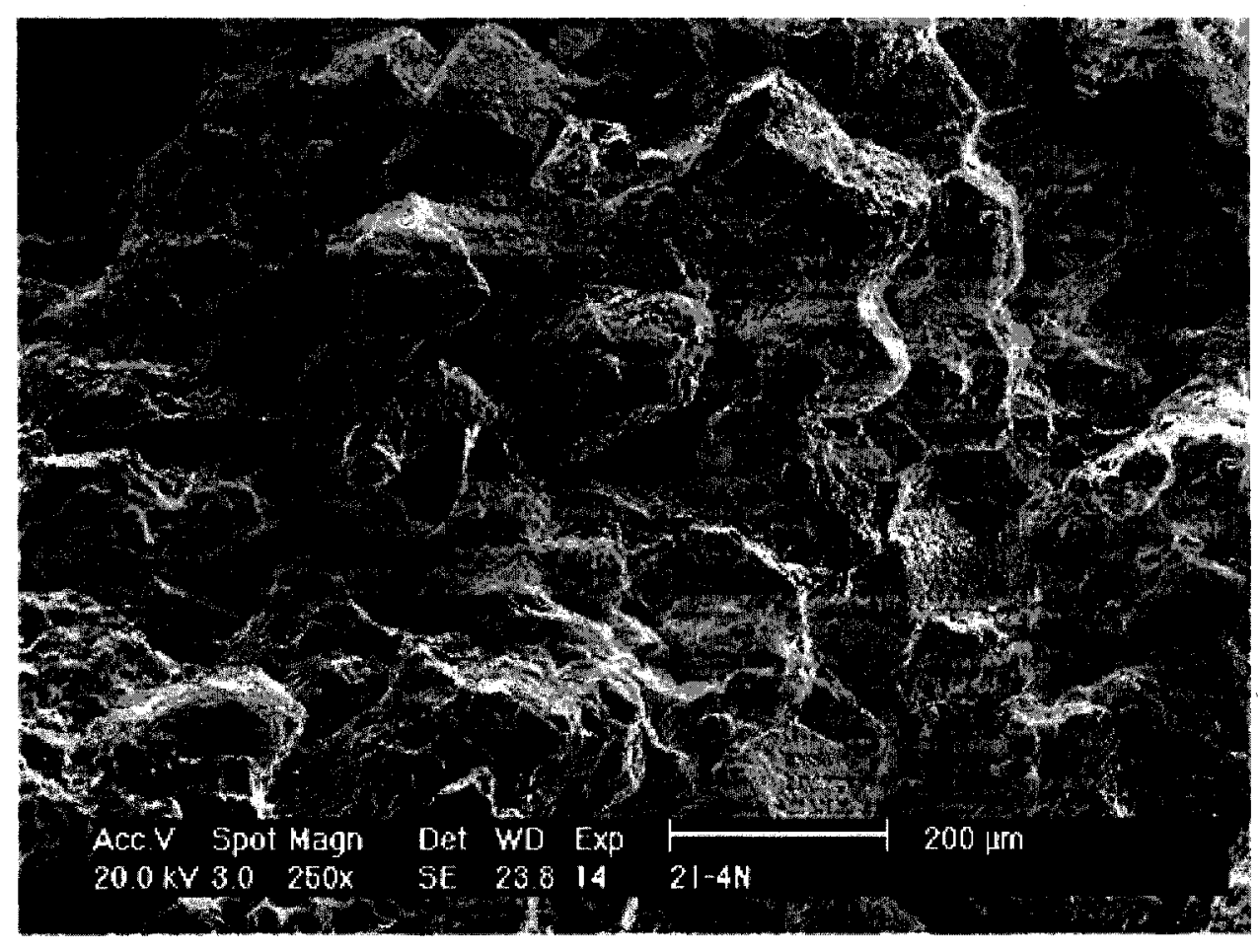

'SGB M"

Figure 86: Creep fracture surfaces from constant load tests at $700^{\circ} \mathrm{C}$ and $196 \mathrm{MPa}$. 

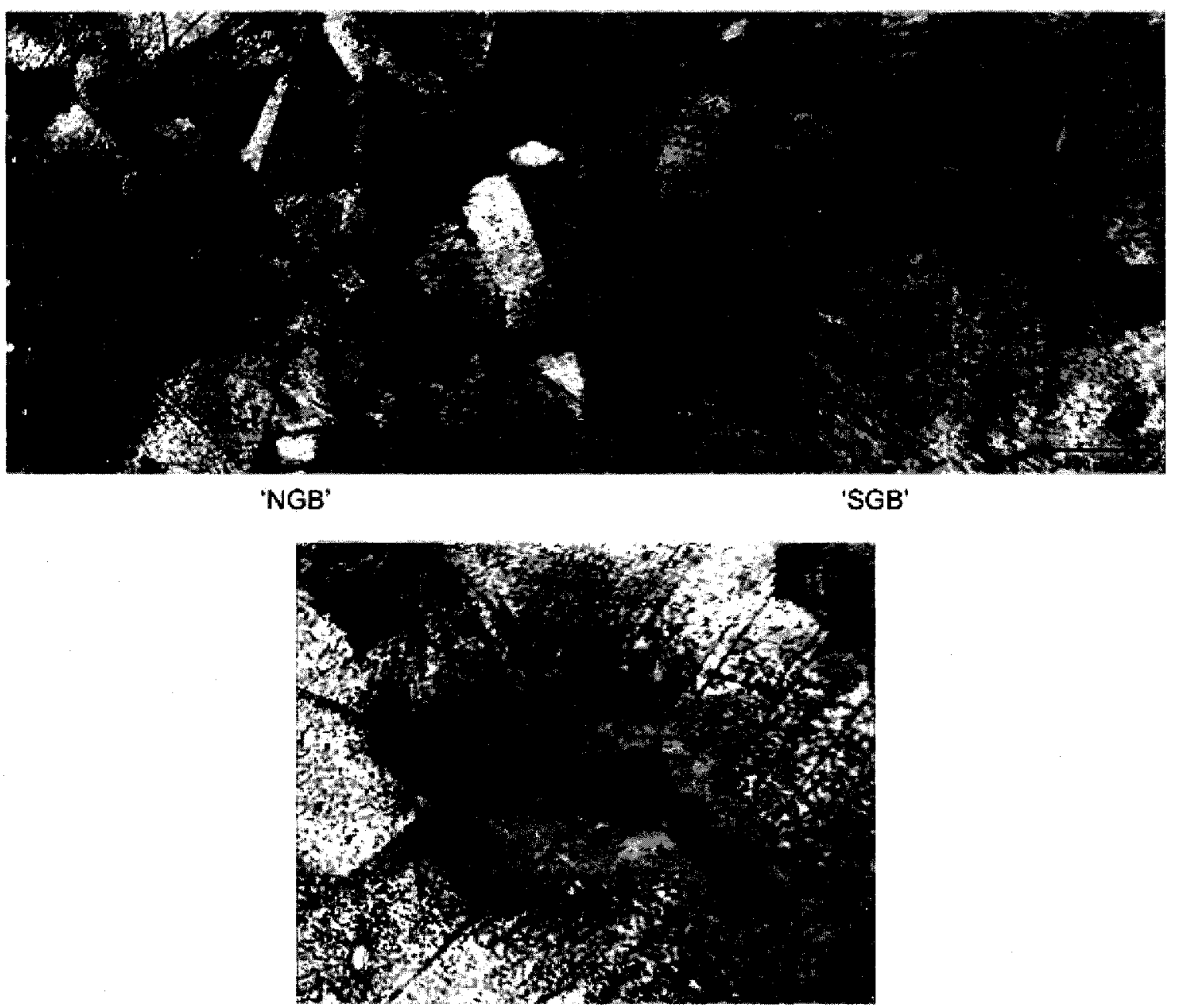

'SGB M'

Figure 87: Gauge section intergranular cracking from constant load tests at $700^{\circ} \mathrm{C}$ and $196 \mathrm{MPa}$. 


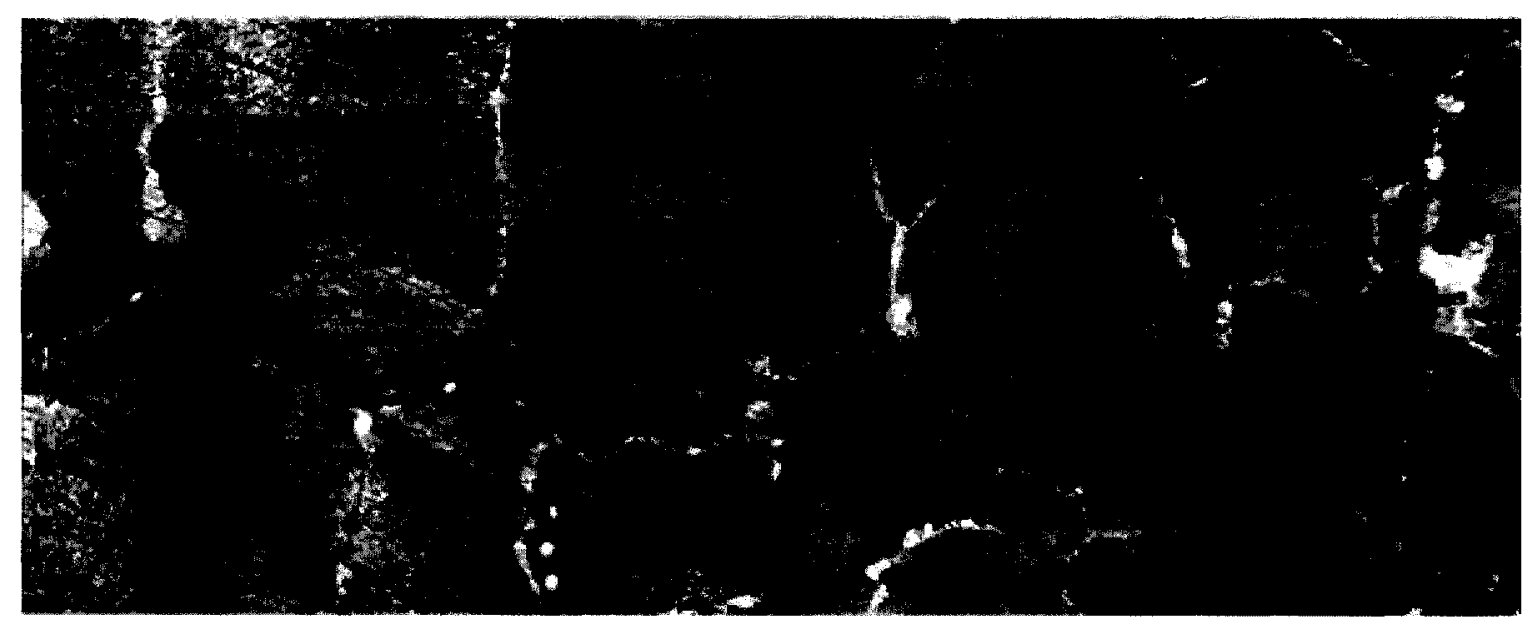

'NGB'

'SGB'

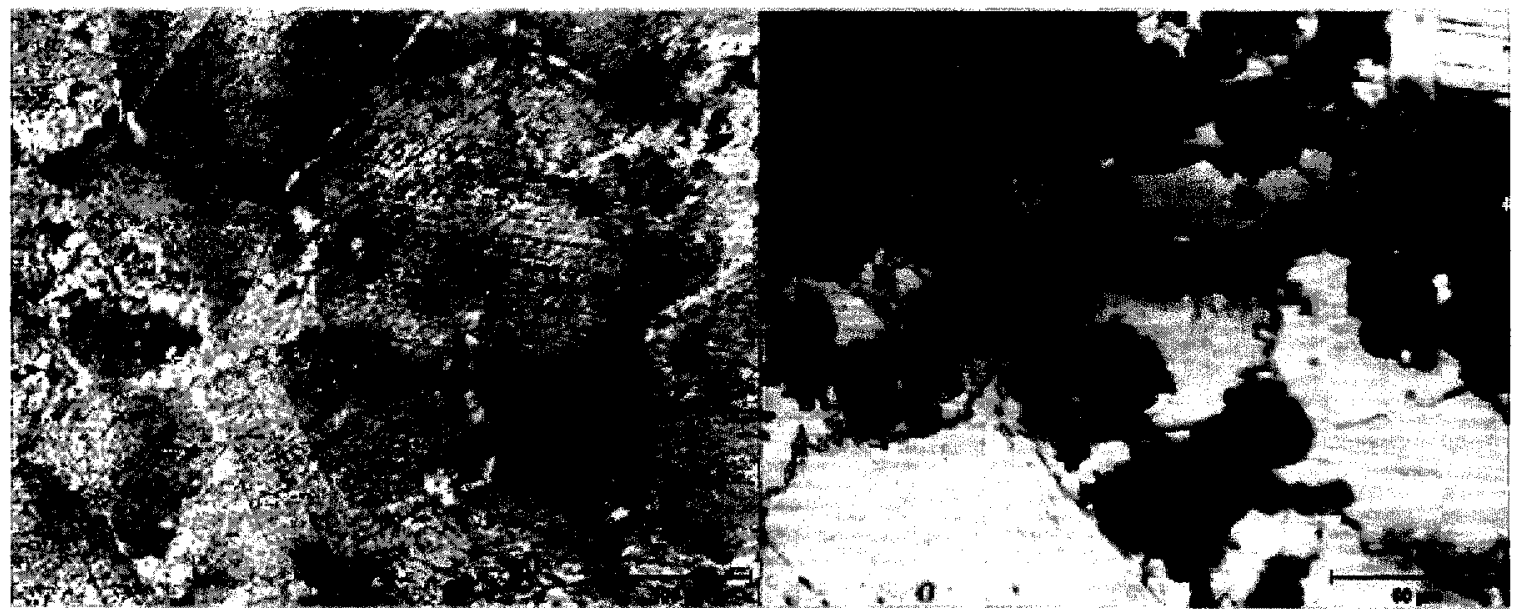

'SGB M"

'SGB' Prematurely Failed

Figure 88: Gauge section intergranular cracking from constant load tests at $900^{\circ} \mathrm{C}$ and $27.4 \mathrm{MPa}$.

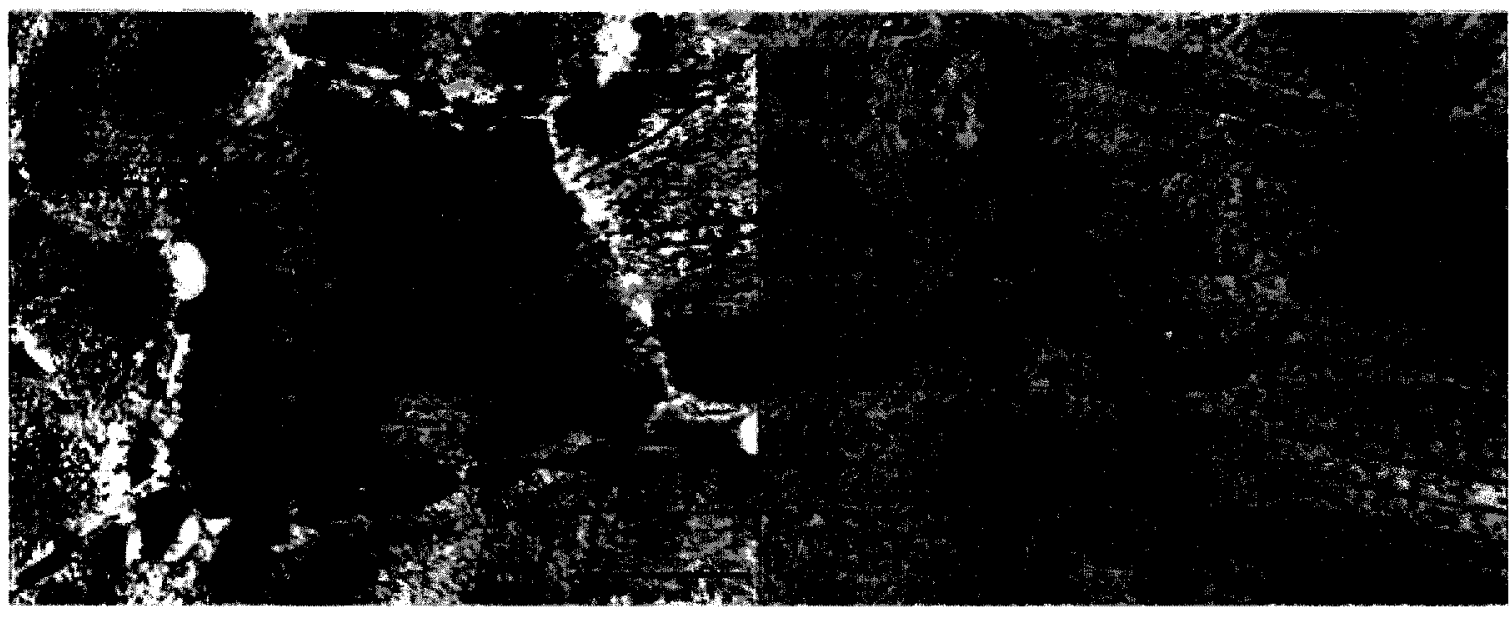

'NGB'

'SGB'

Figure 89: Gauge section intergranular cracking from constant load tests at $925^{\circ} \mathrm{C}$ and $27.4 \mathrm{MPa}$. 
There is also variation in how intergranular cracks appear to originate in the different microstructures at the various testing conditions. At $700^{\circ} \mathrm{C}$, the 'NGB' microstructures appear to form cracks at triple points as seen in Figure 87. The 'SGB' and 'SGB M' microstructures however show cracks around GBR nodules (Figure 90) as well as on grain boundaries away from triple points and other cracks (Figure 91). The grain boundary cavities seen in the 'SGB' and 'SGB M' samples are not prevalent at $700^{\circ} \mathrm{C}$. The tests at $900^{\circ} \mathrm{C}$ however show a marked increase in the number of grain boundary cavities seen in the 'SGB' and 'SGB M' samples (Figure 92). The 'NGB' sample also begins to show grain boundary cavities after the $900^{\circ} \mathrm{C}$ test (Figure 93). The 'SGB' prematurely failed and 'SGB M' samples also show cracks near the GBR nodules (Figure 94). The 'SGB' prematurely failed sample was the only one to show a crack propagating into a GBR nodule.

The $925^{\circ} \mathrm{C}$ constant load tests show a noticeable increase in the number of grain boundary cavities in the 'NGB' sample and the prevalence of cracks near GBR nodules in the 'SGB' sample (Figure 95).

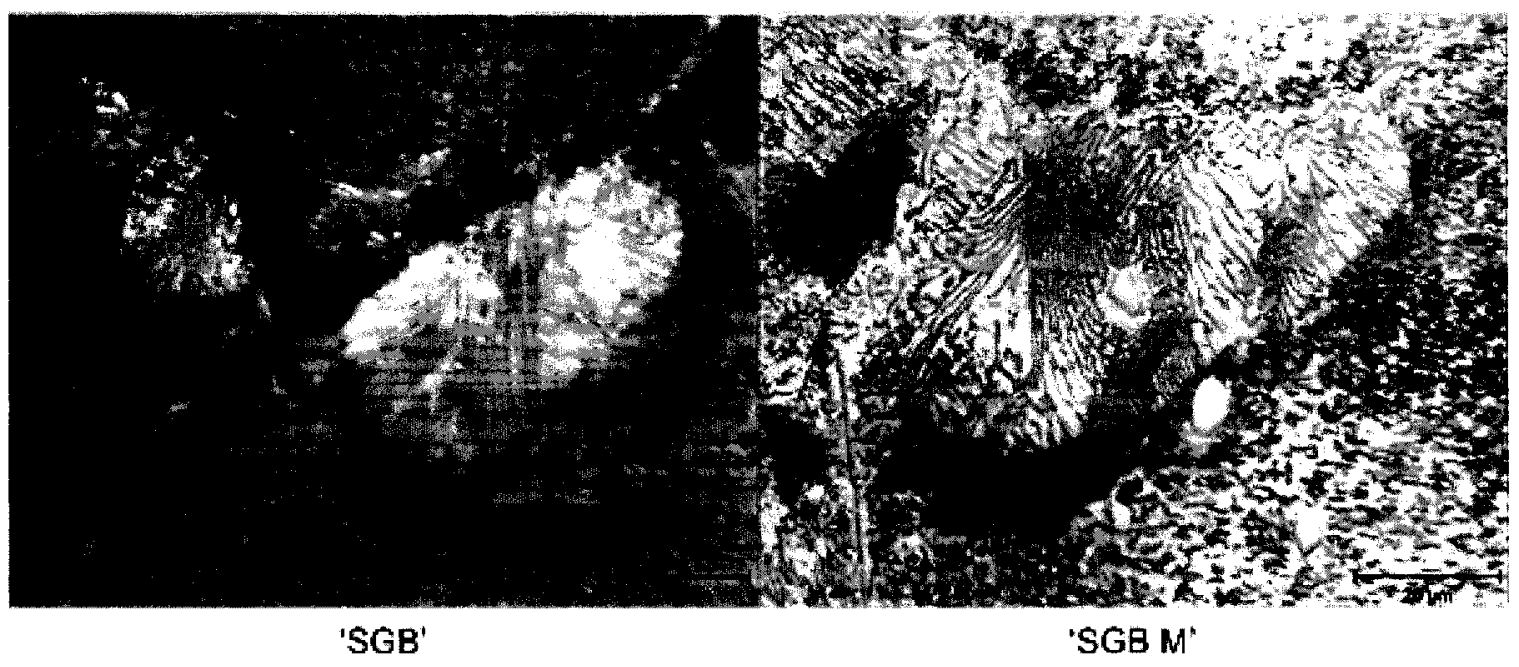

Figure 90: Gauge section intergranular cracks at GBR nodules in 'SGB' and SGB M' samples tested at $700^{\circ} \mathrm{C}$ and $196 \mathrm{MPa}$. 

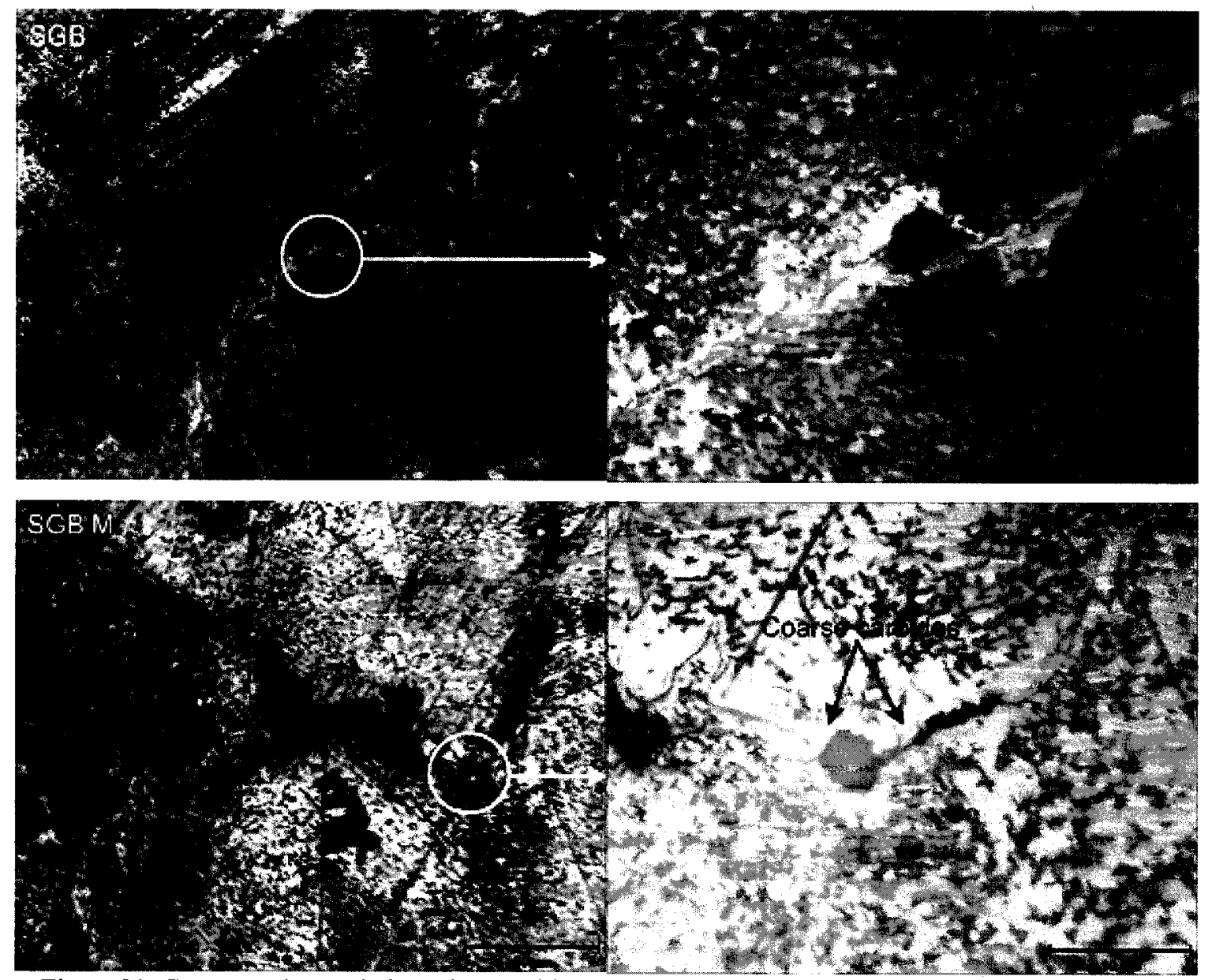

Figure 91: Gauge section grain boundary cavities away from grain boundary triple points in 'SGB' and 'SGB M' samples tested at $700^{\circ} \mathrm{C}$ and $196 \mathrm{MPa}$. 

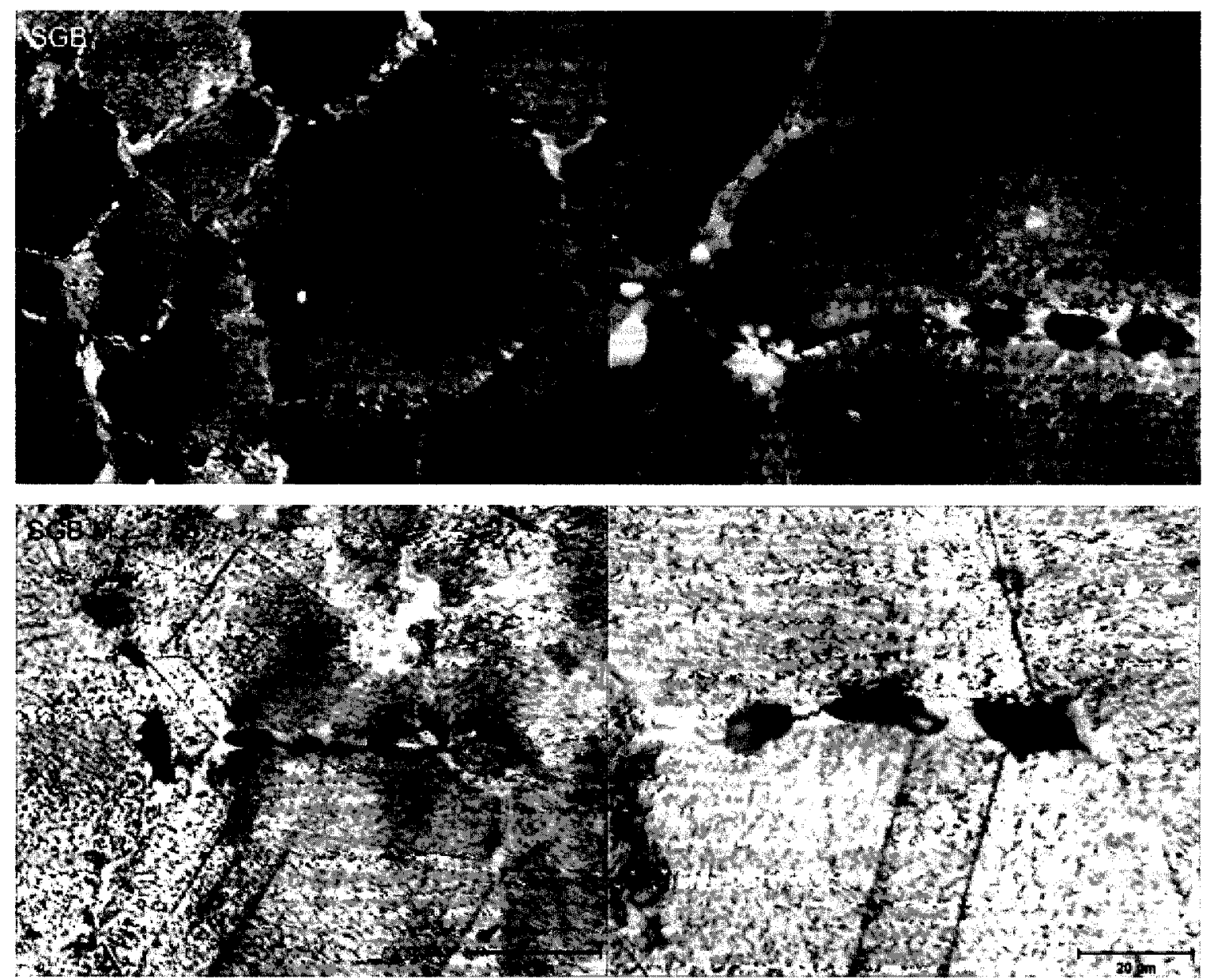

Figure 92: Gauge section grain boundary cavities away from grain boundary triple points in 'SGB' and 'SGB M' samples tested at $900^{\circ} \mathrm{C}$ and $27.4 \mathrm{MPa}$.

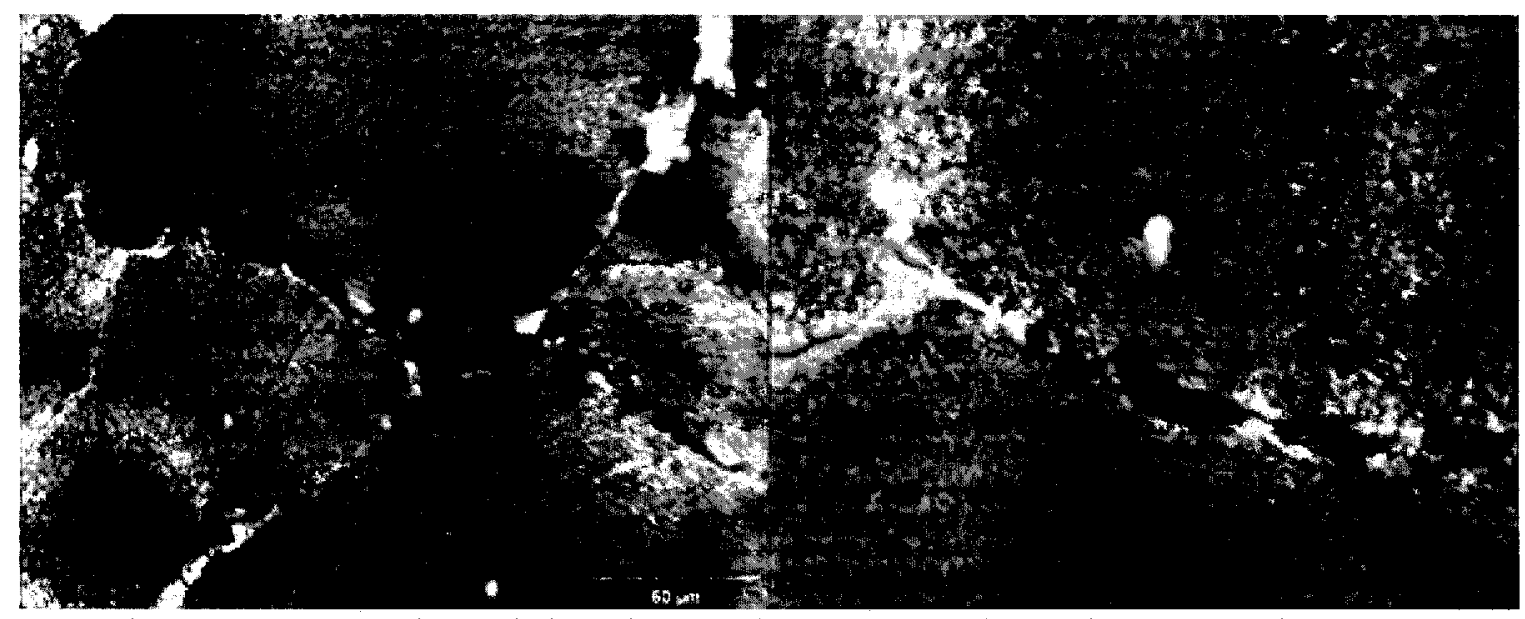

Figure 93: Gauge section grain boundary cavities 'NGB' sample tested at $900^{\circ} \mathrm{C}$ and $27.4 \mathrm{MPa}$. 

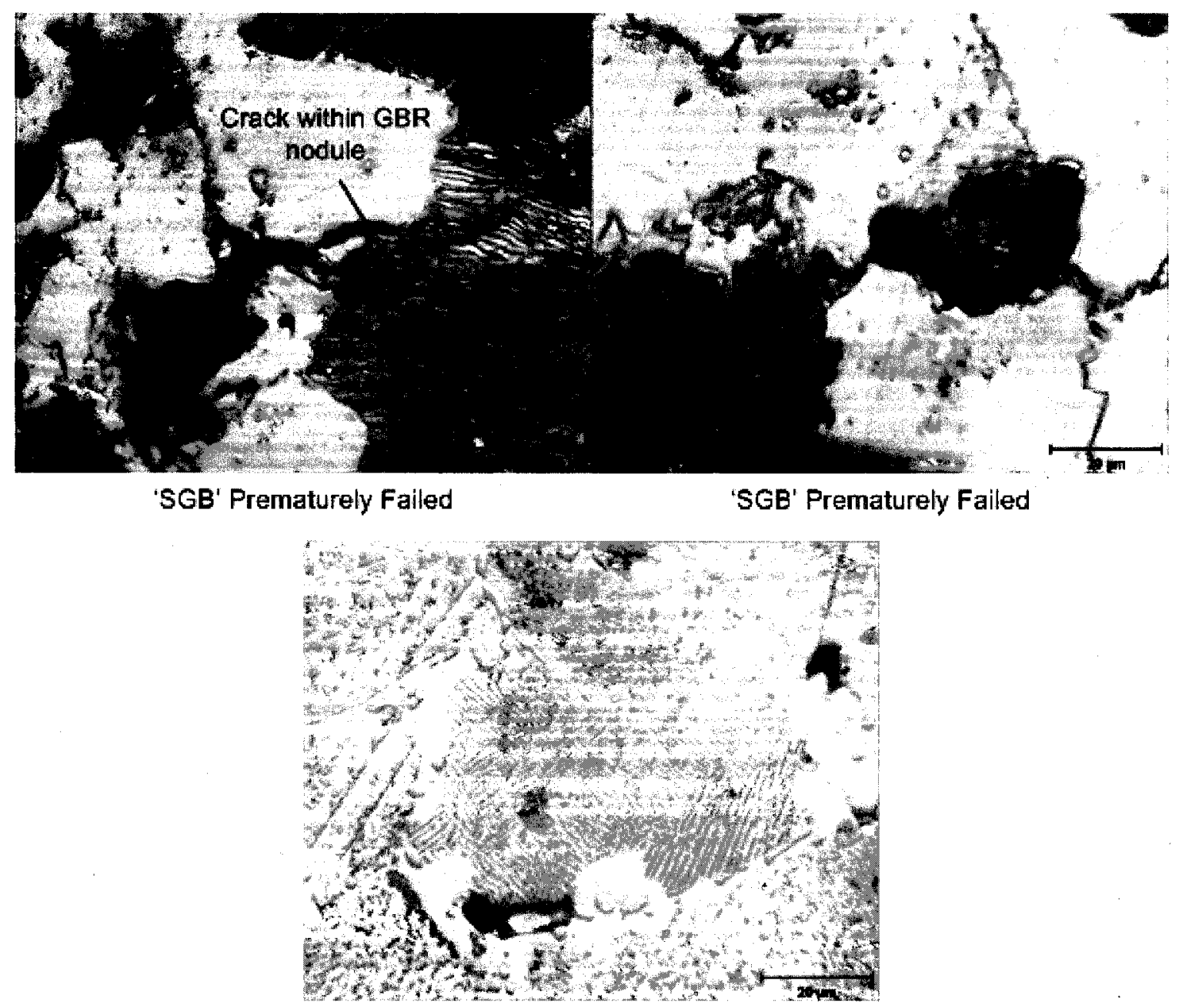

"SGB M"

Figure 94: Gauge section intergranular cracks at and propagating into GBR nodules in 'SGB' prematurely failed and 'SGB M' samples tested at $900^{\circ} \mathrm{C}$ and $27.4 \mathrm{MPa}$. 

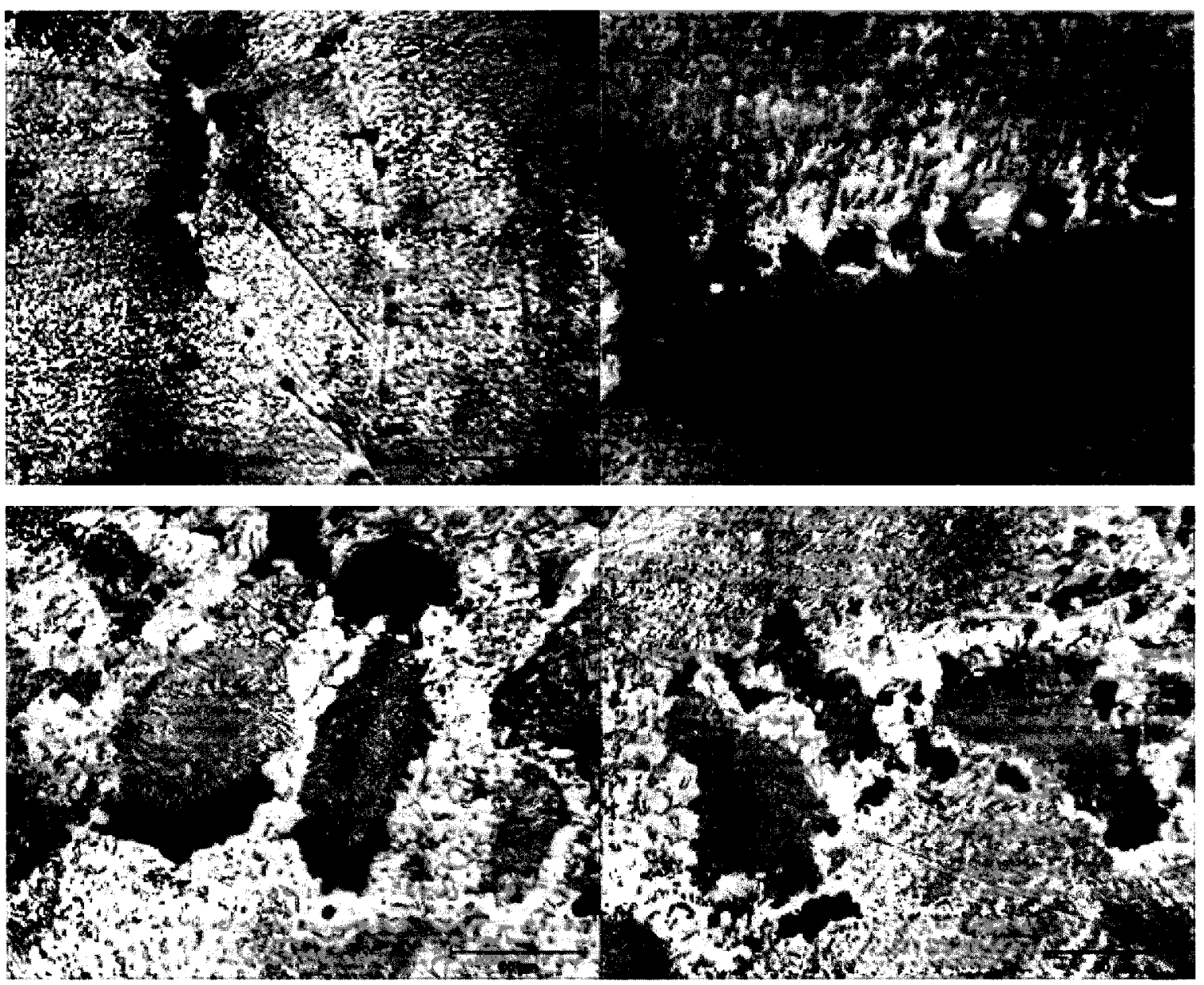

Figure 95: Gauge section micrographs showing an increase in grain boundary cavities in a 'NGB' sample tested at $925^{\circ} \mathrm{C}$ and $27.4 \mathrm{MPa}$, and a prevalence of cracks at GBR nodules in a 'SGB' sample also tested at $925^{\circ} \mathrm{C}$ and $27.4 \mathrm{MPa}$. 


\section{$7 \quad$ Discussion}

\subsection{Heat Treated Microstructures}

As explained in Section 6.1, the 'SGB' microstructure was found to contain grain boundary reaction (GBR) nodules with an area fraction of approximately $16 \%$. This is in excess of the ideal amount of $8-10 \%$ as shown in Section 5 . This result is not unreasonable given that the heat treatment outlined by Tanaka et al. [22-23; 91] states only that furnace cooling is required after the solutionizing step at $1200^{\circ} \mathrm{C}$. The furnace cooling step would thus produce results dependent on the physical characteristics of the furnace being used for the heat treatment. The furnace used in this study of $21-4 \mathrm{~N}$ produced a cooling rate of approximately $6^{\circ} \mathrm{C} / \mathrm{min}$. The study on the effect of cooling rate and amount of GBR precipitated showed that $4^{\circ} \mathrm{C} / \mathrm{min}$ is likely the cooling rate that occurred in the furnace used by Tanaka $e t$ al. This conclusion is supported by the improved creep properties of the 'SGB M' microstructure with respect to the 'SGB' microstructure seen in the constant load tests at $700^{\circ} \mathrm{C}$ and $900^{\circ} \mathrm{C}$. Thus the 'SGB M' microstructure likely corresponds closely to the serrated grain boundary microstructure used by Tanaka et al. [22-23; 91].

A peculiar occurrence is the fact that Tanaka et al. failed to mention that GBR nodules occur during the 'SGB' heat treatment [22-24]. They conducted creep tests to compare microstructures with planar and serrated grain boundaries. However, their omission of the GBR would make it seem that the improvements to creep properties are a result of only the grain boundary serrations. This is misleading as the planar and serrated grain boundary microstructures have significant differences beyond just the changes in grain boundary morphology. Tanaka et al. [91] do mention that the 'SGB' heat treatment 
should produce roughly $8 \%$ GBR in a separate investigation on the effects of the GBR on the creep rupture properties of $21-4 \mathrm{~N}$.

From the micrographs shown in Section 6.1, it is clear that a simple comparison of serrated and planar grain boundary microstructures of $21-4 \mathrm{~N}$ is difficult, as the microstructures show significant differences. This is unavoidable since the GBR occurs with the formation of grain boundary serrations. The most striking difference would be that the 'NGB' microstructure with planar grain boundaries is far more uniform than the 'SGB' or 'SGB M' microstructures with serrated grain boundaries and GBR nodules. Apart from the non-uniformity of the 'SGB' and 'SGB M' microstructures, there is also the possibility of the GBR becoming a liability to creep performance when in excess of 8$10 \%$, as discussed in Section 5.1.2. Also of note between the 'NGB' and 'SGB'/'SGB M' microstructures is the difference in grain boundary carbides. The coarse grain boundary carbides of the 'SGB' and 'SGB M' microstructures could become a liability to the creep properties if they were to form a continuous network, which could occur given the high content of $\mathrm{C}$ and $\mathrm{N}$ in $21-4 \mathrm{~N}$.

The formation of grain boundary serrations being solely due to the GBR is another conclusion of Tanaka et al. difficult to accept given the microstructural results [79-83]. As seen from the micrographs in Section 6.1, there are grain boundary serrations in the 'SGB' and 'SGB M' microstructures where there are no GBR nodules present. The GBR nodules may represent the largest serrations; but they cannot be the cause of all the serrations. As explained in Section 5.1.1, the GBR is likely the result of cellular precipitation on the grain boundaries. Thus the grain boundary serrations in areas free of GBR nodules could be due to cellular precipitation which was deprived of 
sufficient solute to form GBR nodules. The grain boundary serrations could thus be explained solely in terms of cellular precipitation, though as reviewed in Section 3.2.2, work on 304 and 316 SS suggests that grain boundary serrations could be due to lattice distortional strain energy from excess solute near a grain boundary [74]. A more careful study of the formation of grain boundary serrations in $21-4 \mathrm{~N}$ would likely shed further light on whether serrations occur before grain boundary precipitates, or are in fact the result of cellular precipitation.

\subsection{Creep Testing Results and Resulting Microstructures}

Contrary to the results of Tanaka et al. on $21-4 \mathrm{~N}$, there was little to no improvement in creep properties of the serrated grain boundary microstructure over the planar grain boundary microstructure [22-24]. The initial constant load creep tests at $700^{\circ} \mathrm{C}$ and $196 \mathrm{MPa}$ (refer to Section 6.2.1.1, Figure 68) revealed the poor creep performance of the 'SGB' microstructure which had an area fraction of GBR in excess of $8-10 \%$. While there was an improvement in the creep ductility relative to the 'NGB' microstructure, the rupture life was shorter. Even the 'SGB M' microstructure, with an ideal $10 \%$ area fraction of GBR, showed minimal improvement in creep life, but exhibited a higher minimum strain rate. The constant load tests at $900^{\circ} \mathrm{C}$ (refer to Section 6.2.1.2, Figure 69) continued to show results opposite to those of Tanaka et al. (refer to Section 3.3, Figure 32). At these conditions, the serrated grain boundary microstructures showed no improvement in creep rupture life; not even the 'SGB M' microstructure. 
Referring to Table 8 , the $700^{\circ} \mathrm{C}$ constant load tests showed similar rupture lives to those of Tanaka et al. while the $900^{\circ} \mathrm{C}$ constant load tests had rupture lives more than $600 \%$ longer.

Table 8: Comparison of creep rupture lives. Note that 'steel N' corresponds to 'NGB' and 'steel S' corresponds to ' $\mathrm{SGB} \mathrm{M}$ '. (*Results from current investigation at $900^{\circ} \mathrm{C} \& 27.4 \mathrm{MPa}$ are technically not creep rupture lives as the tests were stopped before failure)

\section{Creep Rupture Life (h) $\quad 700^{\circ} \mathrm{C} \& 196 \mathrm{MPa} \quad 900^{\circ} \mathrm{C} \& 27.4 \mathrm{MPa}$}

Tanaka et al. [22]

'steel N'

'steel S'

$\sim 630$

$\sim 310$

\section{Current Investigation}

$\begin{array}{lcc}\text { 'NGB' } & 529,584 & 2039^{*} \\ \text { 'SGB' } & 465,504 & 1788^{*} \\ \text { 'SGB M' } & 604 & 1512^{*}\end{array}$

It should also be noted that the $900^{\circ} \mathrm{C}$ tests were stopped before fracture, meaning that the rupture lives are longer. It is also noticeable that the $700^{\circ} \mathrm{C}$ creep curves (Section 6.2.1.1, Figure 68) are similar to those of Tanaka et al. (Section 3.3, Figure 32) while the $900^{\circ} \mathrm{C}$ creep curves (Section 6.2.1.2, Figure 69) are significantly different. The $900^{\circ} \mathrm{C}$ creep curves from this investigation show creep that is largely dominated by the tertiary stage.

The exceptionally longer creep life and the difference in creep curve shape is perhaps more significant than the lack of improvement to creep properties from the grain boundary serrations. There exist plausible explanations for the lack of improvement to creep properties and they will be explored later. The anomalous results at $900^{\circ} \mathrm{C}$ are difficult to explain however. Even the creep specimen dimensions used by Tanaka et al. are very similar to the ones used in this study. Their gauge length was $30 \mathrm{~mm}$ with a 
gauge diameter of $5 \mathrm{~mm}$, while the dimensions used in this study were $40.64 \mathrm{~mm}\left(1.6^{\prime \prime}\right)$ gauge length with a gauge diameter of $\sim 6.35 \mathrm{~mm}\left(0.25^{\prime \prime}\right)$ [22].

As well, the $21-4 \mathrm{~N}$ chemical compositions are very similar: Referring to Table Table 9 below, there are only minor differences in the $\mathrm{Cr}, \mathrm{Ni}$ and $\mathrm{Mn}$ contents. These differences are unlikely to explain the massive difference in creep life at $900^{\circ} \mathrm{C}$.

Differences in creep testing procedure would also be improbable as an explanation for the anomalous results. Therefore, there appears to be no clear explanation as to why the constant load creep tests at $900^{\circ} \mathrm{C}$ and $27.4 \mathrm{MPa}$ in this study, lasted more than $600 \%$ longer than the constant load tests performed by Tanaka et al. [22-24].

Table 9: Chemical compositions of 21-4N used by Tanaka et al. [22] and test material used in the current study.

\begin{tabular}{ccccccccc}
\hline & $\mathbf{C}$ & $\mathbf{N}$ & $\mathbf{C r}$ & $\mathbf{N i}$ & $\mathbf{M n}$ & $\mathbf{S i}$ & $\mathbf{S}$ & $\mathbf{P}$ \\
\hline $\mathbf{2 1 - 4 N}$ & 0.54 & 0.39 & 21.10 & 4.07 & 9.74 & 0.19 & 0.008 & 0.017 \\
\hline $\begin{array}{c}\text { Test } \\
\text { Material }\end{array}$ & 0.53 & 0.39 & 20.77 & 3.47 & 8.19 & 0.18 & 0.001 & 0.041 \\
\hline
\end{tabular}

Returning now to the unexpected lack of improvement in creep properties from the serrated grain boundaries, it appears that one possible reason is microstructural instability of the serrated grain boundary microstructures. This is somewhat apparent in the crept microstructures from the $700^{\circ} \mathrm{C}$ constant load tests. There is no question though of the microstructural instability when looking at the crept microstructures from the $900^{\circ} \mathrm{C}$ constant load tests. The 'NGB' and 'SGB' microstructures are virtually identical, and the 'SGB M' microstructure appears to be changing in a similar manner. The 'SGB' sample that prematurely failed, shows that the changes in microstructure are not simple. The intragranular precipitates are dissolved and the GBR nodule morphology has 
drastically changed, but there are still grain boundary serrations. The fully tested 'SGB' sample then shows evenly distributed intragranular precipitates, no GBR nodules whatsoever and planar grain boundaries. The instability also arises during simple aging of the microstructures at $900^{\circ} \mathrm{C}$ without an applied stress, though the stress does appear to accelerate the changes (refer to Section 6.4).

Further proof of the microstructural instability can be seen in the $925^{\circ} \mathrm{C}$ and 27.4MPa constant load test results. Although the 'SGB' sample has an excess of GBR nodules, its creep performance at $900^{\circ} \mathrm{C}$ and $27.4 \mathrm{MPa}$ was comparable to that of the 'NGB' sample. The $925^{\circ} \mathrm{C}$ results indicate a severe drop in creep performance, which would be difficult to explain solely by excess GBR. One possible cause is the thermodynamic instability of the microstructure.

Tanaka et al. do not make mention of significant changes to the planar and serrated grain boundary microstructures after testing at $700^{\circ} \mathrm{C}$ and $900^{\circ} \mathrm{C}[22-24]$. This is somewhat expected due to the fact that their $900^{\circ} \mathrm{C}$ tests were substantially shorter than the ones in the current study. However, the similar creep rupture lives of the $700^{\circ} \mathrm{C}$ tests means that some changes in microstructure should have been noted.

The crept microstructures from the $700^{\circ} \mathrm{C}$ tests in this study show that the 'SGB M' microstructure appears fairly stable, though there are some signs of instability due to areas free of grain boundary serrations. Thus given the similar length of the creep tests at $700^{\circ} \mathrm{C}$ in this study and in that of Tanaka et al., it is partly understandable that no major changes in microstructure were reported.

The prematurely failed 'SGB' sample from the $900^{\circ} \mathrm{C}$ tests can also explain the lack of mention of microstructural changes by Tanaka et al. [22-24]. This sample lasted 
$\sim 800 \mathrm{hrs}$ and the sample with the longest rupture life at $900^{\circ} \mathrm{C}$ tested by Tanaka et al. lasted only $\sim 310 \mathrm{hrs}$ [22-24]. The prematurely failed 'SGB' sample still had serrated grain boundaries and GBR nodules, albeit the GBR nodules were different and the precipitate structure had changed significantly. It could reasonably be assumed that at $310 \mathrm{hrs}$, the microstructure may not have been as grossly altered. The fact that serrated grain boundaries remain after nearly $800 \mathrm{hrs}$ in the prematurely failed 'SGB' sample is an important point to note.

Another possible explanation for the poor creep performance of the 'SGB' and 'SGB M' microstructures could be increased susceptibility to intergranular cracking. This can be seen in the micrographs shown in Section 6.5. The micrographs from samples tested at $700^{\circ} \mathrm{C}$ and $196 \mathrm{MPa}$ show that the intergranular cracks appear to be mostly from triple point cracking, though the 'SGB' and 'SGB M' samples show some grain boundary cavities away from grain boundary triple points and wedge cracks, with coarse grain boundary carbides adjacent to the cavities. Cracks at the GBR nodules are also seen in the 'SGB' and 'SGB M' samples.

The $900^{\circ} \mathrm{C}$ and $27.4 \mathrm{MPa}$ tested samples show a large increase in grain boundary cavities for the 'SGB' and 'SGB M' microstructures. Cracks are also seen at GBR nodules in the 'SGB' prematurely failed and 'SGB M' samples. Some of the grain boundary cavities in the 'SGB' sample could have formed at GBR nodules before they dissolved. The prematurely failed 'SGB' sample is also the only one to show a crack propagating into a GBR nodule. At $900^{\circ} \mathrm{C}$, the 'NGB' sample shows an increase in grain boundary cavities with respect to the samples crept at $700^{\circ} \mathrm{C}$. 
At $925^{\circ} \mathrm{C}$ and $27.4 \mathrm{MPa}$, the 'NGB' sample shows a large increase in grain boundary cavities. The 'SGB' sample shows cracks predominantly at GBR nodules. This could indicate that the GBR nodules are sites for crack initiation due to the reduced ductility of the nodules themselves. It is also possible that the coarse grain boundary carbides act as crack initiation points. However, the 'SGB' sample tested at $925^{\circ} \mathrm{C}$ and 27.4MPa shows cracks almost exclusively initiating at the GBR nodules. This could extend to the $900^{\circ} \mathrm{C}$ results as cracks could have formed at GBR nodules and remained after the nodules had disappeared over the course of the test. However, the 'SGB' microstructure does have an excess amount of GBR, possibly making it more susceptible to crack formation.

The GBR nodules are not likely to be the only source of cracks as the 'NGB' samples tested at $900^{\circ} \mathrm{C}$ and $925^{\circ} \mathrm{C}$ also showed substantial amounts of grain boundary cavities. This could be due to the coarse grain boundary carbides which precipitated during the tests as seen in Sections 6.3.2 and 6.3.3. Thus it seems probable that the coarse grain boundary carbides have a negative effect on the creep properties by acting as crack initiation sites. This combined with the GBR nodules also acting as possible crack initiation sites would explain why the 'SGB' and 'SGB M' microstructures performed so poorly with respect to the 'NGB' microstructure. It would also explain why the constant load test results at $900^{\circ} \mathrm{C}$ and $27.4 \mathrm{MPa}$ show creep mostly in the tertiary stage. In essence, the 'SGB' and 'SGB M' microstructures are 'handicapped' from the start of the creep test with a larger amount of potential crack initiation sites. Thus they experience an increase in creep rate sooner than the 'NGB' microstructure which only forms coarse grain boundary carbides as the test progresses, delaying the onset of accelerating creep. 
Thus, any benefit of the serrated grain boundaries in the 'SGB' and 'SGB M' microstructures is outweighed by the inherent flaws in the microstructures, leaving them at a distinct disadvantage to the 'NGB' microstructure. Add to that the microstructural instability of the 'SGB' and 'SGB M' microstructures discussed earlier and it seems fairly clear as to why there was no improvement to creep properties from the serrated grain boundaries. While it would require a large number of creep tests to progressively increasing strains in order to completely observe the development of creep damage in the various microstructures, the larger amount of cracks in the 'SGB' and 'SGB M' microstructures, found near microstructural features absent from the 'NGB' microstructure, indicates that these microstructural features could be at fault for the poor creep performance of the 'SGB' and 'SGB M' microstructures.

Another interesting point to note is that only in the 'SGB' prematurely failed sample were cracks seen propagating within the GBR nodules, and even there it was a rare occurrence. This could be the reason for the premature failure of this sample as the 'SGB' samples tested at $700^{\circ} \mathrm{C}$ and $925^{\circ} \mathrm{C}$, which still had some GBR remaining, showed no cracks within the GBR nodules. This conflicts with the discussion in Section 5.1.2, where cracks were expected to initiate and propagate from within the GBR nodules when the area percent of GBR exceeded $8-10 \%$ at lower temperatures.

An additional point to note is the difference in chemical composition of the $21-4 \mathrm{~N}$ test material in this investigation and in that of Tanaka et al. [22]. The material tested had lower amounts of $\mathrm{Cr}$, $\mathrm{Ni}$ and $\mathrm{Mn}$ which would result in fewer coarse carbides and possibly lower amounts of GBR. And yet, the coarse grain boundary carbides and GBR nodules appear to have a negative impact on creep properties, making the results of 
Tanaka et al. [22-24] even more perplexing in that they actually showed improvements to creep properties with the serrated grain boundary microstructure.

\subsection{Effect of Serrated Grain Boundaries on Creep Rate}

While it is clear that the 'SGB' and 'SGB M' microstructures have thermodynamic stability issues and inherently have more potential crack initiation sites, the results from the $\theta$-Projection analysis of the $700^{\circ} \mathrm{C}$ and $900^{\circ} \mathrm{C}$ constant load test results can be used to shed light on the effect of serrated grain boundaries on creep rate. This is possible since the minimum creep rates occur early on in the creep life, where it can be reasonably assumed that the microstructures are similar to the untested microstructures. Thus the 'NGB' samples have planar grain boundaries and the 'SGB'/‘SGB M' still have serrated grain boundaries, and any creep damage that has occurred in the 'SGB'/'SGB M' microstructures should not overwhelm the beneficial effects of the serrated grain boundaries.

Referring to Table 6.1 in Section 6.2 .1 .1 , the $700^{\circ} \mathrm{C}$ constant load test results show that the creep rates are very similar. This is expected since at $700^{\circ} \mathrm{C}$ and $196 \mathrm{MPa}$, a dislocation creep mechanism is expected to be dominant, which should not be affected by grain boundary morphology. The increasing load tests at $700^{\circ} \mathrm{C}$ (Section 6.2 .2 .1 ) also show that the creep rates are similar. The high stress exponent of approximately 8.1 also suggests that a dislocation creep mechanism is dominant. This stress exponent is consistent with the results of Tanaka et al. at $700^{\circ} \mathrm{C}$ (Section 3.3) where stress exponents of 7.6 and 7.1 were reported. 
The $900^{\circ} \mathrm{C}$ constant load test results show that the creep rates are very similar (refer to Table 6.2). The increasing load tests at $900^{\circ} \mathrm{C}$ (Section 6.2.2.2) however show that the 'SGB' samples have slightly higher creep rates. This is likely due to the fact that the increasing load creep rates are calculated from linear fits of the creep curves where the creep rate appears to be roughly constant. This is also an indication that the 'SGB' microstructure experiences a definite minimum creep rate and that the creep curve is likely devoid of a true secondary stage of creep. There is instead only a transition from primary to tertiary creep. The 'NGB' microstructure on the other hand does appear to experience a roughly steady secondary stage of creep.

A more significant result from the increasing load test results at $900^{\circ} \mathrm{C}$ is that the 'SGB' samples do not show an increase in the stress exponent as the stresses increase. Typically an increase in stress exponent, as seen in the 'NGB' samples, would indicate a change in the creep mechanism. While this may be true in this case, it is more likely that the increase in stress exponent is due to increasing microstructural damage from the continuously increasing loads. The 'SGB' samples then show the increased damage tolerance of the serrated grain boundary morphology, while the grain boundary serrations are still present.

Thus from the constant and increasing load test results at $700^{\circ} \mathrm{C}$ and $900^{\circ} \mathrm{C}$, serrated grain boundaries do not appear to have any effect on the minimum creep rate. The results of the constant load tests at $900^{\circ} \mathrm{C}$ and $27.4 \mathrm{MPa}$ are the most significant since those conditions are the most likely to be controlled by diffusional creep mechanisms. With diffusional creep, it is expected that grain boundary sliding will also be occurring. 
If that is the case, then the creep rate should be affected by the presence of serrated grain boundaries which are known to inhibit grain boundary sliding.

The lack of effect on the creep rate from the serrated grain boundaries could be explained in several ways. The first and simplest explanation would be that there is no link between diffusional creep and grain boundary sliding as hypothesized by creep theory. Another simple explanation could be that the creep conditions are not dominated by diffusional mechanisms, as indicated by the stress exponents above one in the increasing load tests at $900^{\circ} \mathrm{C}$.

The microstructural instabilities of the serrated grain boundary microstructures and the larger number of inherent flaws from the GBR nodules and coarse grain boundary carbides could also be factors in why the serrated grain boundaries had no effect on the creep rate. This would likely be minor since the serrated grain boundaries were present for a significant portion of the creep life, as shown by the 'SGB' sample that failed prematurely and the microstructural damage should be relatively negligible at the low strains at which the minimum creep rates occured.

The largest problem from the microstructural instabilities is the fact that a more extensive creep testing regime could not have been undertaken. Any attempt to test at lower stresses and higher temperatures would have been futile. Tests at lower stresses would likely have increased the time to the minimum creep rate to such an extent that the serrated grain boundary morphology would no longer have been present. As for increasing the temperature further, the constant load tests at $925^{\circ} \mathrm{C}$ and $27.4 \mathrm{MPa}$ show that it would have been equally pointless. 
The results from this investigation of $21-4 \mathrm{~N}$ do not provide a conclusive answer as to what effect if any serrated grain boundaries may have on creep rate. Instead, these results can be considered as an intermediate step. Unfortunately, due to the thermodynamic instability of the serrated grain boundary microstructures and the negative effects of the coarse grain boundary carbides and GBR nodules, it is not suitable for further investigation. Therefore the current conclusion about the effect of serrated grain boundaries on creep rate is that there is no noticeable effect. 


\section{Summary, Conclusions and Recommendations for Future Work}

\subsection{Summary and Conclusions}

Heat treatments to produce serrated and planar grain boundaries in 21-4 were successfully applied including a correction to the serrated grain boundary heat treatment. Constant and increasing load creep tests were performed on the planar and serrated grain boundary microstructures. Crept microstructures were examined using optical microscopy. Long term aging of planar and serrated grain boundary microstructures was also performed. The following can be concluded from this study on the effects of serrated grain boundaries on the creep of $21-4 \mathrm{~N}$ :

- Correct heat treatment to produce grain boundary serrations in $21-4 \mathrm{~N}$ with an optimal amount (8-10\%) of grain boundary reaction is:

1. Solutionize at $1200^{\circ} \mathrm{C}$ for 1 hour, followed by controlled cooling at approximately $4^{\circ} \mathrm{C} / \mathrm{min}$ to $1030^{\circ} \mathrm{C}$, followed by water quenching.

2. Age at $750^{\circ} \mathrm{C}$ for 30 hours, followed by air cooling.

3. Age at $1000^{\circ} \mathrm{C}$ for 3 hours, followed by air cooling.

- Improvement in creep properties from serrated grain boundaries in $21-4 \mathrm{~N}$ is limited to none, due to thermodynamic instability of the microstructure during creep testing and due to increased microstructural damage from coarse grain boundary carbides and grain boundary reaction nodules. This result is in direct contrast to past research on $21-4 \mathrm{~N}$.

- From the creep data gathered, there appears to be no effect on the creep rate due to the grain boundary serrations, even at conditions which could be considered to controlled by diffusional creep mechanisms. 
- $21-4 \mathrm{~N}$ is not suitable for further study within the frame work of the overall research project dealing with the effects of grains boundaries on the creep rate of engineering alloys, as the formation of serrated grain boundaries is accompanied by coarse grain boundary carbides and grain boundary reaction nodules.

\subsection{Recommendations for Future Work}

In light of the results showing the problems associated with the serrated grain boundary microstructure in $21-4 \mathrm{~N}$, no further use of this alloy is envisioned in the overall project seeking to elucidate the role of grain boundaries on the creep rate of engineering alloys.

Instead, the work of Hong et al. on 304 and 316 stainless steels could provide a useful start for further investigation [68-74]. Using austenitic stainless steels again would prove very practical since the testing temperatures and stresses would not have to be as high as for a nickel base superalloy for instance. An outline of work to be done to continue the investigation of serrated grain boundary effects on creep rate is as follows:

- Procure 304 and/or 316 test material, preferably bar stock for ease of creep sample machining. The carbon content has been shown to be an important factor in the formation of serrated grain boundaries in these alloys [74]. Ensure the composition of the 304 includes at least $\sim 0.077 \mathrm{wt} . \% \mathrm{C}$, or at least $\sim 0.067 \mathrm{wt} . \% \mathrm{C}$ for 316. If it is desired to match the compositions used by Hong et al., they are provided below in Table 10 . 
Table 10: Chemical compositions of 304 and 316 used by Hong et al. (wt.\%) [72-73].

\begin{tabular}{ccccccccc}
\hline & $\mathbf{C}$ & Si & Mn & P & S & Cr & Ni & Mo \\
\hline $\begin{array}{c}\text { AISI } \\
\text { 304 }\end{array}$ & 0.077 & 0.5 & 1.5 & 0.02 & 0.016 & 18.2 & 8.3 & 0.2 \\
$\begin{array}{c}\text { AISI } \\
316\end{array}$ & 0.067 & 0.6 & 1.3 & 0.04 & 0.02 & 16.9 & 10.8 & 2.12 \\
\hline
\end{tabular}

- Next the heat treatments used by Hong et al. should be applied to the 304 and/or 316 , and the resulting microstructures examined to ensure grain boundary serrations are present and whether there is a difference in grain boundary carbide morphology between the serrated and planar grain boundaries. The serrated grain boundaries should have planar carbides while the planar grain boundaries should have triangular carbides. The necessary heat treatments are reproduced in Table 11 below. The furnace cooling for the 304 serrated grain boundary heat treatment is $\sim 4^{\circ} \mathrm{C} / \mathrm{min}$, though it would be prudent to also produce samples using $6^{\circ} \mathrm{C} / \mathrm{min}$ and $2^{\circ} \mathrm{C} / \mathrm{min}$ for comparison [70-71].

Table 11: Heat treatments required to produce serrated and planar grain boundaries in 304 and 316 [72-73].

\begin{tabular}{lr}
\hline Specimen & Heat Treatment Process \\
\hline 304 Planar grain boundaries & $1323 \mathrm{~K} / 1 \mathrm{~h} / \mathrm{WQ} \rightarrow 1033 \mathrm{~K} / 50 \mathrm{~h} / \mathrm{WQ}$ \\
304 Serrated grain boundaries & $1323 \mathrm{~K} / 1 \mathrm{~h} \rightarrow \mathrm{FC} \rightarrow 1033 \mathrm{~K} / 50 \mathrm{~h} / \mathrm{WQ}$ \\
316 Planar grain boundaries & $1423 \mathrm{~K} / 1 \mathrm{~h} / \mathrm{WQ} \rightarrow 1123 \mathrm{~K} / 50 \mathrm{~h} / \mathrm{WQ}$ \\
316 Serrated grain boundaries & $1323 \mathrm{~K} / \mathrm{h} / \mathrm{WQ} \rightarrow 1033 \mathrm{~K} / 50 \mathrm{~h} / \mathrm{WQ}$ \\
\hline
\end{tabular}

- Before commencing creep testing, it may be prudent to age samples of 304 and/or 316 with planar and serrated grain boundaries for substantial periods of time to check whether the microstructures may be unstable as with the $21-4 \mathrm{~N}$.

- If creep testing is decided upon, the maximum testing temperature should be restricted well below $900^{\circ} \mathrm{C}$ due to issues encountered during the $21-4 \mathrm{~N}$ testing. 
It may become impossible to remove the creep samples from the specimen grips when testing at too high a temperature.

- Increasing load tests are not recommended as the creep rates obtained may not be sufficiently close to the true minimum creep rates and the accumulating creep damage may cause the results to be suspect.

It should also be mentioned that a substantial amount of work has been carried out on the nickel base superalloy PWA 1113 concurrently with the work on 21-4N. A similar procedure was used where planar and serrated grain boundary microstructures were produced and tested at identical temperatures and stresses. The results are promising so far in that improvements to creep rupture life and ductility have been recorded as expected, suggesting that the PWA 1113 does not suffer from microstructural instability during testing. The stability of the grain boundary serrations could be due to the fact that the serrations are formed through $\gamma^{\prime}$ precipitation, during cooling from $1135^{\circ} \mathrm{C}$ to $1060^{\circ} \mathrm{C}$. Thus the highest testing temperature of $800^{\circ} \mathrm{C}$ is well below the $\gamma^{\prime}$ solvus. Figures 96 to 99 show a selection of creep results of the PWA 1113 testing which highlight some interesting features. 


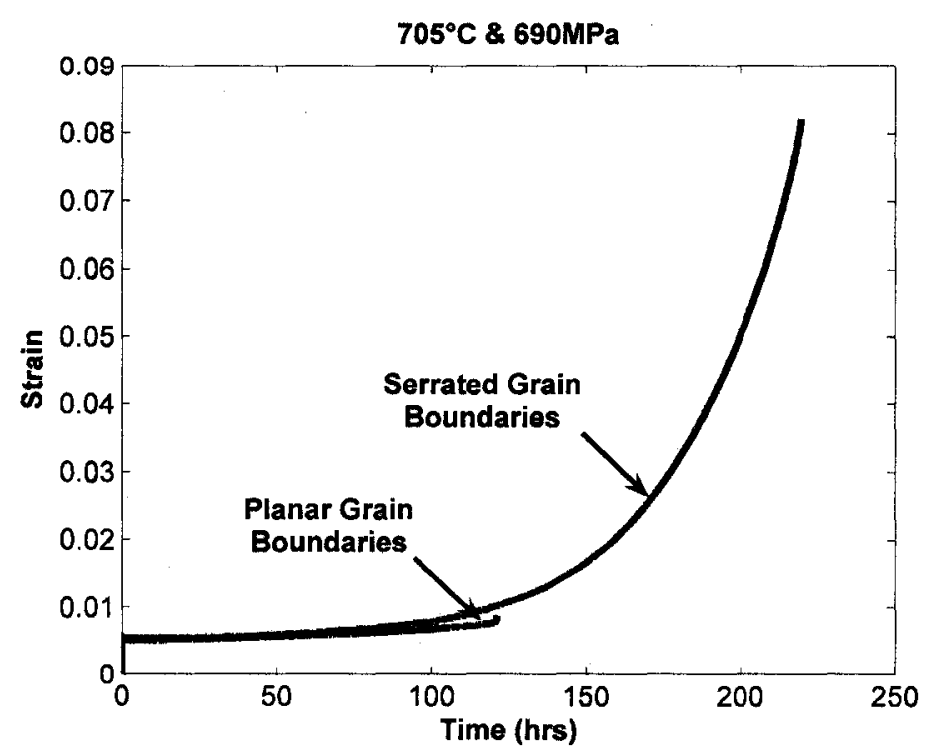

Figure 96: PWA 1113 constant load creep curves at $705^{\circ} \mathrm{C}$ and $690 \mathrm{MPa}$.

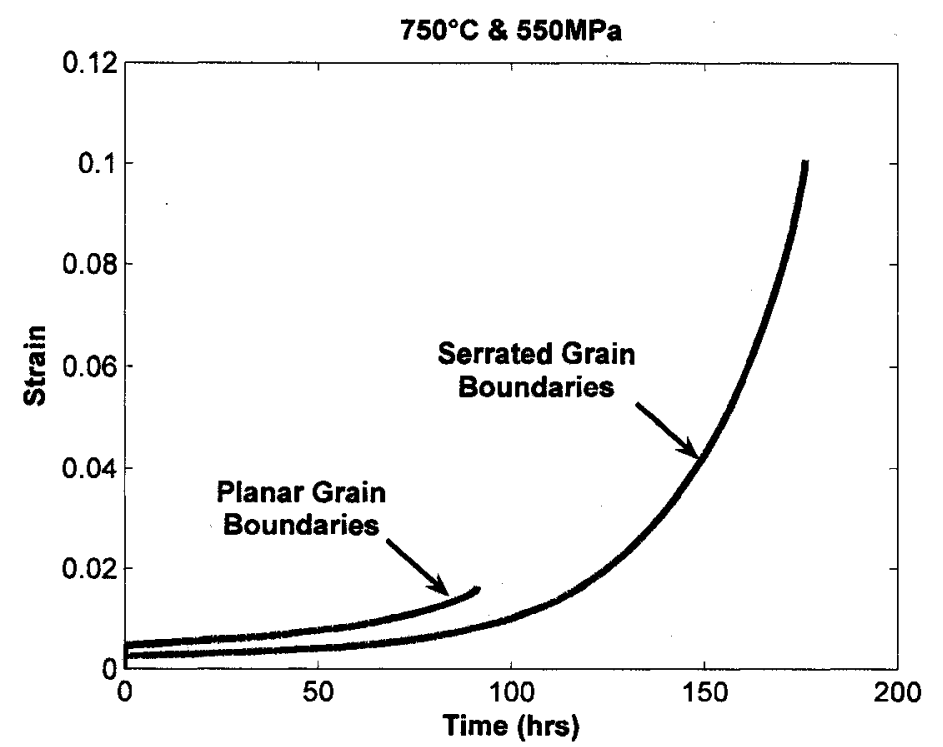

Figure 97: PWA 1113 constant load creep curves at $750^{\circ} \mathrm{C}$ and 550MPa. 


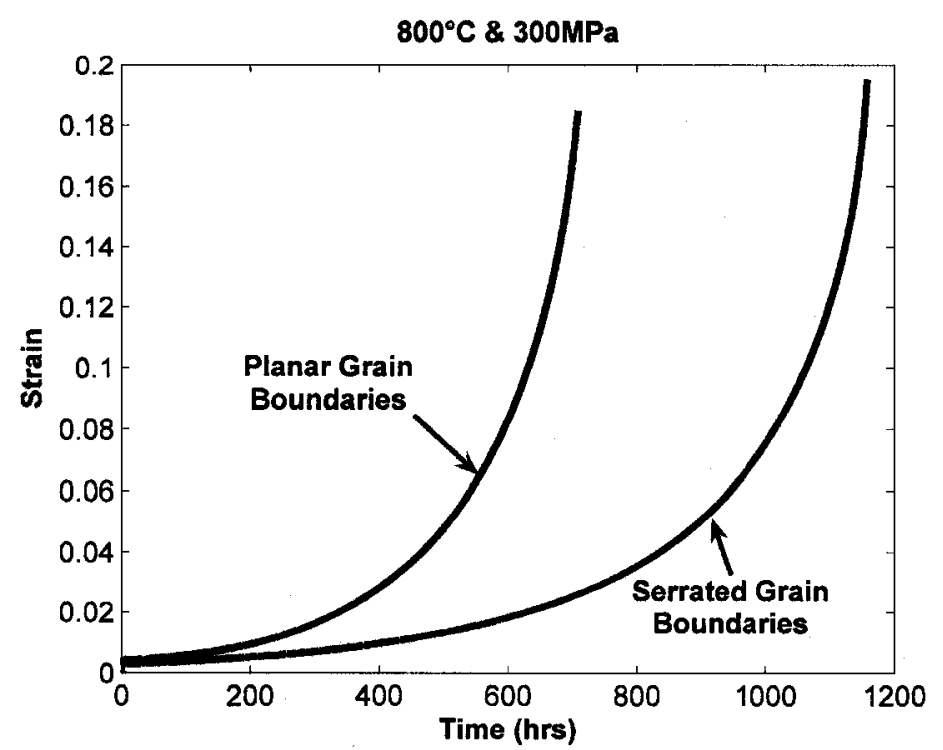

Figure 98: PWA 1113 constant load creep curves at $800^{\circ} \mathrm{C}$ and $300 \mathrm{MPa}$.

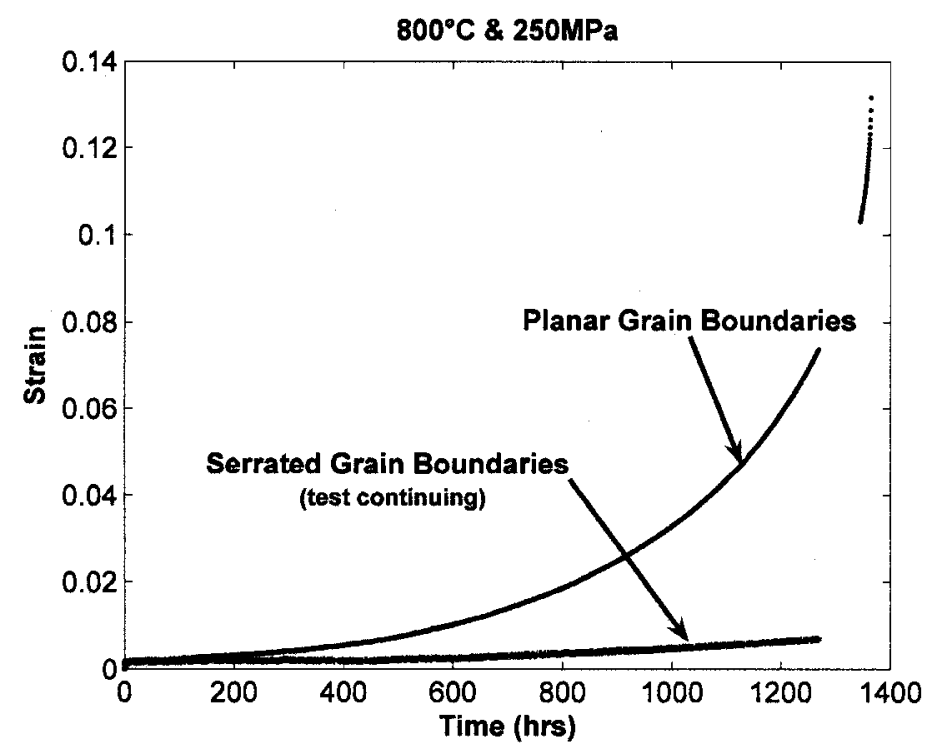

Figure 99: PWA 1113 constant load creep curves at $800^{\circ} \mathrm{C}$ and $250 \mathrm{MPa}$.

Figures 96 and 97 show creep results at high stresses and in the case of Figure 96, a relatively low temperature. The improvement to creep ductility and creep rupture life from the serrated grain boundaries is immediately apparent. As well, it can be seen that the creep rates are similar as expected at such high stresses. Figures 98 and 99 show creep results at stresses and temperatures closer to diffusional creep conditions. The creep rates still appear to be very similar, driving the need for continued creep testing at 
even lower stresses. It is interesting to note that the improvement to creep properties from the grain boundary serrations continues to be improved damage tolerance. This is seen with improved creep ductility, longer creep rupture life and increased time to tertiary creep. Further creep testing continues on this material with increasingly lower stresses to try and enter the diffusional regime of creep. 


\section{References}

[1] F.R.N. Nabaro, H.L. de Villiers, The Physics of Creep. Great Britain: Taylor \& Francis Ltd., 1995

[2] R.E. Reed-Hill, R. Abbaschian, Physical Metallurgy Principles, $3^{\text {rd }}$ Ed. U.S.A.: PWS-KENT Publishing Company, 1992

[3] R.W. Evans, B. Wilshire, Introduction to Creep. London: The Institute of Materials, 1993

[4] Edited by, A.K. Koul, V.R. Parameswaran, J-P. Immarigeon, W. Wallace, Advances in High Temperature Structural Materials and Protective Coatings. Ottawa: National Research Council of Canada, 1994

[5] J. Čadek, Creep in Metallic Materials. Czechoslovakia: Elsevier Science Publishing Company Inc., 1988

[6] O.A. Ruano, O.D. Sherby, Low Stress Creep of Fine-grained Materials at Intermediate Temperatures: Diffusional Creep or Grain Boundary Sliding?, Materials Science and Engineering, Vol.56, No.2, 1982, pp.167-175

[7] O.A. Ruano, J. Wadsworth, O.D. Sherby, Harper-Dorn Creep in Pure Metals, Acta Metallurgica, Vol.36, No.4, 1988, pp.1117-1128

[8] O.A. Ruano, J. Wadsworth, O.D. Sherby, Harper-Dorn and Power Law Creep in $\mathrm{Fe}-3 w t \% \mathrm{Si}$, Scripta Metallurgica, Vol.22, No.12, 1988, pp.1907-1910

[9] O.A. Ruano, J. Wadsworth, J. Wolfentine, O.D. Sherby, Evidence for NabarroHerring creep in metals: fiction or reality?, Materials Science and Engineering, Vol.A165, No.2, 1993, pp.133-141

[10] J. Wolfenstine, O.A. Ruano, J. Wadsworth, O.D. Sherby, Refutation of the relationship between denuded zones and diffusional creep, Scripta Metallurgica et Materialia, Vol.29, No.4, 1993, pp.515-520

[11] G.W. Greenwood, Denuded zones and diffusional creep, Scripta Metallurgica et Materialia, Vol.30, No.12, 1994, pp.1527-1530

[12] B. Burton, G.L. Reynolds, In defense of diffusional creep, Materials Science and Engineering, Vol.A191, No.1-2, 1995, pp.135-141

[13] O.A. Ruano, O.D. Sherby, J. Wadsworth, J. Wolfenstine, Rebuttal to "In defense of diffusional creep", Materials Science and Engineering, Vol.A211, No.1-2, 1996, pp.66-71 
[14] O.A. Ruano, O.D. Sherby, J. Wadsworth, J. Wolfenstine, Diffusional creep and diffusion-controlled dislocation creep and their relation to denuded zones in $\mathrm{Mg}$ $\mathrm{ZrH}_{2}$ materials, Scripta Materialia, Vol.38, No.8, 1998, pp.1307-1314

[15] J. Wadsworth, O.A. Ruano, O.D. Sherby, Deformation by grain boundary sliding and slip creep versus diffusional creep, Creep Behaviour of Advanced Materials for the $21^{\text {st }}$ Century. Proceedings of Symposium. 1999 TMS Annual Meeting, 1999, pp.425-439

[16] K.R. McNee, G.W. Greenwood, H. Jones, Microstructural evidence for diffusional creep in copper using atomic force microscopy, Scripta Materialia, Vol.44, No.2, 2001, pp.351-357

[17] J. Wadsworth, O.A. Ruano, O.D. Sherby, Denuded zones, diffusional creep, and grain boundary sliding, Metallurgical and Materials Transactions A, Vol.33A, No.2, 2002, pp.219-229

[18] K.R. McNee, G.W. Greenwood, H. Jones, Observation and interpretation of some microstructural features of low stress creep, Scripta Materialia, Vol.47, No.9, 2002, pp.619-623

[19] F.R.N. Nabarro, Creep at very low rates, Metallurgical and Materials Transactions A, Vol.33A, No.2, 2002, pp.213-218

[20] O.D. Sherby, O.A. Ruano, J. Wadsworth, Deformation mechanisms in crystalline solids and Newtonian viscous behaviour, Creep Behaviour of Advanced Materials for the $21^{\text {st }}$ Century. Proceedings of Symposium. 1999 TMS Annual Meeting, 1999, pp.397-411

[21] W.F. Smith, Foundations of Materials Science and Engineering, $2^{\text {nd }}$ Ed. U.S.A.: Irwin/McGraw-Hill, 1993

[22] M. Tanaka, H. lizuka, F. Ashihara, Effects of Grain-boundary Configuration on the Creep Rupture Strength and Grain-boundary Sliding in Austenitic Heatresisting Steel, Transactions of the Iron and Steel Institute of Japan, Vol.28, No.2, 1987, pp.129-135

[23] M. Tanaka, O. Miyagawa, T. Sakaki, H. lizuka, F. Ashihara, D. Fujishiro, Creep rupture strength and grain-boundary sliding in austenitic $21 \mathrm{Cr}-4 \mathrm{Ni}-9 \mathrm{Mn}$ steels with serrated grain boundaries, Journal of Materials Science, Vol.23, No.2, 1988, p.621-628

[24] M. Tanaka, H. Iizuka, F. Ashihara, Micromechanisms of grain-boundary strengthening in austenitic $\mathrm{Cr}-\mathrm{Ni}-\mathrm{Mn}$ heat-resisting steels during creep, Strength of Metals and Alloys (ICSMA 8) Proceedings of the $8^{\text {th }}$ International Conference, 1988, pp.579-584 
[25] T. Saga, O. Miyagawa, M. Kobayashi, D. Fujishiro, Structural Change Occurred by Furnace Cooling and Its Effect on Creep Rupture Properties of 21-12N Steel, Tetsu-To-Hagane, Vol.56, No.1, 1970, pp.55-68

[26] J.C. Beddoes, W. Wallace, Heat Treatment of Hot Isostatically Processed IN-738 Investment Castings, Metallography, Vol.13, No.2, 1980, pp.185-194

[27] M. Yoshiba, O. Miyagawa, Effect of Grain Boundary Serration on the Fatigue, Creep and Cyclic Creep Strengths of a Nickel-base Superalloy in Air and in Hot Corrosive Environment, Transactions of the Iron and Steel Institute of Japan, Vol.26, No.1, 1985, pp.69-77

[28] M. Chang, A.K. Koul, P. Au, T. Terada, Damage Tolerance of Wrought Alloy 718 $\mathrm{Ni}$-Fe-Base Superalloy, Journal of Materials Engineering and Performance, Vol.3, No.3, 1994, pp.356-366

[29] H. Iizuka, M. Tanaka, Effect of heat treatment on precipitation behaviour and high temperature strength in a wrought Co-base superalloy, Journal of Materials Science, Vol.21, No.3, 1986, pp.2803-2811

[30] M. Tanaka, H. lizuka, M. Tagami, Effects of grain-boundary configuration on the high-temperature creep strength of cobalt-base L-605 alloys, Journal of Materials Science, Vol.24, No. 7, 1989, pp.2421-2428

[31] M. Tanaka, H. Iizuka, F. Ashihara, Improvement of creep-rupture properties of wrought cobalt-based HS-21 alloys at high temperatures, Journal of Materials Science, Vol.24, No.5, 1989, pp.1623-1628

[32] M. Tanaka, H. Iizuka, Effects of Serrated Grain Boundaries and Cold Work on the Creep-Rupture Properties of Cobalt-base Superalloy L-605, Zeitschrift fur Metallkunde, Vol.81, No.2, 1990, p.149-152

[33] R.A. Lula, Manganese Stainless Steels, Paris, France: The Manganese Center, 1986

[34] T. Tunnecliffe, "Valve Alloys - What Makes Them So Special?", Automotiverebuilder, [Online] September 1999. Available: www.automotiverebuilder.com/ar/ar99946.htm

[35] Automotive Stainless Steels, Committee of Stainless Steel Producers, American Iron and Steel Institute, Washington, D.C., 1985

[36] R.E. Smallman, R.J. Bishop, Modern Physical Metallurgy \& Materials Engineering. Great Britain: Educational and Professional Publishing Ltd., 1999 
[37] M.E. Kassner, M-T. Pérez-Prado, Fundamentals of Creep in Metals and Alloys, Netherlands: Elsevier Ltd., 2004

[38] J-P. Poirier, Creep of Crystals - High Temperature Deformation Processes in Metals, Ceramics and Minerals, Great Britain: Cambridge University Press, 1985

[39] S.S. Sahay, G.S. Murty, Uncertainty in Separating the Strain Contributions of Sliding and Diffusion in Diffusional Creep, Scripta Materialia, Vol.44, No.5, 2001, pp.841-845

[40] P. Kumar, M.E. Kassner, T.G. Langdon, Fufty years of Harper-Dorn creep: a viable creep mechanism or a Californian artifact?, Journal of Material Science, Vol.42, No.2, 2007, pp.409-420

[41] J. Beddoes, J.G. Parr, Introduction to Stainless Steels, U.S.A.: ASM International, 1999

[42] R.C. Gifkins, Grain-boundary Participation in High-temperature Deformation: An Historical Review, Materials Characterization, Vol.32, No.2, 1994, pp.59-77

[43] J. Beddoes, A. Wisniewski, Influence of Grain Boundary Morphology on Creep of a Wrought Ni-Base Superalloy, to appear in proceedings of Creep 2008, May 2008

[44] H.J. McQueen, N.D. Ryan, E.V. Konopleva, X. Xia, Formation and Application of Grain Boundary Serrations, Canadian Metallurgical Quarterly, Vol.34, No.3, 1995, pp.219-229

[45] D-W. Suh, T. Inoue, S. Torizuka, A. Ohmori, K. Nagai, Serration of Grain Boundary in Ni-30Fe Alloy through High Temperature Deformation, ISIJ International, Vol.42, No.9, 2002, pp.1026-1032

[46] K.U. Snowden, The Formation of Boundary Serrations and Cavities During High-Temperature Fatigue, Metals Forum, Vol.4, No.1-2, 1981, pp.106-111

[47] V. Raman, Serrated Grain Boundary Formation during High Temperature Fatigue, Metallurgical Transactions A, Vol.17A, No.6, 1986, pp.1100-1102

[48] M.J. Donachie, S.J. Donachie, Superalloys: A Technical Guide, U.S.A.: ASM International, 2002

[49] R. Thamburaj, A.K. Koul, W. Wallace, T. Terada, M.C. de Malherbe, The Influence of Microstructure Upon the Creep and Fatigue Crack Growth Behaviour in Inconel 718, Time-Dependent Fracture, Vol.1, 1985, pp.245-260 
[50] A.K. Koul, P. Au, N. Bellinger, R. Thamburaj, W. Wallace, J-P. Immarigeon, Development of a Damage Tolerant Microstructure for Inconel 718 Turbine Disc Material, Superalloys 1988, The Metallurgical Society, 1988, pp.3-12

[51] K.N. Tu, D. Turnbull, Morphology of Cellular Precipitation of Tin From LeadTin Bicrystals, Acta Metallurgica, Vol.15, No.2, 1967, pp.369-376

[52] A.K. Koul, R. Thamburaj, Serrated Grain Boundary Formation Potential of NiBased Superalloys and Its Implications, Metallurgical Transactions A, Vol.16A, No.1, 1985, pp.17-26

[53] X.J. Wu, A.K. Koul, Grain Boundary Sliding at Serrated Grain Boundaries, Advanced Performance Materials, Vol.4, No.4, 1997, pp.409-420

[54] A.K. Koul, G.H. Gessinger, On the Mechanism of Serrated Grain Boundary Formation in Ni-based Superalloys, Acta Metallurgica, Vol.31, No.7, 1983, pp.1061-1069

[55] A.K. Koul, D.D. Morphy, Serrated Grain Boundary Formation in Nickel-base Superalloys, Microstructural Science Vol. 11. Proceedings of the Fifteenth Annual Technical Meeting of the International Metallographic Society, 1983, pp.79-88

[56] H.L. Danflou, M. Marty, A. Walder, Formation of Serrated Grain Boundaries and Their Effect on the Mechanical Properties in a P/M Nickel Base Superalloy, Proceedings of the Seventh International Symposium on Superalloys, 1992, pp.63-72

[57] H.L. Danflou, M. Macia, T.H. Sanders, T. Khan, Mechanisms of Formation of Serrated Grain Boundaries in Nickel Base Superalloys, Superalloys 1996, The Metallurgical Society, 1996, pp.119-127

[58] J.M. Larson, Carbide Morphology in P/M IN-792, Metallurgical Transactions A, Vol.7A, No.10, 1976, pp.1497-1502

[59] J.M. Larson, S. Floreen, Metallurgical Factors Affecting the Crack Growth Resistance of a Superalloy, Metallurgical Transactions A, Vol.8A, No.1, 1977, pp.51-55

[60] T.M. Maccagno, A.K. Koul, J-P. Immarigeon, L. Cutlet, R. Allem, G. L'Espérance, Microstructure, Creep Properties, and Rejuvenation of ServiceExposed Alloy 713C Turbine Blades, Metallurgical Transactions A, Vol.21A, No.12, 1990, pp.3115-3125 
[61] L. Letellier, M. Guttmann, D. Blavette, Atomic-scale investigation of grainboundary microchemistry in the nickel-based superalloy Astroloy with a threedimensional atom probe, Philosophical Magazine Letters, Vol.70, No.4, 1994, pp.189-194

[62] M. Chang, A.K. Koul, C. Cooper, Damage Tolerance of P/M Turbine Disc Materials, Superalloys 1996, The Metallurgical Society, 1996, pp.677-685

[63] X. Du, P. Au, A.K. Koul, J-P. Immarigeon, Creep Rejuvenation for T56 Series III IN 738 Second Stage Turbine Blades, SMPL-LTR-ST-2136, 1998

[64] J. Safari, S. Nategh, On the heat treatment of Rene-80 nickel-base superalloy, Journal of Materials Processing Technology, Vol.176, No.1-3, 2006, pp.240-250

[65] Edited by W. Betteridge, J. Heslop, Nimonic Alloys and Other Nickel-Base HighTemperature Alloys, Great Britain: Edward Arnold Publishers Ltd., 1974

[66] M.F. Henry, Y.S. Yoo, D.Y. Yoon, J. Choi, The Dendritic Growth of $\gamma^{\prime}$ Precipitates and Grain Boundary Serration in a Model Nickel-Base Superalloy, Metallurgical Transactions A, Vol.24A, No.8, 1993, pp.1733-1743

[67] D.N. Yoon, M.F. Henry, M.R. Jackson, Precipitation Induced Grain Boundary Migration in Austenitic Alloys, Colloque de Physique, No. C-1, 1990, pp.721-726

[68] U.H. Hyun, S.W. Nam, Crystallographic Investigations on the Serrated Grain Boundaries in an AISI 316 Stainless Steel, Zeitschrift fur Metallkunde, Vol.92, No.12, 2001, pp.1331-1334

[69] H.U. Hong, S.W. Nam, The occurrence of grain boundary serration and its effect on the $M_{23} C_{6}$ carbide characteristics in an AISI 316 stainless steel, Materials Science and Engineering, Vol.A332, pp.255-261

[70] H.U. Hong, S.W. Nam, The Effect of Grain Boundary Carbide Characteristics on the Improvement of Creep-Fatigue Properties in AISI 304 Stainless Steels, TMS Annual Meeting, 2002, pp.247-259

[71] H.U. Hong, S.W. Nam, Improvement of creep-fatigue life by the modification of carbide characteristics through grain boundary serration in an AISI 304 stainless steel, Journal of Materials Science, Vol.38, No.7, 2002, pp.1535-1542

[72] K.J. Kim, H.U. Hong, K.S. Min, S.W. Nam, Correlation between the carbide morphology and cavity nucleation in an austenitic stainless steels under creepfatigue, Materials Science and Engineering A, Vol.387-389, 2004, pp.531-535 
[73] K.J. Kim, H.U. Hong, K.S. Min, S.W. Nam, Effects of Modification of the Carbide Characteristics Through Grain Boundary Serration on Creep-Fatigue Life in Austenitic Stainless Steels, Acta Metallurgica Sinica, Vol.17, No.5, 2004, pp.632-638

[74] K.J. Kim, J. Ginsztler, S.W. Nam, The role of carbon on the occurrence of grain boundary serration in an AISI 316 stainless steel during aging heat treatment, Materials Letters, Vol.59, No.11, 2005, pp.1439-1443

[75] M. Tanaka, H. Iizuka, Effects of high-temperature ageing on the creep-rupture properties of cobalt-base L-605 alloys, Journal of Materials Science, Vol.25, No.12, 1990, pp.5199-5206

[76] M. Tanaka, H. Iizuka, F. Ashihara, Creep-rupture properties and grain-boundary sliding in wrought cobalt-base HS-21 alloys at high temperatures, Journal of Materials Science, Vol.27, No.10, 1992, pp.2636-2640

[77] M. Tanaka, Improvement of Creep-Rupture Properties by Serrated Grain Boundaries in High-Tungsten Cobalt-Base Superalloys, Zeitschrift fur Metallkunde, Vol.84, No.1, 1993, pp.51-56

[78] M. Tanaka, Effects of high-temperature ageing on the creep-rupture properties of high-tungsten cobalt-base superalloys, Journal of Materials Science, Vol.29, No.10, 1994, pp.2620-2628

[79] H. lizuka, M. Tanaka, F. Ashihara, Improvement of Fatigue Crack Growth Resistance by Serrated Grain Boundary at High Temperature, Journal of Engineering Materials and Technology, Vol.113, No.1, 1991, pp.9-14

[80] H. lizuka, M. Tanaka, O. Miyagawa, D. Fujishiro, Effect of Grain-Boundary Strengthening on High-Temperature Fatigue in an Austenitic Heat-Resisting Steel, Transactions of the Japan Institute of Metals, Vol.27, 1986, pp.851-858

[81] H. Iizuka, M. Tanaka, Effects of Grain-Boundary Reaction Precipitates on the Initiation and Growth of Short Cracks under High-Temperature, Low-Cycle Fatigue, Transactions of the Japan Society of Mechanical Engineers Part A, Vol.55, No.515, 1989, pp.1469-1473

[82] H. Iizuka, M. Tanaka, H. Ashihara, Improvement of the Fatigue Crack-Growth Property by Grain-Boundary Reaction Precipitates at High Temperatures, Transactions of the Japan Society of Mechanical Engineers Part A, Vol.54, No.503, 1988, pp.1317-1321

[83] H. lizuka, M. Tanaka, H. Ashihara, Improvement of Low-cycle Fatigue Strength by Serrated Grain Boundary, Strength of Metals and Alloys (ICSMA 8) Proceedings of the $8^{\text {th }}$ International Conference, Vol.2, 1988, pp.689-694 
[84] M. Tanaka, H. Iizuka, Grain-Boundary Crack Initiation and Toughening Mechanism in High-Temperature Creep of an Austenitic Cr-Mn-Ni Steel, JSME, 1986, pp.187-192

[85] M. Tanaka, H. Iizuka, F. Ashihara, Effects of serrated grain boundaries on the crack growth in austenitic heat-resisting steels during high-temperature creep, Journal of Materials Science, Vol.23, No.11, 1988, pp.3827-3832

[86] M. Tanaka, H. Iizuka, F. Ashihara, Creep Crack Growth in an Austenitic Cr-NiMn Steel, Journal of Engineering Materials and Technology, Vol.112, No.3, 1990, pp.353-357

[87] M. Tanaka, Creep Crack Growth and Fractal Dimension of the Grain-boundary Fracture in Austenitic 21Cr-4Ni-9Mn Steel, Zeitschrift fur Metallkunde, Vol.88, No.3, 1997, pp.217-224

[88] Edited by J.P. Frick, Woldman's Engineering Alloys, $8^{\text {th }}$ Ed.,U.S.A.: ASM International, 1998

[89] ASM Specialty Handbook: Stainless Steels Book, U.S.A., ASM International, 1996

[90] M. Tanaka, Grain Refinement by Thermal Cycling in High-nitrogen Austenitic Heat-resistant Steels, Zeitschrift fur Metallkunde, Vol.85, No.6, 1994, pp.446-452

[91] M. Tanaka, O. Miyagawa, T. Sakaki, D. Fujishiro, The Effect of the Grain Boundary Reaction on the Creep Rupture Properties of the Austenitic Heat Resisting Steel, Journal of the Iron and Steel Institute of Japan, Vol.65, No.7, 1979, pp.939-948

[92] M. Tanaka, T. Sakaki, O. Miyagawa, The Deformation and fracture of austenitic Heat Resisting Steel with Grain Boundary Reaction Nodules, Vol.13, No.8, 1978, pp.1658-1670

[93] M. Tanaka, O. Miyagawa, D. Fujishiro, The Effect of Alloying Elements on the Grain Boundary Reaction in Austenitic Heat Resisting Steels, Journal of the Japan Institute of Metals, Vol.41, No.1, 1977, pp.11-20

[94] D.A. Porter, K.E. Easterling, Phase Transformations in Metals and Alloys, $2^{\text {nd }}$ Ed., Great Britain: Chapman \& Hall, 1992

[95] M. Tanaka, T. Sakaki, H. Fujita, Effect of the Grain Boundary Reaction on the Notched Creep Rupture Strength of the Austenitic Heat Resisting Steel, Journal of the Iron and Steel Institute of Japan, Vol.67, No.6, 1981, pp.784-790 
[96] H. Fujita, M. Tanaka, O. Miyagawa, Effect of the microstructure on the deformation and fracture behaviour of an austenitic heat resisting steel, Bulletin of the Japan Society of Mechanical Engineers, Vol.23, No.182, 1980, pp.12671274

[97] D’Agostino Racing Website [Online] September 2007. Available: www.dagostineracing.com

[98] ASM Metals Handbook Ninth Edition - Volume 10 Materials Characterization, U.S.A.: American Society for Metals, 1986

[99] LECO Corporation [Online] September 2007. Available: www.leco.com

[100] ASTM E 139-00, Standard Test Methods for Conducting Creep, Creep-Rupture, and Stress-Rupture Tests of Metallic Materials, American Society for Testing and Materials, 2000

[101] ASM Handbook Formerly Ninth Edition, Volume 8: Mechanical Testing, U.S.A.: American Society for Metals, 1985

[102] ASTM E 112-88, Standard Test Methods for Determining Average Grain Size, American Society for Testing and Materials, 1988

[103] M. Evans, Predicting Times to Low Strain for a 1CrMoV rotor steel using a 6- $\theta$ projection technique, Journal of Materials Science, Vol.35, No.12, 2000, pp.29372948

[104] D.R. Hayhurst, D.A. Lavender, N.G. Worley, A. Salim, An assessment of the $\Theta-$ projection method for the representation and extrapolation of creep data for a $1 \% \mathrm{Cr}, 1 / 2 \% \mathrm{Mo}, 1 / 4 \% \mathrm{~V}$ steel tested at $565^{\circ} \mathrm{C}$, International Journal of Pressure Vessels and Piping, Vol.20, No.4, 1985, pp.289-317

[105] S.G.R. Brown, R.W. Evans, B. Wilshire, A Comparison of Extrapolation Technique for Long-term Creep Strain and Creep Life Prediction based on Equations Designed to Represent Creep Curve Shape, International Journal of Pressure Vessels and Piping, Vol.24, No.3, 1986, pp.251-268 


\section{Appendix A: Typical 21-4N Material Properties}

Table 34. Typhed shon time nom and high temperature tensile propertion, $21-4 \mathrm{~V}$

\begin{tabular}{|c|c|c|c|c|c|c|}
\hline Condition & $\begin{array}{l}\text { Test } \\
\text { Temperature } \\
\mathrm{CO}\end{array}$ & $\begin{array}{l}\text { Uitimate } \\
\text { Tensile } \\
\text { Strength } \\
\text { ksi (MPa) }\end{array}$ & $\begin{array}{l}0.2 \% \text { Yikd } \\
\text { Strength } \\
\mathrm{xil}_{\mathrm{M}} \mathrm{MP}_{\mathrm{a}}\end{array}$ & Elong. & $\begin{array}{l}\text { Red. of } \\
\text { atea of }\end{array}$ & $\begin{array}{l}\text { Bardines } \\
\text { Brinell }\end{array}$ \\
\hline Solution & Room & $162(1117)$ & $102(703)$ & 4 & 9 & 344 \\
\hline Treated & $900(-\times 2)$ & $114(780)$ & $58(40)$ & 20 & 21 & 242 \\
\hline and & $11001500)$ & $10 \times(669)$ & $5 .(365)$ & 18 & 24 & 2211 \\
\hline Aged & $1200(650)$ & $86(593)$ & $48(331)$ & 16 & 23 & $20 x$ \\
\hline & $1400(761)$ & $62(427)$ & $37(255)$ & $: 8$ & 25 & 190 \\
\hline & $1600(870)$ & 3812021 & $25(172)$ & 27 & 39 & 177 \\
\hline
\end{tabular}

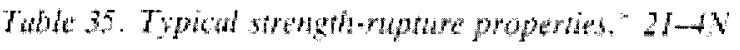

Test

Tempenaturs

F( $\mathrm{C})$

we $(4 x)$

$1100(5) 3)$

$1400)(760)$

\begin{tabular}{ll}
\multicolumn{3}{c}{100 hours } \\
\hline Strugth Elang. Ret. of \\
ksi (MPa)
\end{tabular}

$\sin (68 \mathrm{~s})$

$61424)$

$23(15 s)$
9,11

t.1)

$$
\frac{110.0}{7.0}
$$

\begin{tabular}{|c|c|c|}
\hline \multicolumn{3}{|c|}{ Thto hows } \\
\hline $\begin{array}{l}\text { Strength } \\
\left.\mathrm{B} \times \mathrm{MP}_{\mathrm{i} 1}\right)\end{array}$ & $\underset{\sigma}{E}$ & $\begin{array}{l}\text { ked of } \\
\text { areat } k\end{array}$ \\
\hline
\end{tabular}$$
-
$$

$\begin{array}{lll}83(572) & 8.1 & 90 \\ 50(344) & 5.1 & 5.0\end{array}$

* Material in the whution trested and aged condition

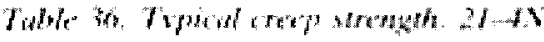

Heat Trestment

$$
\begin{aligned}
& \text { Tist } \\
& \text { lemperattare } \\
& \text { "Fit' (') }
\end{aligned}
$$

Solution

Treeted and

A ped

$$
\begin{aligned}
& \text { IKH) }\{3 k \\
& \text { 1.51 } 1732
\end{aligned}
$$

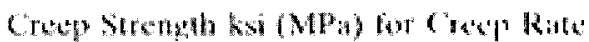
of:

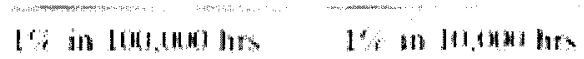

$$
33(227)
$$

$49(357)$

$3.6(25)$$$
7.4(34)
$$

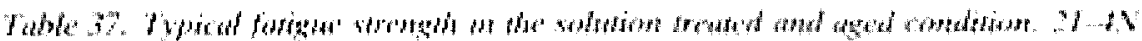

Roum lemperature

Siress, $k+41 l^{\prime}$ )

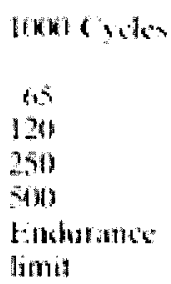

$75(517)$

$(503)$

\begin{tabular}{|c|c|}
\hline $50(344)$ & 21 \\
\hline $4.3(296)$ & $16 \%$ \\
\hline $3 \times(26,1)$ & $S_{434}$ \\
\hline $32(220)$ & 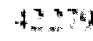 \\
\hline $3(x)$ & 0.25 \\
\hline
\end{tabular}

71 (4k9)

$69 \quad(475)$

$68.5(476)$

$$
\text { limit }
$$

$14 \mathrm{NP}(760 \mathrm{C})$

Strose. ksi MPa

ISKKI Gytles

[33] Lula, R.A., Manganese Stainless Steels, Paris, France: The Manganese Center, 1986 


\section{Appendix B: Metallographic Preparation}

Mount specimen in bakelite and sand off edge on opposite side of specimen surface with belt sander. This will preserve your fingers while holding the sample.

If the sample surface is irregular or coarse, start with the 120 grit belt sander. Place the sample against the belt and apply even pressure. Hold for a few moments and then dip in water to cool the surface. Rotate specimen by $90^{\circ}$ and continue sanding surface until it is flat and all the sanding marks are in the same direction. Remember to continuously cool the sample to avoid possible microstructural changes.

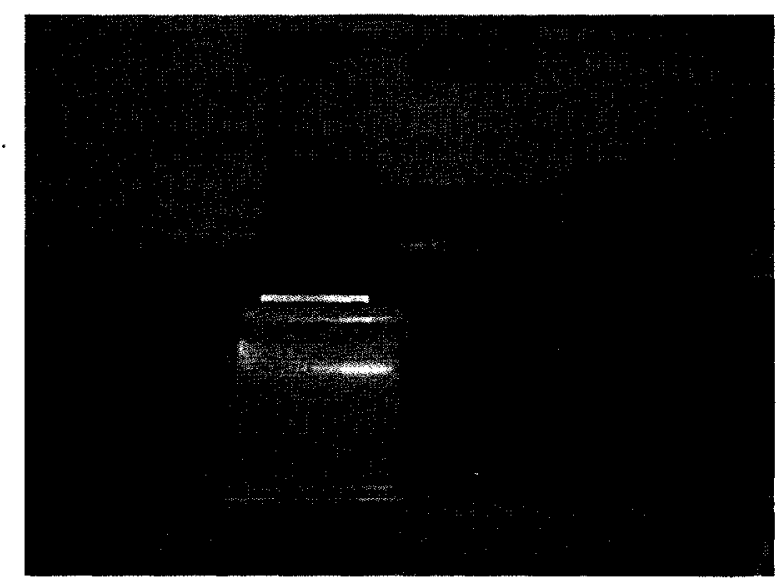

Figure B1: 120grit belt sander for rough sample preparation.

Now proceed to the Handimet Grinder. Replace sanding sheets if necessary. Turn on water flow and begin with the 240 grit sheet. Place the sample on the sheet and push it back and forth on the sheet. Start at the front and push towards the back, then pull back towards the front.

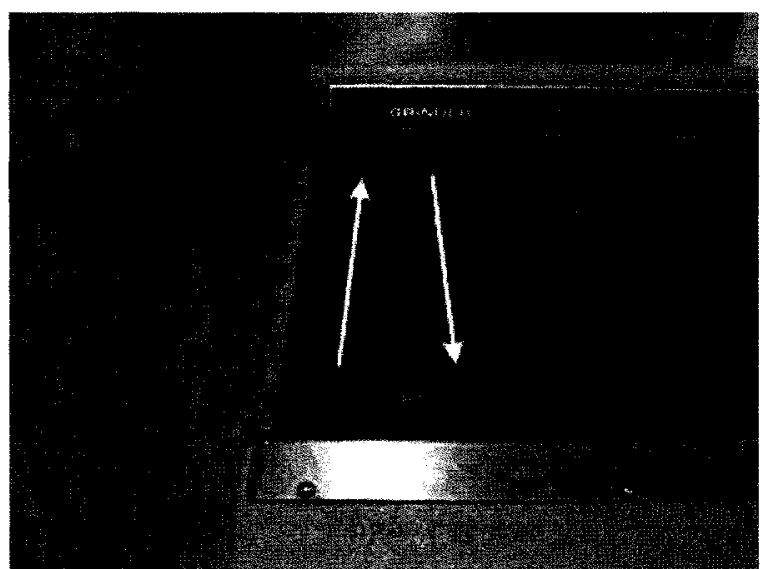

Figure B3: Sample grinding on Handimet Grinder. 
Do ten back and forth strokes and then check the sample surface. If all the sanding lines point in the same direction, rotate $90^{\circ}$ and repeat. Otherwise continue with this orientation. This will ensure a flat specimen surface.

Once grinding is finished after the third $90^{\circ}$ rotation and the sample shows sanding lines are all pointing in the same direction, proceed to 320 grit. This time, just push towards the back and lift the sample to bring it to the front. Do this ten times and check the surface. If all the sanding lines point in the same direction, rotate $90^{\circ}$ and repeat. Otherwise continue with this orientation.

Do the same for the 400 and 600 grits. The procedure is simple but can be time consuming. Always do the four rotations for each level of grit.

Once finished with the 600 grit, rinse the sample surface with water and then use some dish soap to clean it. Rinse the dish soap off and place the sample in a beaker with distilled water and a small amount of acetone. Place the beaker into the ultrasonic cleaner and let it run for $15-20$ minutes. Up to 3 samples fit into an average sized 250 $\mathrm{mL}$ beaker at the same time.

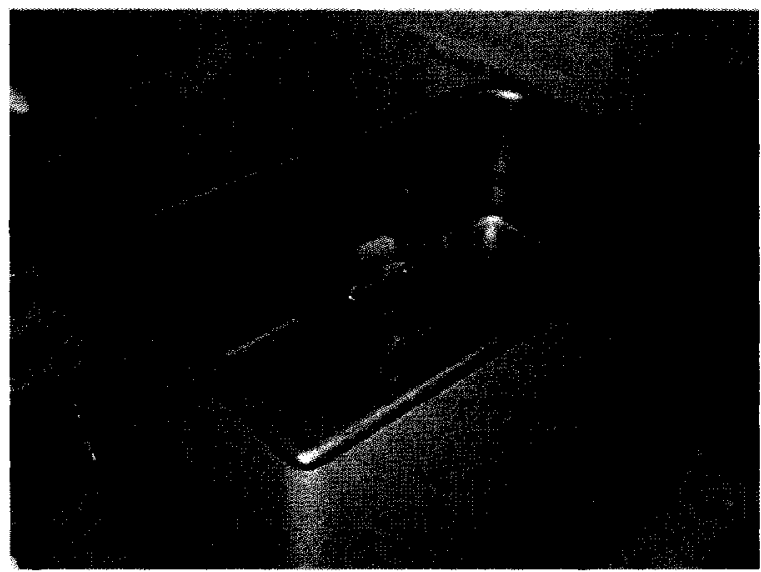

Figure B4: Ultrasonic cleaning of sample.

Once that is done, remove the sample and rinse with water, followed by rinsing with methanol. Blow dry the sample a bit, but it's not necessary to completely dry it. Then rinse with acetone and blow dry completely.

Now comes the diamond polishing step. It is best to wear gloves and a lab coat. This will prevent clothing stains and keep your fingers from becoming raw.

Start with 6 micron diamond polishing compound and a TexMet 2500 polishing cloth. Spray some distilled water on the cloth while it is rotating. Then stop the polishing wheel and apply some polish to the cloth. Use a sample to spread out the polish. 


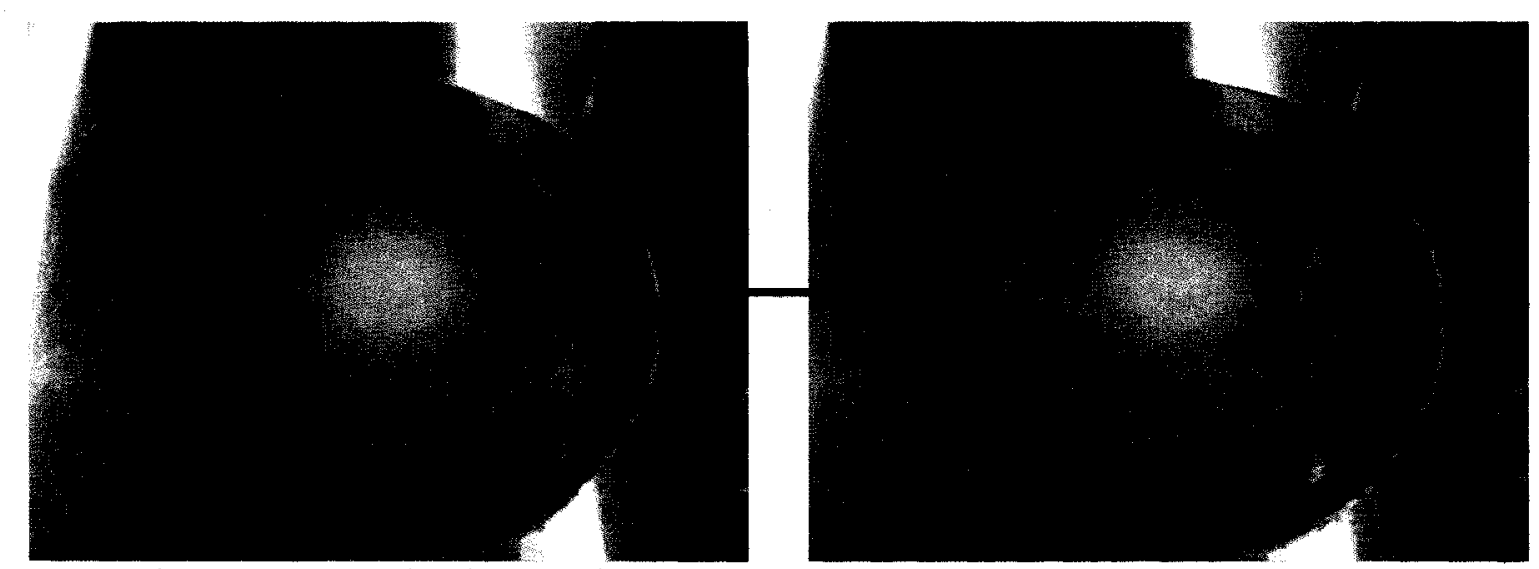

Figure B5: Application of diamond polishing compound onto polishing cloth.

When done, turn on the wheel and apply the sample to the cloth. Move the sample on the cloth against the rotation and slide it from the inside to the outside of the wheel continuously.

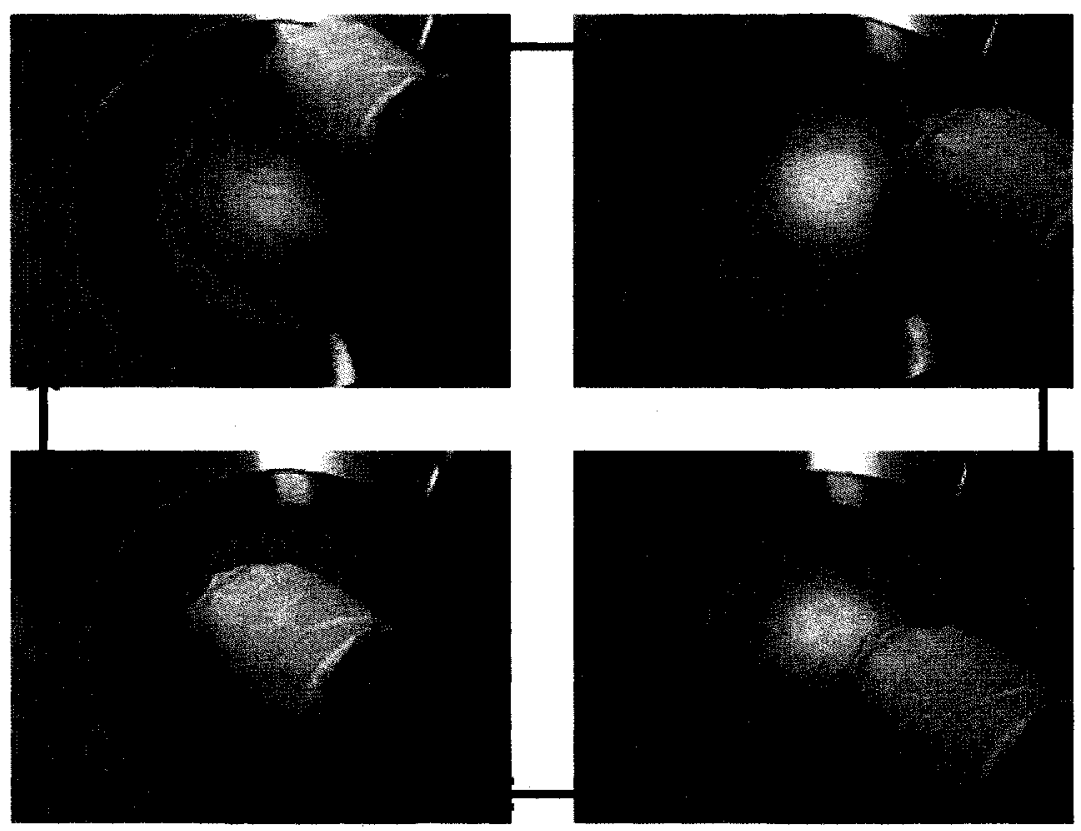

Figure B6: Sample polishing with diamond polishing compound.

Keep the sample moving like that for 60 seconds. Then check the sample surface. The sample should be mirror-like with some hard to see fine scratches. All traces of the 600 grit should be gone. It may be necessary to turn the sample $180^{\circ}$ and do it for another minute.

While polishing, spray distilled water onto the cloth every $20-30$ seconds. Also, polish 4-5 samples before removing the polishing wheel and rinsing it under water. Then apply more polish and continue with the remaining samples. After each sample is 
polished, rinse it carefully under water. The 1 micron procedure is identical to the 6 micron polishing procedure. If it seems that the sample is becoming more scratched from the 1 micron polishing, just add a little more polish and water. Again rinse the samples thoroughly after polishing.

The 0.3 micron alumina is the final polishing step. The alumina powder is mixed with water and needs to be thoroughly shaken before use. The polishing cloth is different for the alumina as it has large naps.

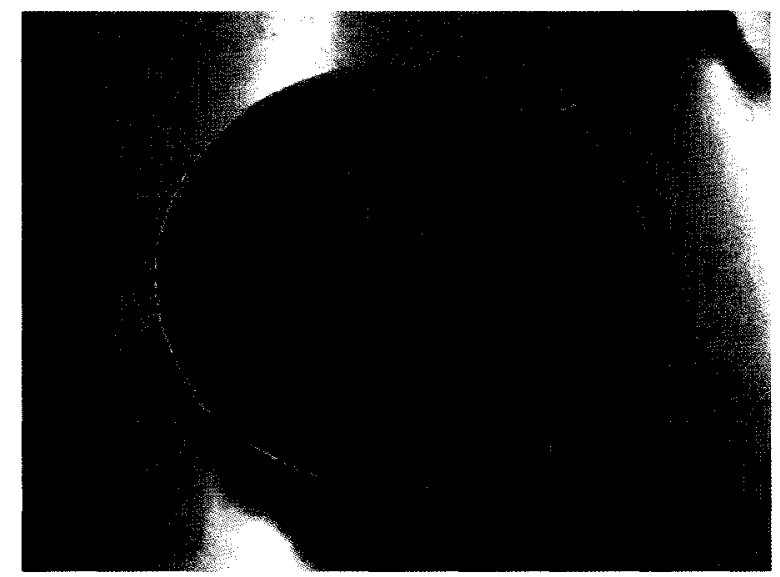

Figure B7: Microcloth for polishing with alumina.

Generally, about 30 seconds of moving the sample side to side is required. If need be, rotate the sample $180^{\circ}$ and polish for another 30 seconds. Rinse samples afterwards. The surface should be like a mirror with no scratches.

Now comes the final cleaning. Rinse the sample with water and apply dish soap. Use Kim Wipes to clean the soapy surface. Rinse again with water and place in a beaker with acetone and distilled water. Again ultrasonically clean for $15-20$ minutes. When done, rinse with water followed by methanol. Blow dry and rinse with acetone. Completely blow dry and store in a sealed container to await etching. 


\section{Appendix C: Creep Testing Procedure}

Preparing for a creep test involves an assortment of steps; not all of which are always necessary.

Going from top to bottom you start with balancing the lever arm. It is necessary to remove the effect of the load support from the testing load. Do this by installing a single connecting rod with a mounted specimen grip. Then move the weight on the lever arm until it is balanced. It is not always necessary to check the balance of the lever arm though it should be done periodically.
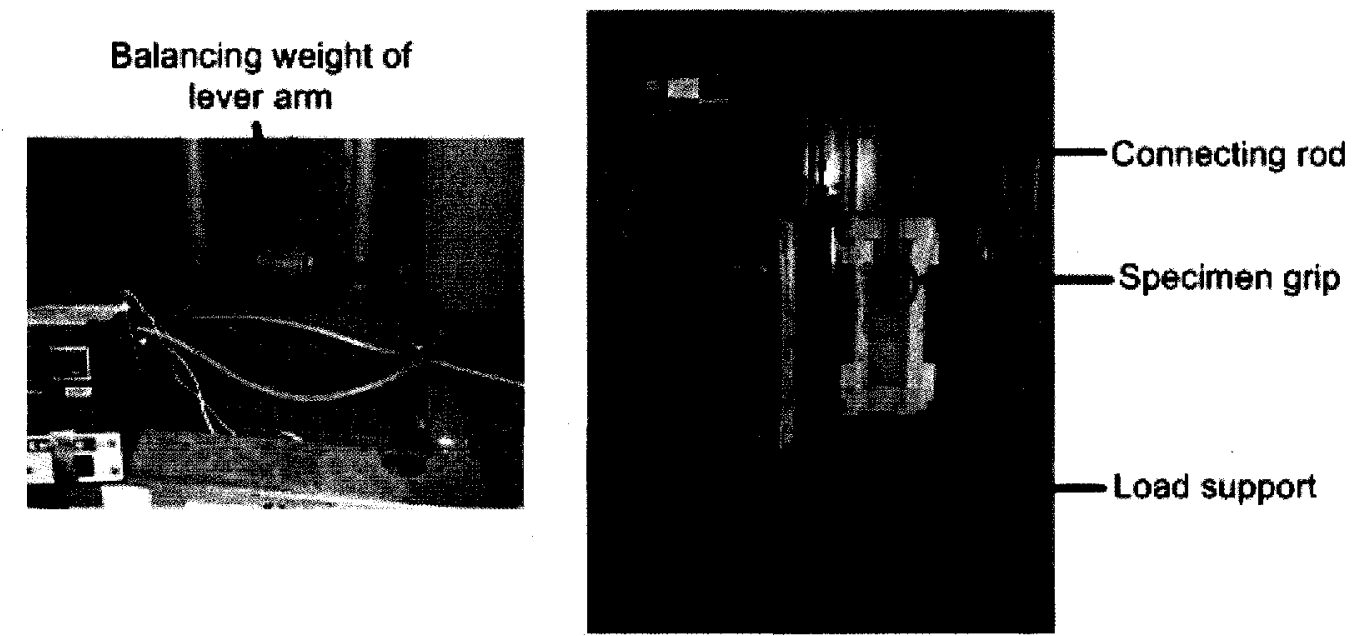

Figure $\mathrm{C} 1$ : Balancing of load train.

Next ensure the level sensing arm is fully functional. Do this by moving it up and down, ensuring that it can move freely without any obstruction except for the lever arm.

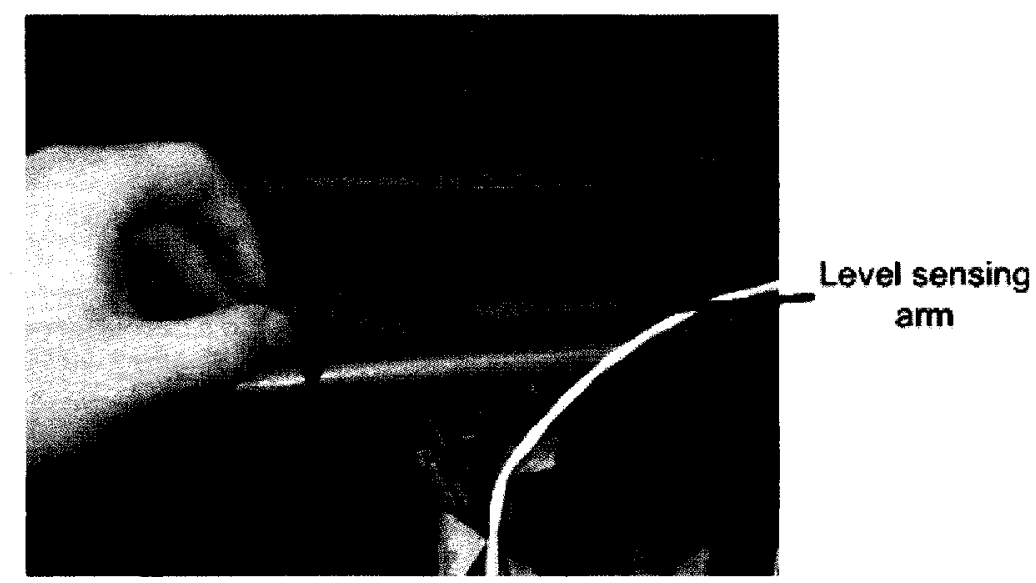

Figure C2: Testing the level sensing arm. 
Turn on the main furnace power. Then use the metal cord attached to the level sensing arm to lower and raise the arm. A series of 'clicks' should be heard as the arm is put through its range of motion. This level sensor controls a switch located in the bottom of the creep frame. It is the switch which produces the 'clicks'.

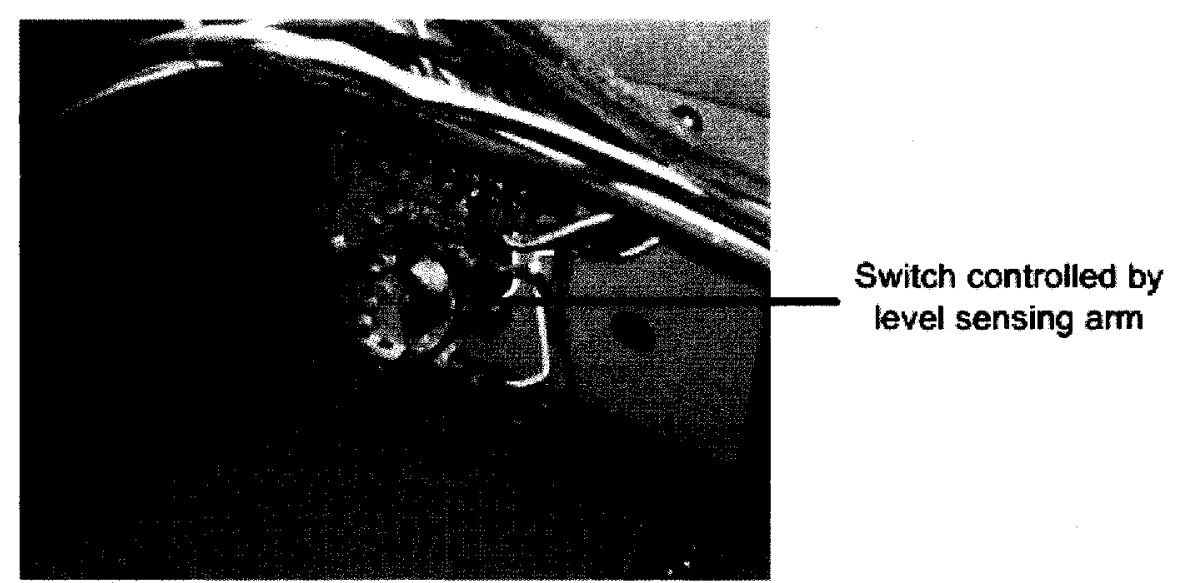

Figure C3: Creep frame power switch controlled by the level sensing arm.

When the level sensing arm is roughly horizontal, the switch is "on", allowing power to flow to the furnace. When the sensor is down left, or rotated counter-clockwise from the horizontal, it turns the switch "off". No power is available to the furnace then. This ensures that when the creep sample physically breaks and the lever arm drops, the furnace will immediately shut off.

The level sensing arm also controls the load train draw head. The draw head is connected to a motor through a chain drive. It pulls on the load train to lift the load and bring the level arm to a horizontal position. As the specimen creeps, the lever arm will lower left. The level sensing arm ensures the lever arm stays horizontal by activating the draw head as needed for extremely brief periods of time.

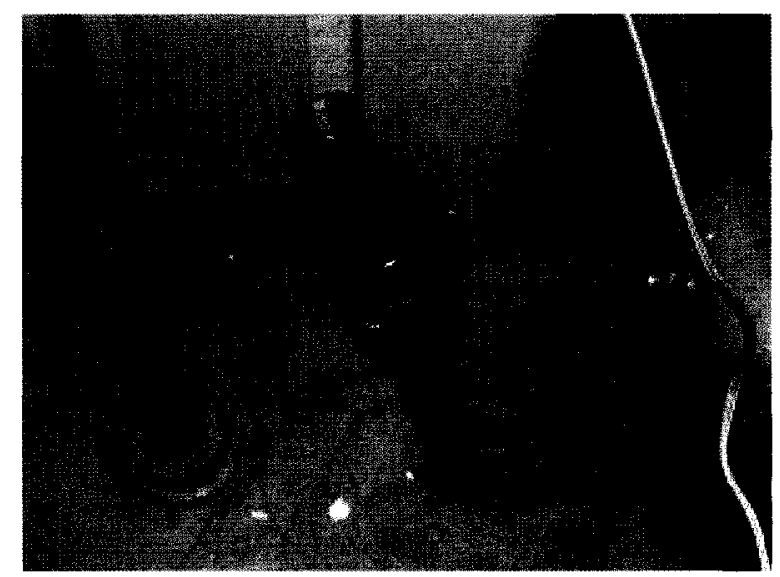

Figure C4: Load train draw head. 
Make sure the level sensing arm is functioning properly before proceeding any further. Once that is done, remove the connecting rod used for balancing the lever arm. Then it is necessary to ensure the threaded load train connections are sufficiently lubricated. Inspect the connections and remove them to clean and lubricate if necessary. Due to the heat from the furnace, use a high temperature anti-seize compound such as Nikal.

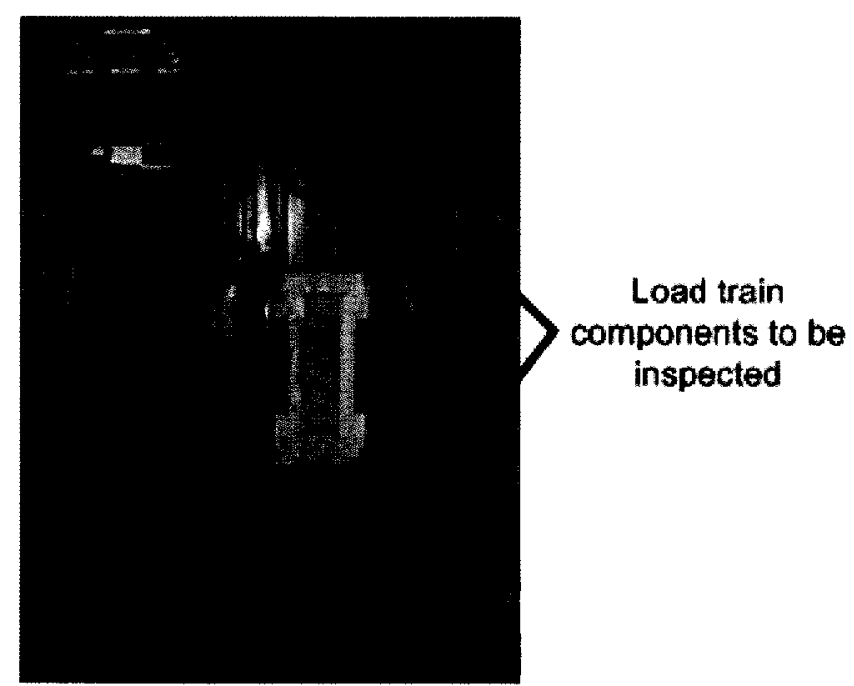

Figure C5: Load train components to be inspected and cleaned/lubricated if necessary.

The only connections that actually need to be cleaned with a wire brush are the couplings that the connecting rods thread into. Here foreign materials are introduced as the rods are removed and installed. Also, the linear couplings should have extra lubricant packed in on both sides if necessary.

Reassemble the load train components and reinstall into the creep frame. Check that the control thermocouple is firmly secured in the furnace. If the control thermocouple were to shift during the test startup or during the actual test, the temperature would likely change rapidly inside the furnace.

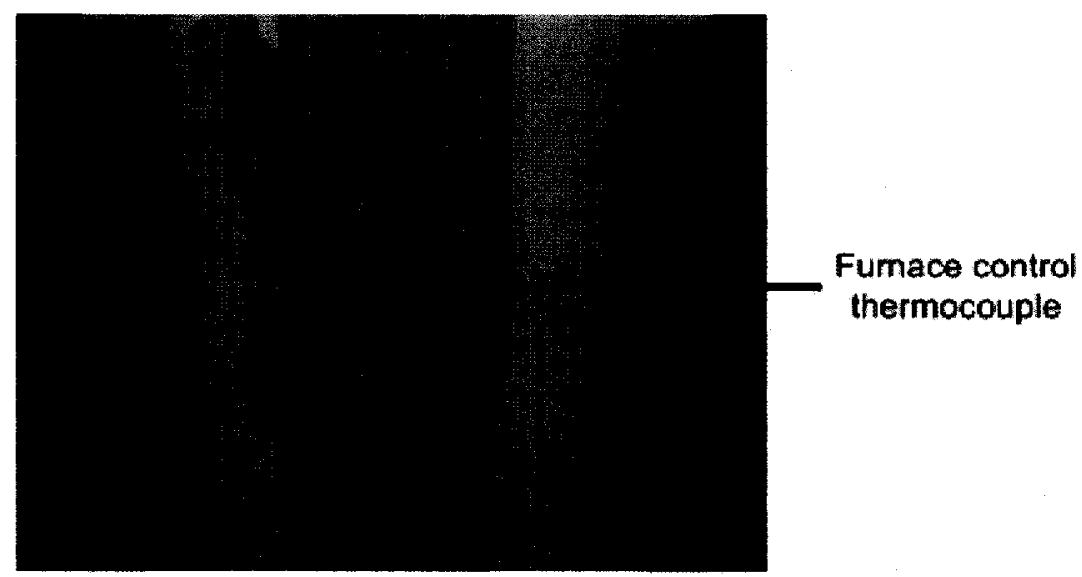

Figure C6: Furnace control thermocouple must be firmly secured. 
Now the creep specimen can be mounted into an extensometer. Before this is done the sample must be inspected and certain dimensions measured in order to calculate the gauge length and mass of load required for the test. The sample inspection involves checking for surface defects such as severe scratches as well as possible dirt and oil from the machining process. Next the sample needs to be measured in certain areas, as shown in Figure C7.

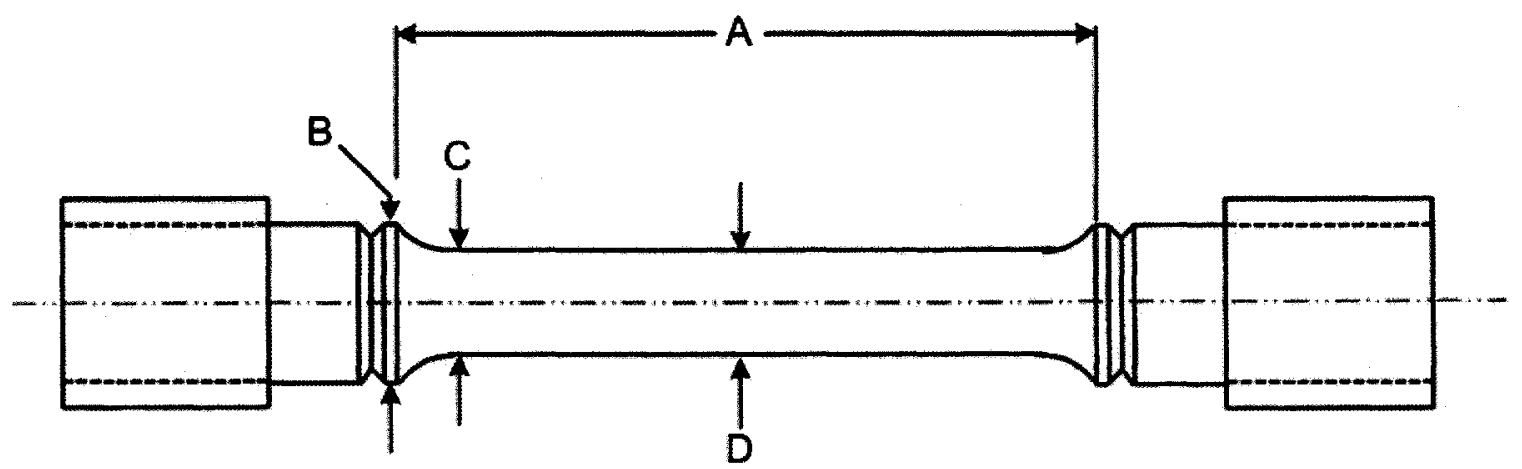

Figure C7: Creep sample dimensions to be measured.

A number of measurements need to be taken for each dimension and the average used. Dimension A is the most difficult to measure while dimension D is critical to obtain as accurate a load as possible.

Dimension D can be input into a built in load calculator in the LabView data acquisition user interface (refer to Figure C8). The built in load calculator can calculate the required mass $(\mathrm{kg}$ ) for a desired stress (MPa) based on a gauge diameter (inches). It can also calculate the resulting stress from a load mass. Refer to Appendix D for more information about the LabView data acquisition system.

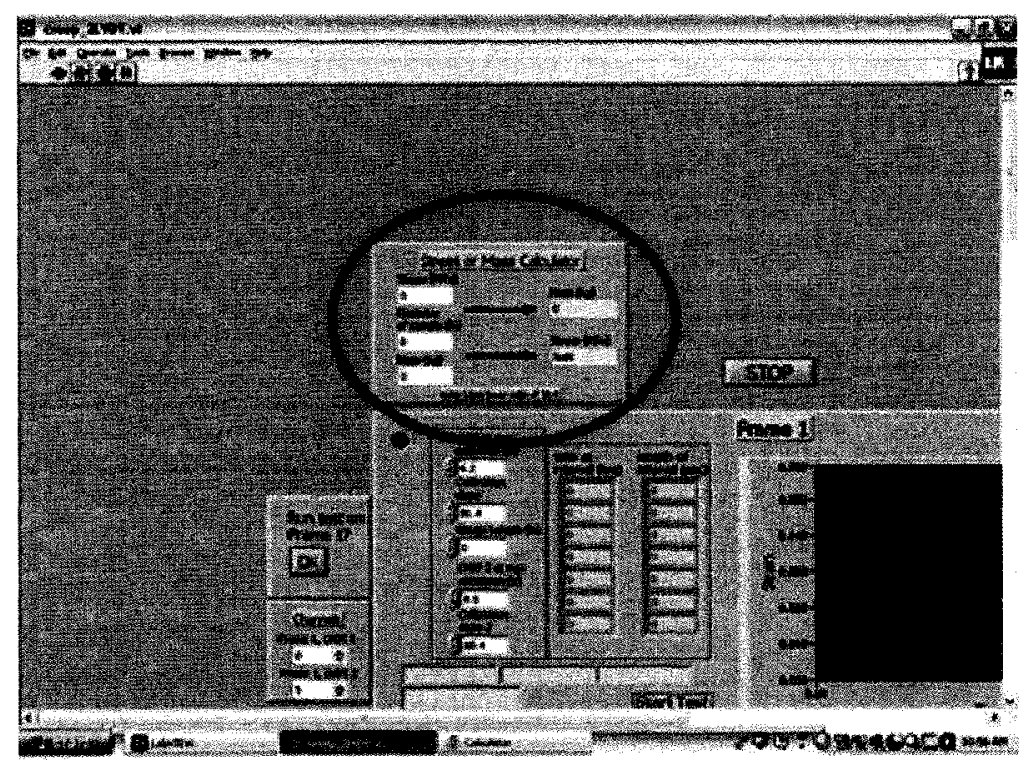

Figure C8: Built in load calculate in the LabView data acquisition user interface. 
Dimensions A, B and C are used to calculate the specimen gauge length. The gauge length in inches is calculated with the following equation:

$$
\text { Gaugelength }=A-2\left[(5 / 16)^{2}-\left((5 / 16)-\left(\frac{B-C}{2}\right)\right)^{2}\right]^{1 / 2}
$$

Equation $\mathrm{C} 1$ is valid for the specimen geometry shown in Section 5 , where the $5 / 16$ is the round radius in inches that tapers the specimen from its shoulders to the gauge length. This equation can be used on other sample sizes as long as they are similar to the geometry shown in Section 5 . The only change required is to replace the $5 / 16$ " round radius to the value of the alternate geometry.

Proceeding onto the installation of the specimen into the extensometer, remove the nuts at the top end of the extensometer and inspect the knife edges. If the knife edges are still sharp enough to properly fit into the grooves machined in the specimen shoulders, install the specimen into the extensometer (refer to Figure C9). Otherwise it will be necessary to replace the knife edges.

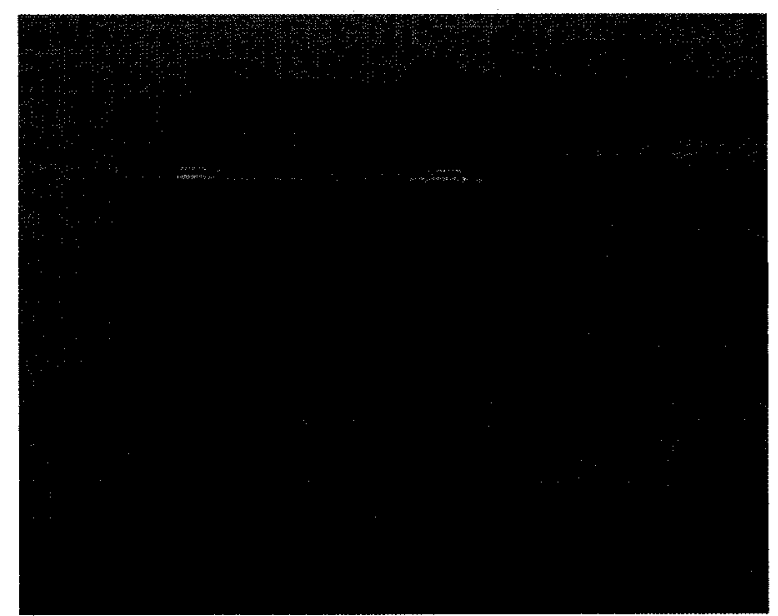

Figure C9: Test specimen being installed into an extensometer.

Replacing the knife edges is fairly simple, involving a $1 / 8$ " pin being hammered to push the knife edges out. Refer to Figure C10. 


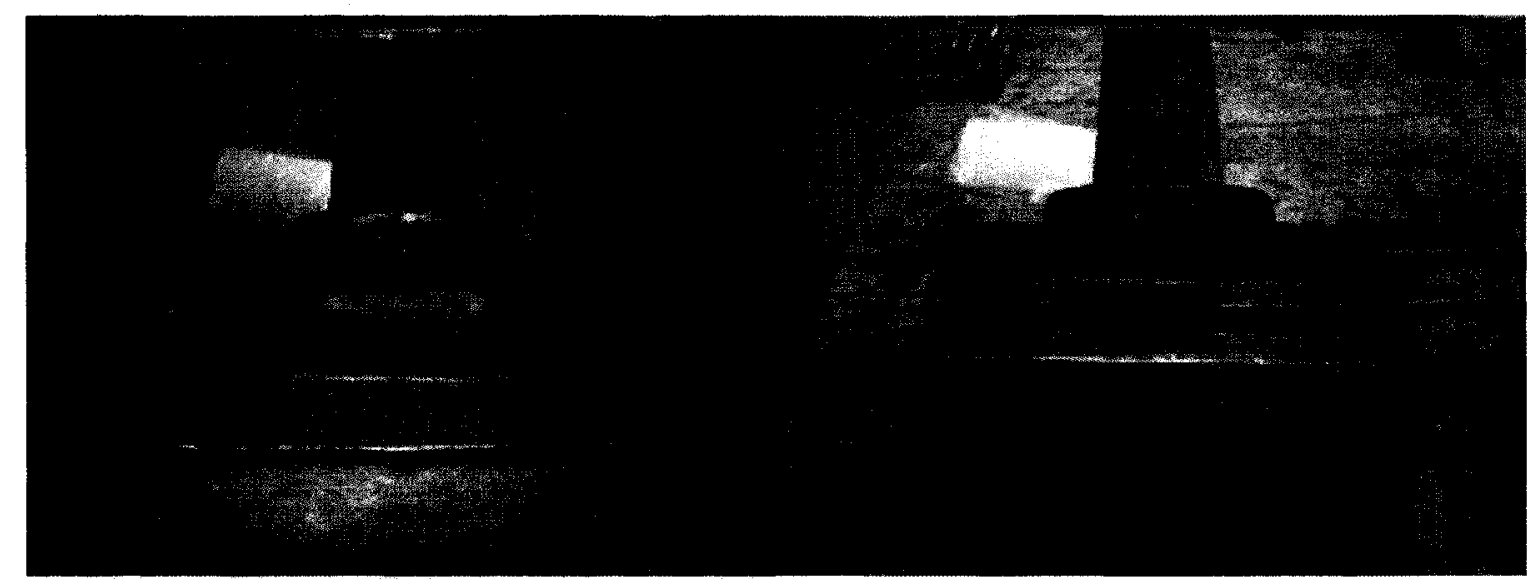

Figure C10: Removal of knife edges with $1 / 8$ " pin driven by a hammer.

If the knife edges are particularly seized, it may be necessary to use a press to remove them. Use the custom built jig to hold the extensometer parts in place while the press pushes the $1 / 8$ " pin to remove the knife edge (refer to Figure C11).

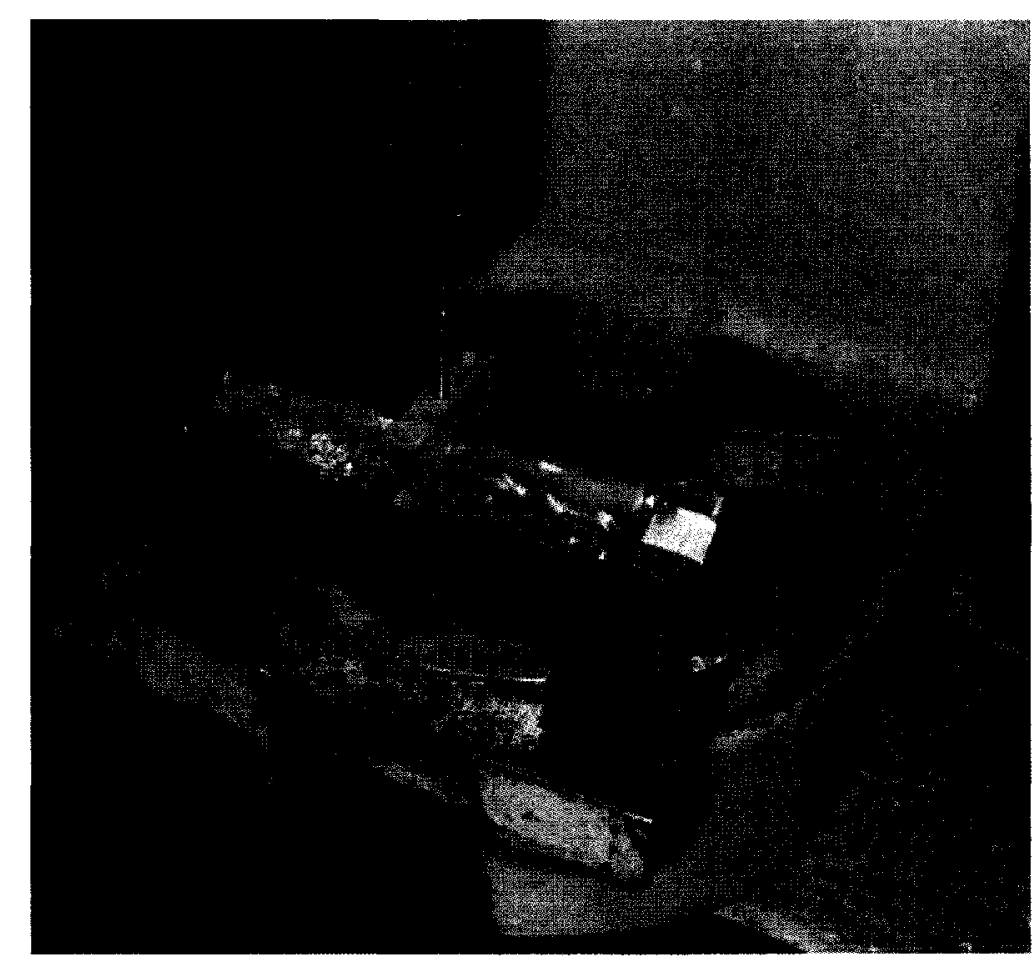

Figure C11: Removal of knife edge with $1 / 8$ " pin with press using custom jig.

Installing new knife edges requires mounting the extensometer parts into a vise and hammering them in.

After a specimen has been installed, take the extensometer to the creep frame in order to test fit the LVDT. Adjust the micrometer holder until it is just at the tip of the 
LVDT. Make sure the micrometer is completely unscrewed or that the tip is pulled back. This will ensure the sample will creep beyond the range of the LVDT before the micrometer holder makes contact with the extensometer body. Refer to Figure C12. Now is also a good time to calibrate the LVDT if this has not already been done (refer to Appendix D).

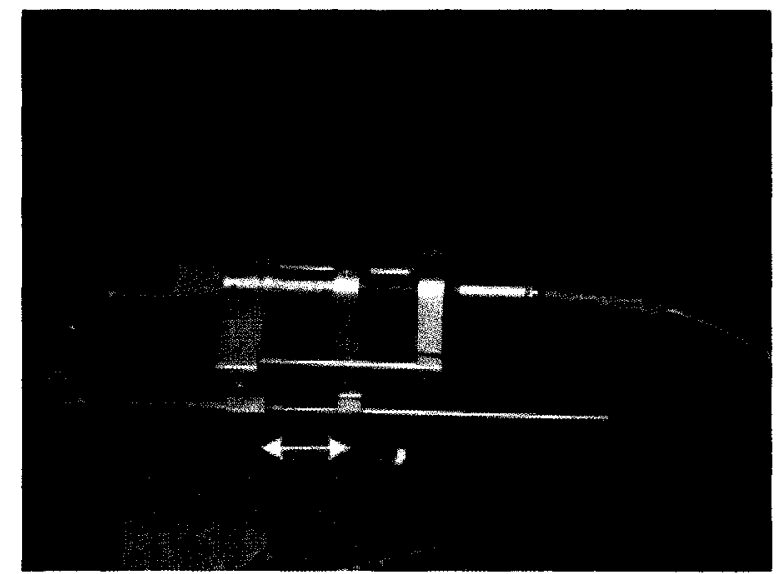

Figure C12: Test fitting LVDT to adjust micrometer position.

Once the LVDT has been test fit in the extensometer, remove the LVDT and the specimen from the extensometer. Check the ease with which the extensometer slides (refer to Figure C13).

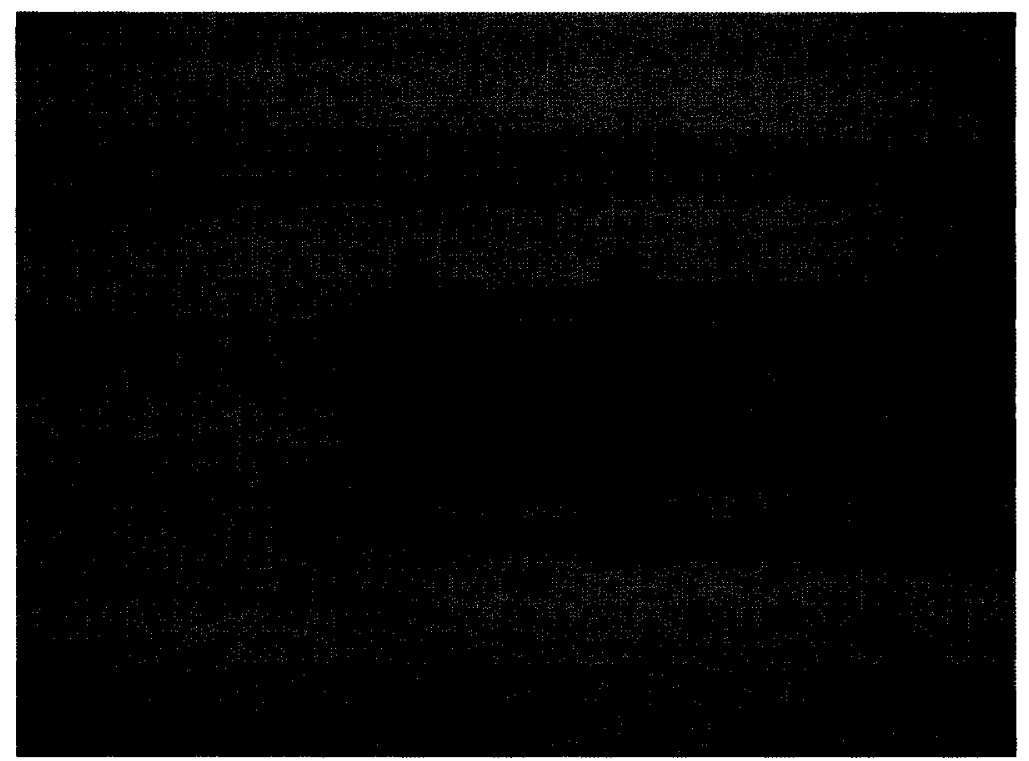

Figure C13: Testing ease with which extensometer slides.

If the extensometer does not slide freely, it may be due the micrometer mount being too tightly secured, the upper extensometer assembly rods may not be straight and there may be oxidation products in the extensometer body (refer to Figure C14). 


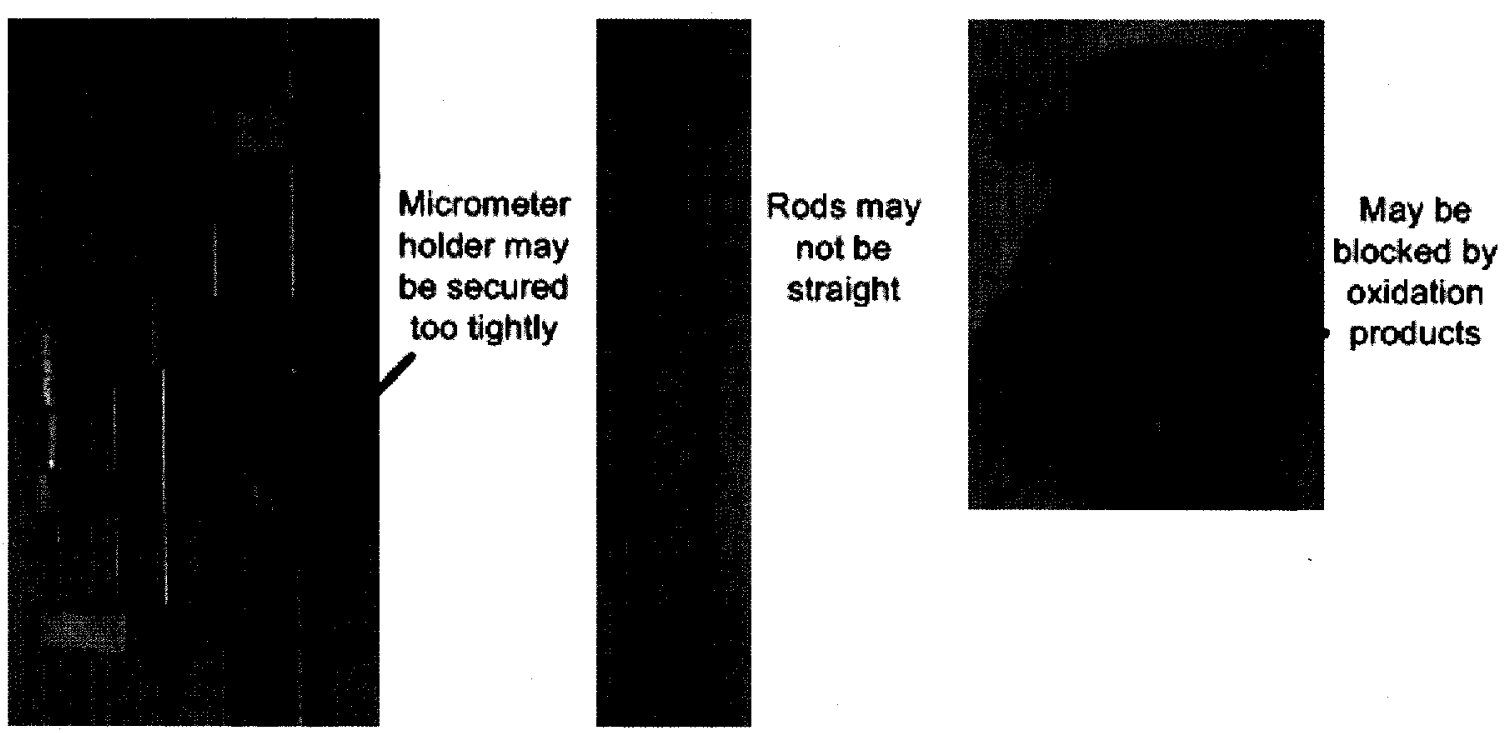

Figure C14: Possible causes for extensometer sliding friction.

Once the extensometer slides freely, get two specimen grips and two connecting rods.

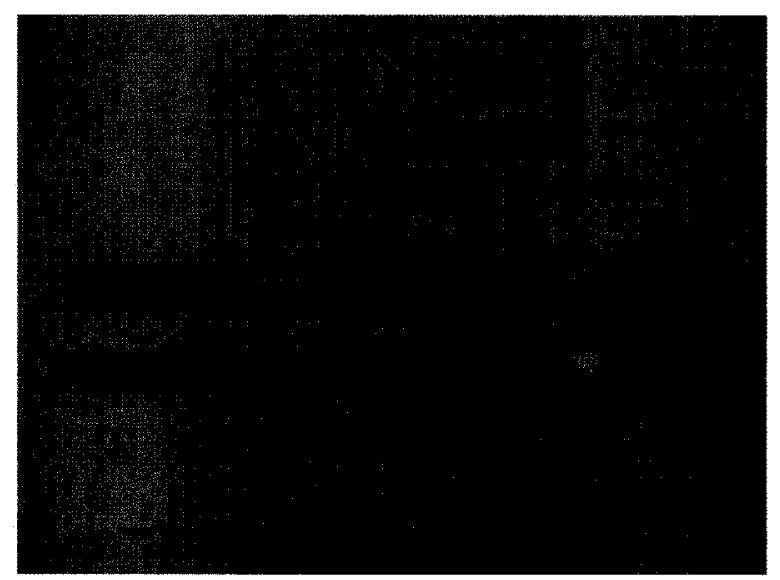

Figure C15: Connecting rods and specimen grips.

Test fit the specimen into the specimen grips; cleaning them if necessary. Try to avoid cleaning them though; to keep the residual anti-seize compound in place. Apply Boron Nitride anti-seize compound to the specimen threads and to the connecting rod ends that will thread into the specimen grips. Also apply some inside the threads of the specimen grips. Do not apply too much or too little. The Boron Nitride at times needs to be diluted with water to ensure it is not too viscous. Its consistency should be such that it is easy to apply a thin and even coat on all the surfaces. Shake and/or stir before using. 
Carefully thread the specimen grips onto the connecting rods. Then thread the sample into one of the specimen grips and mount it into the extensometer, with the connecting rod going into the lower part of the extensometer (refer to Figure C16).

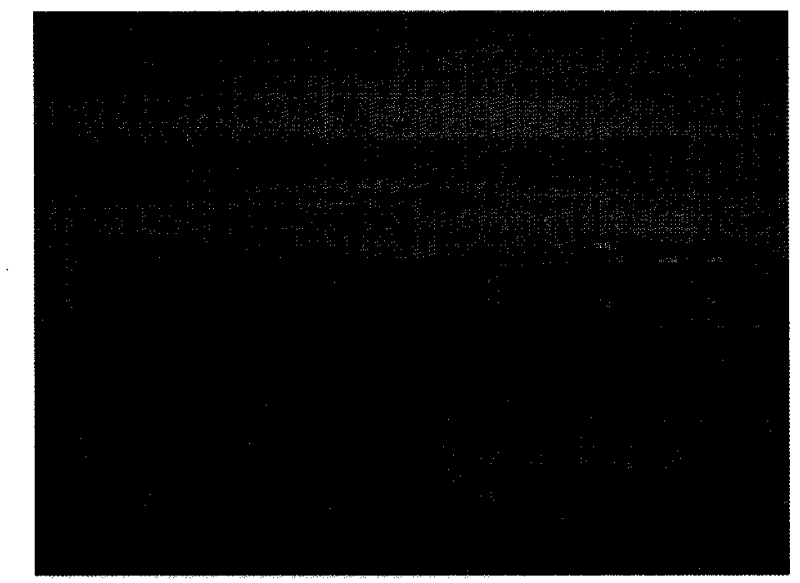

Figure C16: Specimen installed in extensometer.

Ensure the knife edges are properly seated in the specimen grooves. Thread the other specimen grip onto the sample and place the assembly on its side. Use objects to keep the upper connecting rod level with the specimen and weights to ensure the extensometer remains on its side (refer to Figure C17).

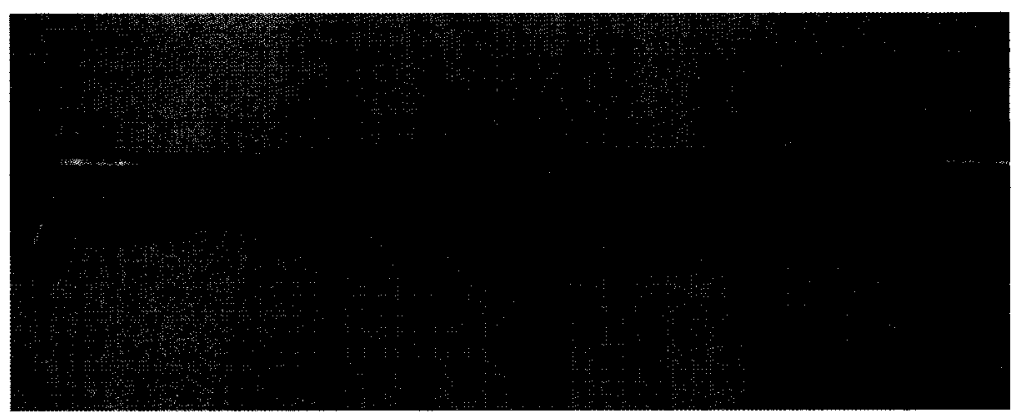

Figure C17: Specimen installed in extensometer with both connecting rods attached.

Test the thermocouples that will be attached to the top and bottom of the specimen. Cut several lengths of wire, $\sim 5-6$ " long each. Start by threading a piece of thermocouple wire through the top thermocouple tip and secure it to the top of the specimen. Then use another wire to secure the thermocouple to the top connecting rod. 


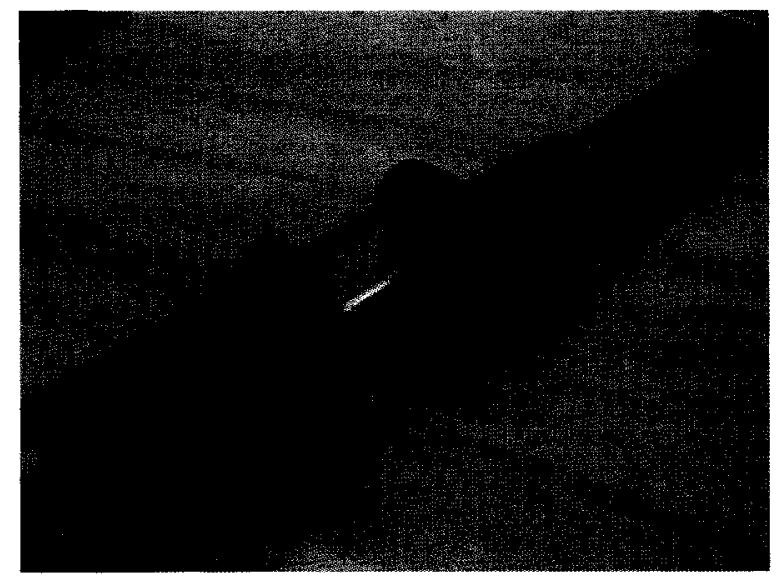

Figure C18: Thermocouple attached to top of specimen and secured to specimen grip with thermocouple wire.

Do the same thing with the second thermocouple by attaching it to the bottom of the specimen. Give the bottom thermocouple more slack when attaching it to the connecting rod so that it may slide freely when the sample creeps.

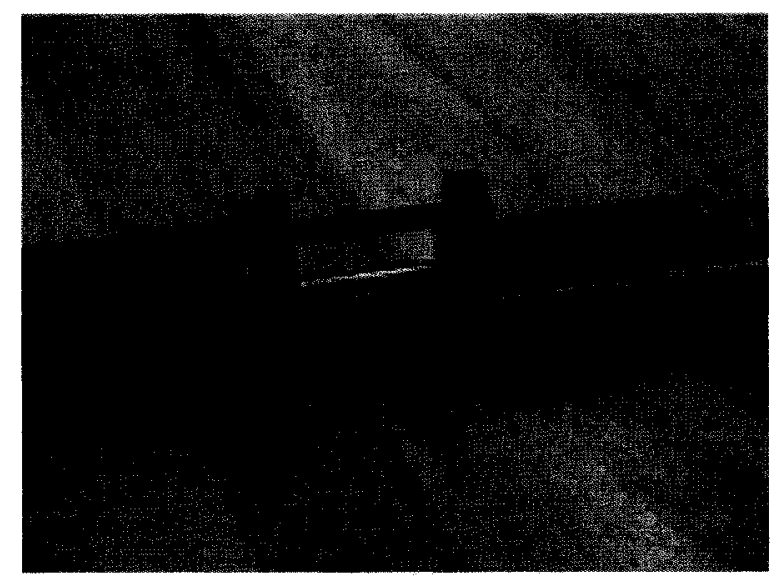

Figure C19: Thermocouples attached to top and bottom of specimen and secured to specimen grip with thermocouple wire.

Finally secure both thermocouples near the top of the connecting rod. 


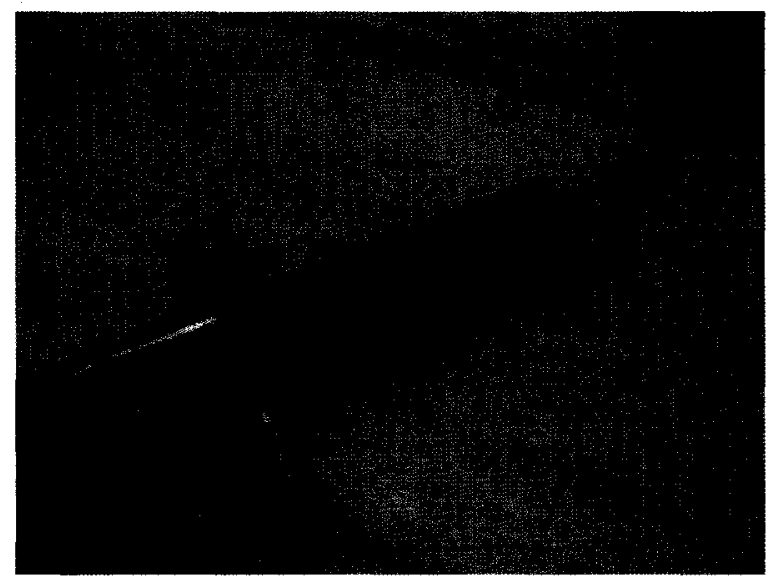

Figure C20: Thermocouples secured to top connecting rod with thermocouple wire.

Install the test assembly into the creep frame. Connect the thermocouples to the Omega DP462 Thermometer. Ensure that the top thermocouple is connected to \#1, and the bottom to \#2. The connectors on the thermometer are labeled accordingly.

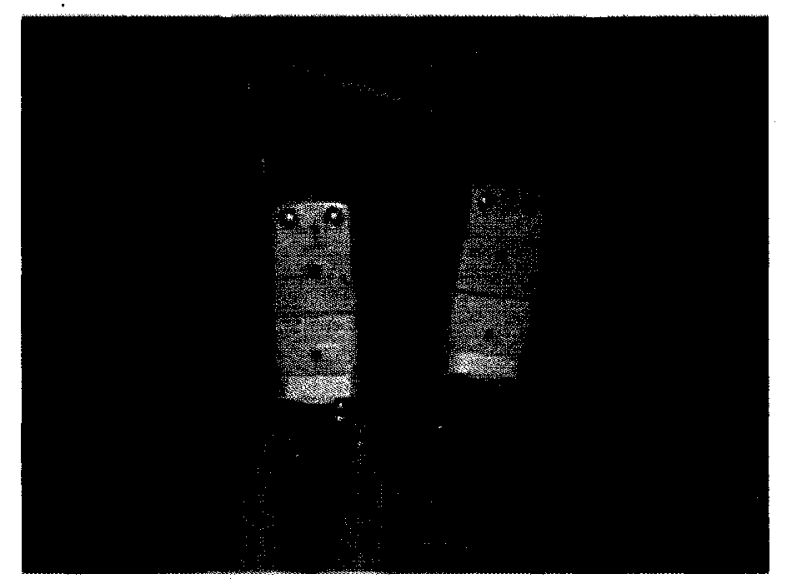

Figure C21: Thermocouples attached to Omega DP462 Thermometer.

Next, get a handful of small flat metal weights as well as one of the largest weights that will be needed for the sample load. For the specific specimen being used to demonstrate this procedure, a load of just over $5 \mathrm{~kg}$ was needed. The closest weight to that available was $4.179 \mathrm{~kg}$. The small assorted weights will be used to support the sample load before the test is started. Place enough of the weights under the load support so that as the lever arm is lowered, a single 'click' is heard followed shortly by the load support resting on the support weights. Then the largest load weight can be placed on the load support to keep it in place. 


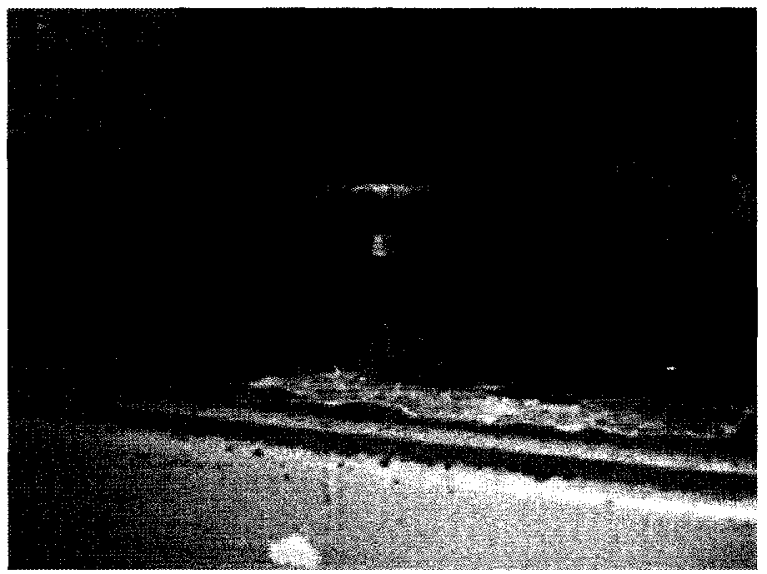

Figure C22: Load support arm positioned in place.

This will allow activation of the furnace, bringing the specimen up to temperature and then attaching the draw head to the load train. The placement just below one 'click' of the level sensing arm means that the lever arm is very close to level, so that the draw head will not need to run for long before it can lift the weights to the proper position.

Next it is necessary to center the furnace with the sample. Align the control thermocouple with the center of the sample. A bit of eyeballing is necessary. Use a $3 / 16$ " allen key to adjust the position of the furnace on the support shaft.
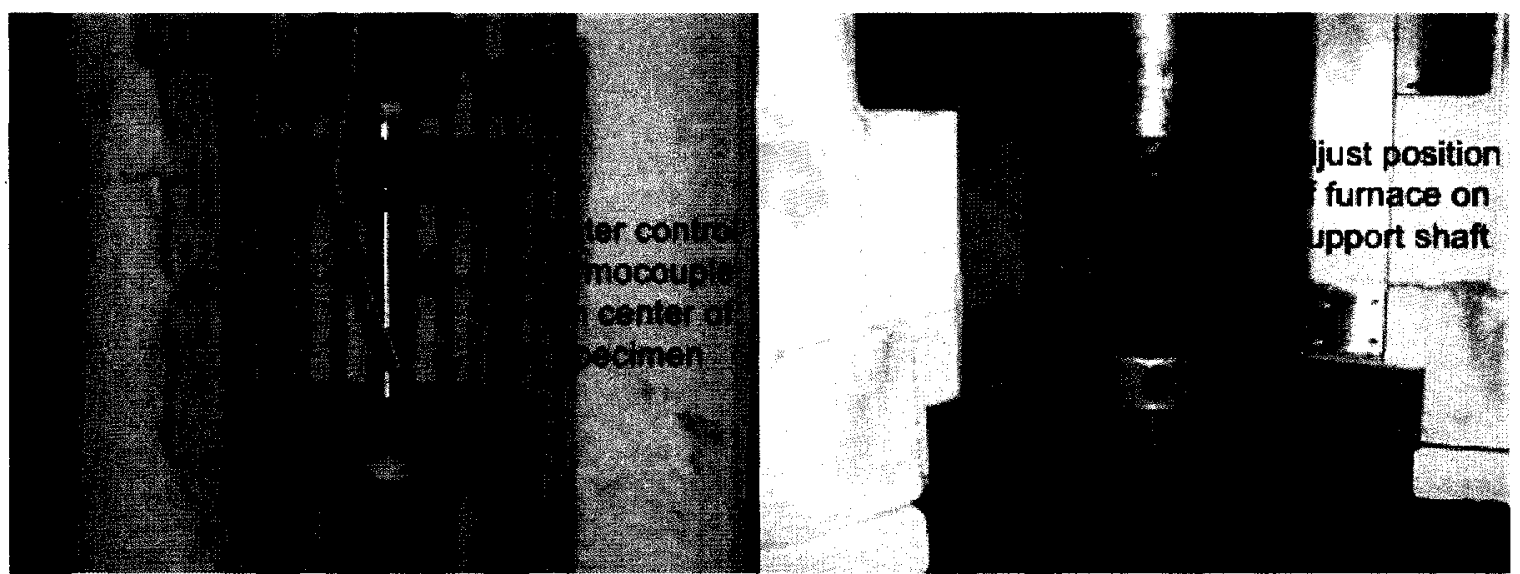

Figure C23: Centering control thermocouple with specimen by adjusting furnace position on support shaft.

Now the furnace can be insulated and closed. Start by placing insulation at the bottom of the furnace opening. 


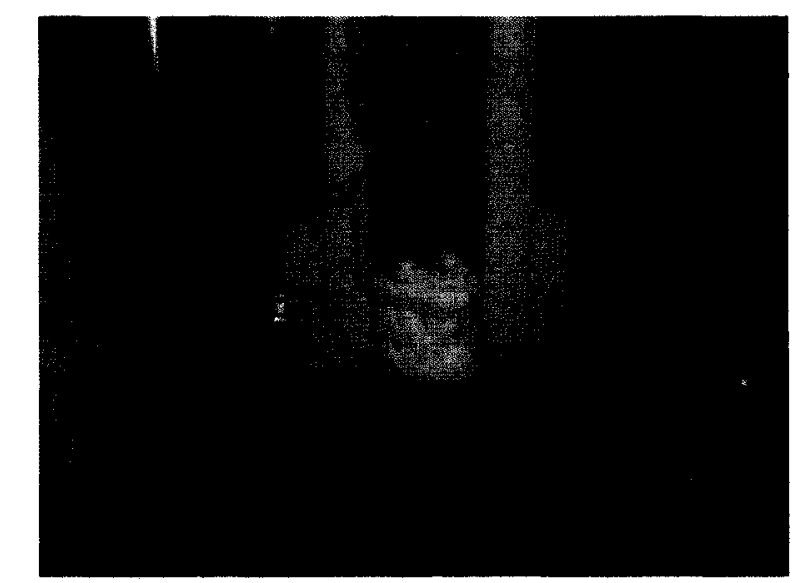

Figure C24: Insulate bottom of furnace opening.

Next, close the furnace carefully and make sure the bottom insulation remained securely in place. Then use the latches to secure the furnace shut. Insulate the top opening in layers.

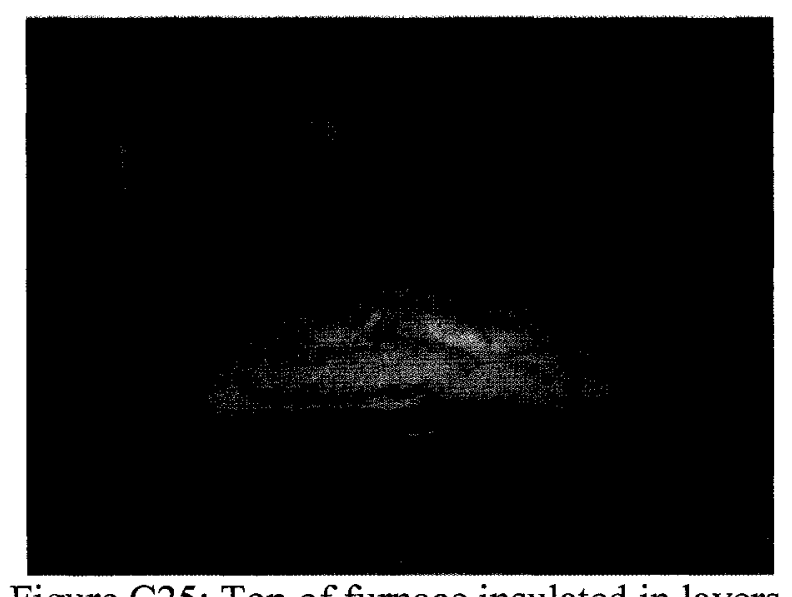

Figure C25: Top of furnace insulated in layers.

Once that is done, turn the "Main Switch" on, and then turn the "Controller" on. Then press the 'Process Variable/Set Point' button on the controller and use the "Incr" and "Decr" buttons to set the first temperature about $150-200^{\circ} \mathrm{C}$ below the test temperature. Then wait 4 seconds and press the Process Variable/Set Point' button again. Turn the "Controller" off and then on again to speed up the furnace start (refer to Figure C26). 


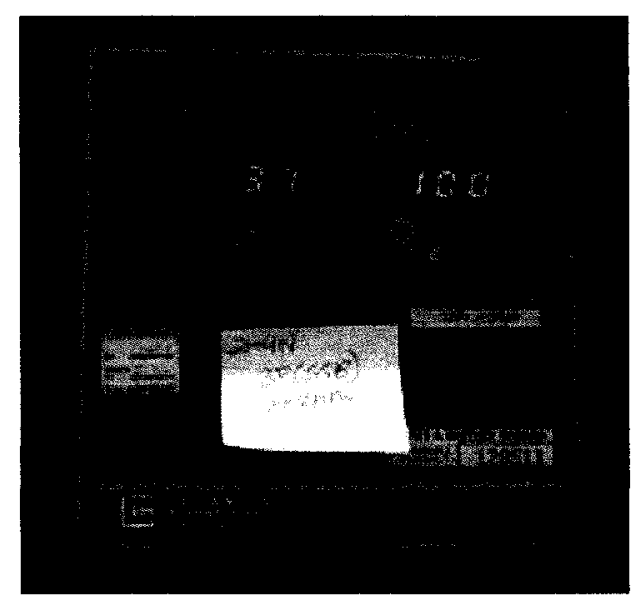

Figure C26: Furnace controller.

While the furnace begins to heat up, load the remaining weights onto the load support arm. Also, set up the data file on the data acquisition system. Refer to Appendix $\mathrm{D}$ for further details on setting up the data file.

Although it would be ideal to get the samples to heat up at the same rate, the reality is that not all the furnaces heat up equally fast. The goal is to bring the temperature up fairly quickly, to within $10-15^{\circ} \mathrm{C}$ of the test temperature. Along the way though, it may be necessary to correct for temperature variations between the bottom and top of the sample. Check for these variations using channels 1 (top) and 2 (bottom) on the Omega DP462 Thermometer. Very large differences, $\sim 5^{\circ} \mathrm{C}$ or more should be corrected once the sample reaches $150-200^{\circ} \mathrm{C}$ below the test temperature. Then, increment by $50^{\circ} \mathrm{C}$ or so and correct if necessary. Fine tuning is done slowly when the temperature gets to within $10^{\circ} \mathrm{C}$ or so of the test temperature. Then, increment the temperature by $2^{\circ} \mathrm{C}$ or so and make adjustments to the bottom and top SCRs. The adjustments are made using control knobs next to the furnace controller (refer to Figure C27). 


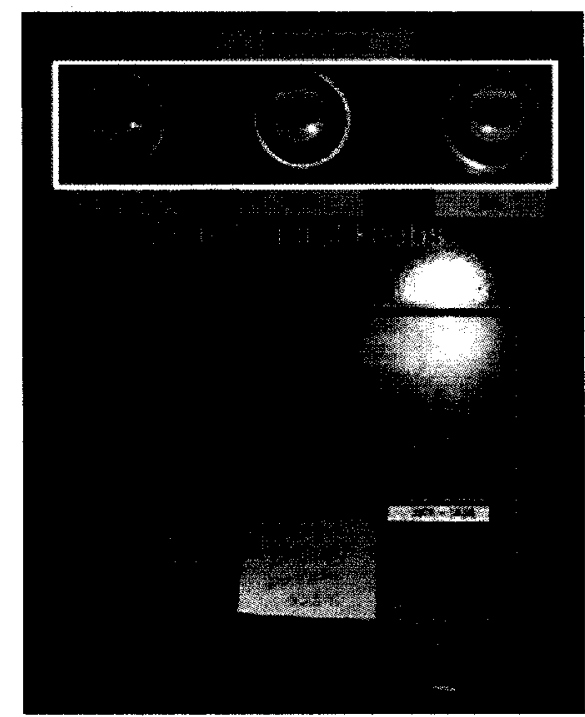

Figure C27: SCR control knobs used to adjust the temperature difference across the specimen.

Changing the value of the control knob changes the firing rate of the furnace SCRs. The control knobs are used to adjust the temperature at the top and bottom of the specimen to be nearly the same. There will likely end up being a difference in the temperature of the control thermocouple and the thermocouples mounted on the specimen. The ones on the specimen should be used for the test temperature. Adjust the control thermocouple temperature as needed to get the right test temperature at the specimen.

The test temperature is not to be exceeded by more than $1^{\circ} \mathrm{C}$. Carefully bring the temperature up. There can be no more than $1{ }^{\circ} \mathrm{C}$ difference between the top and bottom of the specimen, and be within $1{ }^{\circ} \mathrm{C}$ of the test temperature. Once the temperature is at the test temperature, the draw head can be attached to the bottom connecting rod.

Use a pair of vise grips to prevent the connecting rod from rotating. Raise the draw head until it nearly touches the connecting rod. Then thread the draw head on. 


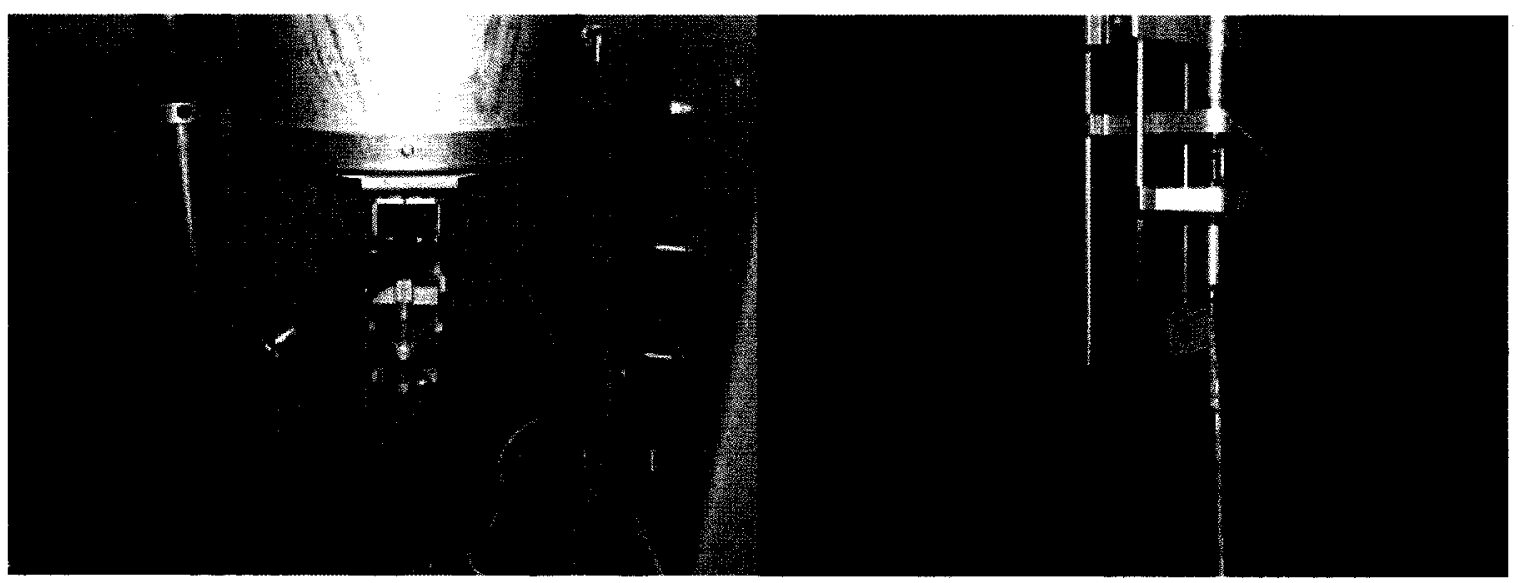

Figure C28: Attaching the drawhead by threading it onto the bottom connecting rod.

Attach the LVDT to its mounting point (refer to Figure C28). Fully compress the LVDT with the micrometer and check the voltage output using the Fluke 45 Dual Display Multimeter. Each LVDT is attached at a specific channel to the data acquisition system. The channels in use currently are $0-5$ for frames $1-5$. Frame five uses channels 4 and 5 due to the dual LVDT extensometer that is used. Uncompress the LVDT to get $1 / 2 \mathrm{~V}$ above the max compressed voltage (refer to Appendix D for further information about the data acquisition system). Run the draw head down until there is tension in the load train. Stop and then run it in short bursts until the load train cannot easily move side to side. Keep checking the LVDT voltage to ensure the load has not been partly applied.

Once that is ready, press the start button in the LabView data acquisition user interface and quickly turn the timer on and set the draw head to "Auto inch down". Finally use an object such as shown to slide the supports out from under the load. Be careful when doing so to avoid disturbing the data being gathered by the LVDT. 


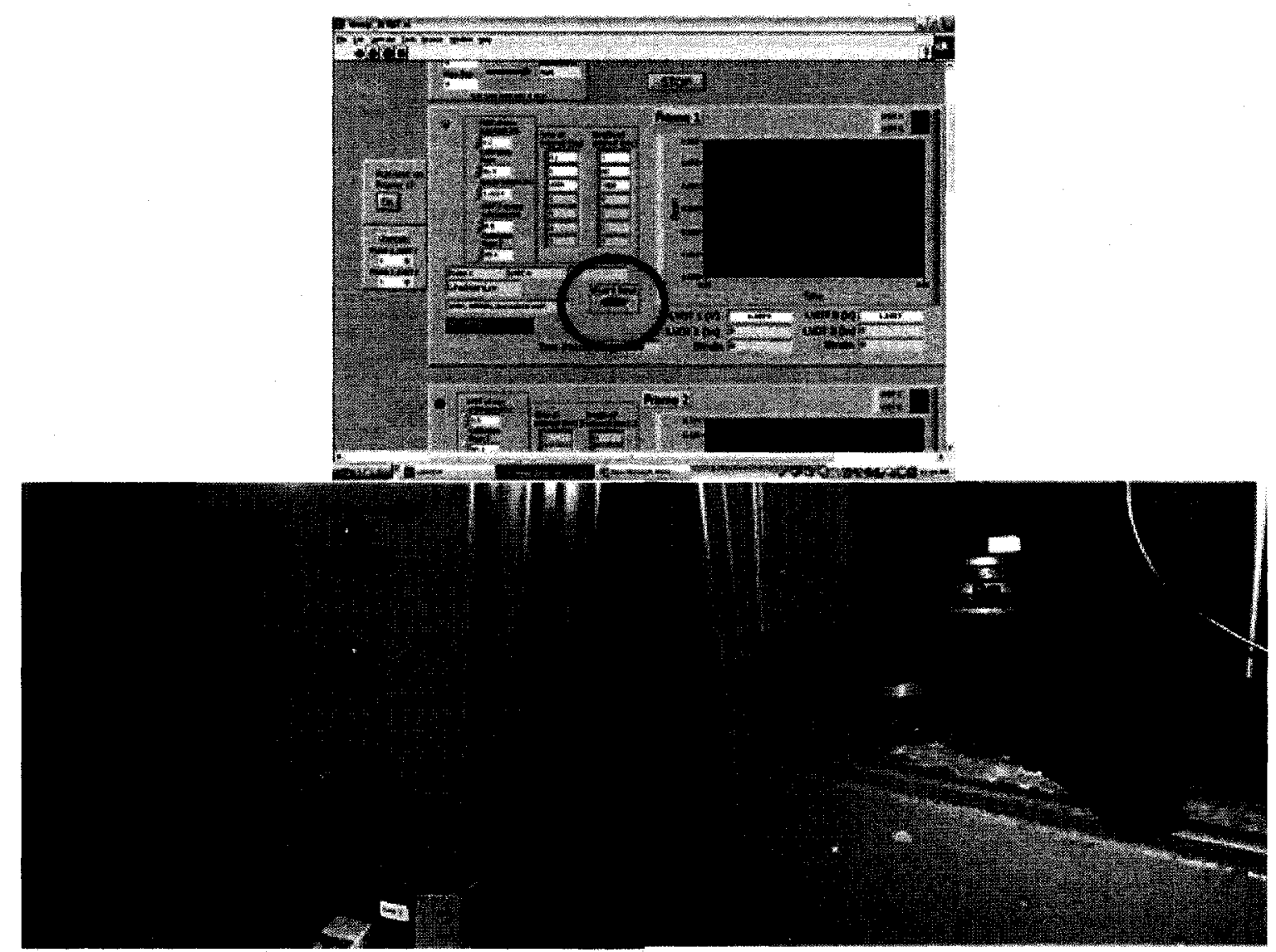

Figure C29: Starting the creep test by pressing the 'Start' button in the LabView data acquisition program and then quickly turning the timer on and setting the draw head to 'Auto Inch Down' followed by removal of the load supports.

When a test specimen fails, the load will drop, shutting off the furnace power and the creep frame timer. The first things to do are to turn off the main creep frame power, turn the furnace controller off, turn the timer off and move the draw head switch to 'neutral'. Then record the length of the creep test from the frame timer.

Remove the LVDT from the extensometer and then remove the insulation from the top of furnace. Open the furnace and remove the bottom insulation. Store the insulation carefully for future use.

Next, disconnect the draw head from the connecting rod at the bottom.

Disconnect the thermocouples from the DP462 connectors and remove the test specimen assembly from the creep frame. Place the assembly on a table and cut the wires that hold the thermocouples. Care should be taken when removing the thermocouples as the portions within the furnace should not be bent or twisted. Bending or twisting may cause the thermocouple wire to fracture. Careful handling allows multiple tests to be run with the same thermocouples. 
Next remove the connecting rods from the specimen and remove the specimen from the knife edges. Inspect the knife edges to ensure they are still sufficiently sharp to keep the specimen firmly in place. If the knife edges are suspect, remove the set and install a new set. 


\section{Appendix D: Data Acquisition System}

The data acquisition system is made up of LVDTs, signal conditioners, a National Instruments USB DAQ and a PC laptop with LabView software. Using the system is fairly straight forward thanks to the LabView software interface.

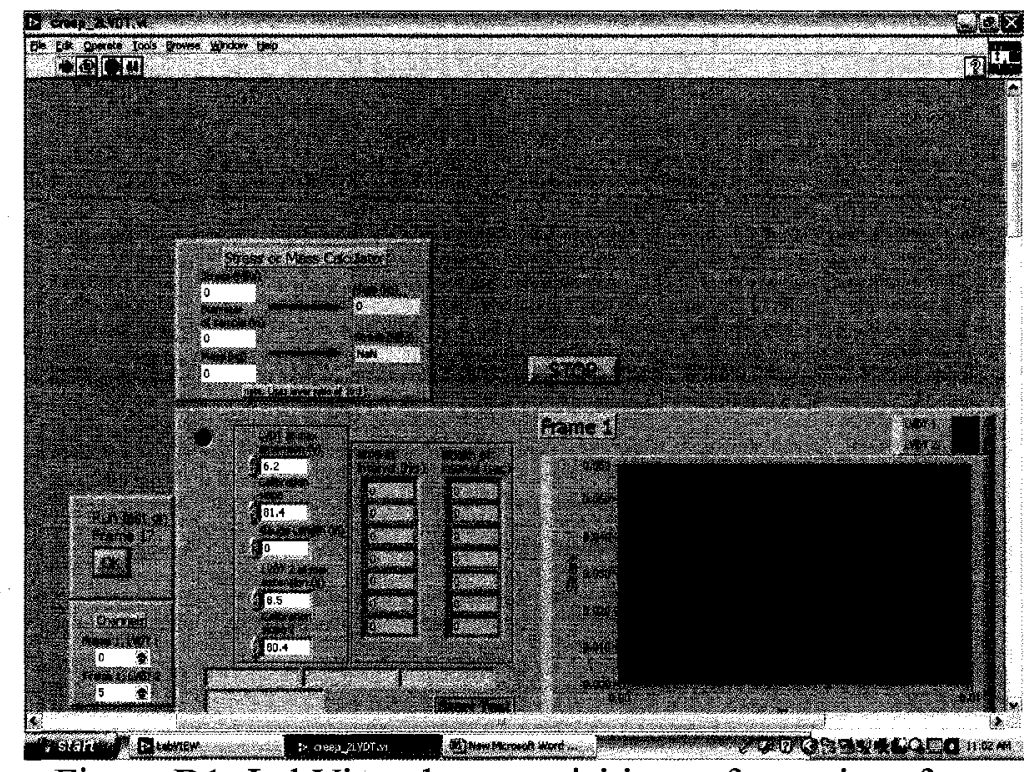

Figure D1: LabView data acquisition software interface.

Before any creep test is run, the LVDT to be used should be calibrated using the extensometer mounted micrometer and a multimeter. The micrometer is used to compress/uncompress the LVDT by known distances while the multimeter is used to measure the voltage signal the LVDT is sending to the DAQ.

The first step is to mount a sample into the extensometer to prevent any movement. Then place the extensometer on the creep frame and mount the LVDT into its holder on the extensometer (refer to Figure D2). 


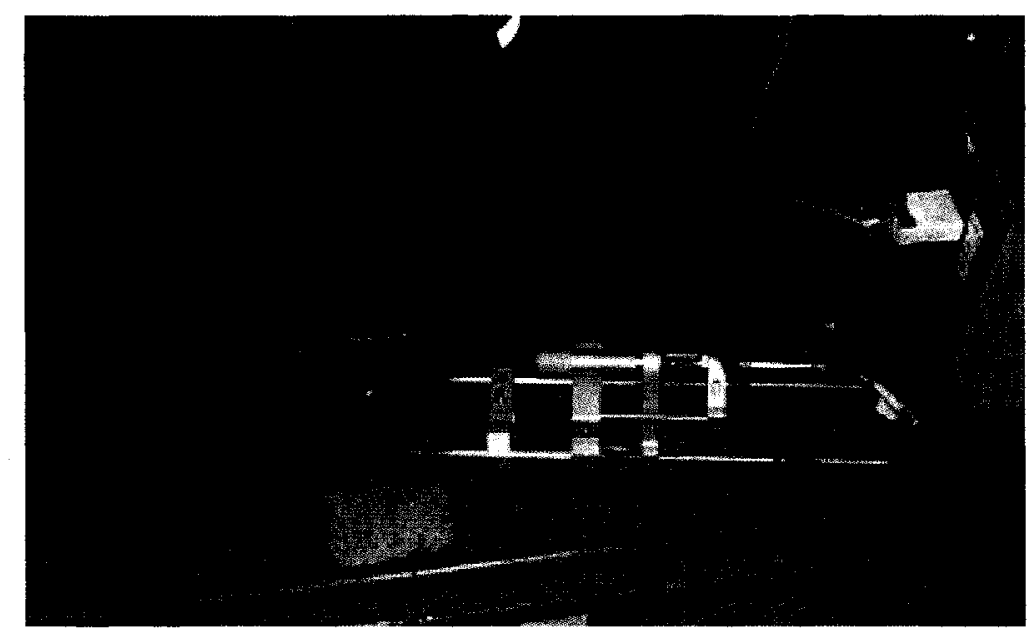

Figure D2: Extensometer with mounted specimen ready to calibrate an LVDT.

Turn on the Fluke 45 multimeter and compress the LVDT to maximum using the micrometer by twisting it until the LVDT is completely compressed. In order to find out what the LVDT voltage signal is, it is necessary to know what channel the specific creep frame has been assigned on the DAQ. The data acquisition system uses the analog terminals of the DAQ and single-ended mode as seen in Figure D3. The analog terminals are labeled 1 to 16. There are in total 8 input channels available, labeled AI0 to AI7. Each shares a common ground, with AI0 and AI4 sharing terminal 1, AI1 and AI5 sharing terminal 4 , and so on.

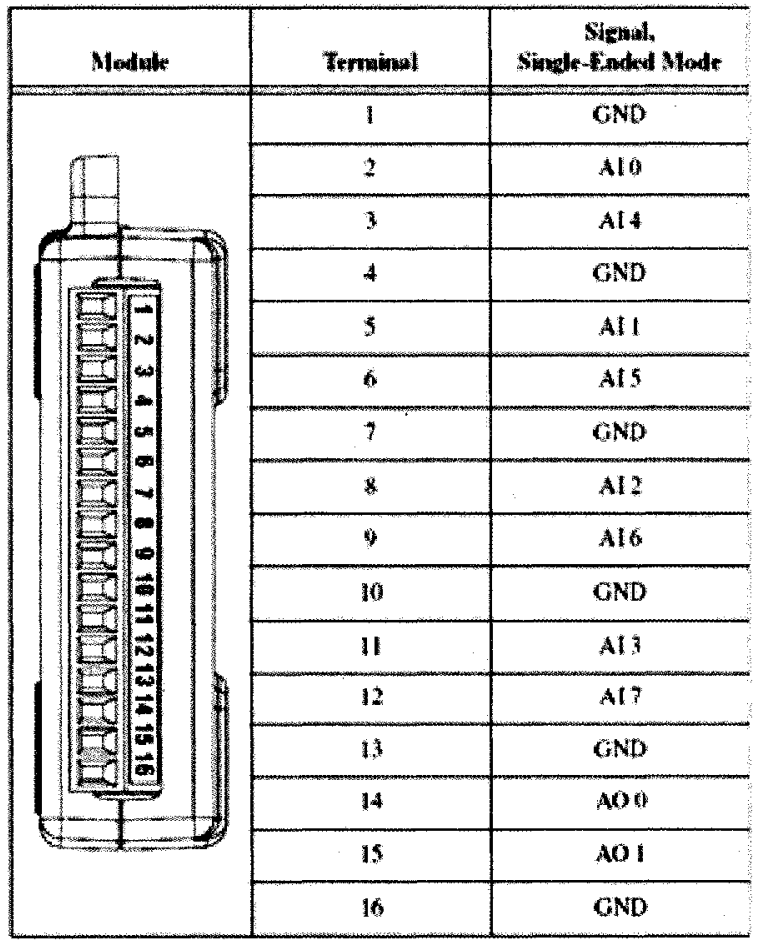

Figure D3: DAQ analog terminal assignments [1]. 
Creep frames 1 to 4 are assigned a single channel each as they use single LVDT extensometers and are assigned channels AI0 to AI3, with creep frame 1 given channel AI0 and so on. Creep frame 5 uses a dual LVDT extensometer and is assigned channels AI4 and AI5. Figure D4 shows the actual DAQ with wiring.

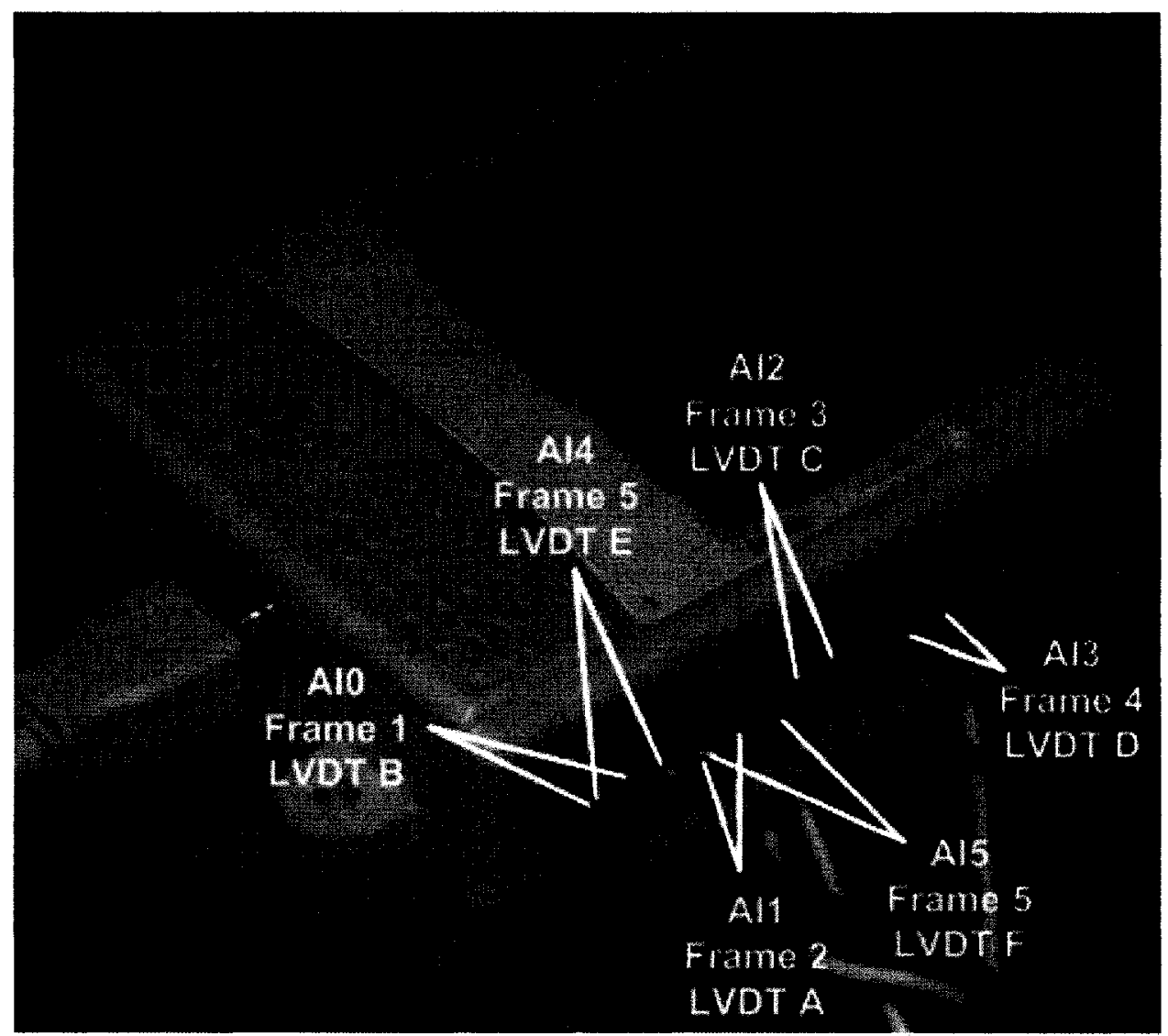

Figure D4: DAQ with wiring marked giving channel and creep frame numbers as well as the LVDT designation.

Now it is necessary to check the LVDT voltage signal. The LVDT being calibrated in this case is LVDT C in creep frame 3. Figure D5 then shows how terminals 7 and 8 are used to measure the LVDT signal with the multimeter probes. 


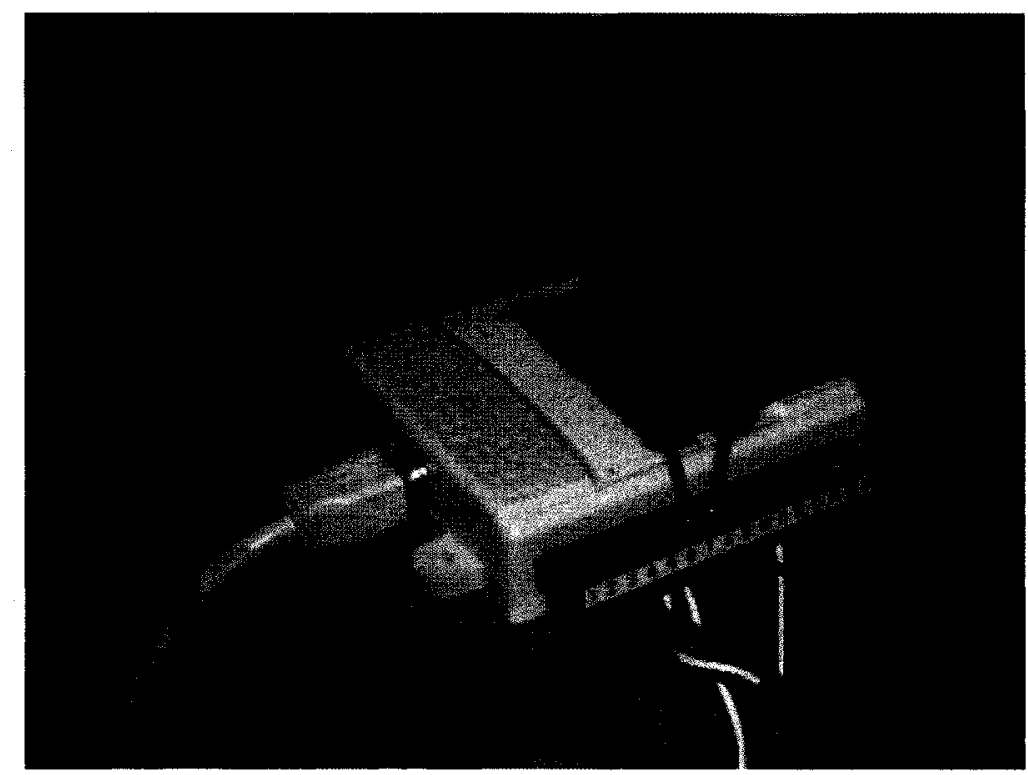

Figure D5: Terminals 7 and 8 being used to record the signal from LVDT C in creep frame 3.

With the LVDT fully compressed, check the voltage signal. Go back to the LVDT and slightly uncompress it with by untwisting the micrometer. Go and check the voltage again. The voltage should read approximately $0.5 \mathrm{~V}$ greater than the fully compressed reading which should be negative if the multimeter probes are used such that the black probe is connected to the GND terminal for the specific channel being measured. Adjust the micrometer position to get close enough to a multiple of 5 on the micrometer scale: $0,5,10,15,20$. It will be easier to calibrate the LVDT by turning the micrometer to easy to read positions.

Construct a table with displacement and LVDT voltage in order to record the LVDT voltage from the current micrometer position up to fully extended or uncompressed. Just rotate the micrometer by one full turn (which is 0.025 " displacement) and record the voltage with the micrometer. So starting with the position approximately $0.5 \mathrm{~V}$ above the fully compressed voltage signal, record the voltage. Then untwist the micrometer by one full turn and record the voltage. This is the voltage at a displacement of 0.025 ". Untwist the micrometer again by one full turn and record the voltage. This is the voltage for a displacement of 0.050 ". Continue doing this until the LVDT is fully uncompressed. Record the voltage when the LVDT is fully uncompressed.

Repeat this process five times and then plot the displacement and voltage data. Check that there is a linear change in voltage between the displacements. Find the average slope (V/inch) from the data. Also find the average of the uncompressed voltages. These two values will be input into the data acquisition software in order to correlate the changes in LVDT signal voltage to the creep specimen strain and to give a maximum LVDT signal voltage, above which the data acquisition system will stop recording. 
With the LVDT calibration complete, if the LabView program is not currently running, start LabView and open the file labeled "creep_2LVDT". Figure D6 shows the screen that will come up when the file is open. Click the 'Run' button to run the program.

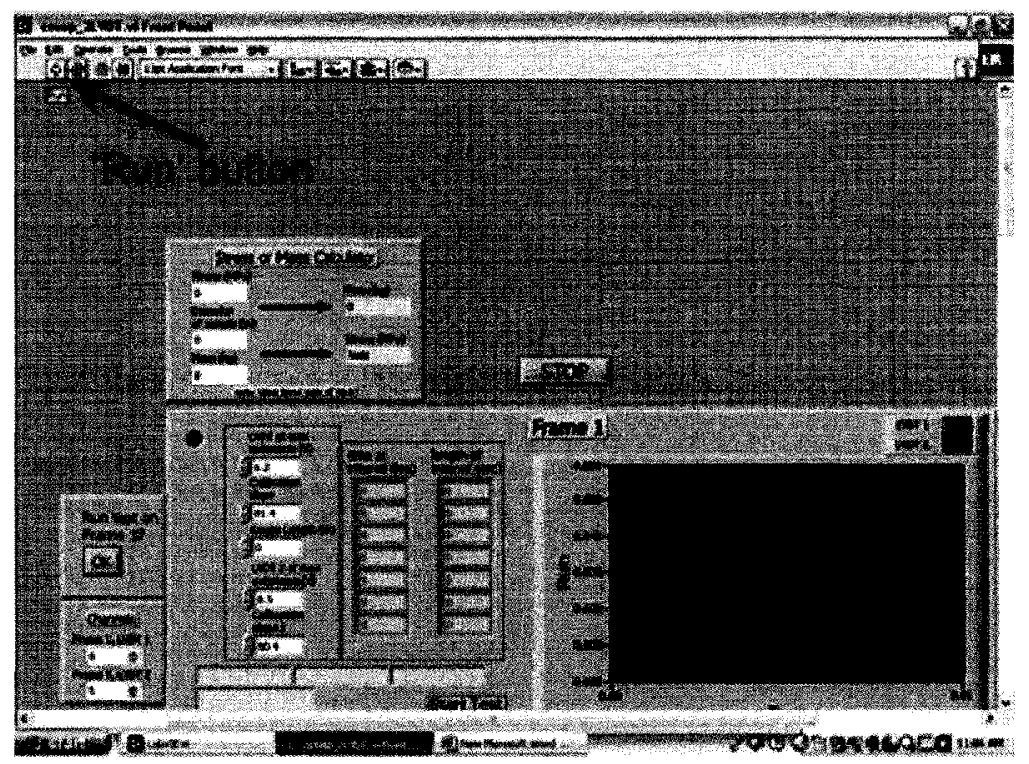

Figure D6: Data acquisition program after initial start up.

Now it is assumed that the LVDT calibration has been completed and the test specimen has been measured with the gauge length and diameter known as well as the load required. With the data acquisition program running, the screen should look as shown in Figure D7.

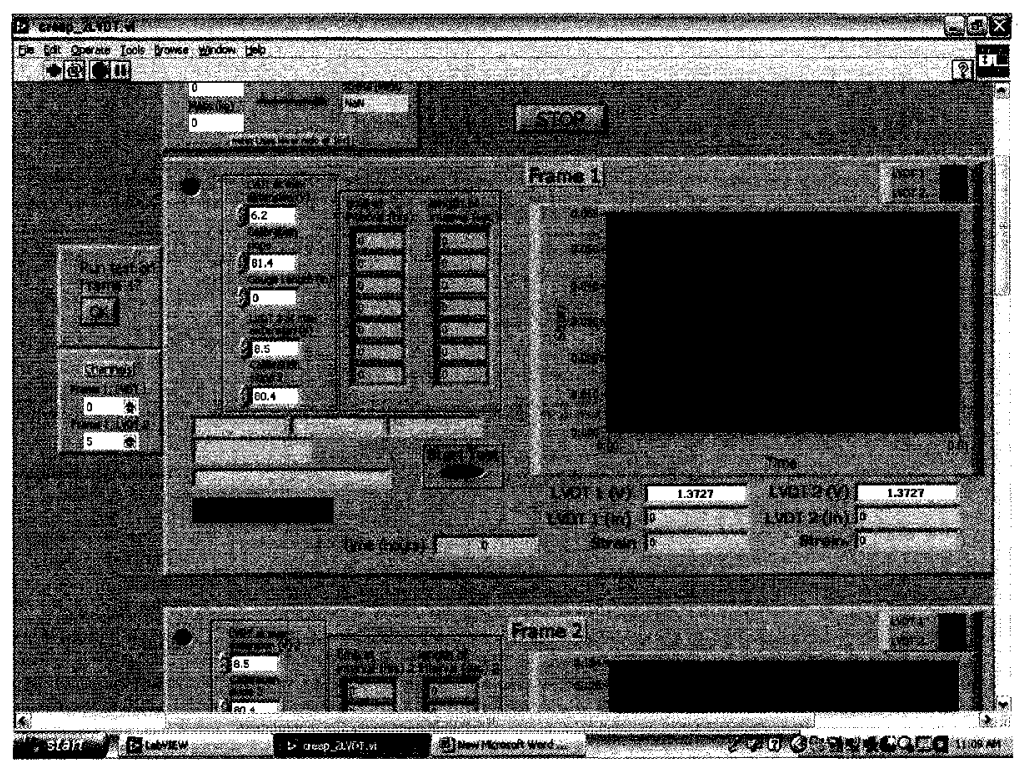

Figure D7: Operating data acquisition program. 
Now it is necessary to input the LVDT calibration values, the gauge length, the data sampling frequency and sampling intervals as well as ensuring the proper DAQ channel(s) is(are) selected. Referring to Figure D8, under the heading 'LVDT at max extension (V)' input the uncompressed voltage found from the LVDT calibration. Under 'Calibration slope', input the value found from the LVDT calibration relating change in voltage to displacement. The 'Gauge Length (in)' entry is self explanatory and the 'Channels' section at the bottom left is also simple. In the case of testing on creep frame 5 which has two LVDT's, the proper channel must be selected in the 'Channels' section and the appropriate calibration values have to be entered in the prompts below the 'Gauge Length (in)' entry for the second LVDT. Otherwise for single LVDT creep frames, leave those entries alone.

Finally the 'time at interval (hrs)' and 'length of interval (sec)' should be entered. The 'time at interval (hrs)' is the length of time in hours that the data acquisition software will collect data at the 'length of interval (sec)' specified in seconds. The most commonly used entries for these two prompts are shown in Table D1.

Table D1: Most common entries for 'time at interval (hrs)' and 'length of interval (sec)'.

\begin{tabular}{cc}
\hline Time at interval (hrs) & Length of interval (sec) \\
\hline 0.1 & 1 \\
1 & 60 \\
9999 & 1800 \\
\hline
\end{tabular}

The result of the entries seen in Table D1 is that for 6 minutes ( 0.1 hours), the data acquisition system will collect data every 1 second, followed by a period of 1 hour where data is collected every 1 minute ( 60 seconds), and followed by 9999 hours where data is collected every 0.5 hour (1800 seconds).

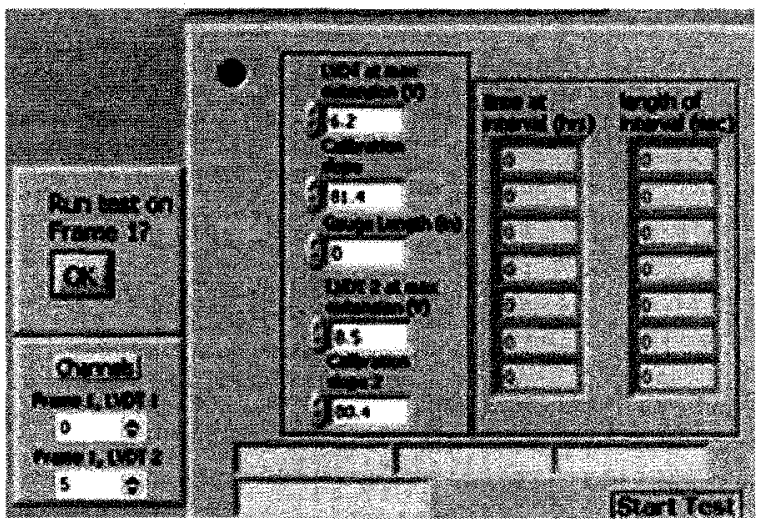

Figure D8: Important prompts requiring data entry before the creep test can be started. 
With the prompts shown in Figure D8 completed, the 'OK' button below 'Run test on Frame \#', shown on the left can be pressed. A window will pop up with a suggested file name for the test data which will be recorded. It is recommended to just record the file name for reference and press ' $\mathrm{OK}$ ' (refer to Figure D9). The file format is '.csv'.

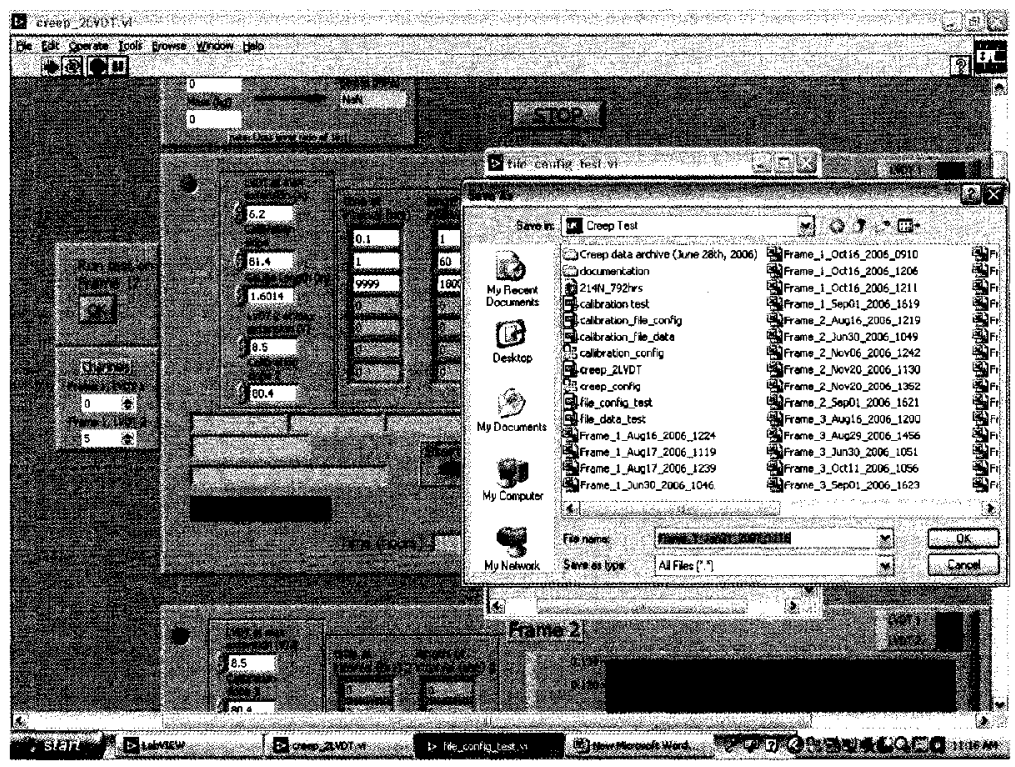

Figure D9: File name window pops up after pressing 'OK' under 'Run test on Frame \#?'.

The next window visible is just a reminder of the remaining settings that must be input and test information that should be recorded to identify the test conditions and test specimen. Press 'OK' to continue.

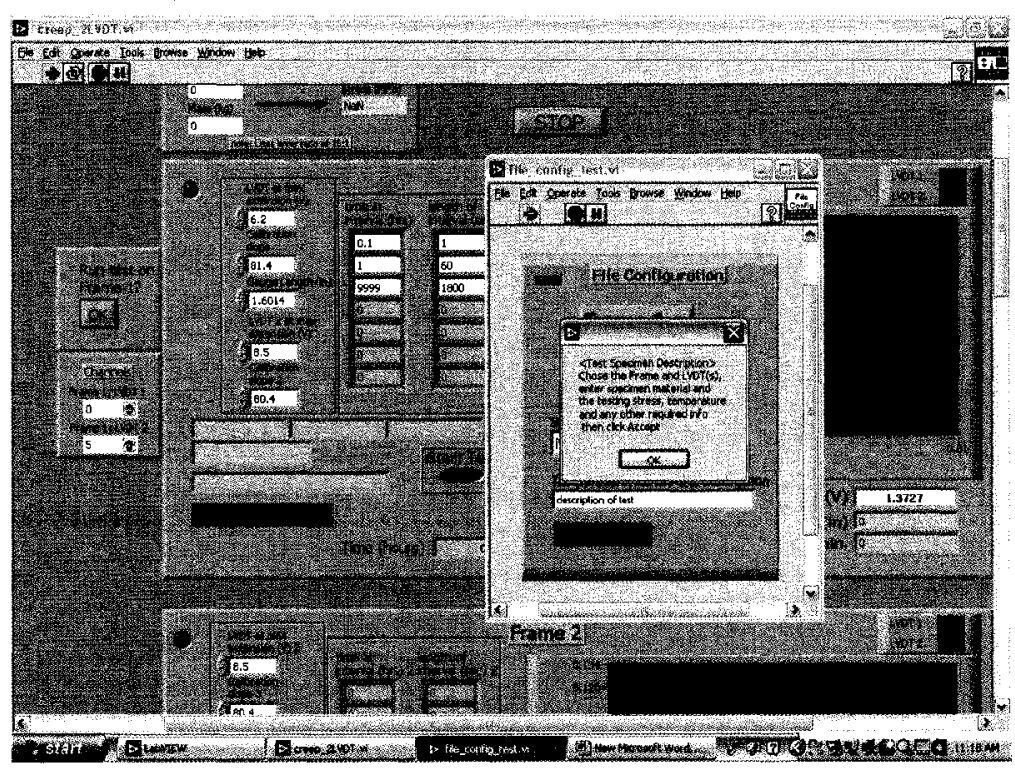

Figure D10: Reminder window of what must be input to configure the data file. 
Following from Figure D11, the next set of steps will be outlined in the Figure captions.

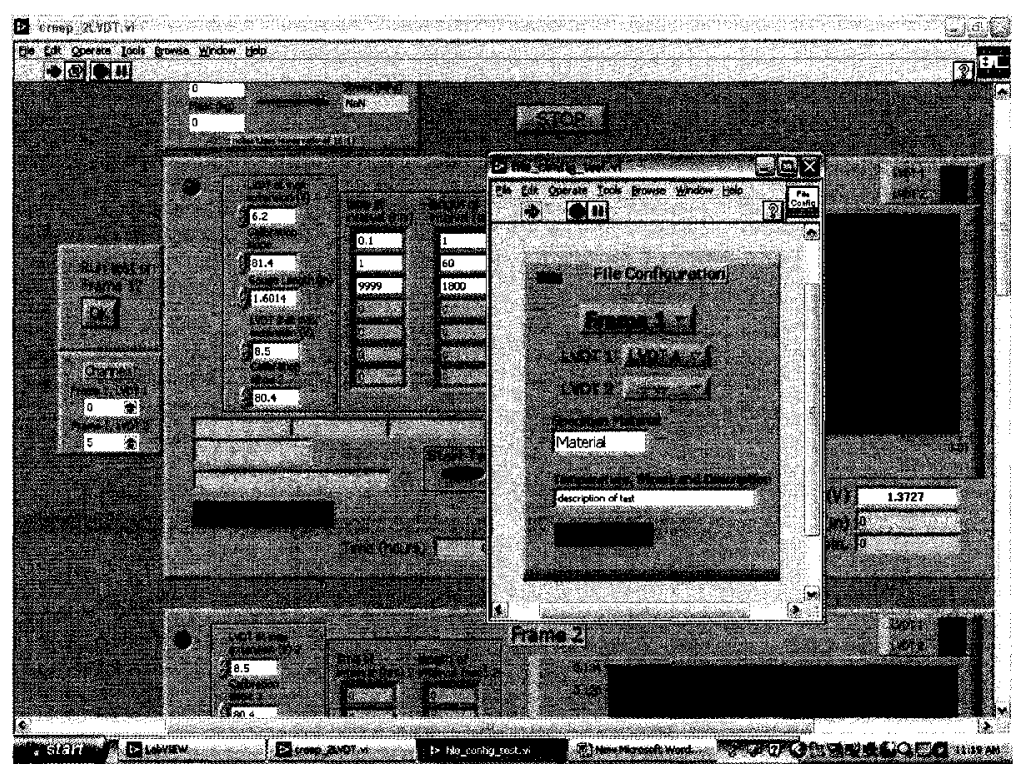

Figure D11: Window requiring various inputs in order to complete data file configuration.

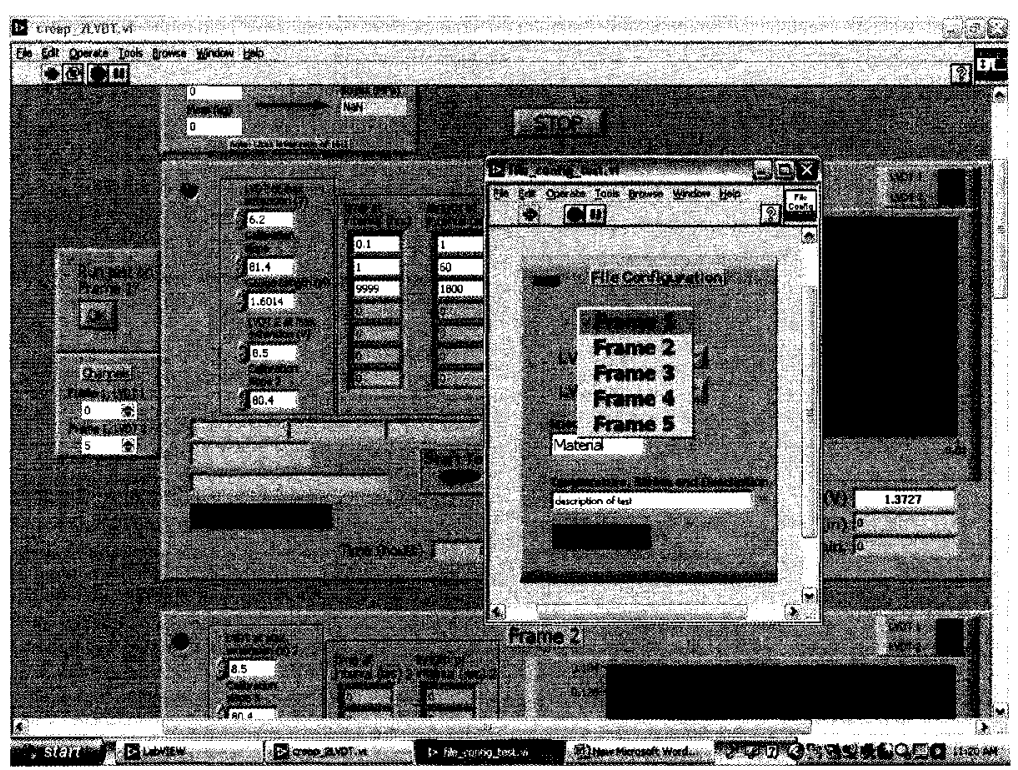

Figure D12: Ensure correct frame is selected. 


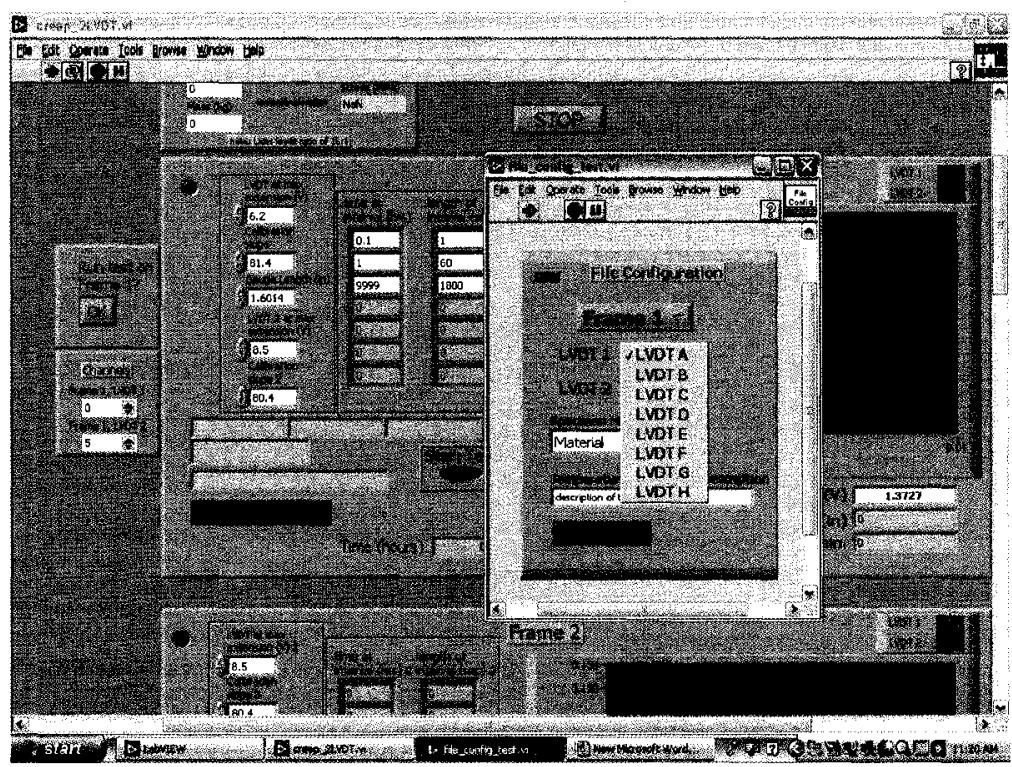

Figure D13: Choose correct LVDT for future reference of what LVDT was used.

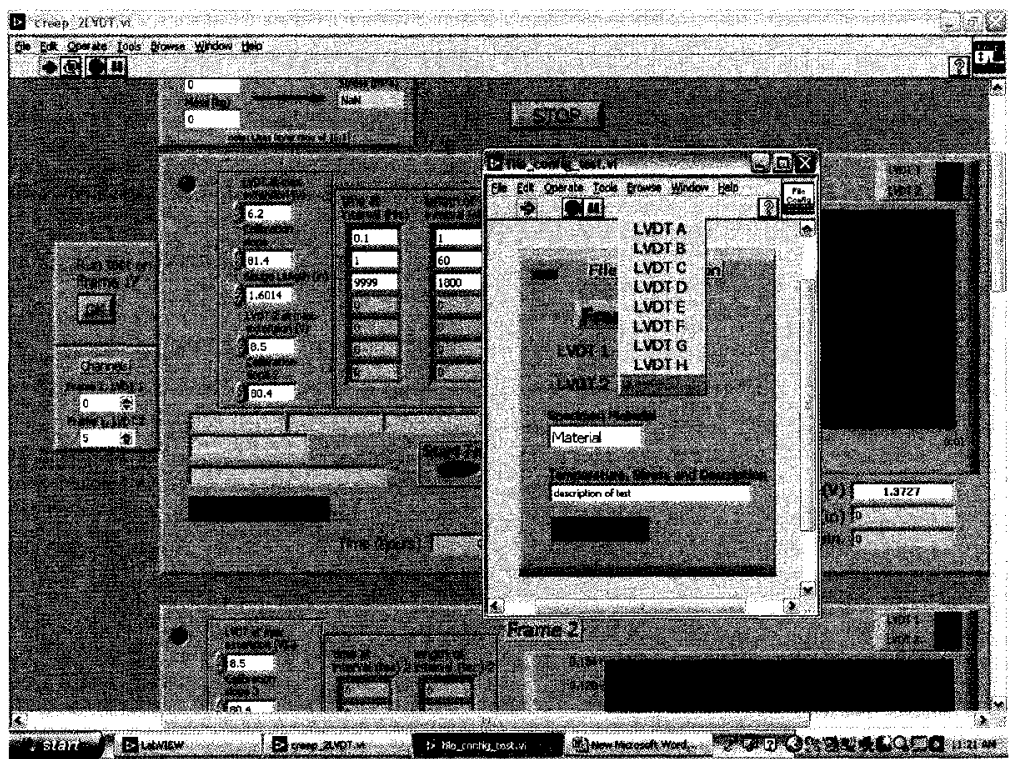

Figure D14: IMPORTANT! If only using one LVDT, select the last option '-----' under 'LVDT 2'. Otherwise, if using two LVDT's, select the appropriate one. 


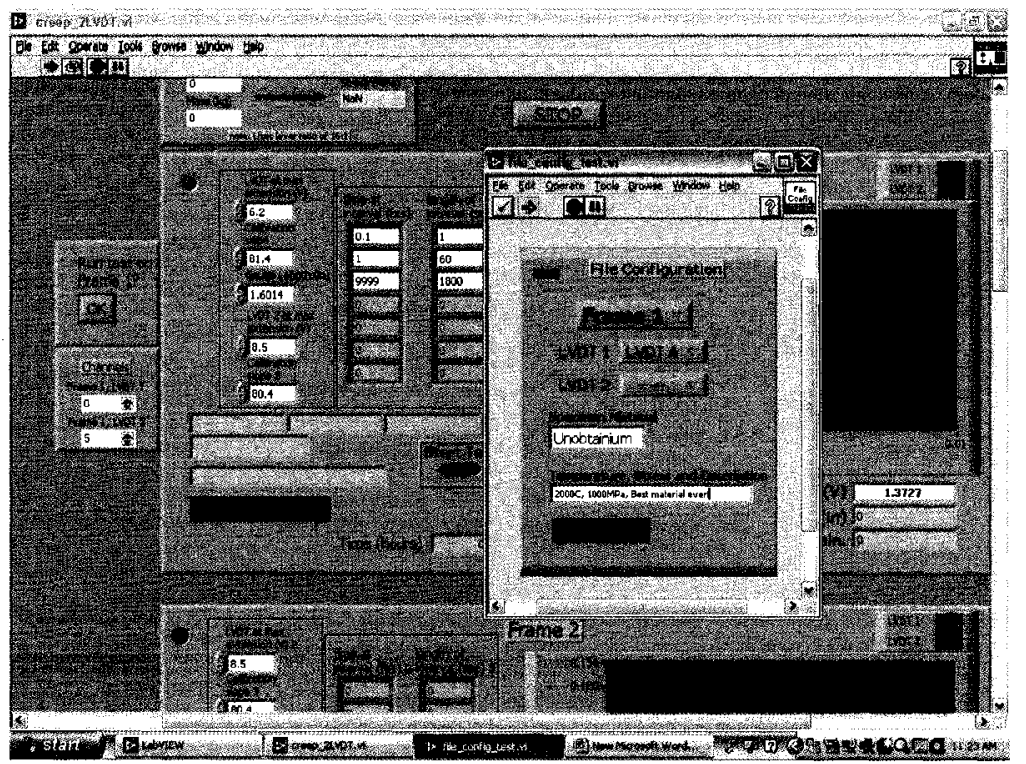

Figure D15: Next enter information about the material, temperature, stress in the text prompts. Record any and all pertinent information such as the sample designation, the actual load used, the gauge length, gauge diameter, etc. Afterwards hit 'Accept'.

After the data file is fully configured, the data acquisition interface will look as shown in Figure D16, with the 'File Configured' highlighted in green.

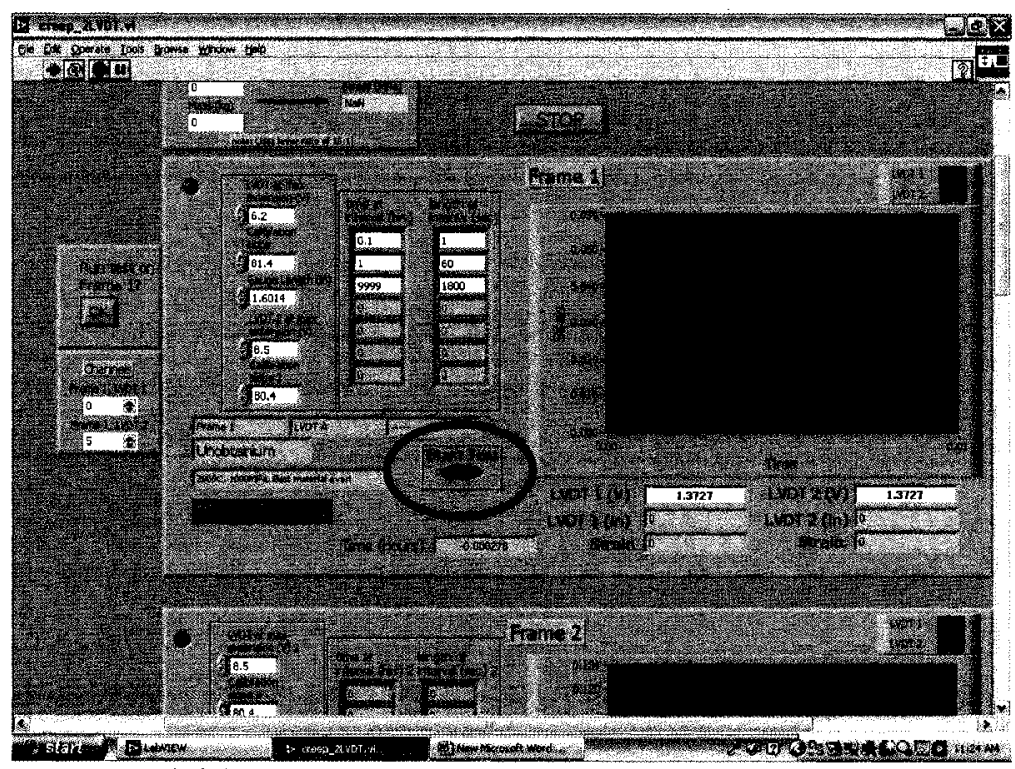

Figure D16: Data acquisition interface fully configured for Frame 1 and ready to begin testing.

When the creep test is ready to begin, press the 'Start Test' button and then turn the creep frame timer to 'On' and set the drawhead to 'Auto Inch Down' simultaneously. Likely a few seconds of zero displacement will recorded after the data recording has been 
started and the test has actually been started in the creep frame. The creep data will be saved to the data file as the data is collected and displayed in the plot on the right.

Once a creep test is completed, the green circle in the top left will no longer be lit and the 'File Configured' will be highlighted in red as seen in Figure D17. This indicates the data file has been saved and may be used. Prior to the test completing, the data file cannot be modified in any way, in including copying.

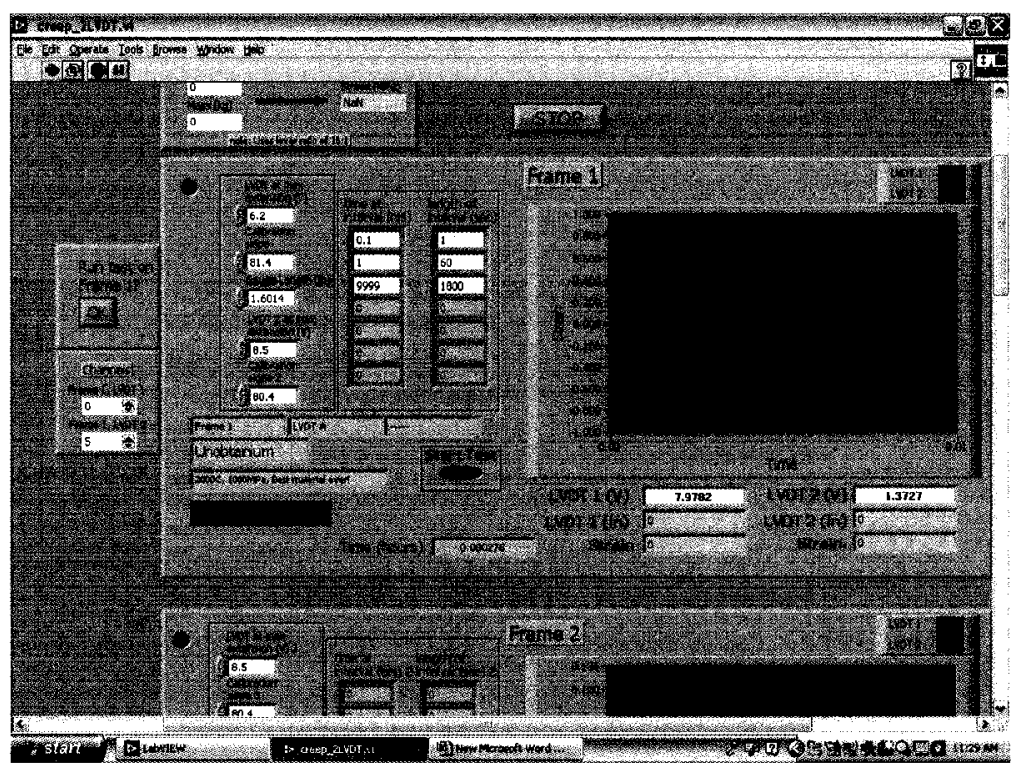

Figure D17: Data acquisition interface after test is completed.

With the file closed, it may be imported into Microsoft Excel for instance. To do so, open Microsoft Excel and go to Data $>>$ Import External Data $\gg$ Import Data (refer to Figure D18).

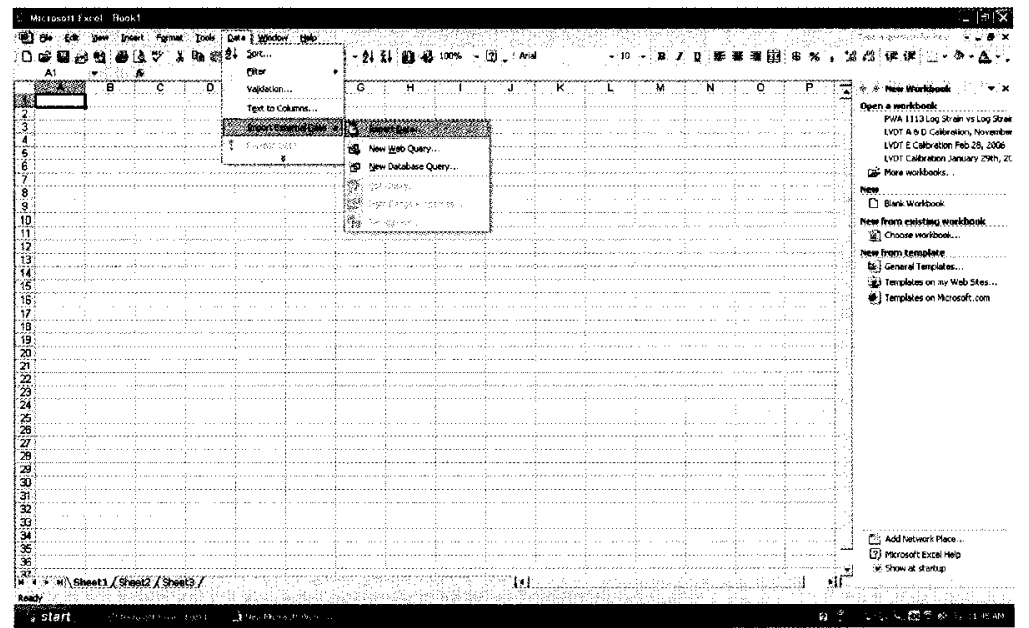

Figure D18: Importing creep data file into Microsoft Excel. 


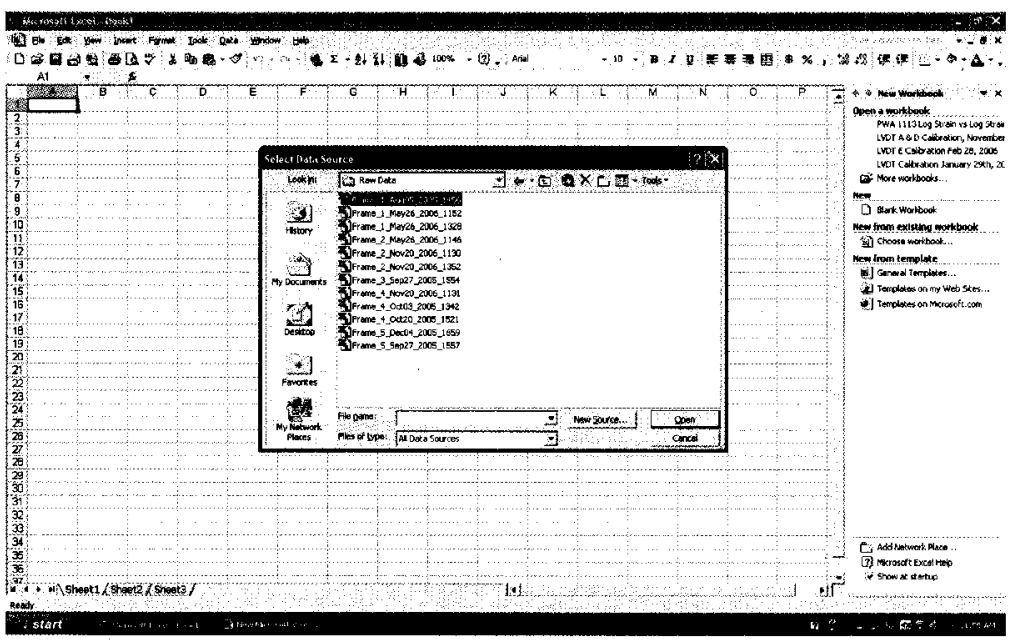

Figure D19: Select creep data file (.csv).

Text Import Wizar d - Step 1 of 3

The Text Wizard has determined that your cata is Delimited

If this is correct, choose Next, or choose the data type that best describes your data.

Chiginal data type

if Dolinited - Gharacters such os commas or tabs separate each field.

a Fixed widh . Fields are digned in columns with spaces betwean each field.

start import at nows $\sqrt{1} \quad \mathbf{I}$ File grigin $\longdiv { 4 3 7 : \text { OEM United States } }$

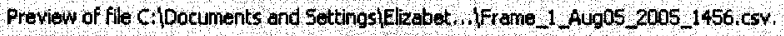

Creep Testrand 1

2 bate $/$ Titwe : Auqust 05 2005 02:57p

B $r$ reme 1

4 Lont a

5 gpecinen Haterial:21 4N, $3 \mathrm{~A}$

1

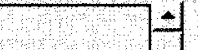

(1)

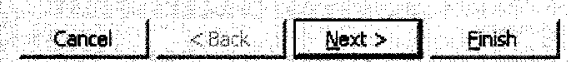

Figure D20: Select 'Delimited', and 'Start import at row' set to 1. 


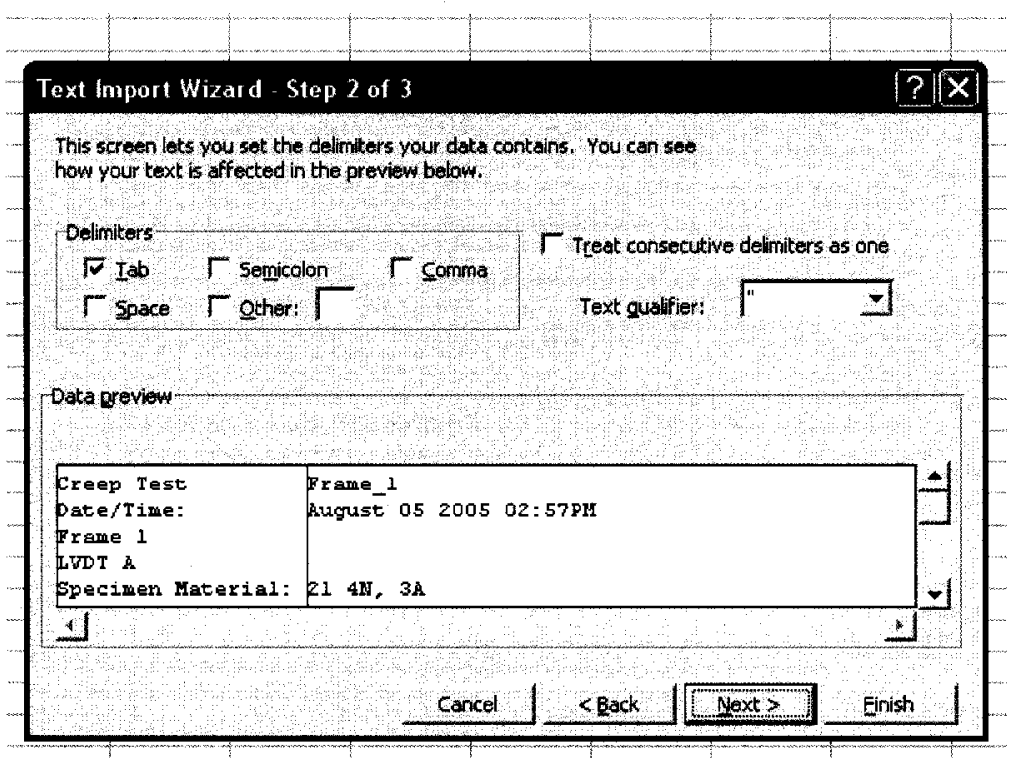

Figure D21: Select 'Delimiters' to 'Tab'.

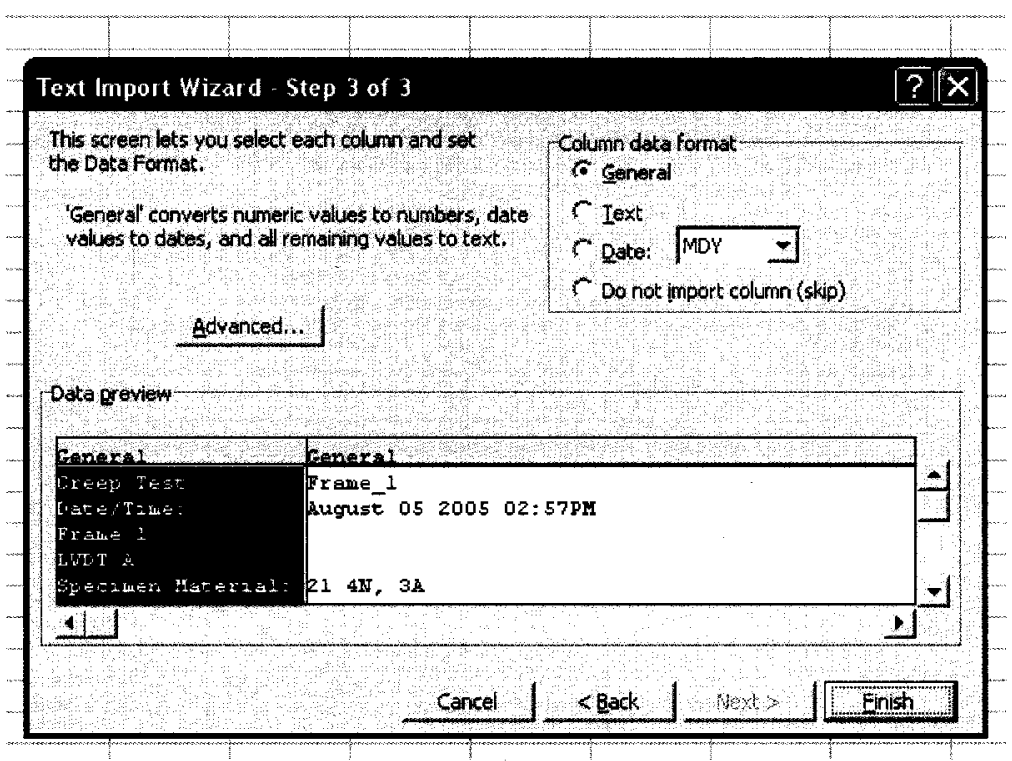

Figure D22: Select 'Column data format' to 'General', then hit 'Finish' in the bottom right. 


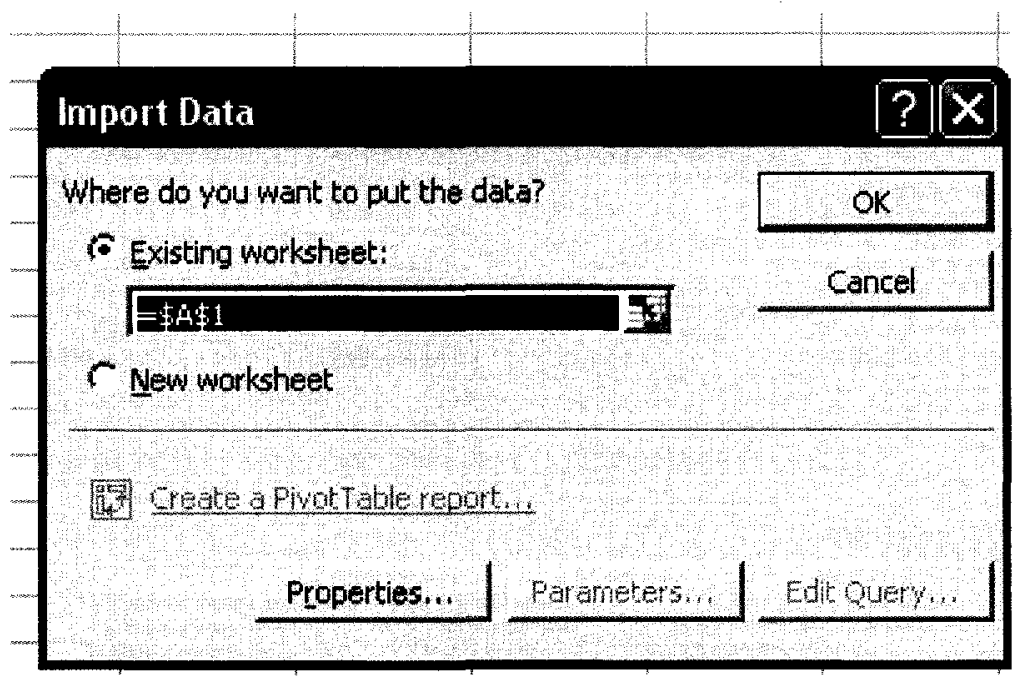

Figure D23: Choose to either import the data into an existing worksheet, or to create a new one.

Note that the options shown in Figure D20 to D22 are generally correctly set by Microsoft Excel, requiring little user input. If the data import went correctly, it should look as shown in Figure D24.

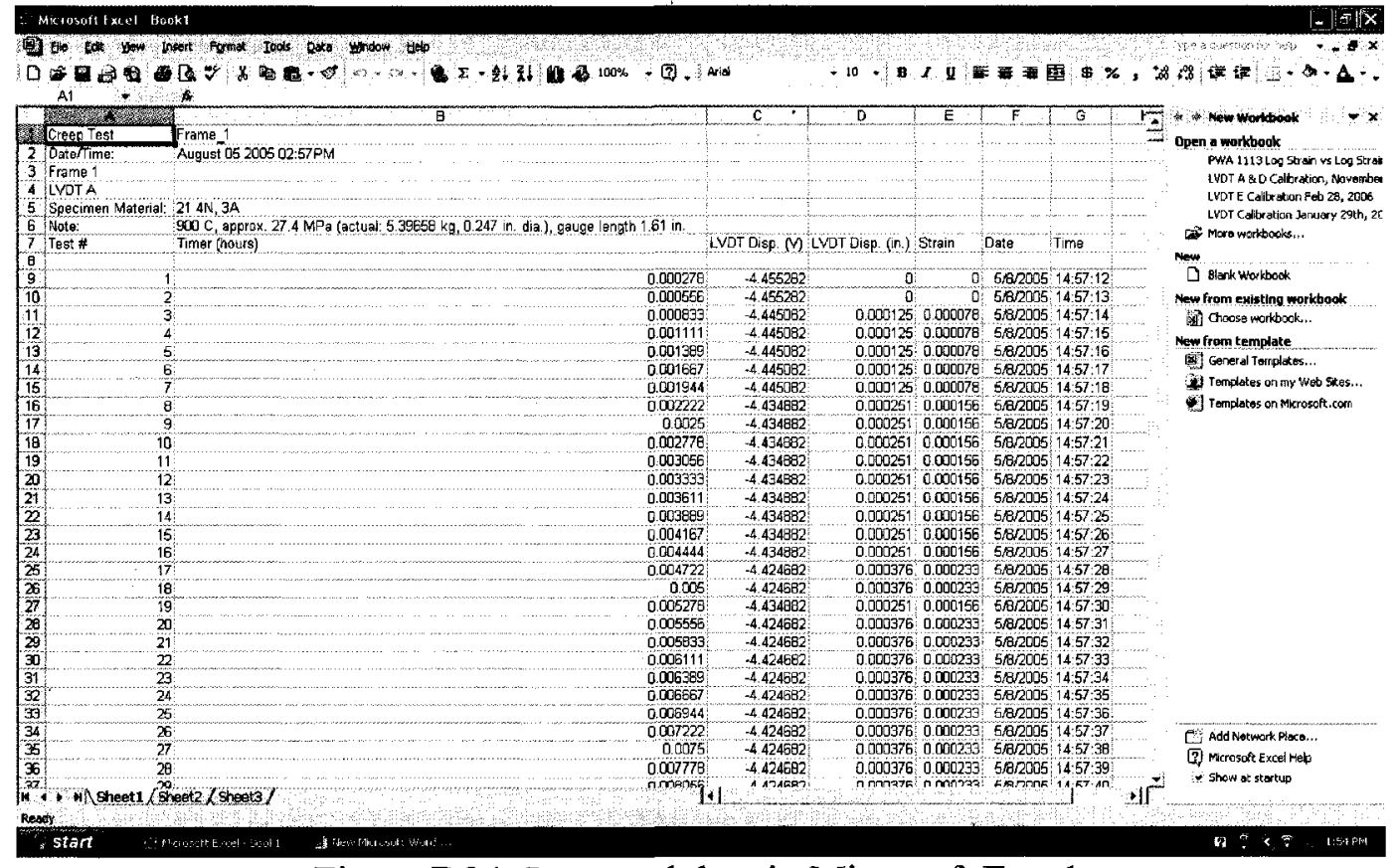

Figure D24: Imported data in Microsoft Excel.

Figure D24 shows that the time of each data point is recorded, including the elapsed time of the internal timer as well as the date and actual time. As well, the LVDT voltage signal is recorded as well as the LVDT displacement which is calculated from the 
calibration slope and the specimen strain, calculated from the displacement and gauge length.

References:

[1] "NI-USB-6008", National Instruments Products and Services, [Online] July 2007, Available: http://sine.ni.com/nips/cds/view/p/lang/en/nid/14604 


\section{Appendix E: $\theta$ Projection Analysis Results}

$7^{\circ} \mathrm{C} \& 196 \mathrm{MPa}$

\begin{tabular}{|c|c|c|c|c|c|}
\hline$\theta$ Coefficient & NGB 1 & NGB 2 & SGB M & SGB 1 & SGB 2 \\
\hline$\theta_{1}$ & 0.001778159 & 0.00257451 & 0.000299356 & 0.000260165 & 0.005469197 \\
\hline$\overline{\theta_{2}}$ & 87.34549732 & 259.1464027 & 0.232163686 & 0.30499213 & 0.030866819 \\
\hline$\theta_{3}$ & 0.004966776 & 0.006735941 & 0.002117822 & 0.013855746 & 0.005066369 \\
\hline$\theta_{4}$ & 0.003698469 & 0.003404356 & 0.005727296 & 0.003335954 & 0.005633253 \\
\hline$\theta_{5}$ & 0.000756463 & 0.000752146 & 0.000294748 & 0.000210168 & \\
\hline$\theta_{6}$ & 0.115820668 & 0.019970132 & 0.197088045 & 0.304607133 & \\
\hline$\theta_{7}$ & 0.000812773 & $9.64 \mathrm{E}-05$ & $7.84 \mathrm{E}-05$ & 0.002243943 & \\
\hline$\theta_{8}$ & 0.014404709 & 0.101715558 & 0.096481232 & 124.0523016 & \\
\hline$\theta_{9}$ & 0.001090698 & 0.000893086 & 0.003126727 & 0.000294422 & \\
\hline$\theta_{10}$ & 0.014394588 & 0.020989207 & 0.004419088 & 0.305544282 & \\
\hline$\theta_{11}$ & 0.001160815 & 0.000777233 & 0.00038411 & 0.003304235 & \\
\hline$\theta_{12}$ & 0.014390675 & 0.020152599 & 0.218001746 & 0.024245209 & \\
\hline$\theta_{13}$ & & 0.000146604 & 0.00328132 & & \\
\hline$\theta_{14}$ & & 0.240672803 & 177.888469 & & \\
\hline$\overline{\theta_{15}}$ & & 0.000653858 & 0.000168832 & & \\
\hline$\theta_{16}$ & & 0.019182113 & 0.254363281 & & \\
\hline$\theta_{17}$ & & & 0.003767805 & & \\
\hline$\theta_{18}$ & & & 0.004419277 & & \\
\hline$\theta_{19}$ & & & 0.003178378 & & \\
\hline$\theta_{20}$ & & & 0.004419103 & & \\
\hline$\theta_{21}$ & & & 0.003485898 & & \\
\hline$\theta_{22}$ & & & 0.004419194 & & \\
\hline
\end{tabular}


$900^{\circ} \mathrm{C} \& 27.4 \mathrm{MPa}$

\begin{tabular}{|c|c|c|c|c|}
\hline$\theta$ Coefficient & NGB & SGB M & SGB & SGB Prematurely Failed \\
\hline$\theta_{1}$ & 0.000665685 & 0.001024783 & 0.000142581 & 0.000172231 \\
\hline$\theta_{2}$ & 0.000807018 & 0.000478845 & 0.052167391 & 0.085855873 \\
\hline$\theta_{3}$ & 0.00585146 & 0.00769349 & 0.008838412 & 0.005203081 \\
\hline$\theta_{4}$ & 0.001229358 & 0.001302117 & 0.001093122 & 0.001378583 \\
\hline$\theta_{5}$ & 0.000317554 & 0.000367594 & 0.000197407 & 0.000173602 \\
\hline$\theta_{6}$ & 0.056398565 & 0.154250929 & 0.052207293 & 0.086878684 \\
\hline$\theta_{7}$ & 0.000214613 & 0.000339838 & 0.000186376 & 0.00017834 \\
\hline$\theta_{8}$ & 0.000833371 & 0.835753196 & 0.052172401 & 0.090436223 \\
\hline$\theta_{9}$ & 0.000532419 & 0.000706651 & 0.000317665 & 0.000173705 \\
\hline$\theta_{10}$ & 0.000812878 & 49.76813468 & 52.4920347 & 0.086955484 \\
\hline$\theta_{11}$ & 0.000351435 & 0.001060624 & 0.000363523 & 0.00017894 \\
\hline$\theta_{12}$ & 0.056401244 & 0.000478833 & 0.520901152 & 0.090889312 \\
\hline$\theta_{13}$ & 0.000332224 & 0.000350467 & 5.61E-05 & 0.000178331 \\
\hline$\theta_{14}$ & 0.440549912 & 0.384096612 & 0.052159907 & 0.090430001 \\
\hline$\theta_{15}$ & 0.000861093 & 0.001143331 & 0.000140581 & 0.000172231 \\
\hline$\theta_{16}$ & 0.000800829 & 0.00047881 & 0.020410945 & 0.085855873 \\
\hline$\theta_{17}$ & 0.000392961 & 0.001085041 & & \\
\hline$\theta_{18}$ & 0.057071168 & 0.000478826 & & \\
\hline$\theta_{19}$ & & 0.000961911 & & \\
\hline$\theta_{20}$ & & 0.000478869 & & \\
\hline$\theta_{21}$ & & 0.001403394 & & \\
\hline$\theta_{22}$ & & 0.000478762 & & \\
\hline
\end{tabular}


$925^{\circ} \mathrm{C} \& 27.4 \mathrm{MPa}$

\begin{tabular}{ccc}
\hline $\boldsymbol{\theta}$ Coefficient & NGB & SGB \\
\hline$\theta_{1}$ & 0.000154559 & 0.000472121 \\
\hline$\theta_{2}$ & 0.164744966 & 0.117222038 \\
\hline$\theta_{3}$ & 0.004584519 & 0.007999926 \\
\hline$\theta_{4}$ & 0.001672522 & 0.004743334 \\
\hline$\theta_{5}$ & 0.000154399 & 0.000472121 \\
\hline$\theta_{6}$ & 0.164681524 & 0.117222027 \\
\hline$\theta_{7}$ & 0.000153496 & 0.000472121 \\
\hline$\theta_{8}$ & 0.164322621 & 0.11722203 \\
\hline$\theta_{9}$ & 0.000154889 & 0.000472121 \\
\hline$\theta_{10}$ & 0.164875922 & 0.117222035 \\
\hline$\theta_{11}$ & 0.000154467 & 0.000472121 \\
\hline$\theta_{12}$ & 0.16470849 & 0.11722203 \\
\hline$\theta_{13}$ & 0.000155228 & \\
\hline$\theta_{14}$ & 0.165010061 & \\
\hline$\theta_{15}$ & 0.00015448 & \\
\hline$\theta_{16}$ & 0.164713394 & \\
\hline & & \\
\hline
\end{tabular}

